Keywords: Pump, mixing, blending, nuclear waste, transfers, sludge, sludge simulant

Retention: Permanent

\title{
Blending Study for SRR Salt Disposition Integration: Tank 50H Scale-Modeling and Computer-Modeling for Blending Pump Design, Phase 2
}

Robert A. Leishear

Michael R. Poirier

Mark D. Fowley

May 2011

Savannah River National Laboratory

Savannah River Nuclear Solutions, LLC Aiken, SC 29808

Prepared for the U.S. Department of Energy under contract number DE-AC09-08SR22470.

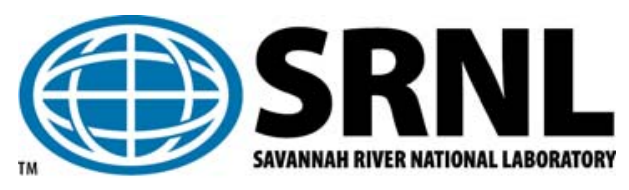


SRNL-STI-2011-00151

5/26/11 Revision 0

\section{DISCLAIMER}

This work was prepared under an agreement with and funded by the U.S. Government. Neither the U.S. Government or its employees, nor any of its contractors, subcontractors or their employees, makes any express or implied:

1. warranty or assumes any legal liability for the accuracy, completeness, or for the use or results of such use of any information, product, or process disclosed; or

2. representation that such use or results of such use would not infringe privately owned rights; or

3. endorsement or recommendation of any specifically identified commercial product, process, or service.

Any views and opinions of authors expressed in this work do not necessarily state or reflect those of the United States Government, or its contractors, or subcontractors.

\section{Printed in the United States of America \\ Prepared for \\ U.S. Department of Energy}


AUTHORS:

\section{REVIEWS AND APPROVALS}

R. A. Leishear, Principal Investigator

Date

Engineering Development Laboratory

M. R. Poirier, Principal Investigator

Date

Advanced Characterization and Processing

M. D. Fowley, Principal Investigator

Date

Engineering Development Laboratory

REVIEWER:

M. R. Duignan

Date

Engineering Development Laboratory

APPROVALS:

B. J. Giddings, Manager

Date

Engineering Development Laboratory

S.L. Marra, Manager

Date

Environmental \& Chemical Process Technology Research Programs

W. B. Van Pelt, Project Engineering Manager

Date

Savannah River Remediation, LLC

K. D. Harp, Project Operations

Date

Savannah River Remediation, LLC 
SRNL-STI-2011-00151

5/26/11 Revision 0

\section{Preface and Acknowledgments}

Savannah River National Laboratory (SRNL) research for the Salt Disposition Integration (SDI) Project is expected to yield several million dollars in cost savings to SRS. Specifically, recommendations are provided in this report for Savannah River Remediation (SRR) design and installation requirements for blending pumps to blend salt solutions, and transfer pump installation requirements for H-Area Tank Farm (HTF) or F-Area Tank Farm (FTF) waste tanks. SRNL recommends a single, non-rotating pump for each Blend Tank. For facility safety, blender pumps are required to blend salt solutions without disturbing a settled layer of solids on the tank bottom, referred to as sludge. Additionally, research was completed to investigate the effects of sludge disturbance during transfer pump operations to minimize sludge transfer to the Salt Waste Processing Facility (SWPF) facility.

To support this research, a total of 126 pilot scale tests, 260 material property tests, and 39 Computational Fluid Dynamics (CFD) models were completed over 15 months. In addition to design, procurement, and fabrication, 38 initial tests were completed in six weeks from start to finish of the task: 13 work days to complete fabrication, and 16 work days to the first test. During subsequent research, many technical obstacles were overcome to advance mixing technology in liquid radioactive waste storage tanks, and provide project recommendations.

The research documented in this report is the product of a team effort, which included SRR and SRNL staff members, who each contributed support to project success. The research team spanned many technical disciplines, which included: nuclear engineering, corrosion engineering and materials science; nuclear waste processing; pump design: chemical processing and modeling; fluid mechanics and blending; pilot scale testing, statistical analysis; mechanical and electrical design and fabrication; and CFD modeling. A list of major contributors includes:

SRNL Technician Staff: Mike Armstrong, Vernon Bush, Andrew Foreman, Tim Forehand, Lowell Hicks, Chris Baxley, Dick Skeens, Steve Rikard, and Chris Rose.

SRNL Managers and Staff: Billy Giddings, Doug Sumpter, Sharon Marra, Steve Hensel, Patricia Lee, Frank Pennebaker, Michael Stowell, Leroy Williams, Tommy McCoy, and Jim Buchanan.

SRNL Engineering Staff: Robert Leishear, Mark Fowley, Michael Poirier, Si Lee, Tim Steeper, Mike Restivo, Michael Williams, Tommy Edwards, Mark Duignan, Chris Martino, John Pareizs, Erich Hansen, David Koopman, David Stefanko, David Best, David Missimer, Bruce Wiersma, and John Steimke.

SRR Managers: Keith Harp, Bill Van Pelt, David Burke, and Kevin Lancaster.

SRR Engineering Staff: Ken Parkinson, Bob Ervin, and Billy West. 
SRNL-STI-2011-00151

5/26/11 Revision 0

\section{EXECUTIVE SUMMARY}

The Salt Disposition Integration (SDI) portfolio of projects provides the infrastructure within existing Liquid Waste facilities to support the startup and long term operation of the Salt Waste Processing Facility (SWPF). Within SDI, the Blend and Feed Project will equip existing waste tanks in the Tank Farms to serve as Blend Tanks where 300,000 - 800,000 gallons of salt solution will be blended in 1.3 million gallon tanks and qualified for use as feedstock for SWPF. Blending requires the miscible salt solutions from potentially multiple source tanks per batch to be well mixed without disturbing settled sludge solids that may be present in a Blend Tank. Disturbing solids may be problematic both from a feed quality perspective as well as from a process safety perspective where hydrogen release from the sludge is a potential flammability concern.

To develop the necessary technical basis for the design and operation of blending equipment, Savannah River National Laboratory (SRNL) completed scaled blending and transfer pump tests and computational fluid dynamics (CFD) modeling. A 94 inch diameter pilot-scale blending tank, including tank internals such as the blending pump, transfer pump, removable cooling coils, and center column, were used in this research. The test tank represents a 1/10.85 scaled version of an 85 foot diameter, Type IIIA, nuclear waste tank that may be typical of Blend Tanks used in SDI. Specifically, Tank 50 was selected as the tank to be modeled per the SRR, Project Engineering Manager. SRNL blending tests investigated various fixed position, non-rotating, dual nozzle pump designs, including a blending pump model provided by the blend pump vendor, Curtiss Wright (CW).

Primary research goals were to assess blending times and to evaluate incipient sludge disturbance for waste tanks. Incipient sludge disturbance was defined by SRR and SRNL as minor blending of settled sludge from the tank bottom into suspension due to blending pump operation, where the sludge level was shown to remain constant. To experimentally model the sludge layer, a very thin, pourable, sludge simulant was conservatively used for all testing. To experimentally model the liquid, supernate layer above the sludge in waste tanks, two salt solution simulants were used, which provided a bounding range of supernate properties. One solution was water $\left(\mathrm{H}_{2} \mathrm{O}+\mathrm{NaOH}\right)$, and the other was an inhibited, more viscous salt solution. The research performed and data obtained significantly advances the understanding of fluid mechanics, mixing theory and CFD modeling for nuclear waste tanks by benchmarking CFD results to actual experimental data. This research significantly bridges the gap between previous CFD models and actual field experiences in real waste tanks.

A finding of the 2009, DOE, Slurry Retrieval, Pipeline Transport and Plugging, and Mixing Workshop was that CFD models were inadequate to assess blending processes in nuclear waste tanks. One recommendation from that Workshop was that a validation, or bench marking program be performed for CFD modeling versus experiment. This research provided experimental data to validate and correct CFD models as they apply to mixing and blending in nuclear waste tanks.

Extensive SDI research was a significant step toward bench marking and applying CFD modeling. This research showed that CFD models not only agreed with experiment, but demonstrated that the large variance in actual experimental data accounts for misunderstood discrepancies between CFD models and experiments. Having documented this finding, SRNL was able to provide correction factors to be used with CFD models to statistically bound full scale CFD results. Through the use of pilot scale tests performed for both types of pumps and available engineering literature, SRNL demonstrated how to effectively apply CFD results to salt batch 
mixing in full scale waste tanks. In other words, CFD models were in error prior to development of experimental correction factors determined during this research, which provided a technique to use CFD models for salt batch mixing and transfer pump operations.

This major scientific advance in mixing technology resulted in multi-million dollar cost savings to SRR. New techniques were developed for both experiment and analysis to complete this research. Supporting this success, research findings are summarized in the Conclusions section of this report, and technical recommendations for design and operation are included in this section of the report.

\section{Design}

1. The design parameter for opposing, dual nozzle, blending pumps is defined by $U o D$, where $U o$ is the discharge velocity for each pump nozzle, and $D$ is the nozzle diameter.

2. For a Tank 50 design waste tank with cooling coils and a center, roof support column, pump design recommendations are:

a. For adequate blending, $\quad U_{0} D>5.10 \mathrm{feet}^{2} /$ second, and

b. To prevent sludge disturbance, $U_{0} D<6.10 \mathrm{feet}^{2} /$ second

3. For a Tank 50 design waste tank design with a center column but without cooling coils, pump design recommendations are:

a. For adequate blending, $\quad U_{0} D>3.58 \mathrm{feet}^{2} /$ second, and

b. To prevent sludge disturbance, $\quad U_{0} D<4.85 \mathrm{feet}^{2} /$ second.

4. Within the $U o D$ ranges given above, a single blending pump can blend salt contents for a Tank 50 waste tank design.

5. Nozzle diameter effects were investigated for the range of 1-1/2" - 3-5/8" full scale nozzles. Conclusions with respect to $U_{0} D$ and blending times are valid for this range of UoD.

6. Blender pump discharge nozzles and discharge flow should be angled upward $15^{\circ}$ from horizontal and oriented parallel to a tangent to the tank wall with the nozzle discharge located at the approximate mid-height of the 1,225,000 gallon tank level to prevent disturbance of sludge with physical properties consistent with the very thin, conservative sludge simulant used in this research.

7. The velocity at the sludge surface required to entrain a minimum, acceptable amount of sludge during blending is $0.268 \mathrm{ft} / \mathrm{second}$, using a sludge simulant.

8. For CFD scale-up, the theoretical velocity required to prevent any sludge entrainment at all during a transfer is $0.022 \mathrm{ft} / \mathrm{second}$. A different, more conservative acceptance criterion of no sludge entrainment was used for transfer pump testing using a sludge simulant, since a limited number of tests prevented scale-up of sludge entrainment.

9. A transfer pump with a 2" high suction screen and a flat, bottom plate installed should be placed $\geq 9.5$ " above the sludge to prevent any sludge entrainment.

10. A transfer pump with a 6" high suction screen and a flat, bottom plate installed can be placed $\geq 5.43$ " above the sludge without sludge entrainment.

11. A transfer pump without a bottom plate requires a $25.76 \mathrm{inch}$, or greater, sludge clearance to prevent disturbance of a conservatively modeled sludge.

\section{Operations}

1. Tracer quantities of acid and base were added to a pilot scale tank to determine recommended minimum blending times, where the quantity of tracer material scaled up to a several hundred gallon addition to Tank 50. Predicted blending times are statistically compensated to provide the maximum blending times with $95 \%$ confidence, which is a common acceptance criterion for experimental results. Consequently, average blending times may be as much as $70 \%$ less than the predicted maximum values. 
2. The term "similar fluid" requires definition, where similar solutions have similar viscosity and density. Quantifying material property differences to quantitatively define "similar" solutions was not performed during this research.

3. The maximum predicted full scale blending times are recommended as follows for a Tank 50 design without cooling coils, a center roof support column, and similar fluids.

a. At $U o D=4.85 \mathrm{feet}^{2} /$ second the recommended blending time is 4.86 hours.

b. At $U o D=3.58 \mathrm{feet}^{2} / \mathrm{second}$ the recommended blending time is 6.58 hours.

4. The maximum predicted full scale blending times are recommended as follows for a Tank 50 design with cooling coils, a center roof support column, and similar fluids.

a. At $U o D=6.10 \mathrm{feet}^{2} / \mathrm{second}$ the recommended blending time is 8.89 hours.

b. At $U o D=5.10 \mathrm{feet}^{2} /$ second the recommended blending time is 10.63 hours.

5. When large quantities of salt solutions which are denser than, or the same as, the tank contents are added to a tank, blending may possibly be completed by the transfer process without operating the blending pump at all. Recommended blending times ensure that the tank contents are fully blended, since the quantitative effects of transferring denser fluids into less dense fluids at full scale were not further investigated. Further investigation is recommended, since only one test was performed for this condition.

6. When less dense solutions are added to denser solutions in a tank, blending times may increase to several days or longer. The effects of batch salt concentrations on blending times during bulk transfers at full scale were not further evaluated for the addition of less dense salt solutions to denser salt solutions. Further investigation is recommended, since only one test was performed for this condition.

7. For full scale blending, a settling time of 33 days is required to prevent sludge disturbance, based on testing of a conservative, slow settling sludge simulant.

8. Changes in the riser location for fluid additions (transfers into the pilot scale tank) had little effect on blending times. 


\section{TABLE OF CONTENTS}

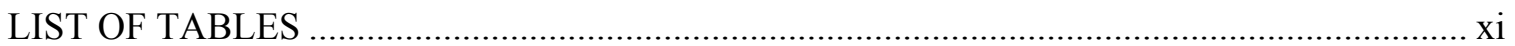

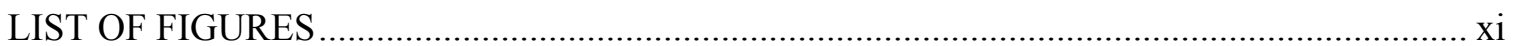

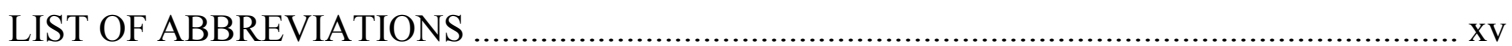

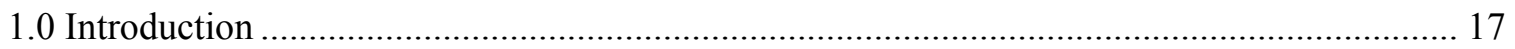

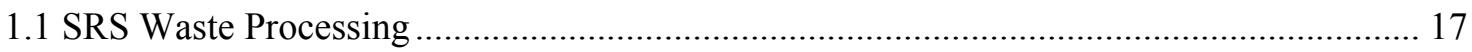

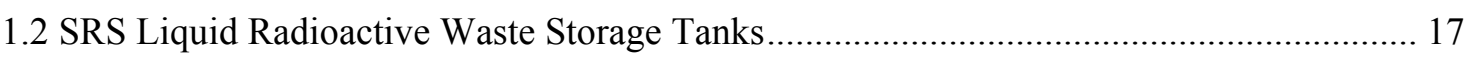

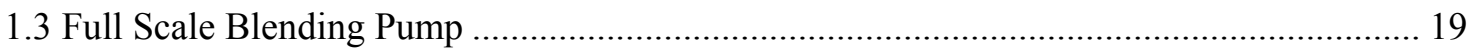

1.4 Full Scale Transfer Pump for Transfers from the Tank ................................................... 21

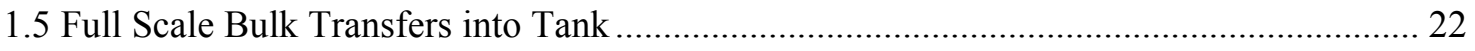

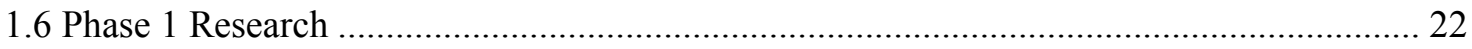

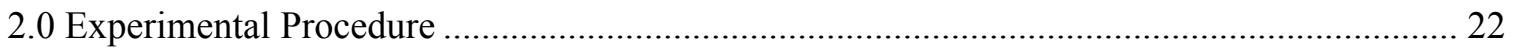

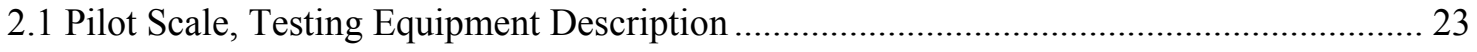

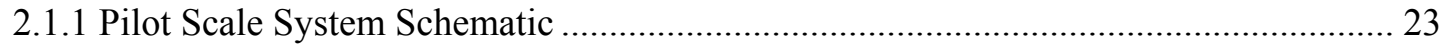

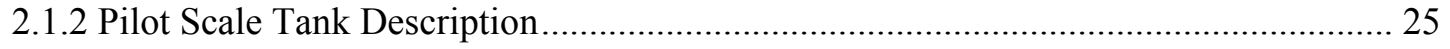

2.1.3 Pilot Scale Blending Pump Model Details ...................................................................... 26

2.1.4 Pilot Scale Transfer Pump Model Details .................................................................... 28

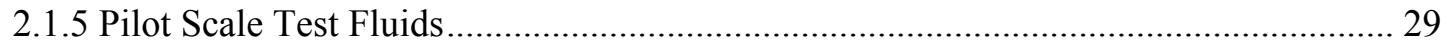

2.1.6 Instrumentation and Pilot Scale Equipment Installation ............................................. 30

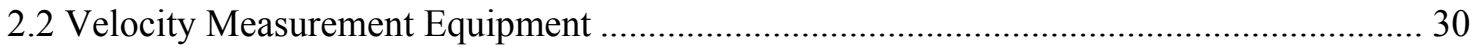

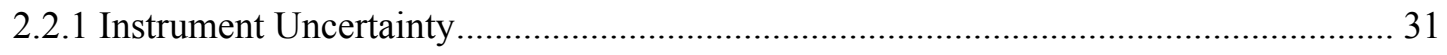

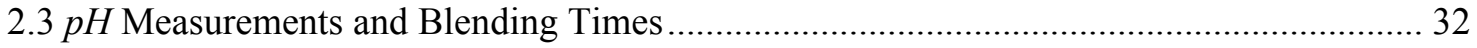

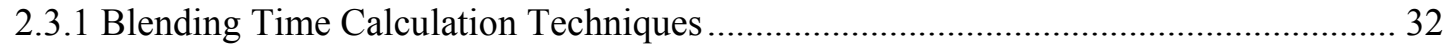

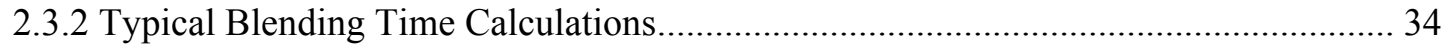

2.4 Monitoring Sludge Concentration Using Turbidity Measurements.................................... 35

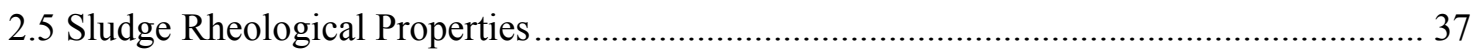

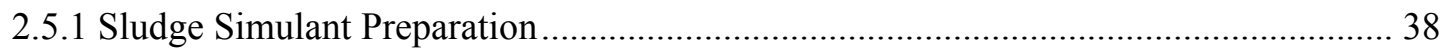

2.5.2 SB6 Sludge Simulant Addition to the Pilot Scale Tank ................................................ 38

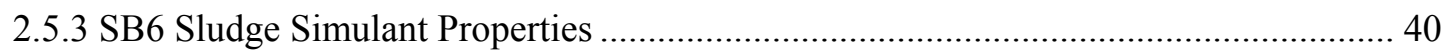

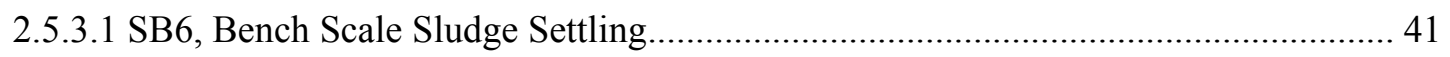

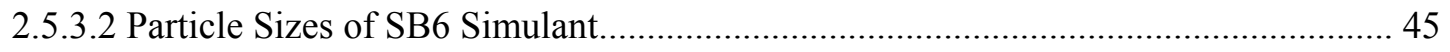

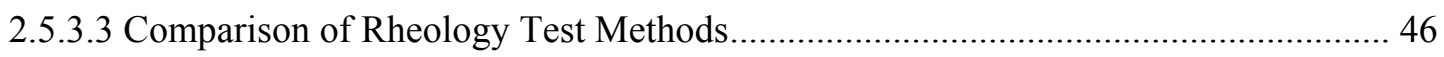

2.5.3.4 Summary of SB6 Simulant Particle Size and Yield Stress Changes......................... 47

2.5.3.5 Chemical Composition of SB6 Simulant ................................................................. 47 


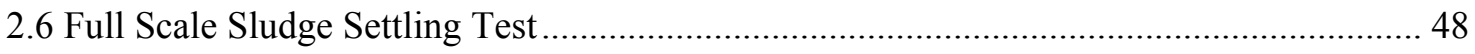

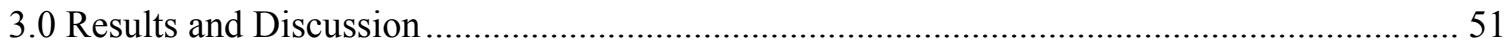

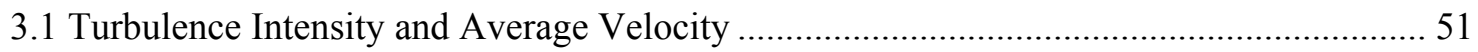

3.1.1 Velocity Data and Comparison to CFD Models ............................................................ 55

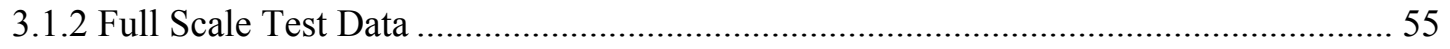

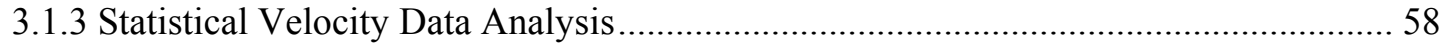

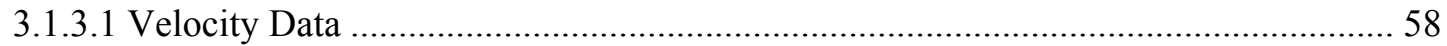

3.1.3.2 First Approximation for Velocity Comparison of CFD to Experiment ...................... 60

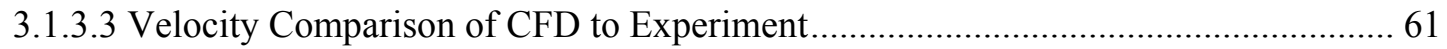

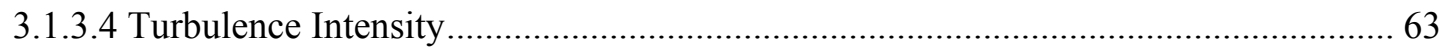

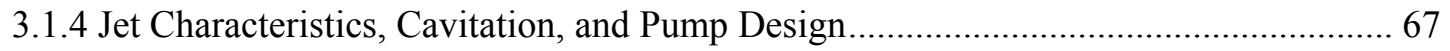

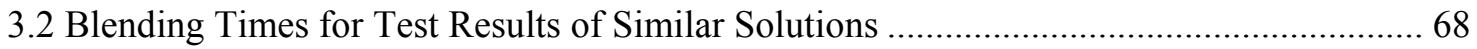

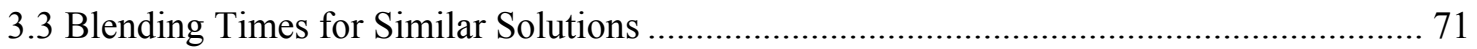

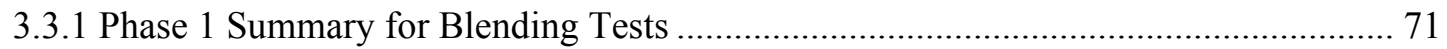

3.3.2 Phase 2, Pilot Scale Blending Results for Similar Solutions ........................................ 73

3.3.3 Statistical Analysis and CFD Results for Blending of Similar Solutions ...................... 78

3.3.4 Comparison of Test Results to Published Results.......................................................... 80

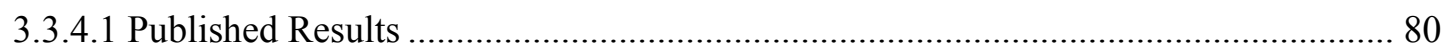

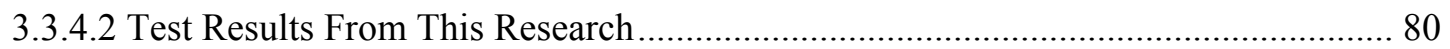

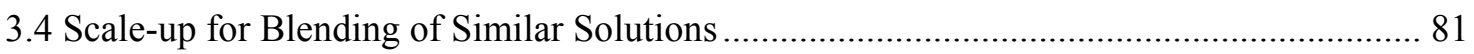

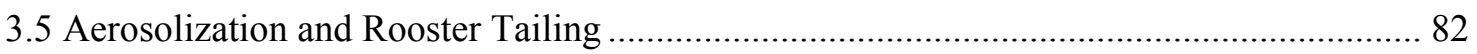

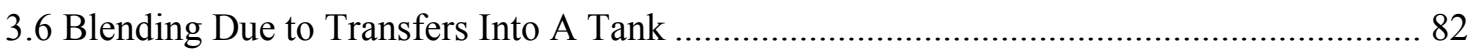

3.6.1 Blending During Transfers of Similar Solutions or Transfers of Denser into Less Dense

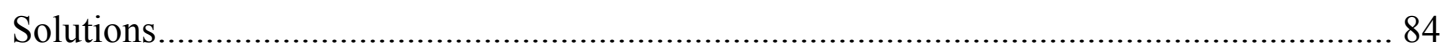

3.6.2 Blending During Transfers of Less Dense Solutions into Denser Solutions.................. 85

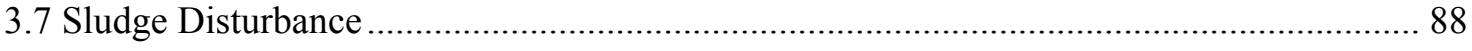

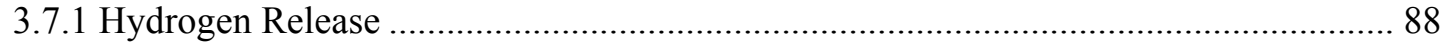

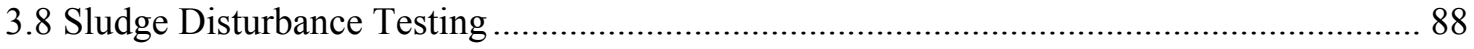

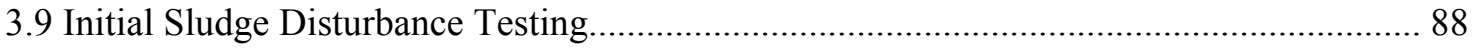

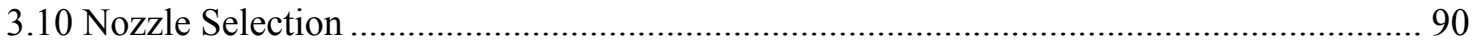

3.11 Sludge Disturbance in a Pilot Scale Tank Without Coils ................................................. 90

3.11.1 Pilot Scale UoD for a Tank Without Coils Containing $\mathrm{NaNO}_{2}$ Solution.................... 91

3.11.2 Pilot Scale UoD for a Tank Without Coils Containing Water ................................... 93

3.11.3 Velocity Acceptance Criterion for a Tank Without Coils ........................................... 94 
3.11.4 Sludge Disturbance in a Full Scale Tank Without Coils .......................................... 96

3.11.5 Blending Time in a Full Scale Tank Without Coils for Similar Fluids....................... 96

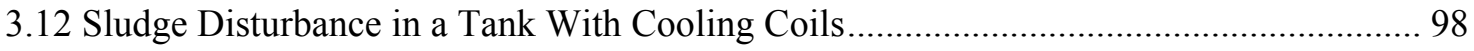

3.12.1 Velocity Acceptance Criterion for a Tank With Coils ................................................ 98

3.12.2 Sludge Disturbance in a Full Scale Tank With Coils .................................................. 99

3.12.3 Blending Time in a Full Scale Tank With Coils for Similar Fluids ............................ 99

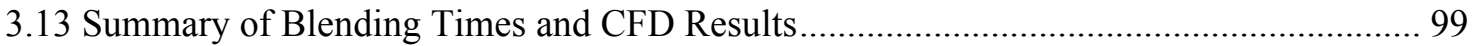

3.14 Material Property Effects on Sludge Disturbance During Blending............................... 101

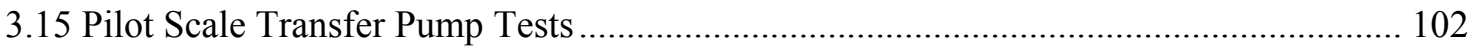

3.15.1 Sludge Transfer for a Pump Without a Bottom Plate................................................ 103

3.15.2 Pilot Scale Sludge Transfer Tests for a Pump With a Bottom Plate Installed .......... 106

3.15.3 CFD Models for a Transfer Pump With a Bottom Plate Installed ............................ 110

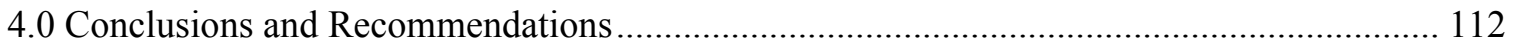

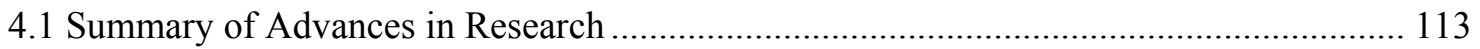

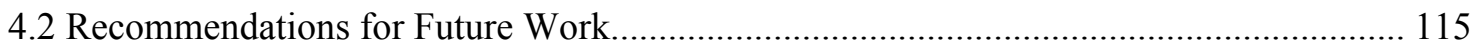

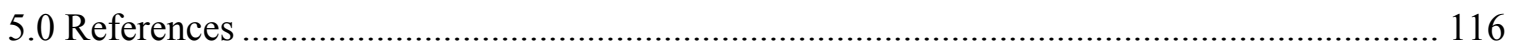

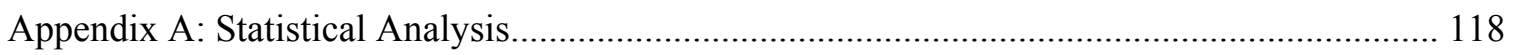

Appendix B: Velocity Test Data for Constant Pump Flow Rates ............................................ 153

Appendix C: Sodium Concentration Measurements During Blending Tests .............................. 158

Appendix D: ADMP, Partial Velocity Data at the Elevation of the Jet Nozzles.......................... 161 


\section{LIST OF TABLES}

Table 2-1: Percent Solids Concentrations ( $\mu \mathrm{g} / \mathrm{g}$ : As-received and After Test Completion............ 48

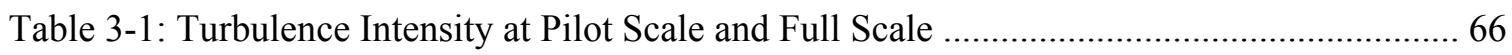

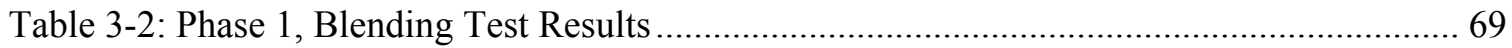

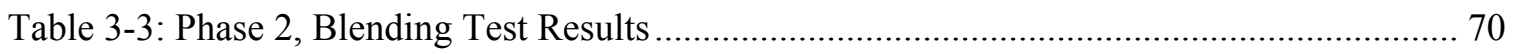

Table 3-4: Pilot Scale Test Groupings for Comparison to CFD Models...................................... 74

Table 3-5: CFD and Statistical Data for Blending Tests ............................................................ 79

\section{LIST OF FIGURES}

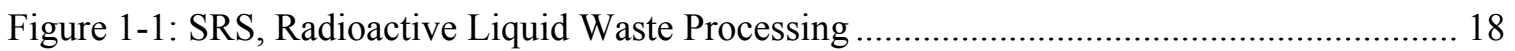

Figure 1-2: Full Scale, Cooling Coil Installation .................................................................... 19

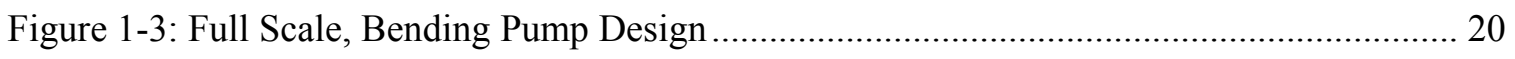

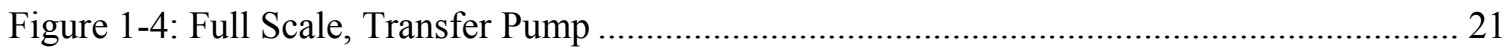

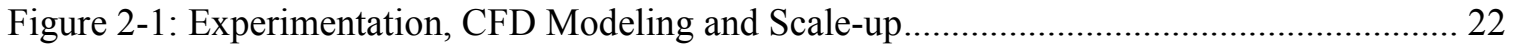

Figure 2-2: Detailed Piping and Instrumentation Diagram .................................................... 24

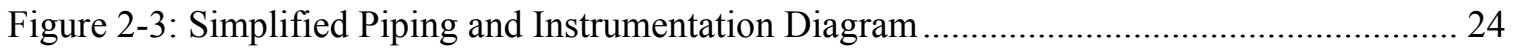

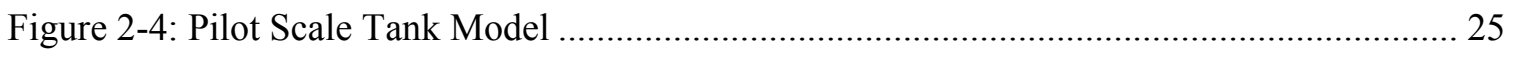

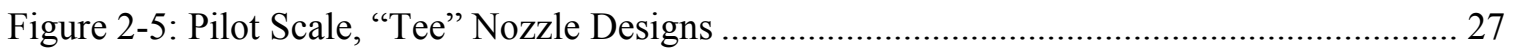

Figure 2-6: Final Pilot Scale Blending Pump Nozzle Design and Installation............................. 28

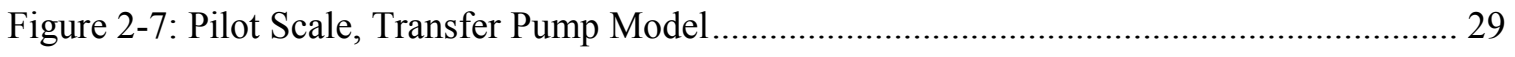

Figure 2-8: Phase 2, Locations of Turbidity Probes, $p H$ Probes, and Velocity Probes................. 30

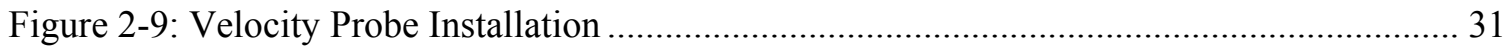

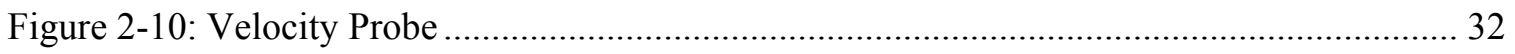

Figure 2-11: Typical Phase 1, Pilot Scale Blending Test Result, Test 25, $U o D=0.47 \mathrm{ft}^{2} /$ second 34

Figure 2-12: Pilot Scale Tank Contents Not Blended During Phase 1 Testing, Test 22, UoD=0.09

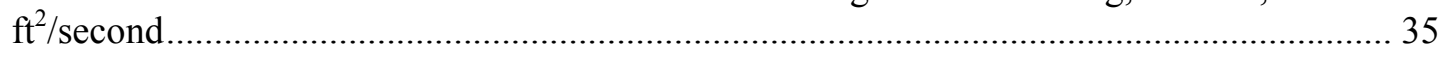

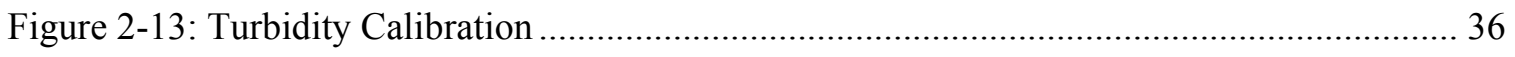

Figure 2-14: Typical Sludge Properties Obtained by Diluting Radiocative Waste Samples ........ 37 
Figure 2-15: As-received SB6 Simulant Rheology Results From a 55 Gallon Drum 38

Figure 2-16: SB6 Simulant Rheology Data After Initial Blending of SB6 and $\mathrm{NaNO}_{2}$ Plus $\mathrm{NaOH}$ Using Standard Vane. 39

Figure 2-17: Final SB6 Simulant Rheology Results at Test Completion, Density $=1.316 \mathrm{~g} / \mathrm{ml} . .39$

Figure 2-18: Settling of As-received SB6 and Settling of SB6 Mixed with Supernate. 40

Figure 2-19: Settling Comparison for SB6 Simulant and Radioactive SB6 Sludge / Waste. 41

Figure 2-20: Rheology Testing Settled SB6 in Water Plus $\mathrm{NaOH}$ and in $\mathrm{NaNO}_{2}$ plus $\mathrm{NaOH}$, Supernate Simulant 42

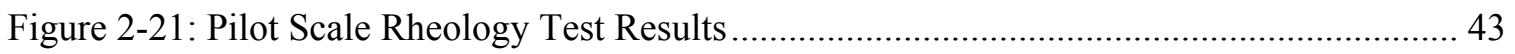

Figure 2-22: Pilot Scale Rheology Test Results 44

Figure 2-23: As-received, SB6 Simulant Particle Size Distribution for Partially Settled, Incompletely Mixed Sample 45

Figure 2-24: As-received, SB6 Simulant Particle Size Distribution for Fully Mixed Sample...... 45

Figure 2-25: SB6 Simulant Particle Size Distribution After Initial Mixing of SB6 with $\mathrm{NaNO}_{2}$ and $\mathrm{NaOH}$ 46

Figure 2-26: SB6 Simulant Final Particle Size Distribution After Test Completion 46

Figure 2-27: SB6 Simulant Rheology Data After Initial Blending of SB6 and $\mathrm{NaNO}_{2}$ Plus $\mathrm{NaOH}$ Using Modified Vane 47

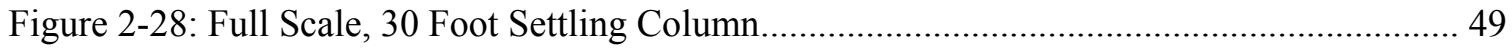

Figure 2-29: Settled Bed Height in Full Scale Settling Column Test.......................................... 50

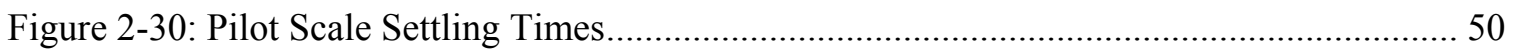

Figure 2-31: Settling Column, Turbidity Measurements.......................................................... 51

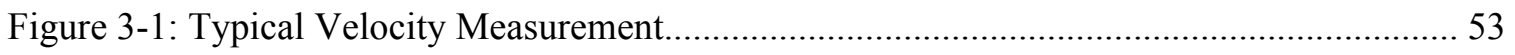

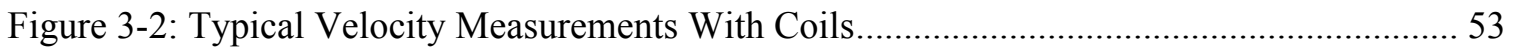

Figure 3-3: Typical Velocity Measurements Without Coils .................................................... 54

Figure 3-4: Variation of the Mean Velocity During a Test .......................................................... 54

Figure 3-5: ADMP, Operating With the Water Level Near the Pump Discharge Centerline ....... 56

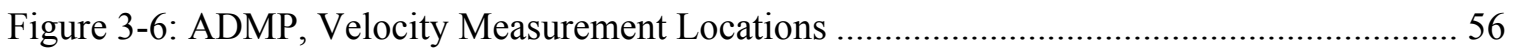

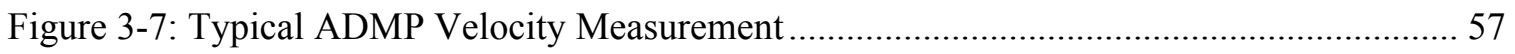

Figure 3-8: Comparison of ADMP Experimental Data to CFD Results ...................................... 57

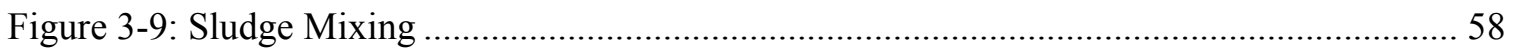




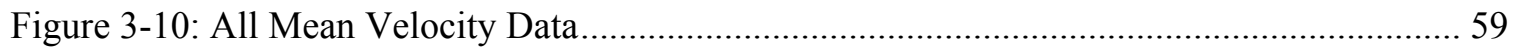

Figure 3-11: Mean Velocity for Full Scale and Pilot Scale Data ................................................. 60

Figure 3-12: Variation of Experimental Mean Velocities Compared to CFD Velocities ............. 61

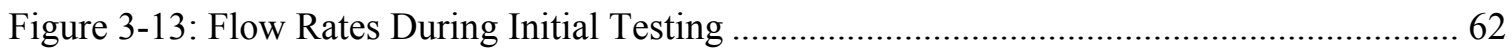

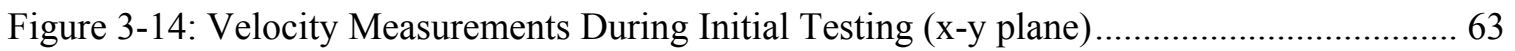

Figure 3-15: Turbulence Intensity at a Lower Pump Speed (x and y directions) ......................... 65

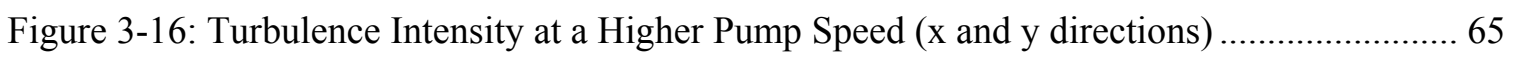

Figure 3-17: Typical Pump Flow Rates During a Phase 2 Blending Test.................................... 68

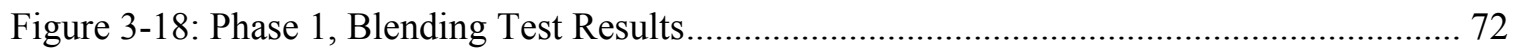

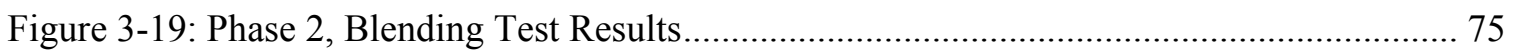

Figure 3-20: Blending Tests Used to Establish a Bounding CFD Correction Factor.................... 76

Figure 3-21: Blending Times for a Tank without Coils at the UoD Required to Disturb Sludge 76

Figure 3-22: Blending Times for a Tank with Coils at the UoD Required to Disturb Sludge ...... 77

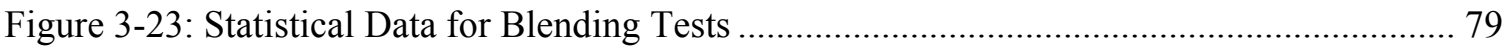

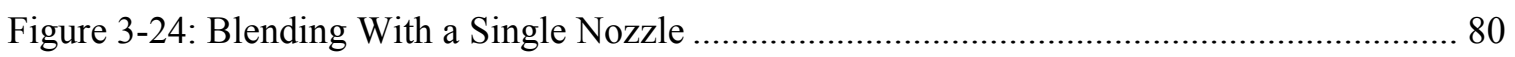

Figure 3-25: Simplified Schematic for Transfers Into the Pilot Scale Tank ............................... 83

Figure 3-26: $\mathrm{pH}$ Measurements for Transfer of $\mathrm{NaNO}_{3}$ to Water .............................................. 84

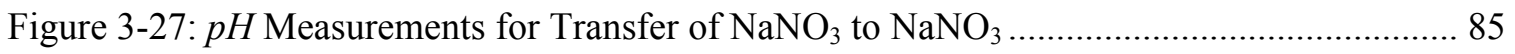

Figure 3-28: Interface Layer, Level Changes During Blending of a Stratified Salt Solution,

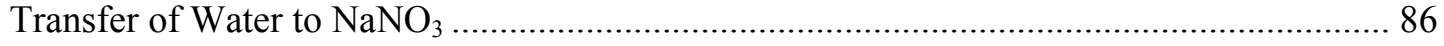

Figure 3-29: Interface Layer Between Water and Salt Solution Layers, Transfer of Water to $\mathrm{NaNO}_{3}$

Figure 3-30: $p H$ Changes Due to Blending After Transfer of Water to $\mathrm{NaNO}_{3}$, Transfer of Water to $\mathrm{NaNO}_{3}$

Figure 3-31: Example of Significant Sludge Disturbance, Velocities at the Sludge Plane 89

Figure 3-32: Example of Significant Sludge Disturbance, Concentrations Determined From Turbidity Probes.

Figure 3-33: Concentrations Due to Incremental $U o D$ Changes in a Tank Without Coils Filled With $\mathrm{NaNO}_{2}$ Solution

Figure 3-34: Concentrations at $U o D \approx 0.58 \mathrm{ft}^{2} /$ second in a Tank Without Coils Filled With $\mathrm{NaNO}_{2}$ Solution 
SRNL-STI-2011-00151

5/26/11 Revision 0

Figure 3-35: Concentrations Due to Incremental $U o D$ Changes in a Tank Without Coils Filled With Water 93

Figure 3-36: Concentrations at $U o D \approx 0.58 \mathrm{ft}^{2} /$ second in a Tank Without Coils Filled With Water

Figure 3-37: Velocities at the Sludge Layer for a Pilot Scale, Slip Plane Model, $U o D=0.58$

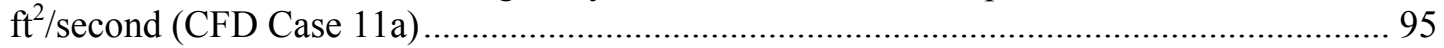

Figure 3-38: Velocities at the Sludge Layer Elevation for a Pilot Scale Blending Model, $U o D=$ $0.58 \mathrm{ft}^{2} /$ second (CFD Case $11 \mathrm{~b}$ )......

Figure 3-39: Velocities for a Full Scale Tank Without Coils, $U o D=6.3 \mathrm{ft}^{2} /$ second (CFD Case 13)

Figure 3-40: Velocities for a Full Scale Tank Without Coils, $U o D=5.1 \mathrm{ft}^{2} /$ second (CFD Case 20a, Slip Plane Sludge Model).

Figure 3-41: Velocities for a Full Scale Tank Without Coils, $U o D=5.1 \mathrm{ft}^{2} /$ second (CFD Case 20, Wall Plane Blending Model).....

Figure 3-42: Velocities at the Sludge Layer for the Pilot Scale, Slip Plane Model, $U o D=0.70$ $\mathrm{ft}^{2} /$ second (CFD Case 12b).

Figure 3-43: Velocities at the Sludge Layer for the Full Scale, Slip Plane Model, $U o D=7.3$

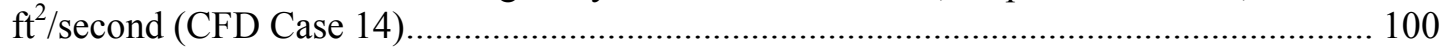

Figure 3-44: Velocities at the Sludge Layer for the Full Scale, Blending Model, $U o D=6.1$

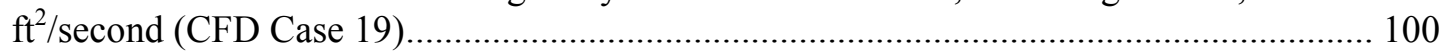

Figure 3-45: Velocities at the Sludge Layer for the Full Scale, Slip Plane Model, $U o D=6.1$

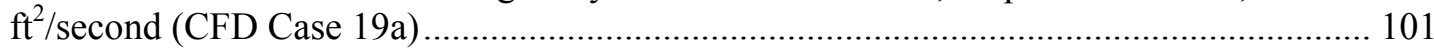

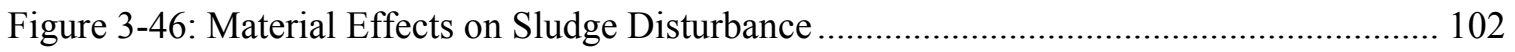

Figure 3-47: Initial Sludge Disturbance for a Transfer Pump Without a Bottom Plate .............. 104

Figure 3-48: Transfer Pump Sludge Disturbance Test Without a Bottom Plate Installed........... 105

Figure 3-49: Velocities When the Transfer Pump is 9/16” Above the Sludge Layer, ................ 106

Figure 3-50: Variable Height Transfer Pump Sludge Disturbance Tests With a Bottom Plate

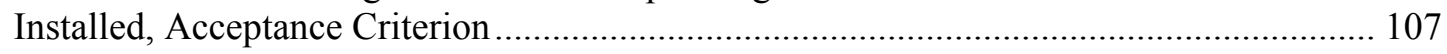

Figure 3-51: Sludge Disturbance When a Pump with a Bottom Plate is Installed Near or On the Sludge Surface 108

Figure 3-52: Transfer Pump Tests at a 3/8" Sludge Clearance for a Pump with a Bottom Plate, $\mathrm{NaNO}_{2}$ 109

Figure 3-53: Sludge Disturbance Tests when the Transfer Pump is 3/8" Above the Sludge Layer, $\mathrm{NaNO}_{2}, 1.1 \mathrm{gpm}(\mathrm{CFD}$ Case 16a, $0.028 \mathrm{ft} /$ second Maximum Velocity at the Surface) ...... 111 


\section{LIST OF ABBREVIATIONS}

\begin{tabular}{|c|c|}
\hline$A D M P$ & Advanced Design Mixing Pump \\
\hline$C$ & Correlation constant \\
\hline$C^{\prime}{ }_{i}$ & Normalized concentration \\
\hline$C_{i}$ & Measured variable concentration \\
\hline$C_{0}$ & Initial concentration \\
\hline$C_{\infty}$ & Final equilibrium concentration \\
\hline$C F D$ & Computational fluid dynamics \\
\hline$C W$ & Curtiss Wright \\
\hline$D A S$ & Data acquisition system \\
\hline$D$ & Pump nozzle diameter, feet \\
\hline$D S S$ & Decontaminated salt solution \\
\hline$E D L$ & Engineering Development Laboratory \\
\hline$E C R$ & Effective cleaning radius \\
\hline$F N U$ & Formazin Nephelometric Units \\
\hline gpm & Gallons per minute \\
\hline$K$ & Constant \\
\hline$M S T$ & Monosodium titanate \\
\hline$n$ & Number of velocity measurements \\
\hline$P \& I D$ & Process and Instrumentation Drawing \\
\hline SB6 & SRS, Sludge Batch 6 \\
\hline$S B P$ & Submersible blender pump \\
\hline$S D I$ & Salt Disposition Integration project \\
\hline$S E$ & Strip effluent \\
\hline$S R N L$ & Savannah River National Laboratory \\
\hline$S R R$ & Savannah River Remediation, LLC \\
\hline$S W P F$ & Salt Waste Processing Facility \\
\hline$S p G$ & Specific gravity \\
\hline$T$ & Tank diameter, feet \\
\hline$T T Q A P$ & Task Technical Quality Assurance Plan \\
\hline$U T L$ & Upper tolerance limit \\
\hline$V_{i}$ & Instantaneous velocity, feet/second \\
\hline$V_{f}$ & Velocity fluctuation, feet/second \\
\hline$V_{n}$ & Velocity fluctuation, feet/second \\
\hline$V^{\prime}$ & Turbulence intensity \\
\hline
\end{tabular}




$\begin{array}{ll}V & \text { Velocity, feet/second } \\ V_{a v g} & \text { Average velocity, feet/second } \\ V_{x} & \text { Velocity in the } \mathrm{x} \text { direction, feet/second (radial) } \\ V_{x y} & \text { Resultant velocity in a horizontal plane at a point, feet/second } \\ V_{x y z} & \text { Resultant velocity at a point, feet/second } \\ V_{y} & \text { Velocity in the y direction, feet/second (tangential) } \\ V_{z} & \text { Velocity in the z direction, feet/second (vertical) } \\ V F D & \text { Variable frequency drive } \\ U o & \text { Feet/second } \\ U o D & \text { Pump design parameter, } \mathrm{ft}{ }^{2} / \text { second } \\ W A C & \text { Waste Acceptance Criteria } \\ \rho & \text { Density, mg/l } \\ \tau & \text { Yield stress, Pascals }\end{array}$




\subsection{Introduction}

Savannah River Remediation (SRR) will prepare and transfer 300,000 to 800,000 gallon batches of salt solution as feedstock for the Salt Waste Processing Facility (SWPF). Previous Tank Farm mixing applications focused on suspension of solids for removing those solids for further processing. Blending of miscible salt solutions from a variety of source tanks into a single wellblended batch without disturbing any settled solids is a new mixing application for the Tank Farms. Conceptually, a submersible centrifugal pump will be used to provide blending function. Research was required to define the appropriate technical basis for the submersible blender pumps (SBP). After completion of blending, a centrifugal transfer pump will transfer the blended salt solution batch from a Blend tank to Tank $49 \mathrm{H}$ which will serve as the feed tank for SWPF. The transfer pump is required to transfer the blended liquid to a downstream tank, and prevent excessive sludge transfer from the tank. The requirements for blending time, pump dimensions and flow rates, and the effects of sludge disturbance were initially unknown, and pilot scale experimental testing combined with CFD modeling were selected as research techniques.

\subsection{SRS Waste Processing}

Radioactive liquid waste is stored in forty-nine (49), 750,000 - 1,300,000 gallon, underground tanks at the Savannah River Site (SRS ) in three different waste forms. The top of an underground storage tank is shown in Figures 1-1A, and the waste forms typically contained in a waste tank are shown in Figure 1-1B. These waste forms are liquid salt solutions referred to as supernates, precipitated salts referred to as saltcake, and denser fluids referred to as sludge on the tank bottom. Note that about half of the residual waste radioactivity is contained in the sludge which is only eight percent of the total waste volume (Figure 1-1B).

Research presented here focused on supernate preparations in waste tanks prior to transfer to the Salt Waste Processing Facility (SWPF, Figure 1-1E). At SWPF, separations processes yield three products: strip effluent (SE) containing concentrated Cesium, a monosodium titanate (MST)/sludge stream containing strontium and actinides, and a low level decontaminated salt solution (DSS) stream. The SE and MST/sludge streams are transferred to the Defense Waste Processing Facility (DWPF, Figure 1-1D), where they are incorporated into molten glass for future disposition. Decontaminated salt solutions are transferred to the Saltstone facility (Figure 1-1C), where the decontaminated salt solutions are mixed with grout for permanent disposition at SRS in South Carolina.

\subsection{SRS Liquid Radioactive Waste Storage Tanks}

The Blend and Feed Project within the SDI portfolio will configure selected waste tanks as Blend Tanks where batches of salt solution feed for SWPF will be received, blended, and qualified. The project will also prepare Tank $49 \mathrm{H}$ as the feed tank for SWPF. Some Type IIIA tanks, which may serve as blend tanks, contain approximately three miles of serpentine, two inch diameter cooling coils and a center roof support column, as shown in Figure 1-2.

In preparing batches of SWPF feed, salt solutions will be transferred from other waste tanks into blend tanks, where different salt solution may stratify in the blend tanks (Figure 1-1F). Sludge may already be present in the blend tanks initially, or sludge may accumulate on the tank floors over time during transfers of salt solutions into waste tanks, since small amounts of sludge may be entrained in salt solutions transferred from other waste tanks into the blend tanks. One important goal of the blending operations in the SDI blend tanks is to ensure a well-mixed composite salt solution batch while also ensuring that the amount of solids in the waste prior to transfer to SWPF meets the SWPF Waste Acceptance Criteria $(<1200 \mathrm{mg} / \mathrm{L})$. Not only is sludge 
disturbance a potential issue for meeting the SWPF feed requirements, sludge disturbance is also important for potential trapped hydrogen releases. Hydrogen release can potentially cause flammable conditions. Minimizing sludge disturbance facilitates both of these goals. This report provides research results for sludge disturbance studies, as well as related blending research and CFD modeling, with respect to blending and transfer pump designs.

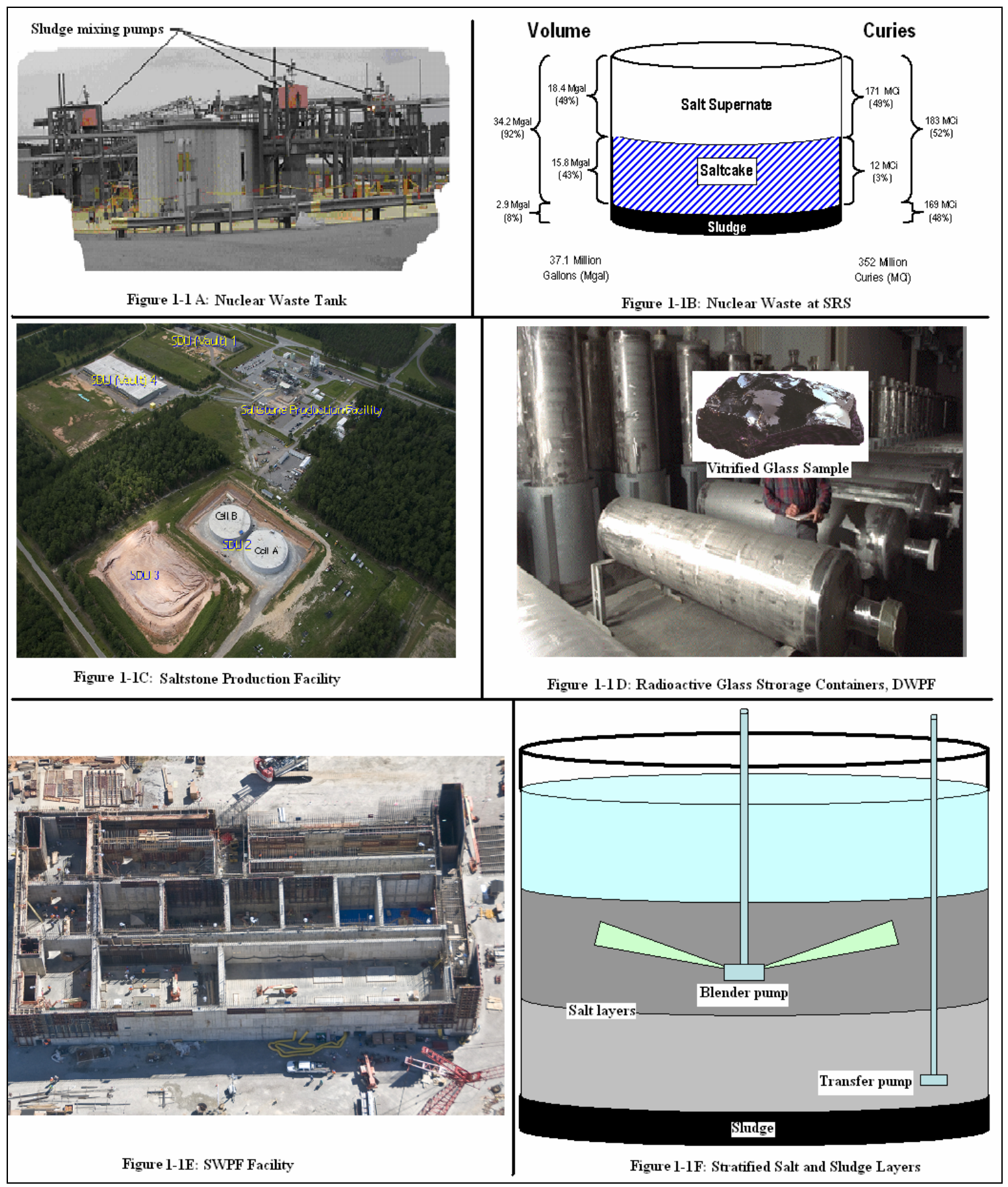

Figure 1-1: SRS, Radioactive Liquid Waste Processing 


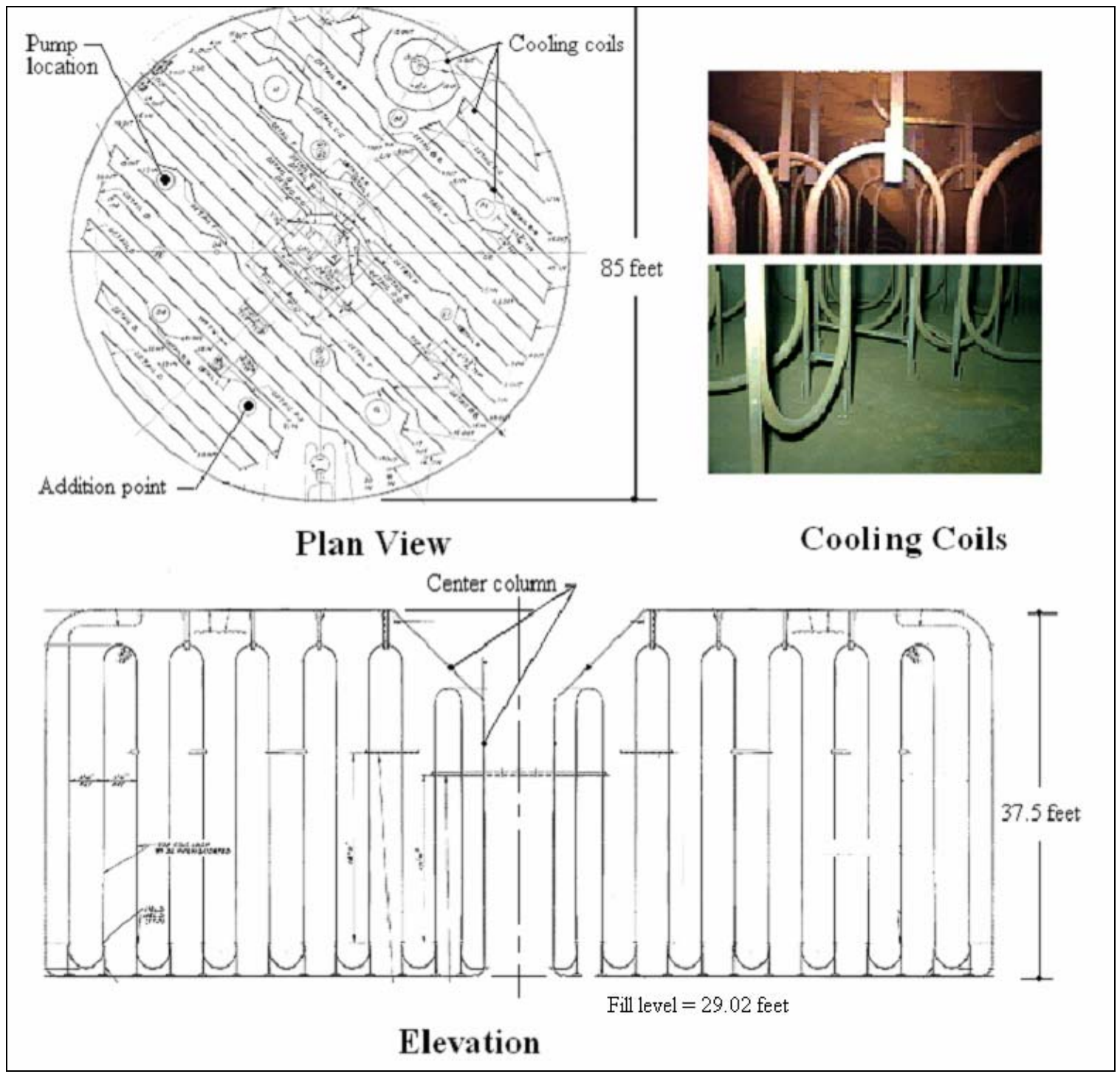

Figure 1-2: Full Scale, Cooling Coil Installation

\subsection{Full Scale Blending Pump}

The flow through the full-scale blender pump can be visualized using Figure 1-3. A cross section is shown on the left side of the figure, and an exploded view is shown on the right hand side. The flow path through the pump is followed from numbers 1 through 6 on the figure. The flow enters all around the suction screen at points labeled (1), passes up into the pump suction inlet at point (2), to the eye of the pump impeller (3), through the rotating vanes of the impeller as the fluid velocity increases (4), down through circuitous vertical passages to a directional cone (5), and out through the pump nozzles into the tank (6). Part of the flow also cools the submersible motor (not shown). A pump assembly drawing and photo of the machined pump casing are also provided in the figure. 

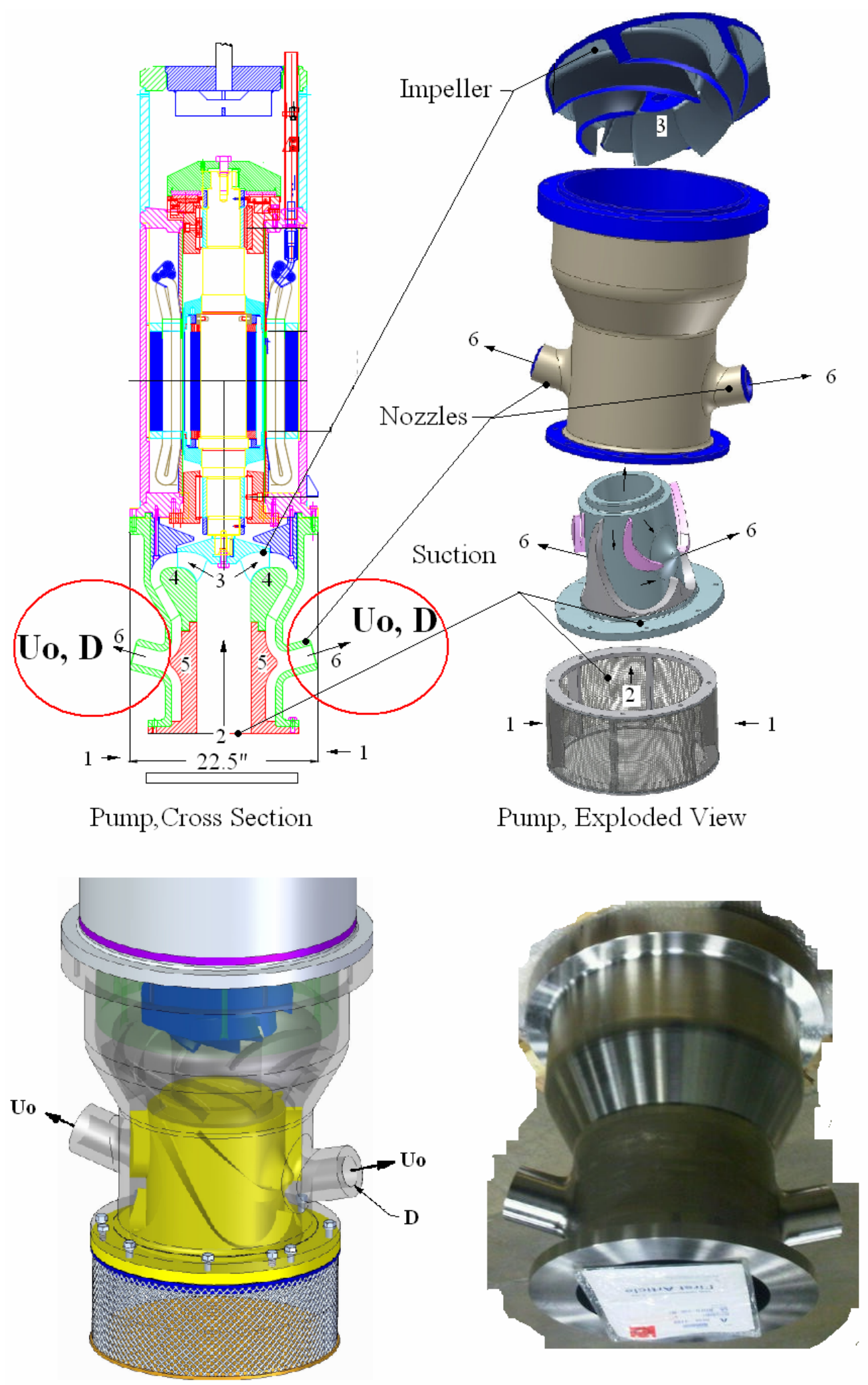

Pump Assembly

$\mathrm{D}=2.25^{\prime \prime}$

Pump Casing

Figure 1-3: Full Scale, Bending Pump Design 


\subsection{Full Scale Transfer Pump for Transfers from the Tank}

A full-scale Transfer pump is shown in Figure 1-4. Fluid enters through the suction screen, cools the motor, and then exits the pump. A transfer pump mounted from the top of the tank is shown, along with a detailed view of the "business end" of the pump.

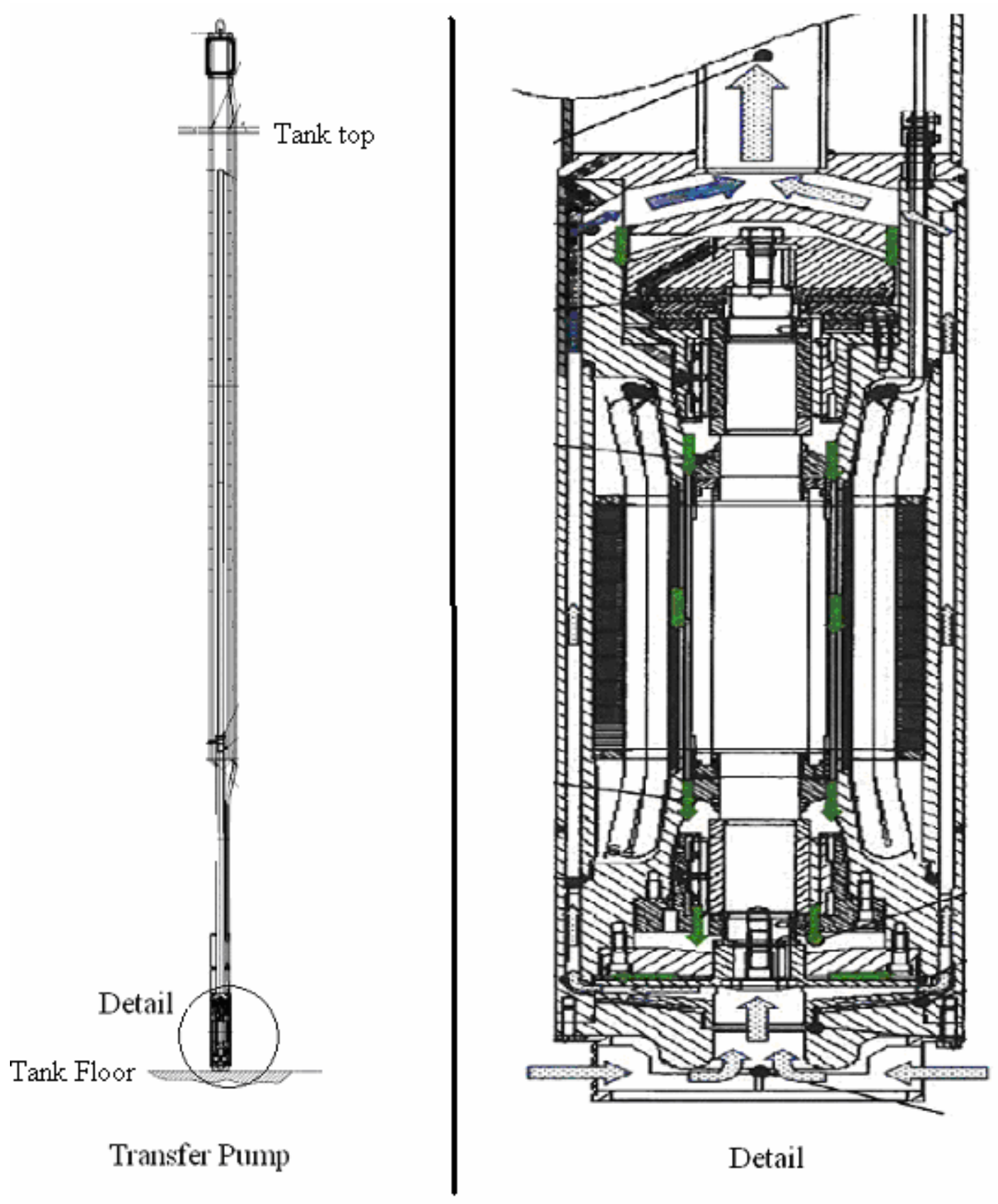

Figure 1-4: Full Scale, Transfer Pump 


\subsection{Full Scale Bulk Transfers into Tank}

In a separate set of blending tests, bulk transfers into the pilot scale tank were performed to provide insight into the effects of incoming transfers on blending in a full scale tank. Bulk transfers into the tank have different requirements than transfers out of the tank. Specifically, flow rates requirements are different per SRR to protect bounding flow rate assumptions for facility operations. Piping diameters and pump rates (typically 3" diameter, Schedule 40 pipe and $75 \mathrm{gpm}$ at full scale) were scaled down for EDL testing. The transfer pipe, or downcomer, was located above the waste level as specified in the TTQAP (Leishear, et al [2], but the final design of the downcomer was undetermined at the time of testing. However, the downcomer was modeled as straight section of pipe, which was assumed to provide a conservative result with respect to bulk transfers. The effects of incoming transfers on sludge disturbance were not investigated.

\subsection{Phase 1 Research}

Phase 1 research was performed to provide preliminary pump recommendations to enable SRR to proceed at risk, while the remaining research was completed. This report is an extension of the Phase 1 research (Leishear, Fowley, and Poirier [1]); and as such, all references, assumptions, operating parameters, dimensions, and equipment descriptions in the Phase 1 report are tacitly assumed in this document unless otherwise noted. Additional assumptions, risks, and test requirements are listed in the Phase 2, Task Technical and Quality Assurance Plan (TTQAP, Leishear, Fowley, and Poirier [2]). Also, two papers have been published in the engineering literature to document this research (Leishear, Fowley, Poirier, Lee, Steeper, and Parkinson [3 and 4]). Sufficient Phase 1 results are provided here to support recommendations and conclusions.

\subsection{Experimental Procedure}

The framework of this research is summarized in Figure 2-1. Pilot scale tests were performed with and without coils, and velocity measurements were available from full scale testing. Then, CFD models were performed for pilot scale and full scale conditions. CFD models were performed independently of experimental research to prevent biasing of modeling results. At the end of research, CFD and experiment were combined to obtain final results, where data analyses were performed using a combination of theory and CFD results.

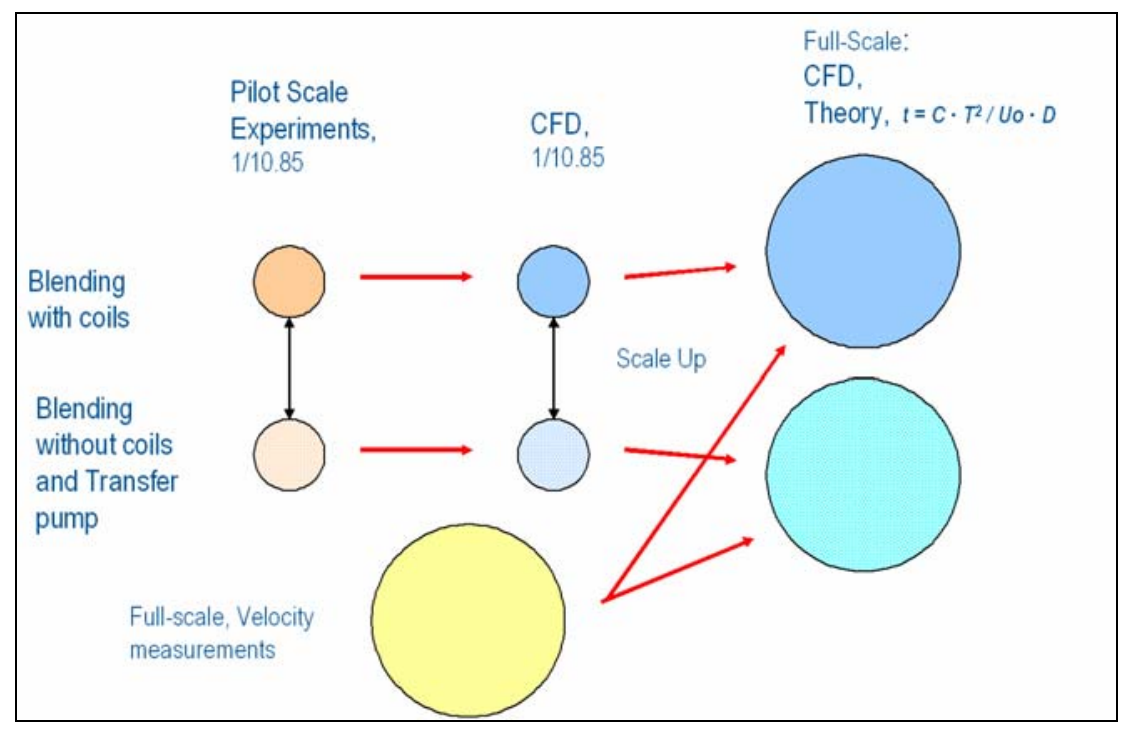

Figure 2-1: Experimentation, CFD Modeling and Scale-up 
Following an equipment description, experimental procedures for this research can be roughly separated by primary measurement techniques, i.e., velocity measurements, blending test techniques, turbidity measurement methods, material property tests (rheology), and settling tests. Other processes and measurement techniques to establish material properties are noted as required. Details of the pump designs, equipment setup, solids, and fluids follow.

\subsection{Pilot Scale, Testing Equipment Description}

A schematic for the test system is shown in Figure 2-2. A data acquisition system (DAS) recorded and calculated variables, such as $p H$, concentration, turbidity, flow rates, temperature, horsepower, motor speed, density, pump nozzle diameter, pump discharge jet velocity at the nozzle, and $U o D$ during testing. Tank temperatures were typically $70^{\circ} \mathrm{F}$ during tests as recorded on the DAS. An external centrifugal pump re-circulated the fluid into the tank through two diametrically opposed nozzles and back to the recirculation pump through the pump model suction. A variable frequency drive (VFD), and PID controller (proportional, integral, derivative controller) were used to control the motor speed and pump flow rates.

SRNL pilot scale testing dimensions were geometrically (linearly) scaled, and the pump discharge velocity remained constant at both pilot scale and full scale to ensure that jet velocities were comparable at equivalent locations in both tanks.

For most testing, simulated cooling coils were installed, but the coils were removed in some tests to quantify the effects of cooling coils on blending. In addition to acid and base testing, a blue dye was added to the pilot scale test tank to qualitatively visualize blending, and videos of the dye dispersion were recorded. The blue dye testing tentatively provided an indication of the slowest and fastest blended areas to determine optimal locations for $\mathrm{pH}$ probes. For acid and base testing, pump parameters were varied to investigate blending effects (section 2.3). Parameters considered were nozzle length, nozzle diameter, nozzle velocity, and pump orientation. Pump orientations included nozzle positions parallel to the vertical tank wall (referred to as the $0^{\circ}$ position), perpendicular to the vertical tank wall $\left(90^{\circ}\right)$, and at an angle of $45^{\circ}$ to the vertical tank wall.

As noted, equipment such as the Data Acquisition System (DAS), piping, and operational requirements are discussed in detail in the Phase 1 report. However, the pilot scale tank, instrument locations, and some of the piping were modified for Phase 2 testing.

\subsubsection{Pilot Scale System Schematic}

Major equipment consisted of pilot scale pump models, tank internals, external pumping, flow monitors, chemical addition locations (hoppers), $p H$ probes, and turbidity probes. Equipment is shown in the Piping and Instrumentation Diagrams (P\&ID) in Figure 2-2 and Figure 2-3. 
SRNL-STI-2011-00151

5/26/11 Revision 0

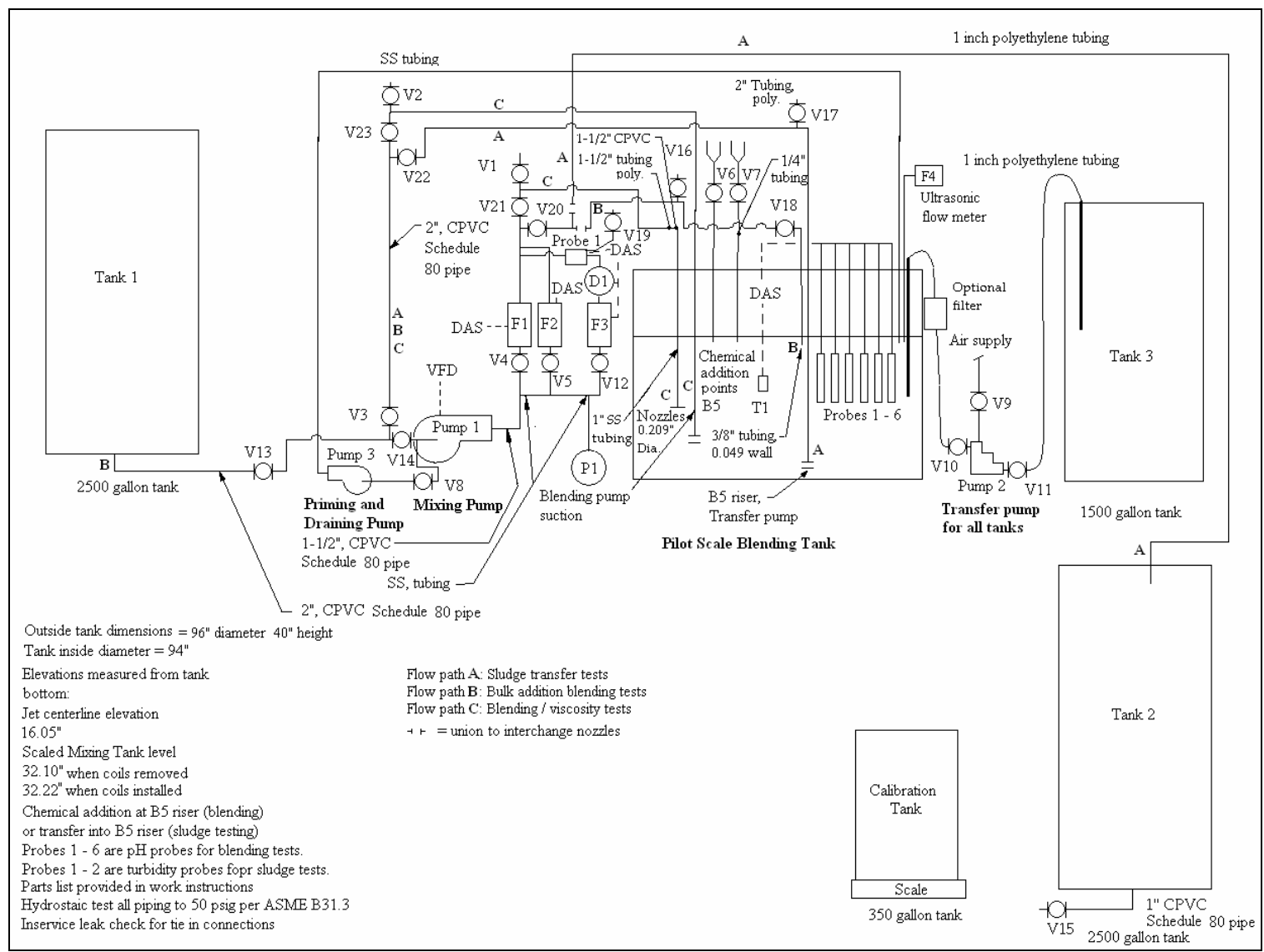

Figure 2-2: Detailed Piping and Instrumentation Diagram

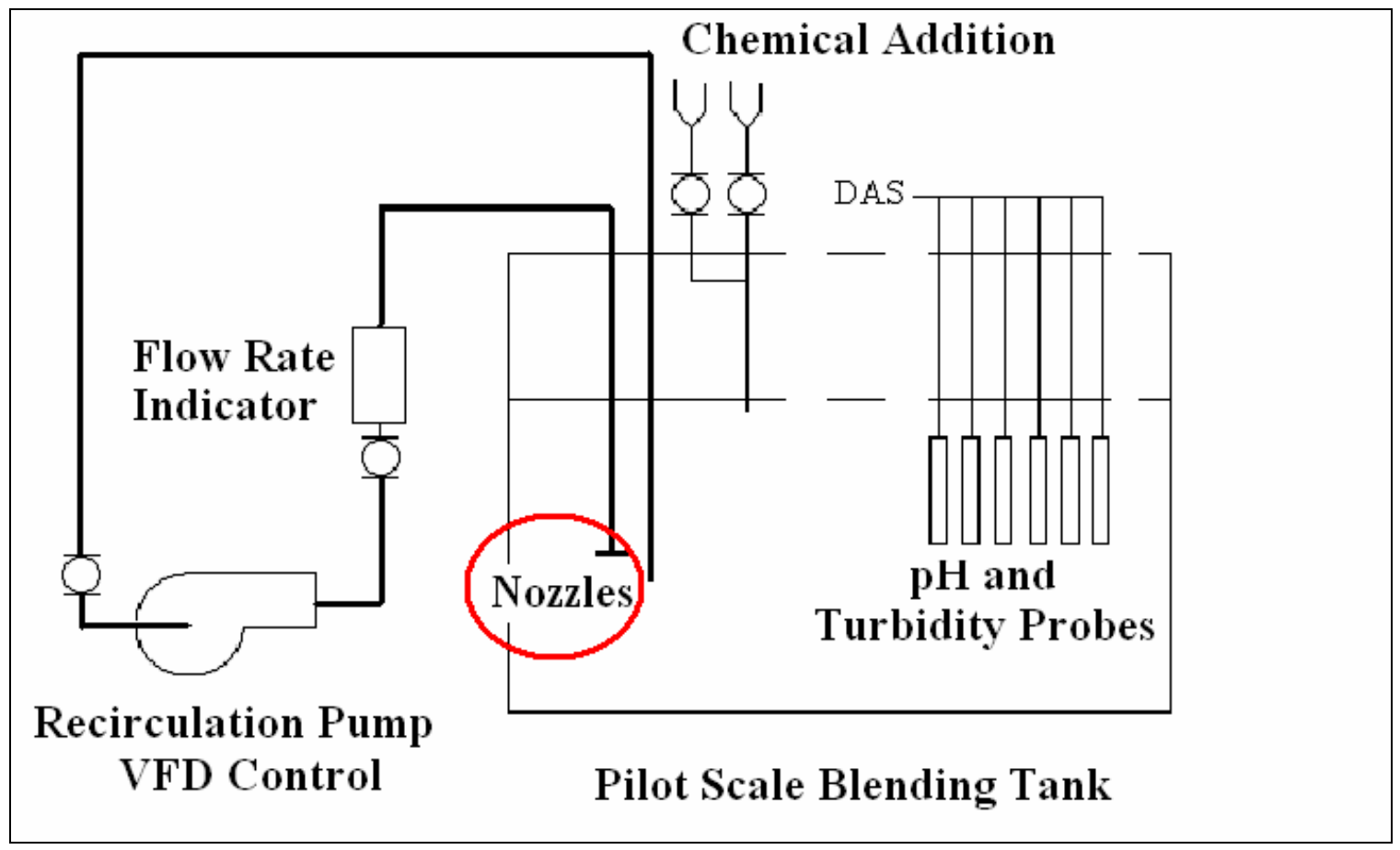

Figure 2-3: Simplified Piping and Instrumentation Diagram 


\subsubsection{Pilot Scale Tank Description}

The polyethylene 94 inch inside diameter tank used in Phase 1 was replaced by a transparent, acrylic tank of the same diameter, where waste tank components were geometrically scaled $(1 / 10.85)$. The total volume used in the pilot scale tank was 939 gallons, where the total fluid level was $32.1 \pm 0.5$ inches, and the sludge level used in testing approximately $3 / 4$ inch, where 24.6 gallons of SB6 simulant was initially added to the tank. Scaling was performed in accordance with available techniques (Poirier and Qureshi [5], Paul, et al. [6]), and further design details and scaling assumptions are available in the Phase 1 report. Models of those coils are shown in Figure 2-4. Some tests were performed using installed cooling coil models and some tests were performed without cooling coils. A centrally mounted, vertical support column, which supported the tank roof of a full scale tank was scaled and installed in the pilot scale tank. Transfer pumps and blender pumps were geometrically scaled, where the blending pump was located in the B3 riser location, and the transfer pump was raised up and down as required at the B5 riser location. The velocities at the pump discharge nozzles were equal to blender pump nozzle velocities at full-scale. Transfer pump suction inlet velocities were the same at both pilot and full scale (130 gpm at full-scale, $1.1 \mathrm{gpm}$ at pilot scale). For a pump with bottom plate, velocities were determined at the perimeter of the bottom plate, and for a transfer pump without a bottom plate, similar flow rates were used. Pump model dimensions were approximated while vendor design was in process. The scaled cooling coils, central support column, the scaled nozzle location (B5 riser), and chemical addition locations are also shown in Figure 2-4.

Chemical additions at the B5 riser location were valve controlled to ensure consistent test results, and the quantity of acid or base added to the tank varied between one and one and half liters. For Tank 50, chemical addition quantities scaled up to $326-489$ gallons. In other words, most blending tests were performed for the evaluation of several hundred gallon additions to Tank 50 . This technique adequately evaluated requirements for pump design, while minimizing test costs.

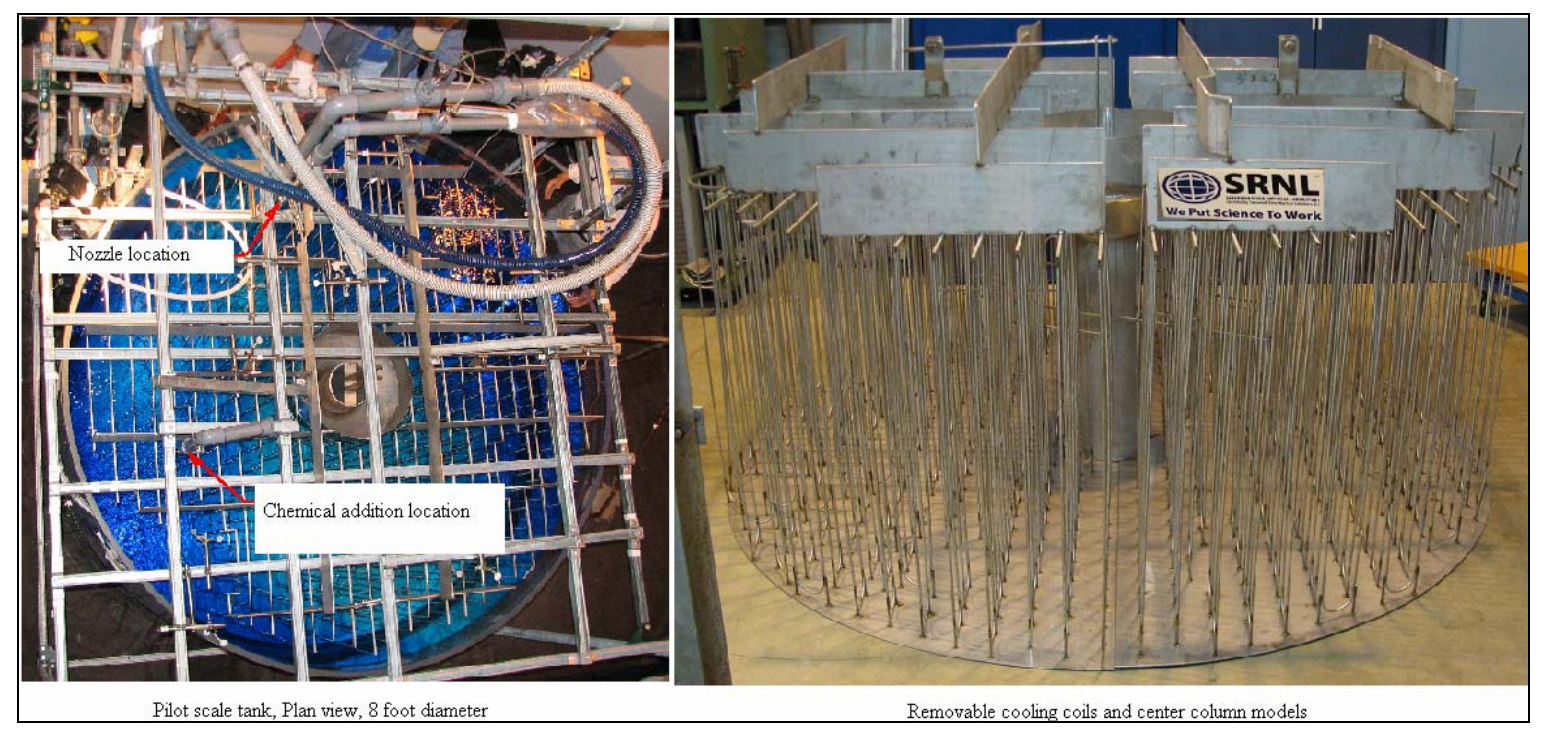

Figure 2-4: Pilot Scale Tank Model

(Design by T. Steeper) 


\subsubsection{Pilot Scale Blending Pump Model Details}

Phase 1 research investigated the effects of different nozzle lengths, diameters and velocities to establish a recommended $U o D$ and pump orientation for blending. Phase 2 research focused on a 0.209" tee nozzle blender design, a supplied CW blending pump model design, sludge disturbance, and transfer pump requirements. In fact, the recommended $U o D$ from Phase 1 research was initially specified for a CW supplied pump model, and that specification resulted in sludge disturbance for all nozzle velocities investigated at pilot scale. The CW pump model was modified by adding replaceable nozzles which were required to recommend the final nozzle design, and additional tests were successfully performed. Models for blender pumps were developed prior to, and parallel, to the final pump design. The simplified pump models used for Phase 1 testing are shown in Figure 2-5, where the models were scaled down from SRS pumps referred to as Quad Volute and Standard slurry pumps, and a "design tee", which was of the same nozzle diameter as the final design.

As Phase 1 blending tests progressed, different versions of the nozzles shown in Figure 2-5 were installed at different orientations with respect to the nozzle center line. Initially, simple tee junction nozzles and suction pipe with a drilled pipe cap on the end of the pipe were used for blending tests, as shown in Figure 2-5.

Following preliminary Phase 1 recommendations, a nozzle with $D=0.209$ " was selected by the pump manufacturer (CW) to start pump design. The final design (CW model) is shown in Figure 2-6. To represent the pump suction, a pipe was installed parallel to the supply pipe attached to the nozzle assembly. The suction inlet dimensions, cross section of the CW pump model, and assembled CW pump installed in the tank are each shown in Figure 2-6. The CW nozzle design was used for most Phase 2 blending tests, and variations of the $\mathrm{CW}$ design were used for all Phase 2, blending pump sludge disturbance tests. Further details are available in the TTQAP. 
SRNL-STI-2011-00151

5/26/11 Revision 0

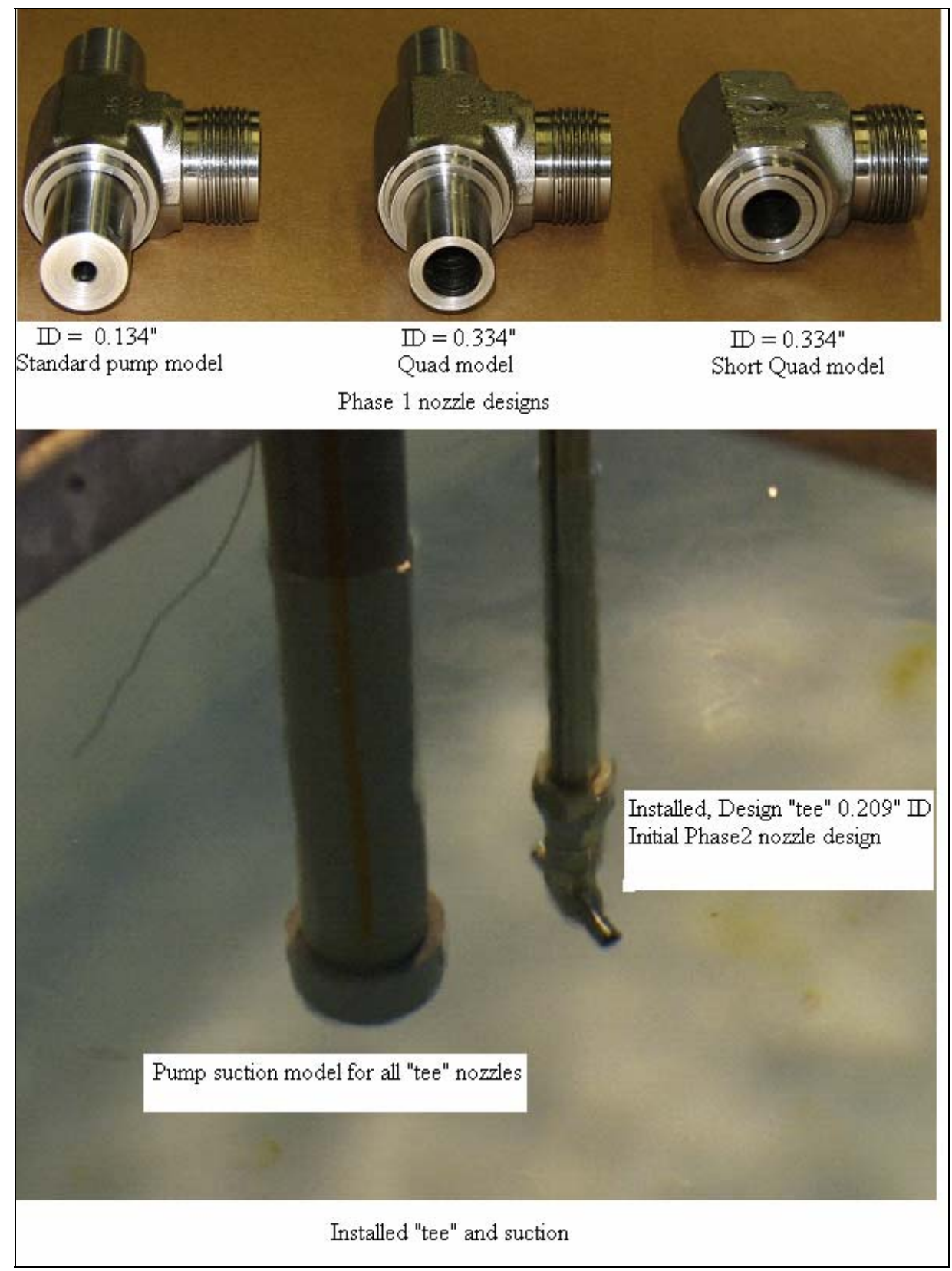

Figure 2-5: Pilot Scale, “Tee” Nozzle Designs 

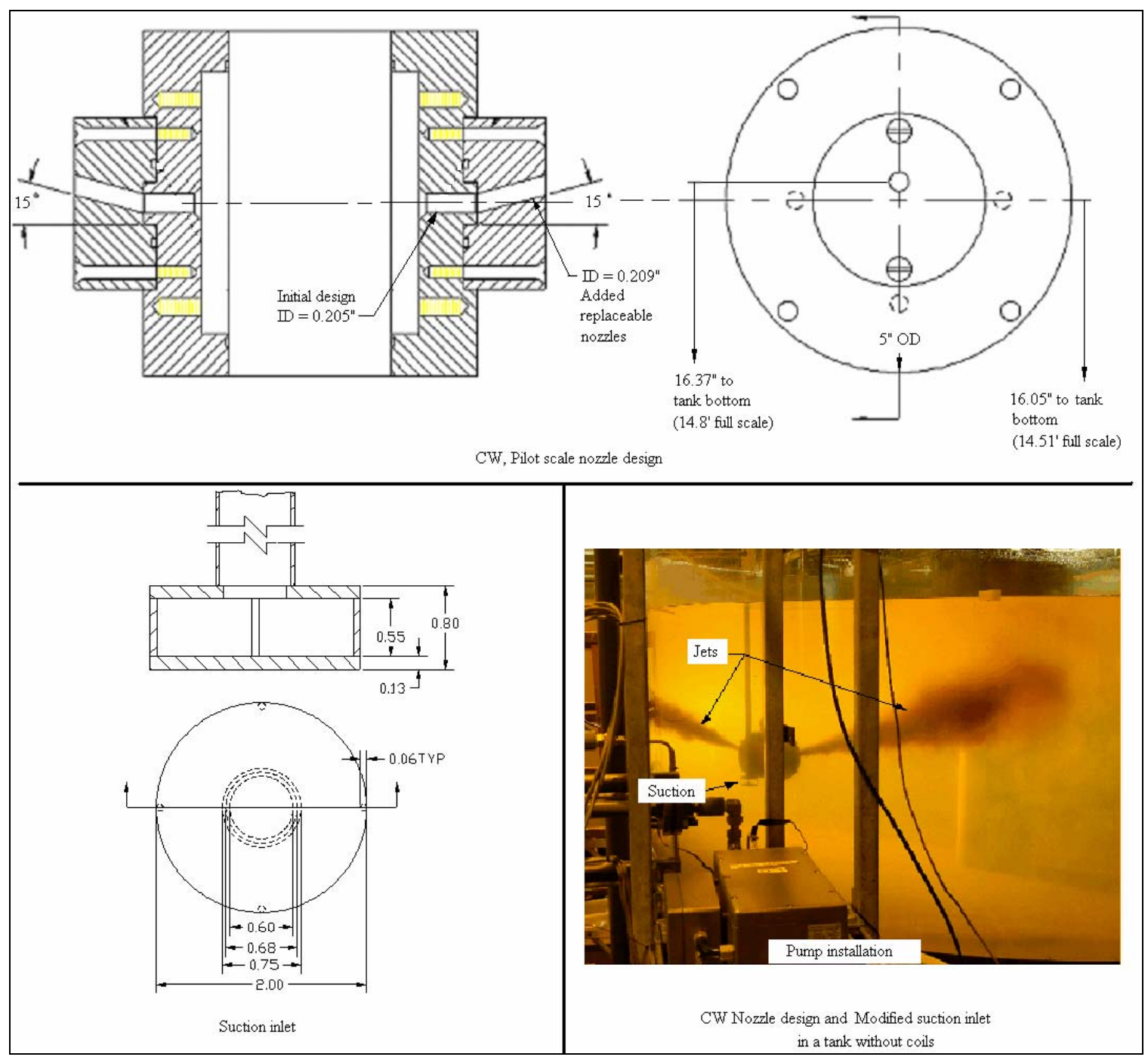

Figure 2-6: Final Pilot Scale Blending Pump Nozzle Design and Installation

\subsubsection{Pilot Scale Transfer Pump Model Details}

To model transfers to SWPF, the transfer pump suction inlet was similar to the blender suction inlet (Figure 2-7) in that tests were performed with a bottom plate, which was both removed and installed for different tests. Transfer pump suction inlet velocities were scaled from full scale (130 gpm at full-scale), and were suspended from the superstructure above the tank similar to blending pump installation. The experimentally modeled transfer pump does not reflect the final transfer pump design, and further modeling of the final pump design is recommended. The research goal was to validate a CFD models with experimental models to enable future use of CFD modeling for the final transfer pump design. 
SRNL-STI-2011-00151

5/26/11 Revision 0

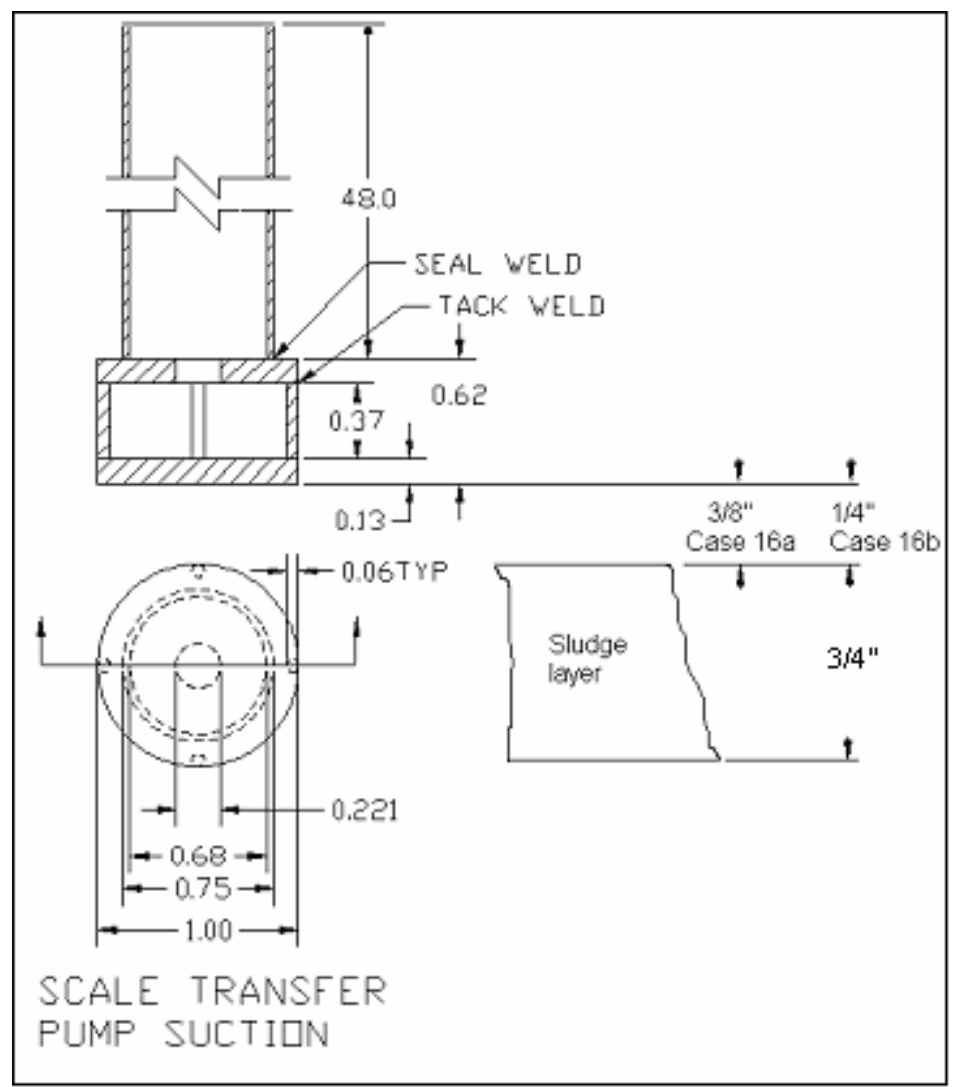

Figure 2-7: Pilot Scale, Transfer Pump Model

\subsubsection{Pilot Scale Test Fluids}

Fluids used for sludge disturbance testing included simulated SRS Sludge Batch 6 (SB6), and solutions to imitate a nearly transparent supernate. The sludge simulant was selected to provide a very conservative suspension for sludge disturbance investigations (see section 2.5), since it is slow settling and has low yield stress. Although a single non-Newtonian sludge simulant was used, different Newtonian supernate simulants were used for testing, which consisted of sodium

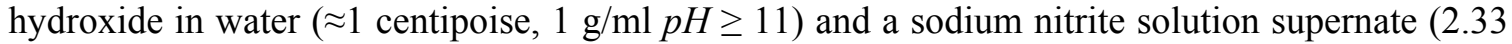
centipoise, $1.317 \mathrm{~g} / \mathrm{ml}, \mathrm{NaNO}_{2}$ ) with $\mathrm{NaOH}$ added to reach $p H \geq 11$. Salt simulants were selected to imitate 6.4 molar sodium supernate solutions, as specified by SRR. These two solutions were selected to investigate the effects of supernate properties on sludge disturbance (i.e., density and kinematic viscosity). The actual molarities were closer to 5.8 due to filtering, where salt solutions were filtered with a 0.2 micron filter to remove impurities from commercial grade salts. However, kinematic viscosity was shown to be at a maximum value, since the addition of more salt to solution had negligible effect on kinematic viscosity.

For $p H$ testing, another salt supernate simulant was used. Sodium nitrate $\left(\mathrm{NaNO}_{3}, 2.35\right.$ centipoise, $1.257 \mathrm{~g} / \mathrm{ml}$ ) was blended to approximate a kinematic viscosity similar to the $\mathrm{NaNO}_{2}$ solution used for sludge disturbance. 


\subsubsection{Instrumentation and Pilot Scale Equipment Installation}

In Figure 2-8, the locations are shown for fixed $\mathrm{pH}$ probes indicated by the designation $\mathrm{PH}$, and turbidity probes indicated by TUR. Also shown in Fig 2-8 are details of the cooling coils, riser locations, where chemical additions were made, and pump installation.

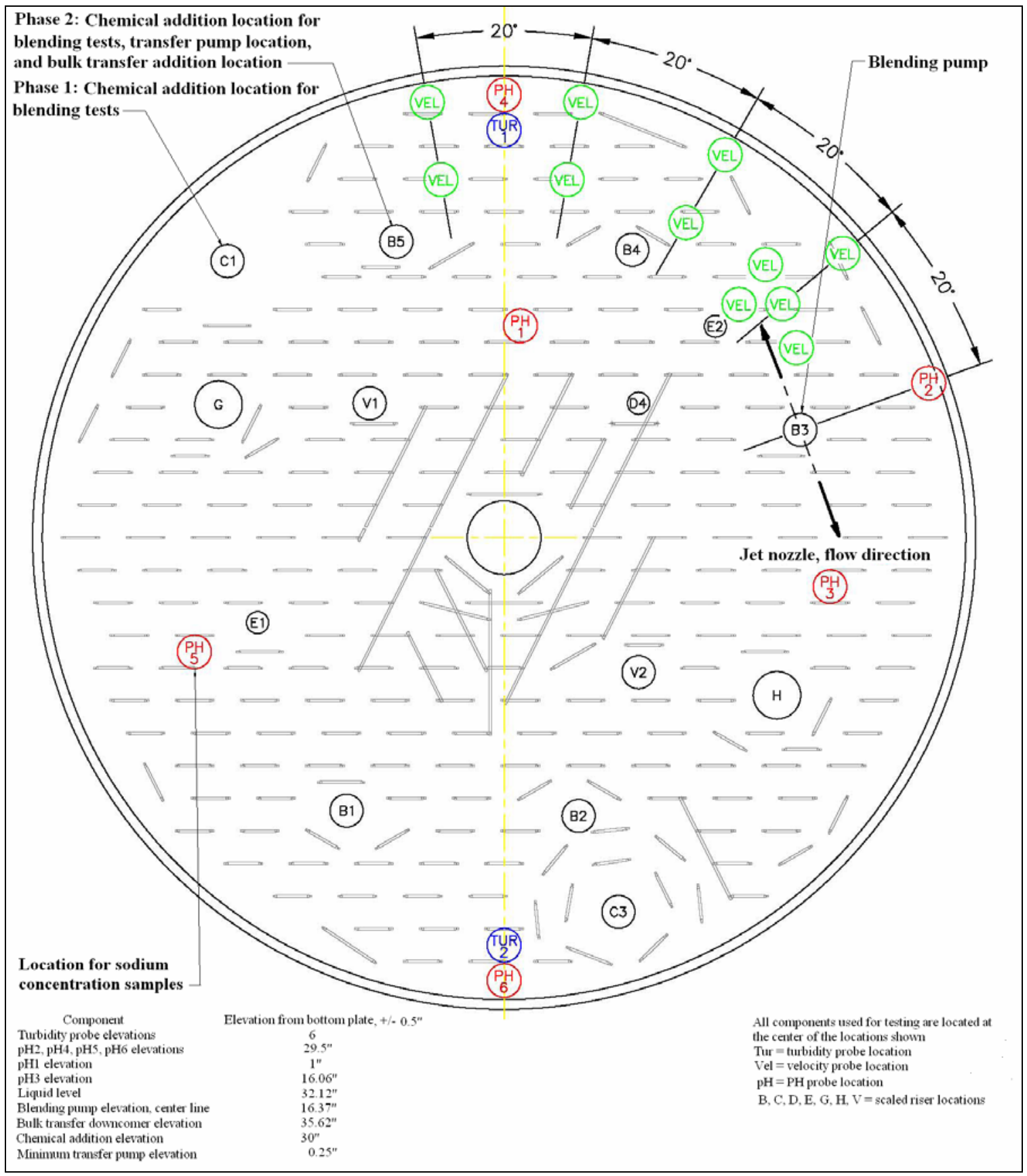

Figure 2-8: Phase 2, Locations of Turbidity Probes, $p H$ Probes, and Velocity Probes

\subsection{Velocity Measurement Equipment}

Most velocity measurement locations are shown in Figure 2-8, where detailed dimensions are provided in the CFD report (Lee [16]). A single, moveable velocity probe was attached to a rod suspended from the tank superstructure. The probe was moved to numerous elevations and radial 
locations, where the orthogonal axes of the electromagnetic sensor were aligned as shown with respect to $\mathrm{X}$ and $\mathrm{Y}$ directions in Figure 2-9. That is, velocities were measured in the $\mathrm{X}$ direction parallel to the vertical tank wall, and the $\mathrm{Y}$ direction perpendicular to the vertical tank wall. Two dimensional fluid velocity measurements were thus obtained, using a Marsh McBirney, model 511, electromagnetic velocity probe. Figure 2-10 shows the factory calibrated Marsh McBirney equipment, used to collect velocity data. The equipment consisted of a transducer probe, cable, and DAS. The instrument measured two dimensional flows in a plane normal to the longitudinal axis of the electromagnetic sensor, which was parallel to the tank bottom. The panel meters provided visual observation of flow, and the consequent analog output voltages were recorded with the DAS at $3 \mathrm{~Hz}$ for 3 - 10 minutes. The measured $\mathrm{X}$ and $\mathrm{Y}$ velocity vectors were then added to obtain an absolute velocity vector. Using this equipment, 20 ( $\mathrm{X}$ and $\mathrm{Y}$ ) velocity measurements per minute were obtained at each data point to capture variations in velocity, during velocity tests that lasted three to ten minutes. The application of the raw velocity data is discussed in section 3.1.1.

\subsubsection{Instrument Uncertainty}

As discussed in the Phase 1 report, instrument uncertainties negligibly affected pilot scale blending time calculations. The $\mathrm{pH}$ error was $0.24 \mathrm{pH}$ units. Tank temperature was monitored with a thermocouple that had a $\pm 1.7^{\circ} \mathrm{C}$ error. At the end of testing, there was a $4 \%$ error with $95 \%$ confidence of the $\mathrm{F} 1$, flow meter used to monitor pump flow rates, even though an error $<1 \%$ was noted at the beginning of testing. $p H$ probes were located within $\pm 1 / 4$ " of locations specified in the Phase 1 report. The accuracy of probe locations was ensured by attaching rods to the probe assembly to accurately obtain elevations and distance from the tank wall. At full scale, the accuracy of probe location was \pm 1 ". Velocity probes were located within $\pm 1 / 4$ " of locations specified in the CFD report (S. Lee [16]). Velocity probes had an uncertainty of $\pm 2.15 \%$ at full scale with 95\% confidence (see Figure 3-14). Phase 2 scale-up results were compensated for velocity and flow rate measurement uncertainties. The same velocity probes were used at both scales.

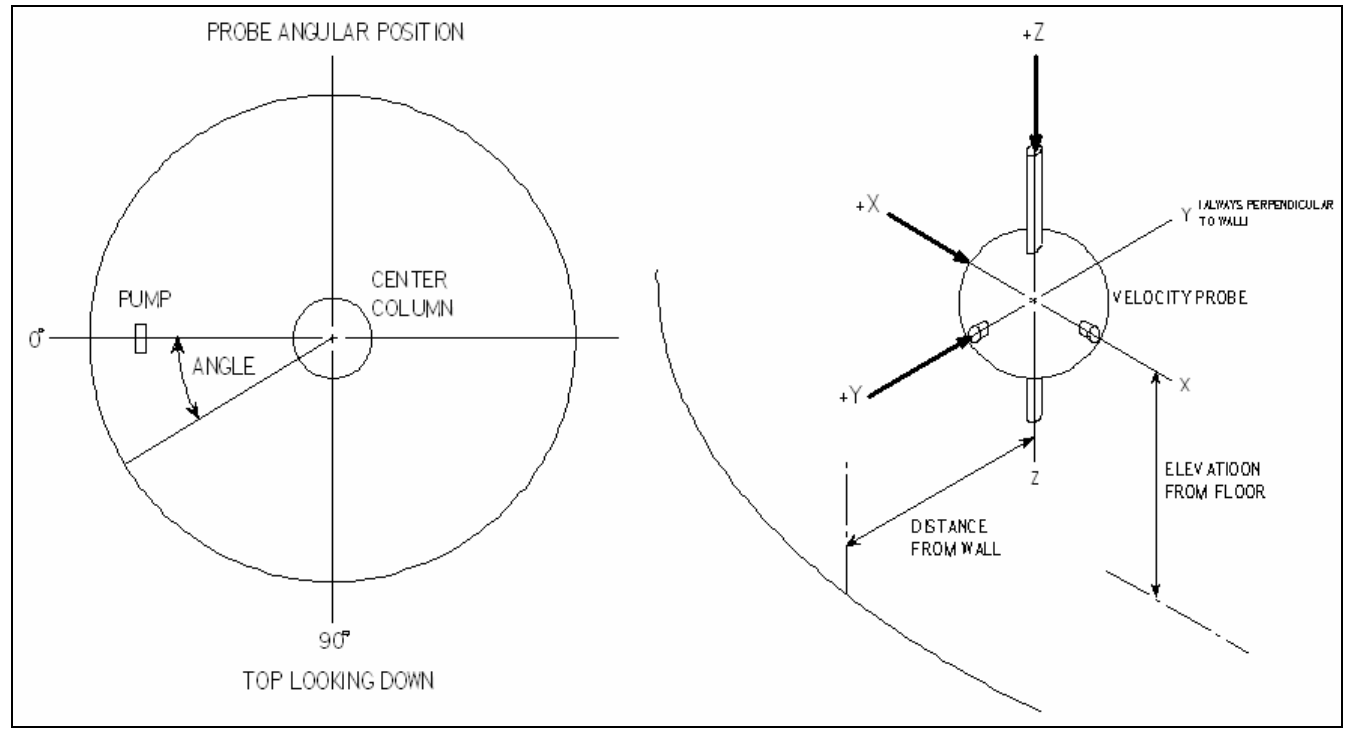

Figure 2-9: Velocity Probe Installation 


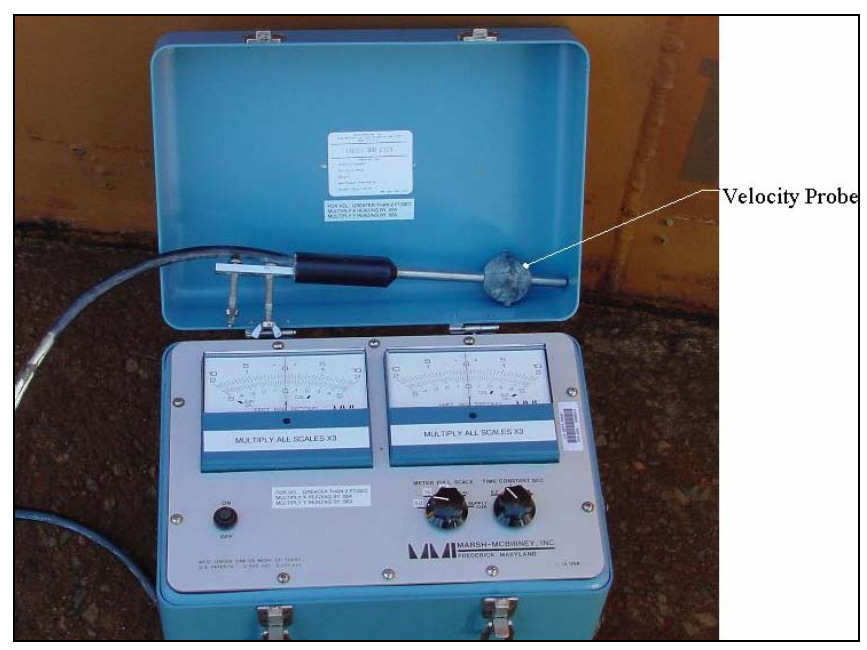

Figure 2-10: Velocity Probe

\section{$2.3 \mathrm{pH}$ Measurements and Blending Times}

Blending times are required for many process industries. In pilot-scale testing $p H$ can be used to evaluate blending time where $p H$ data is typically normalized between values of 0 and 1 , using the techniques described in the Phase 1 report. A $95 \%$ blending time occurs when tank contents attain a concentration throughout the tank within $\pm 5 \%$ of the total change in concentration. To determine $95 \%$ blending times, acid and base tracers were added to the eight foot diameter tank, and the $p H$ data was recorded and normalized on the DAS output to monitor blending. Six $p H$ probes were located throughout the tank to provide a thorough understanding of blending processes. Blending times were established when the normalized $p H$ converged between 0.95 and 1.05 on the graphs. Seventy nine different tests were performed to evaluate the effect of changes in $U o D$ on the blend time. From this data, uncertainties were calculated.

\subsubsection{Blending Time Calculation Techniques}

Much detailed discussion is provided about blending times in the Phase 1 report, and pertinent discussion is updated here to provide a comprehensive discussion of blending. The controlling factor or design parameter for blending is expressed as $U_{0} D$ (feet ${ }^{2} /$ second), where $U_{0}$ is the discharge velocity of a blending pump nozzle, and $D$ is the inside diameter of the pump nozzle. Different nozzle diameters and flow rates were used to vary $U o D$. The diameters of the nozzles used in testing were scaled from 1-1/2", 2-1/4", and 3-5/8" full scale nozzles (see Figure 2-5 for scaled nozzle designs). Equations describing the blending time for miscible liquids in tanks mixed with single horizontal turbulent jet located in one corner of the tank are typically of the general form

$$
\mathrm{t}=\left(\mathrm{C} \cdot \mathrm{T}^{2}\right) /\left(\mathrm{U}_{0} \cdot \mathrm{D}\right)=\left(3.72 \cdot \mathrm{T}^{2}\right) /(\mathrm{Uo} \cdot \mathrm{D}) \quad \text { Equation } 1
$$

where $t$ is the blending time, $C$ is a correlation constant, and $T$ is the tank diameter (Grenville and Tilton [7 and 8], Dimenna, et al [9]).

This equation shows that the blend time is a function of $U o D$, where $C$ is typically in the range: $3.0<C<4.5$. The most recently predicted value for $C$ was 3.0. Grenville noted that this value for $C$ was valid for tank volumes up to 3 million gallons. Experimentally, the constant was required for the pilot scale models, since this value is based on experimental data presented in the literature for tanks blended without a center column or coils, and a single jet nozzle with a centerline coincident to the tank radius. Accordingly, the 3.0 value for $C$ provided only an 
estimate to find flow rates and pilot scale blending times. The value for this constant was investigated as this study extended this simplified blending equation to a tank with dual nozzles in a tank without cooling coils. This study showed that this simple equation was consistent with test results, even though $C$ is affected by the number and location of nozzles. For Phase 1 testing, $C=3.72$ when the maximum blending time values were considered for dual opposing nozzles in an 8 foot diameter tank without cooling coils.

To quantify blending performance, blending times were determined using commercial $95 \%$ blending criteria. The Hydronium ion concentrations $\left[\mathrm{H}^{+}\right]$were calculated from $\mathrm{pH}$ measurements and normalized to establish mixing times for 95\% mixing (Paul, et. al [6]). The 95\% mixing criteria is a generally accepted criterion which defines the time following the addition of a tracer at which the concentrations throughout the tank are within $\pm 5 \%$ of the bulk concentration. Normalization is a common practice for empirically quantifying mixing using concentration measurements. The $95 \%$ mixing time provided blending acceptance criteria, but lacked accuracy to quantify chemical concentrations throughout blended liquids.

From Paul, et al [6], $p H$ probes are commonly used to establish $95 \%$ blending times, which are determined from concentrations after adding a reactive tracer. To do so, a normalized concentration is calculated, where

$$
\mathrm{C}_{\mathrm{i}}^{\prime}=\frac{\mathrm{C}_{\mathrm{i}}-\mathrm{C}_{0}}{\mathrm{C}_{\infty}-\mathrm{C}_{0}}
$$

where $C^{\prime}{ }_{i}$ equals the normalized concentration, $C_{i}$ equals the measured variable concentration, $C_{0}$ equals the initial concentration, and $C_{\infty}$ equals the final equilibrium concentration. The $95 \%$ blending time equals the time required for the normalized probe output to reach and remain within 95 to $105 \%$. Equations 3 to 8 provide relationships between concentration and $p H$. For the $p H$ probe response, Equation 2 is rewritten as

$$
\begin{array}{cc}
\text { Normalized } & \text { Equation 3 } \\
\mathrm{pH}=-\log \left[\mathrm{H}^{+}\right]=\frac{\left[\mathrm{H}^{+}\right]-\left[\mathrm{H}^{+}\right]}{\left[\mathrm{H}^{+}\right]_{\infty}-\left[\mathrm{H}^{+}\right]_{0}} & \text { Equation 4 } \\
{\left[\mathrm{H}^{+}\right]=10^{-\mathrm{pH}}} & \text { Equation 5 } \\
\mathrm{pOH}=-\log \left[\mathrm{OH}^{-}\right] & \text {Equation 6 } \\
{\left[\mathrm{OH}^{-}\right]=10^{-\mathrm{pOH}}=10^{\mathrm{pH}-14}} & \text { Equation 7 } \\
\mathrm{pH}+\mathrm{pOH}=14 & \text { Equation 8 }
\end{array}
$$

and

Typical acceptance criteria for good blending in process industries are defined by $95 \%$ blending (normalized $\left[\mathrm{H}^{+}\right]$), where a typical process is paint mixing. For pharmaceutical industries, where product quality is more critical, $99 \%$ blending is sometimes used, where the normalized $\left[\mathrm{H}^{+}\right]=$ $0.99 \rightarrow 1.01$. The Phase 1 report showed that $99 \%$ blending is not recommended, or achievable, with commercially available instrumentation. A $95 \%$ blending time is the recommended acceptance criteria for this research. Probe uncertainty and solution buffering also affected blending as discussed in the Phase 1 report, since they are related to the determination of $95 \%$ blending. Diffusion of the tracers in the tank was negligible when compared to the blending effects of the jet nozzle. 


\subsubsection{Typical Blending Time Calculations}

A typical derivation of the maximum blending time is shown in Figure 2-11. In Figure 2-11, the $\mathrm{pH}$ probes converge within the $95 \%$ blending criterion near a 32 minute blending time. In Figure $2-12$, blending did not occur within a 24 hour scaled blending time, where the $p H$ probes reached equilibrium values only after the pump was operated at maximum flow. Detailed test procedures, test results, and discussions of all Phase 1 tests are provided in the Phase 1 report.

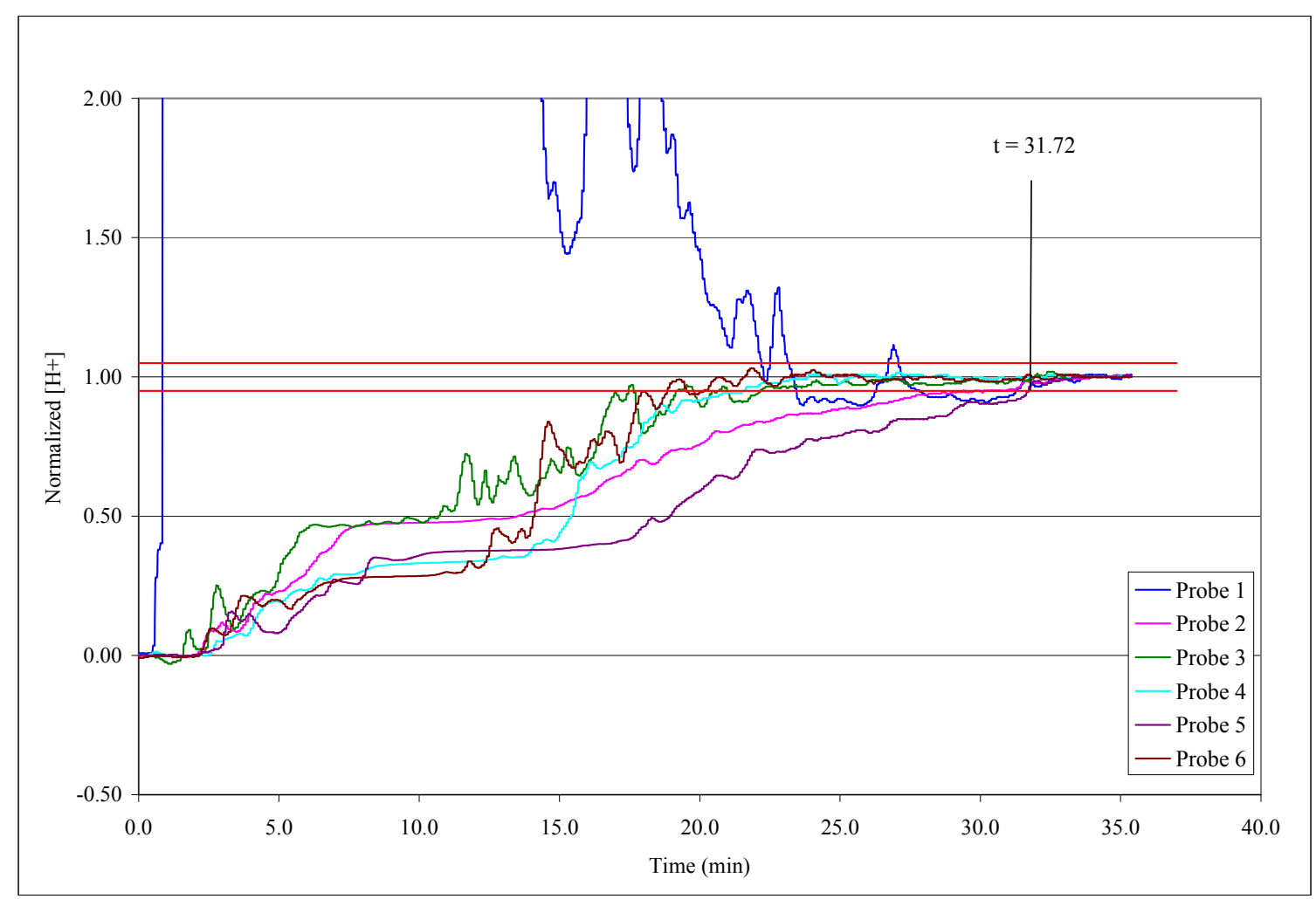

Figure 2-11: Typical Phase 1, Pilot Scale Blending Test Result, Test 25, UoD =0.47 $\mathrm{ft}^{2} /$ second 


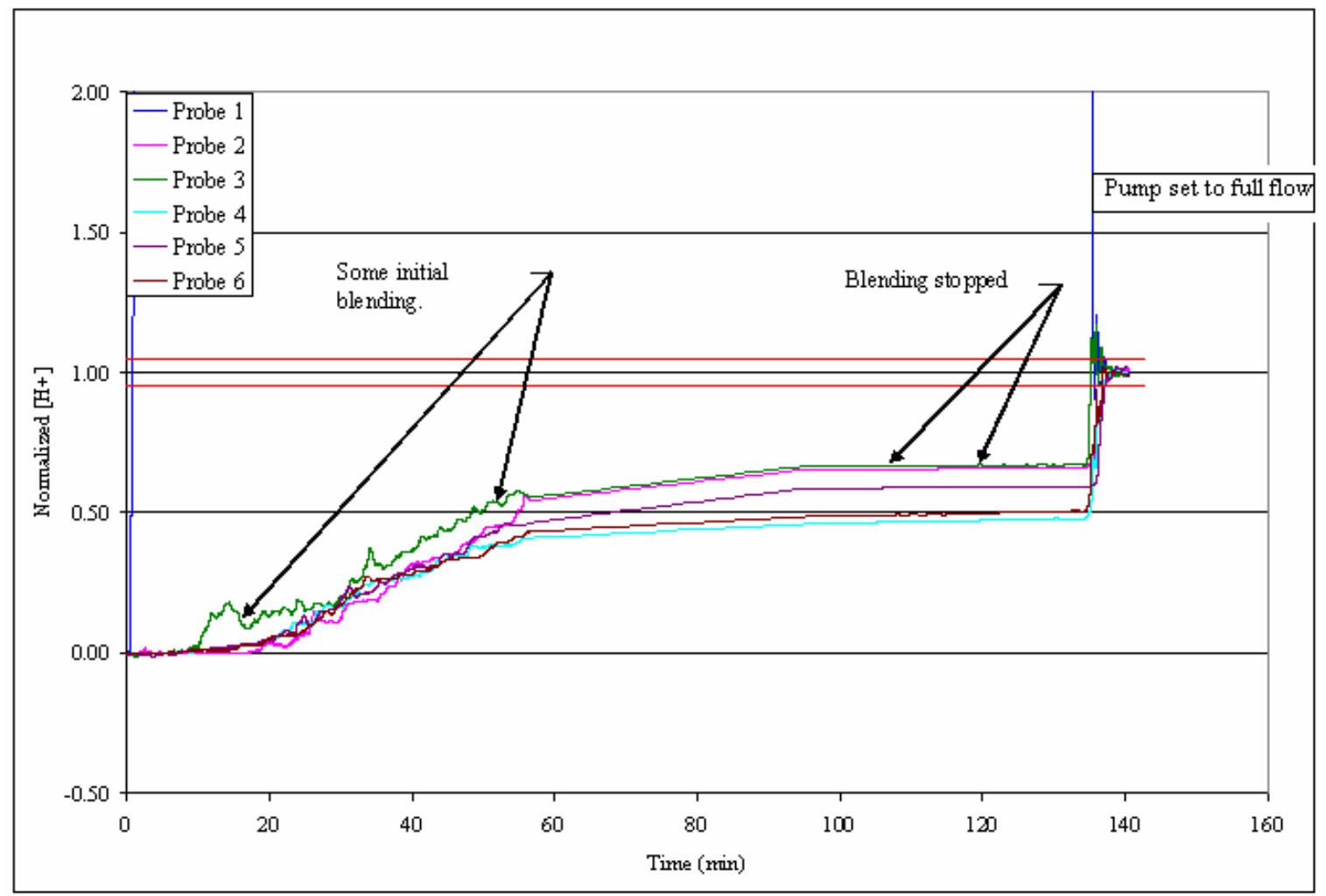

Figure 2-12: Pilot Scale Tank Contents Not Blended During Phase 1 Testing, Test 22, $U o D=0.09 \mathrm{ft}^{2} /$ second

\subsection{Monitoring Sludge Concentration Using Turbidity Measurements}

In general, density meters are inaccurate for monitoring the low sludge concentrations tested, and turbidity probes provided a better technique for monitoring solids concentrations in slurries. Selected for this task, the Hach Solitax ${ }^{\circledR}$ turbidity probe measures turbidity in Formazin Nephelometric Units (FNU). The probe contained an infrared light source and photoreceptor at $90^{\circ}$ to the source. The amount of light reflected back to the photoreceptor determines the turbidity reading and can provide a measure of concentration. The turbidity can be affected by particle shape, color, size, and distribution. Multiple calibrations using known concentrations of SB6 simulated sludge solids were performed to develop a relationship between turbidity and concentration (weight percent undissolved solids), and to demonstrate repeatability. As shown in Figure 2-13, two probes were used (indicated by pairs of lines). Consider first the lower pair of probe results. The turbidity levels off at about 0.13 weight percent, and then decreases. As more light is absorbed by the particles, or scattered into the particle field within the suspension, the amount of reflected light measured by the sensor decreases, and consequently the accuracy of the sensor decreases. In other words, the probes are most accurate up to at least 0.1 weight percent in the SB6 simulant, which is above the required range of $0-0.09$ weight percent required for this study. Beyond this value, the results are still accurate, but the possibility of confusing two different results at the same value is possible.

Figure 2-13 also describes the appearance of different concentrations of sludge slurries. Several calibration samples are shown below the figure, where each sample is related to the weight percent undissolved solids directly above it on the graph. Of particular interest, the 0.09 weight percent acceptance criterion yields a nearly black suspension. The concentration may be small, but the effect of entrained solids seems large. 
Settling properties also affected the turbidity measurements used to monitor sludge disturbance. When calibrations were initially performed, the upper curves were obtained. These results were obtained by immersing the turbidity sensor into a container of slurry with a known concentration of SB6 sludge, and allowing the turbidity reading to stabilize. However, agitation of the turbidity sample contents during calibrations yielded different results as shown by the lower curves in Figure 2-13. This material behavior is attributed to a fast settling rate of solids. When more solids are agitated into solution, the turbidity is lower since more light is absorbed or scattered. The calibration sample contents were agitated continually with a peristaltic pump to obtain the lower curves for all slurries. Agitation of the sample was not performed for the upper curves. That is, stirring the sample contents decreased the amount of light reflected back to the sensor by suspending more of the denser solids, as shown by the upper and lower sets of curves. Concentrations during pilot scale were expected to occur between these two limits, where the lower curves provided data for well mixed slurries, and the upper curves provided data for slurries that were allowed to settle for several minutes. After a few minutes, turbidity stabilized and fast settling characteristics were assumed to be effectively compensated. Calculations were conservatively performed to the lowest curve, since fast settling effects are not consistently repeatable.

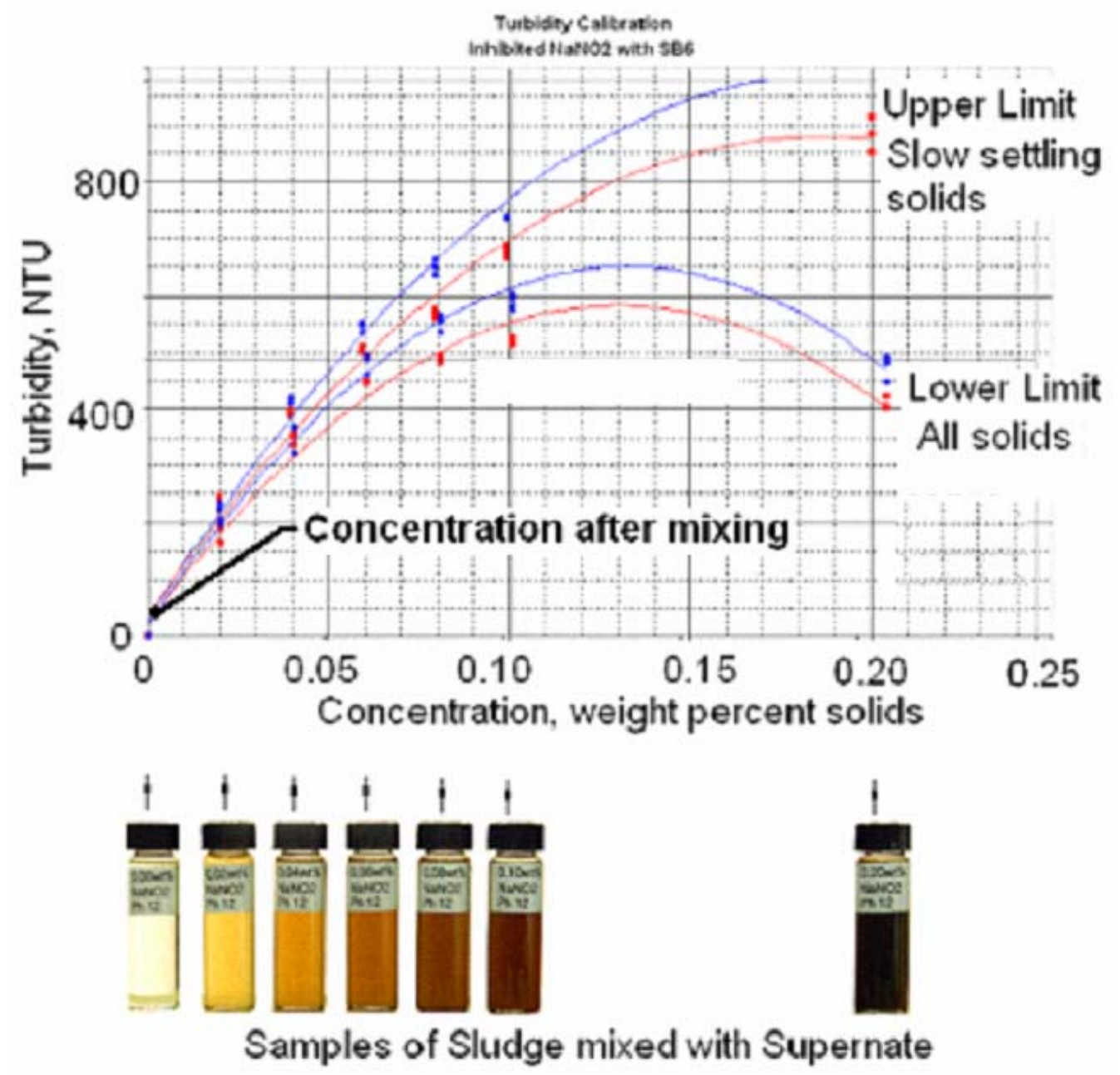

Figure 2-13: Turbidity Calibration 


\subsection{Sludge Rheological Properties}

Radioactive waste rheological properties are highly variable, and largely unknown in many cases. Some historical data is supplied in Figure 2-14 to present this variability for yield stress. The quantity of hydrogen entrapment by sludge is dependent on material properties, but this relationship is not well-defined. Even so, a sludge simulant was required for testing. The sludge simulant was prepared using a procedure for a recently qualified, SRS, sludge batch simulant, referred to as Sludge Batch 6 simulant. The simulant was qualified to reflect the chemical properties of Sludge Batch 6 , which is a blend of different tank wastes to be processed in the Tank Farms. This particular sludge is a slow settling sludge, since the sludge settles slowly after mixing into suspension in a full-scale waste tank. The non-radioactive SB6 simulant contained aluminum, iron, manganese, and nickel compounds. Although SB6 is referred to as slow-settling, individual compounds in suspension settled at different rates, and SB6 settling behavior directly affected sludge disturbance behavior during the time required to complete a test.

As solutions are transferred into the Blend and Feed tanks, sludge is expected to be entrained into the stream. The selected simulant was SB6, which was considered to be conservatively bounding for the purposes of this test. Specifically, the selected simulant had the lowest yield stress and largest settling time of any simulant processed to date. This sludge disturbance research conservatively assumed that if this simulant remains undisturbed during testing, any actual sludge will also remain undisturbed in the waste tanks. Validation of this assumption through sludge property testing throughout future processing is recommended.

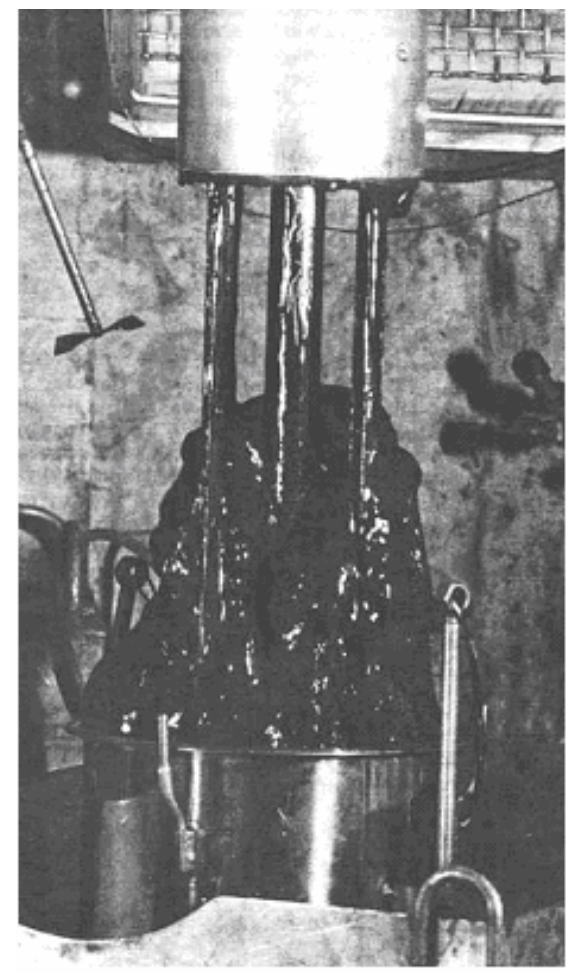

High yield stress radioactive sludge
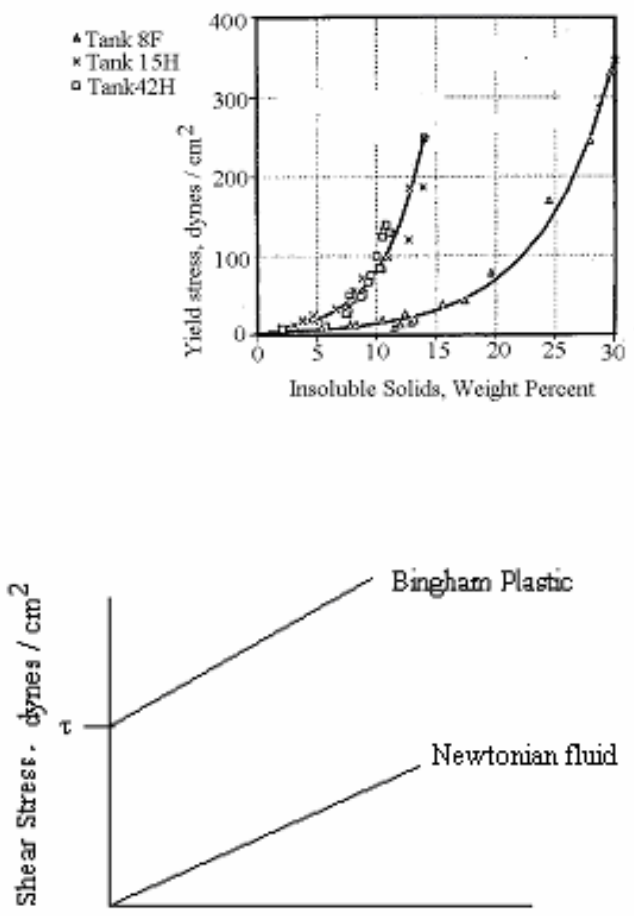

Shear Rate, $\mathrm{cm} / \mathrm{cm} / \mathrm{sec}$ mad

Figure 2-14: Typical Sludge Properties Obtained by Diluting Radiocative Waste Samples

(Stone [11], Hamm and Ebra [12]) 


\subsubsection{Sludge Simulant Preparation}

SB6 simulant was prepared (Herman, et al [10]), based on bench scale processing and testing of the qualified simulant. Rheological properties were not specified and varied widely for delivered SB6 simulants. Three 55-gallon batches were received at SRS: Batches 1, 2, and 3. Batch 1 and 3 were similar in that they were the thinnest suspension, and poured easily. Batch 2 was much thicker, where a boat paddle stood up in the middle of the 55-gallon drum without support. Unwashed radioactive SB6 sludge was removed from a waste tank after blending several waste streams, and was measured to have a yield stress of 3.6 Pascal and 6 weight percent insoluble solids (data provided by e-mail from T. Pareizs). Data with respect to settling times was unavailable. Batch 1 simulant had an as delivered yield stress of 1.55 Pascal, SpG of 1.16, and 9.05 weight percent insoluble solids $(<1 \%$ uncertainty at $95 \%$ confidence) after thorough mixing (Figure 2-15), where mixing of the 55-gallon drum was required since settling had occurred. Batch 1 simulant was selected as the test simulant since it had the lowest yield stress of any simulant to date. The lower the yield stress, the more likely it will be disturbed during salt blending. The selection of Batch 1 simulant provided a lower limit for sludge rheological properties to be used in modeling. Rheology testing methods are discussed in section 3.5.3.3.

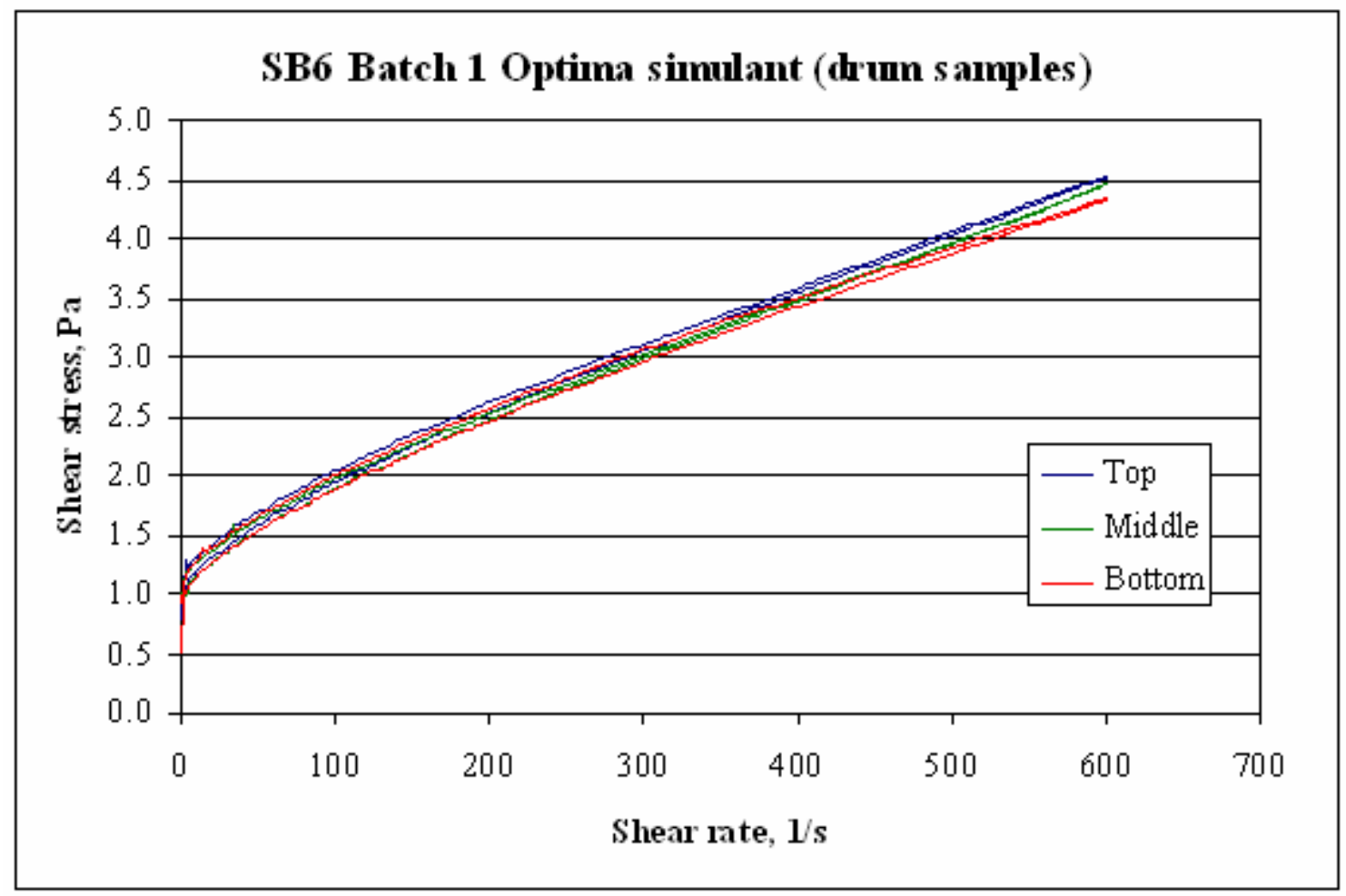

Figure 2-15: As-received SB6 Simulant Rheology Results From a 55 Gallon Drum

\subsubsection{SB6 Sludge Simulant Addition to the Pilot Scale Tank}

After Batch 1, SB6 simulant was mixed with simulated supernate simulant, the yield stress decreased to approximately 0.8 Pascal (Figure 2-16), even though the yield stress was also significantly affected by supernate concentration. When the SB6 was added to the bottom of the tank with a peristaltic pump, it floated to the surface, and then particles rained from the surface to the tank bottom. The yield stress was also affected by tank chemistry, where SB6 mixed with water had a higher yield stress than SB6 mixed with $\mathrm{NaNO}_{2}$. In addition, non-Newtonian SB6 fluid properties varied with respect to time due to settling, and this time dependence had a 
significant effect on testing. Time dependence of sludge properties was also observed by Poirier and Herman [13]. The yield stress for a sludge sample after all testing was complete decreased slightly, as shown in Figure 2-17.

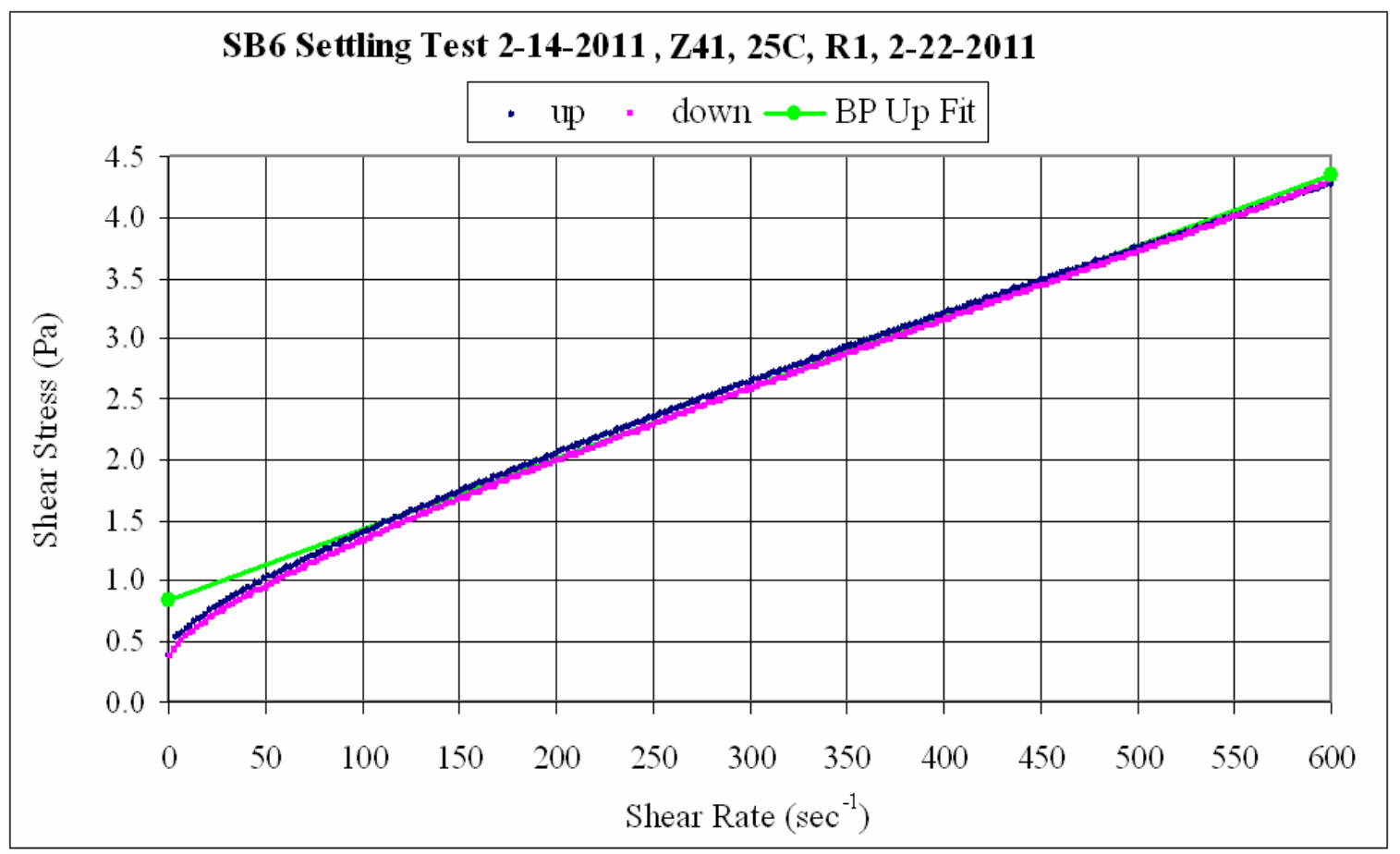

Figure 2-16: SB6 Simulant Rheology Data After Initial Blending of SB6 and $\mathrm{NaNO}_{2}$ Plus NaOH Using Standard Vane

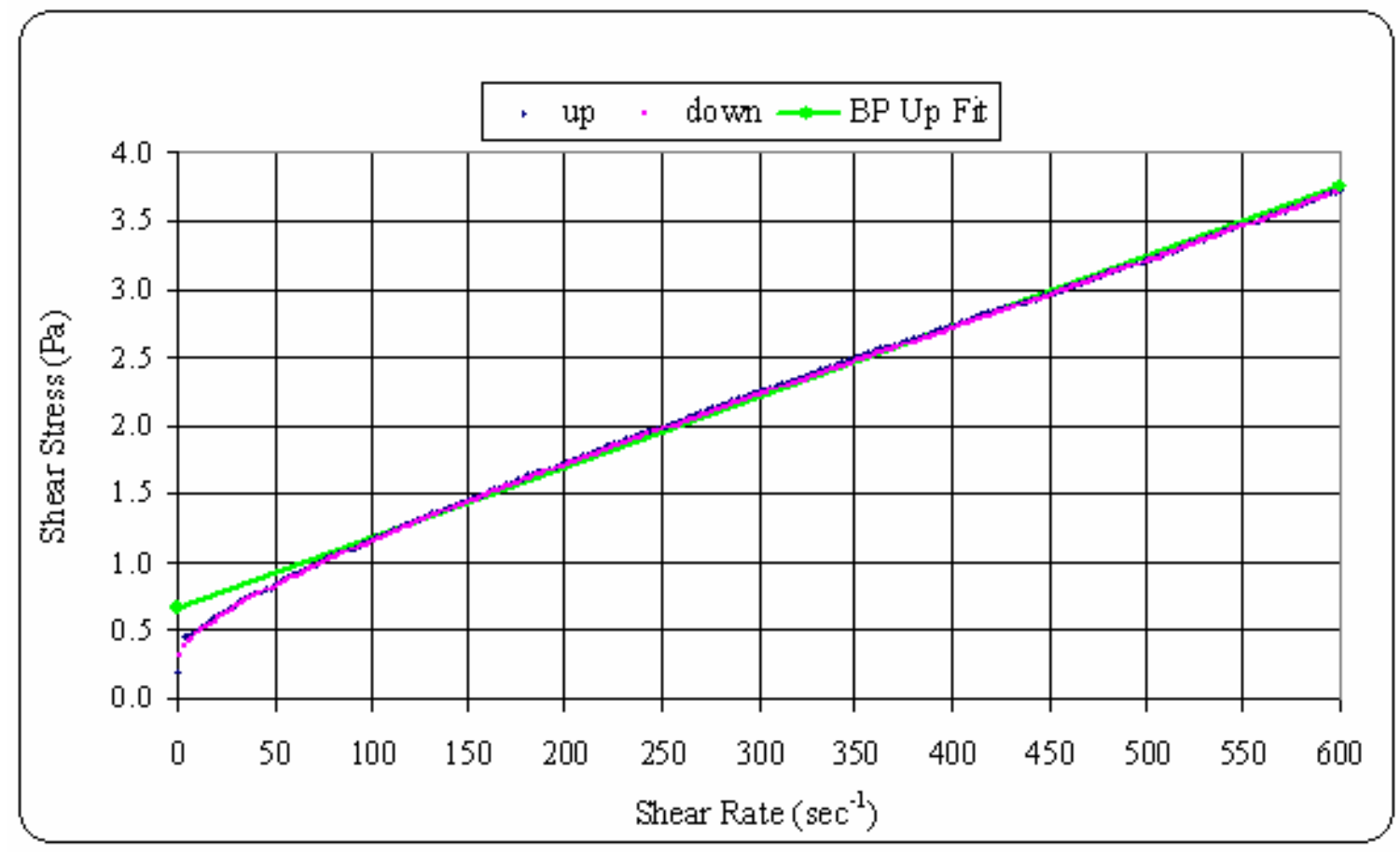

Figure 2-17: Final SB6 Simulant Rheology Results at Test Completion, Density $=1.316 \mathrm{~g} / \mathrm{ml}$ 


\subsubsection{SB6 Sludge Simulant Properties}

Particle sizes, rheological properties, and chemical compositions were evaluated to provide insight into both sludge settling and sludge disturbance. For example, the general behavior of settling SB6 sludge is observed in Figure 2-18. The as-received SB6 simulant is shown on the left side of the figure after nearly six days, where clear supernate was evident above the settling sludge. Figure 2-19 provides a comparison between SB6 simulant and radioactive SB6 waste. Time dependent yield stress data is unavailable for 3.6 Pascal, radioactive SB6 waste. However, time dependence of yield stress was considered for the SB6 simulants. Referring again to Figure 2-18, a mixture is shown for SB6 simulant with $\mathrm{NaNO}_{2}$ and 0.01 molar $\mathrm{NaOH}$. Overnight, most of the solids settled, and supernate was nearly clear after a few days for a 32.1 inch fluid level test.

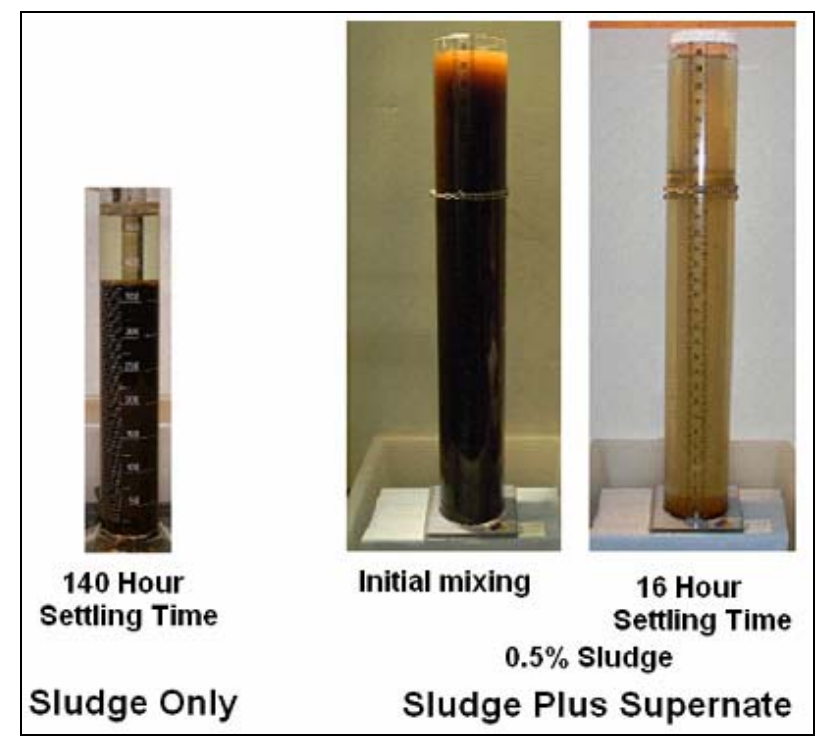

Figure 2-18: Settling of As-received SB6 and Settling of SB6 Mixed with Supernate 


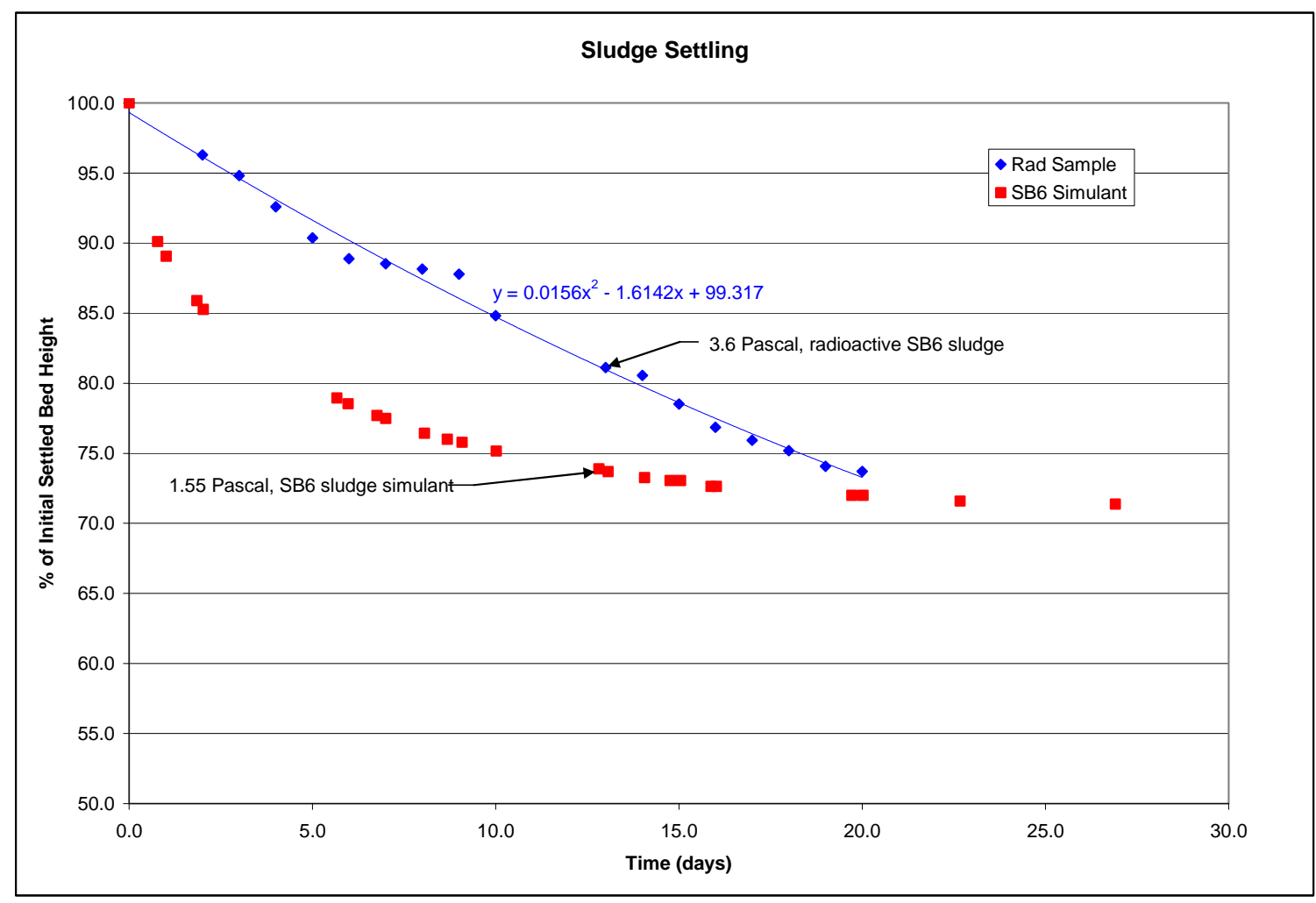

Figure 2-19: Settling Comparison for SB6 Simulant and Radioactive SB6 Sludge / Waste

(Rad. data from J. Pareizs)

\subsubsection{SB6, Bench Scale Sludge Settling}

Testing showed several behaviors of settled sludge simulants. During the settling of SB6 in $\mathrm{NaNO}_{2}$, the yield stress of the sludge increased as it was compacted. Figure 2-20 summarizes the investigation of sludge compaction during settling of salt / sludge suspension of comparable depth to the pilot scale tank, where Figure 2-21 and Figure 2-22 provide the test results used to generate the curve shown in Figure 2-20. In a 6 inch diameter settling column, 15/16 inch of SB6 simulant was added to obtain a 32.1 inch total fluid level, which was the same as the fluid level used in the pilot scale tank. These settling columns were fabricated to have removable lower sections to permit testing without disturbing the settled sludge bed. Both water with $\mathrm{NaOH}$ and $\mathrm{NaNO}_{2}$ were tested with SB6 and $\mathrm{NaOH}$ to prevent rag formation. The Rag is a term to describe a gelatinous layer that forms on sludge surfaces exposed to solutions with insufficient caustic in solution. A $p H$ of 11 was recommended and bench scale testing demonstrated that rag formation was prevented when the $p H$ was maintained above this level during bench scale rag testing. Samples were rheologically tested using a Haake rheometer shown in Figure 2-20. This instrument rotates at $1 / 5 \mathrm{rpm}$, and the torque on the submerged vane is converted to yield stress, where the yield stress is the fluid stress required to mobilize the sludge. The vane used for testing is also shown in the figure, along with a typical test result and a graph of the rheology tests performed for both simulants over a six week period. Note that results for water are different than results for $\mathrm{NaNO}_{2}$ simulant. When testing was performed by slowly mixing the SB6 with simulant, the water / SB6 had higher yield stresses. Yield stresses were comparable before and after testing, but particle sizes decreased slightly during testing. 


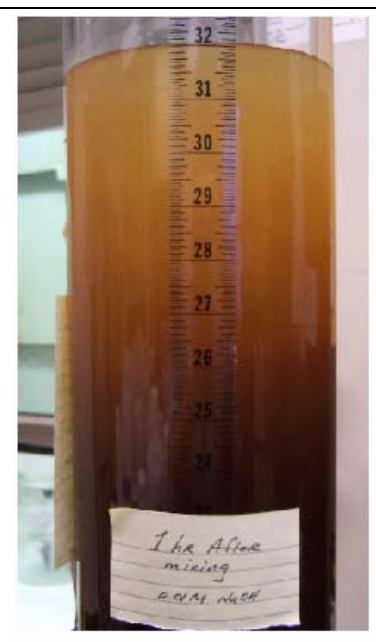

1 hour settling time

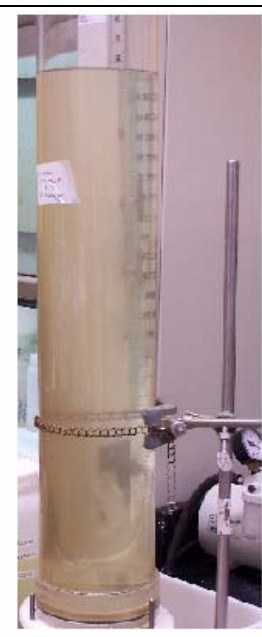

16 hour settling time

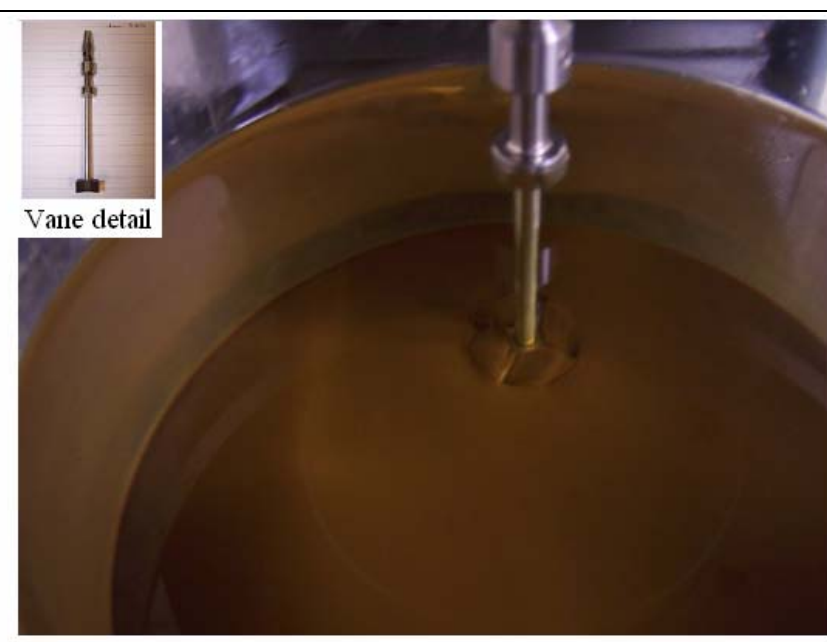

Rheology tests for settled sludge

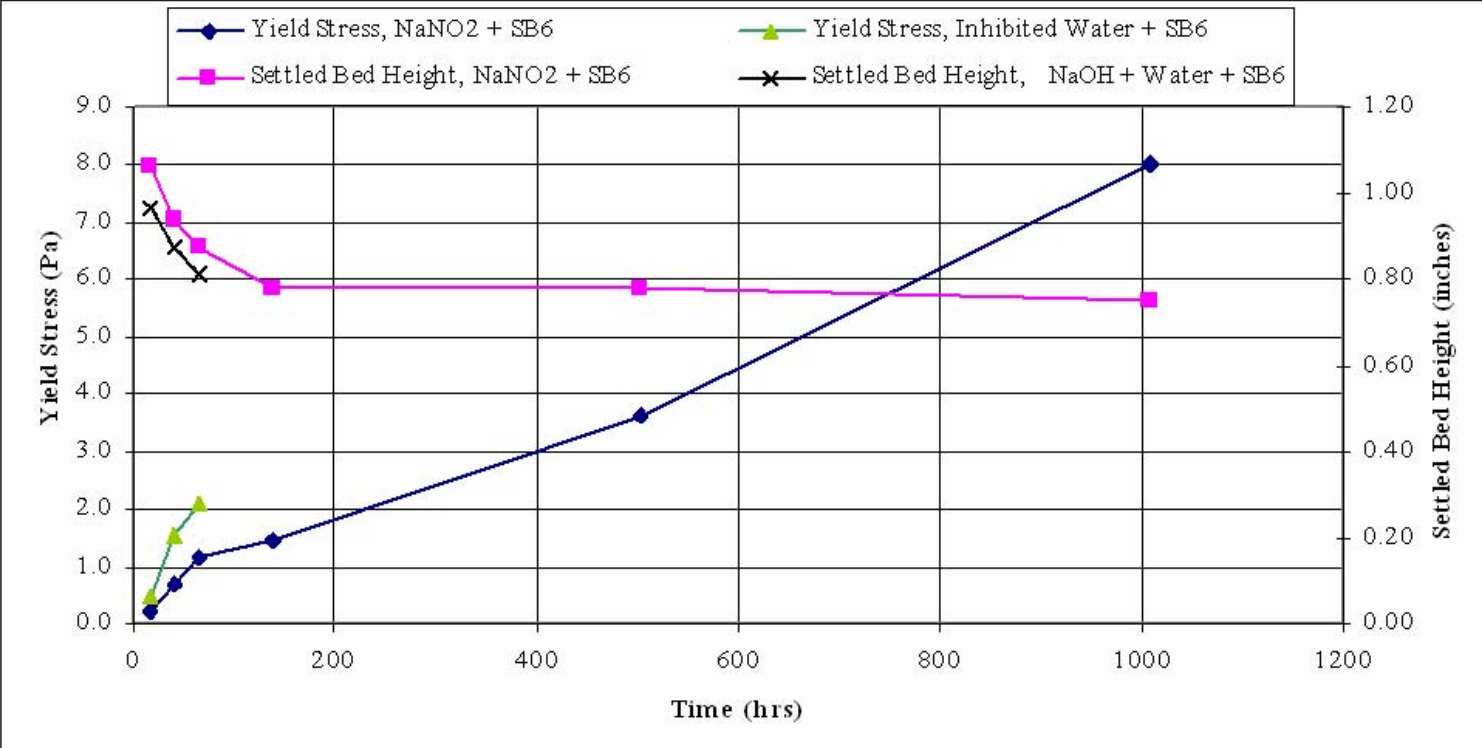

Time dependent material properties

Figure 2-20: Rheology Testing Settled SB6 in Water Plus $\mathrm{NaOH}$ and in $\mathrm{NaNO}_{2}$ plus $\mathrm{NaOH}$, Supernate Simulant

(E. Hansen) 

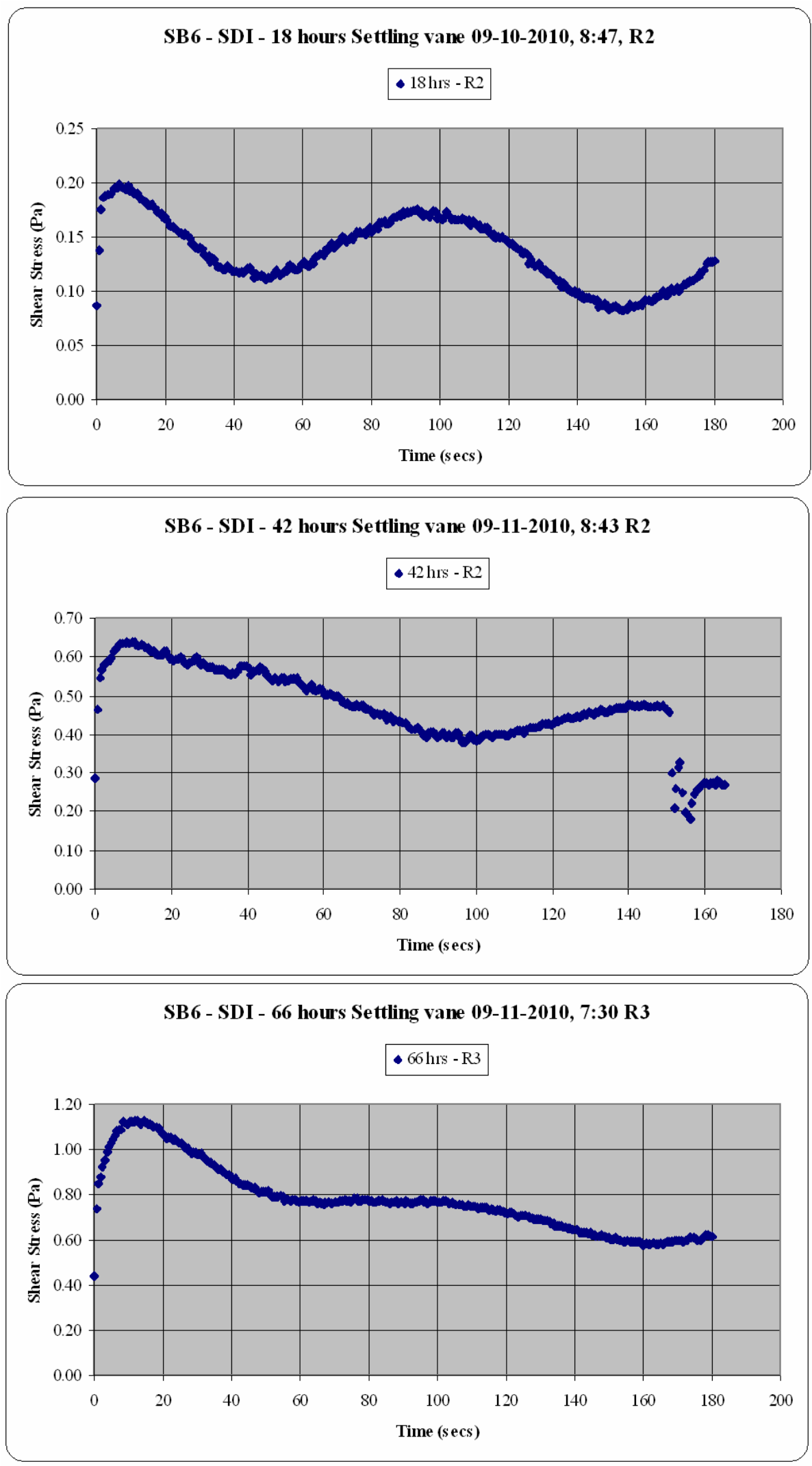

Figure 2-21: Pilot Scale Rheology Test Results 

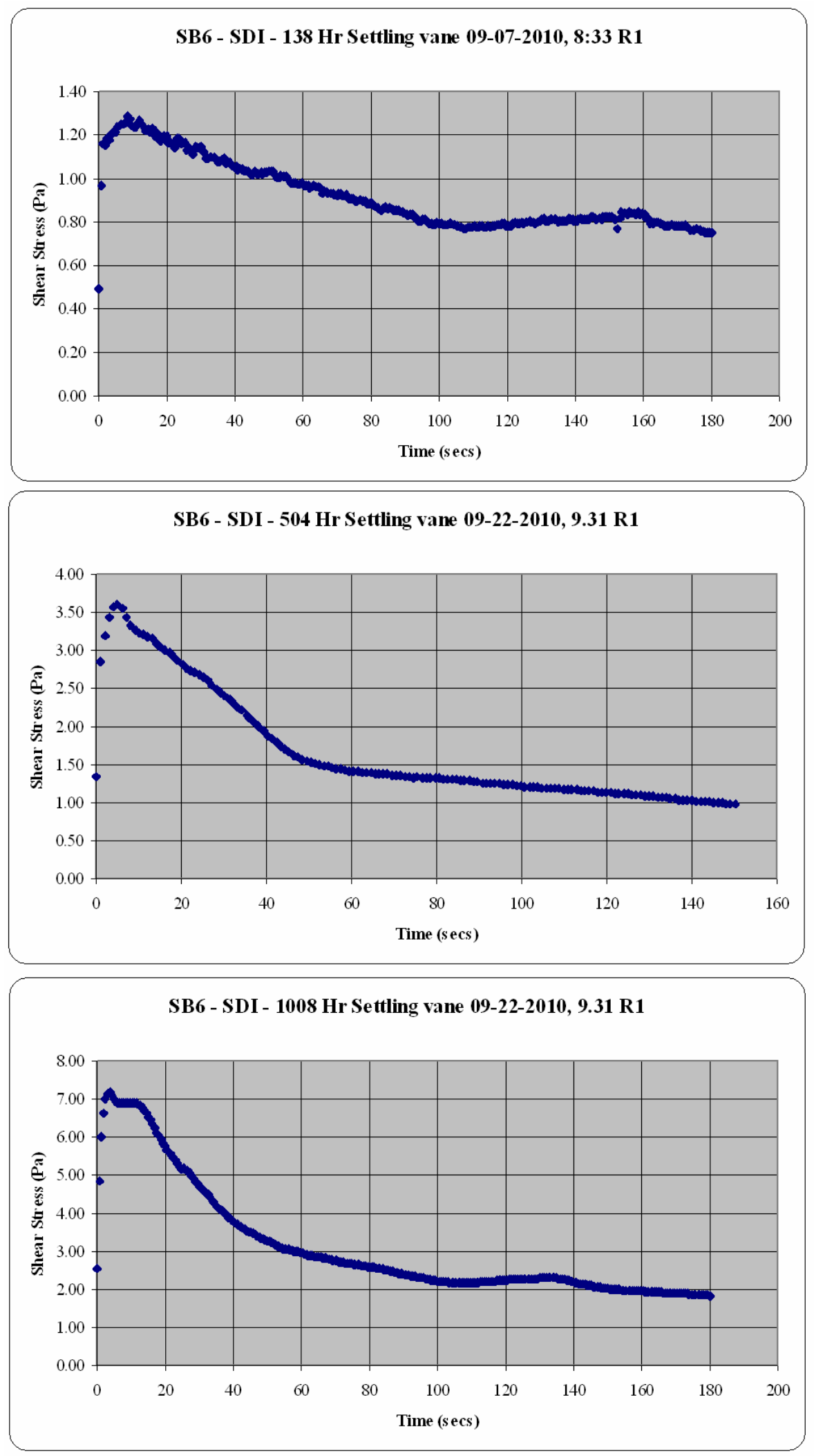

Figure 2-22: Pilot Scale Rheology Test Results

(E. Hansen) 


\subsubsection{Particle Sizes of SB6 Simulant}

Particle size testing was also used to monitor sludge properties throughout testing, where the percentage of the number of particles is presented in the figures provided here (number average basis). For the as- received SB6 simulant, note that the particle sizes are small 7 micron average size, where the denser particles settled without adequate pre-mixing (Figure 2-23). Figure 2-24 shows that same material after the drum containing the material was thoroughly mixed. In other words, the as-received simulant settled before it was initially sampled. This result led to the observation that the SB6 settled rather fast with respect to test requirements, although the SB6 was referred to as slow settling. The changing material properties required monitoring throughout testing. Figure 2-25 shows that the particle sizes actually decrease in size as the SB6 was added to the salt simulant solution. Figure 2-26 shows the final particle size distribution after testing. And the particle sizes were reduced slightly due to pump processing throughout testing.

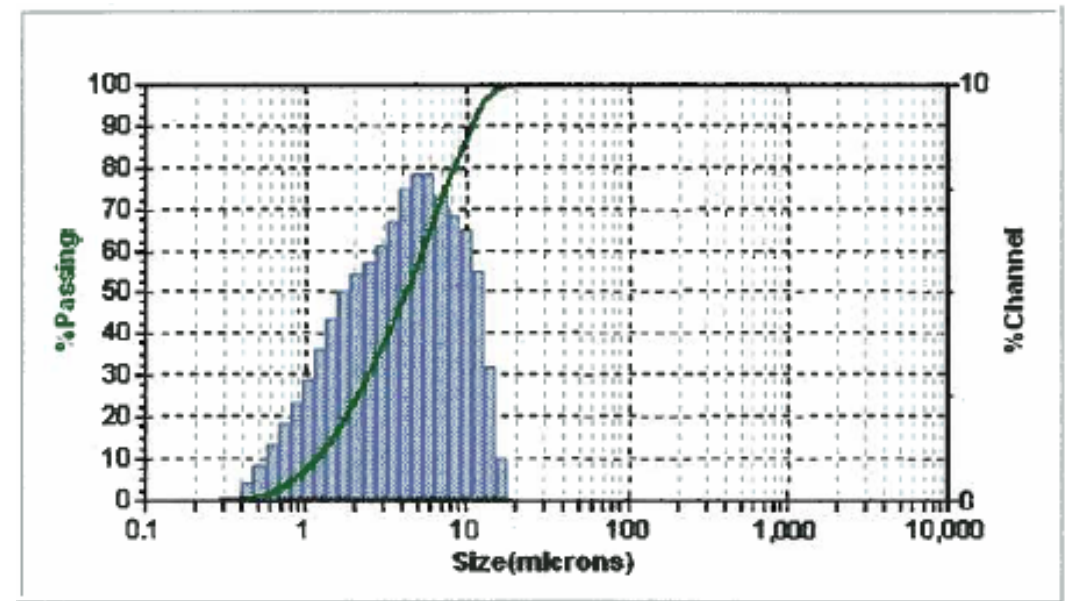

Figure 2-23: As-received, SB6 Simulant Particle Size Distribution for Partially Settled, Incompletely Mixed Sample

(D. Missimer)

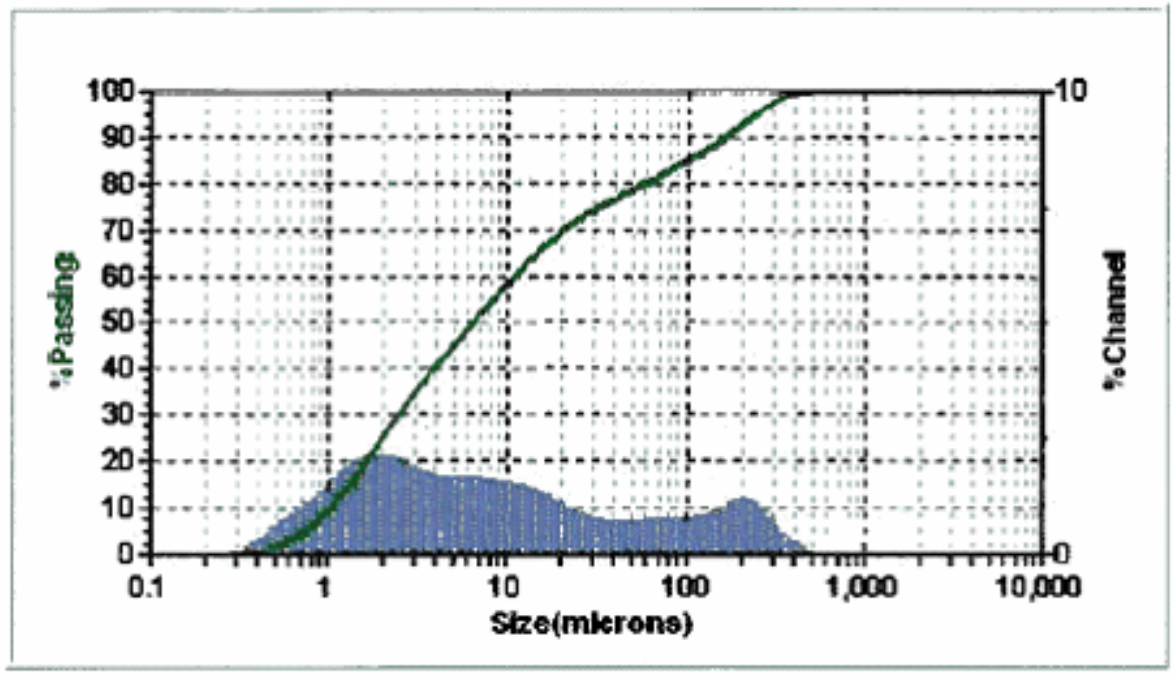

Figure 2-24: As-received, SB6 Simulant Particle Size Distribution for Fully Mixed Sample 


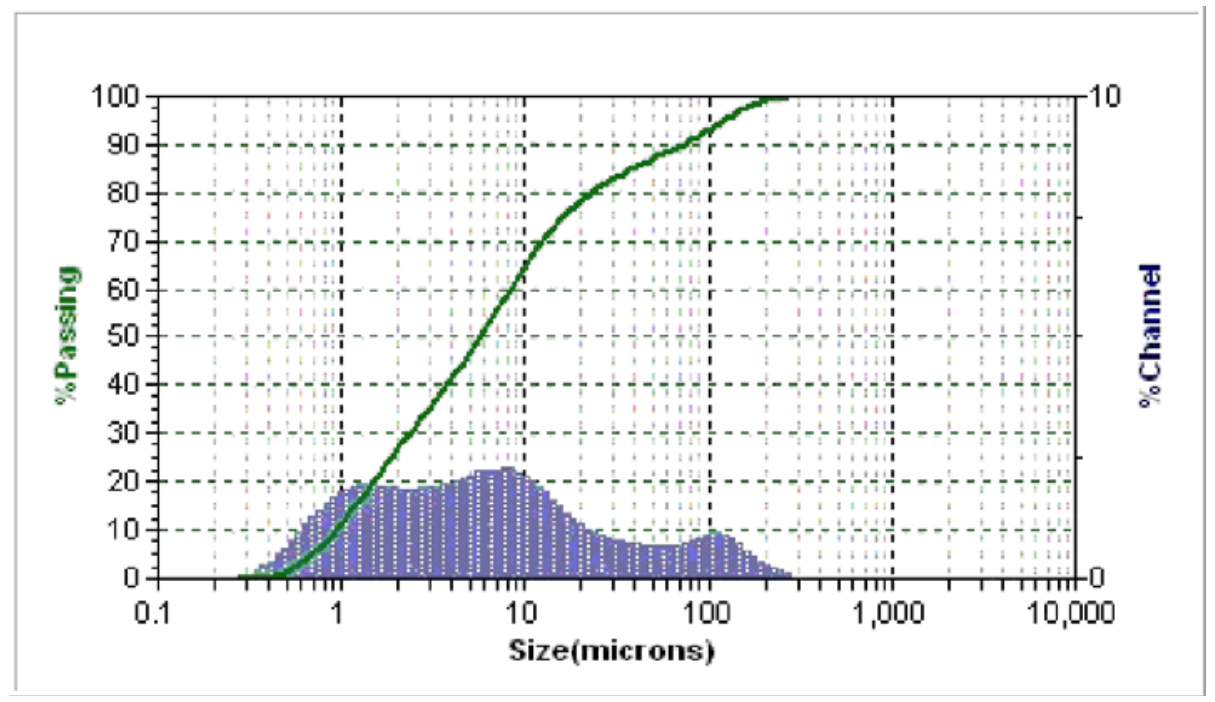

Figure 2-25: SB6 Simulant Particle Size Distribution After Initial Mixing of SB6 with $\mathrm{NaNO}_{2}$ and $\mathrm{NaOH}$

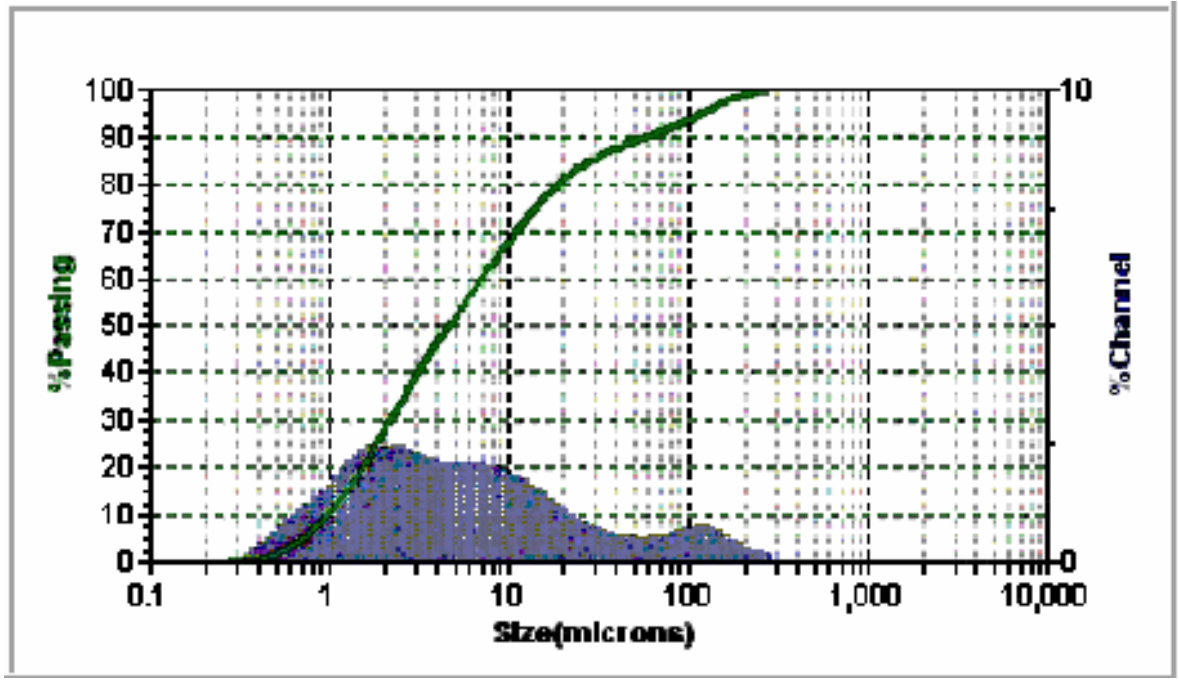

Figure 2-26: SB6 Simulant Final Particle Size Distribution After Test Completion

(D. Koopman)

\subsubsection{Comparison of Rheology Test Methods}

Figure 2-16 and Figure 2-27 also show the similarities, and differences, between results obtained from a standard vane test used for rheological testing which varied the shear rate, and a shorter vane test, which applied a constant shear stress for this application. Both tests provide a yield stress, but the measured yield stress is somewhat different as measured from the two techniques. The low fluid depth required to imitate pilot scale tank conditions required a shorter height vane for full submergence to obtain adequate results. The type of test was also varied, and although the predicted yield stress varied due to technique, close inspection of Figure 2-16 and Figure 2-27 show that the yield stresses are quite similar near 0.5 Pascals. One technique provides a constant torque using concentric cylinder viscosity tests, while the other technique provides a constant strain rate using a vaned impeller for testing. Each technique determines a slightly different yield stress. When using the data for this research, the differences in technique were considered. 


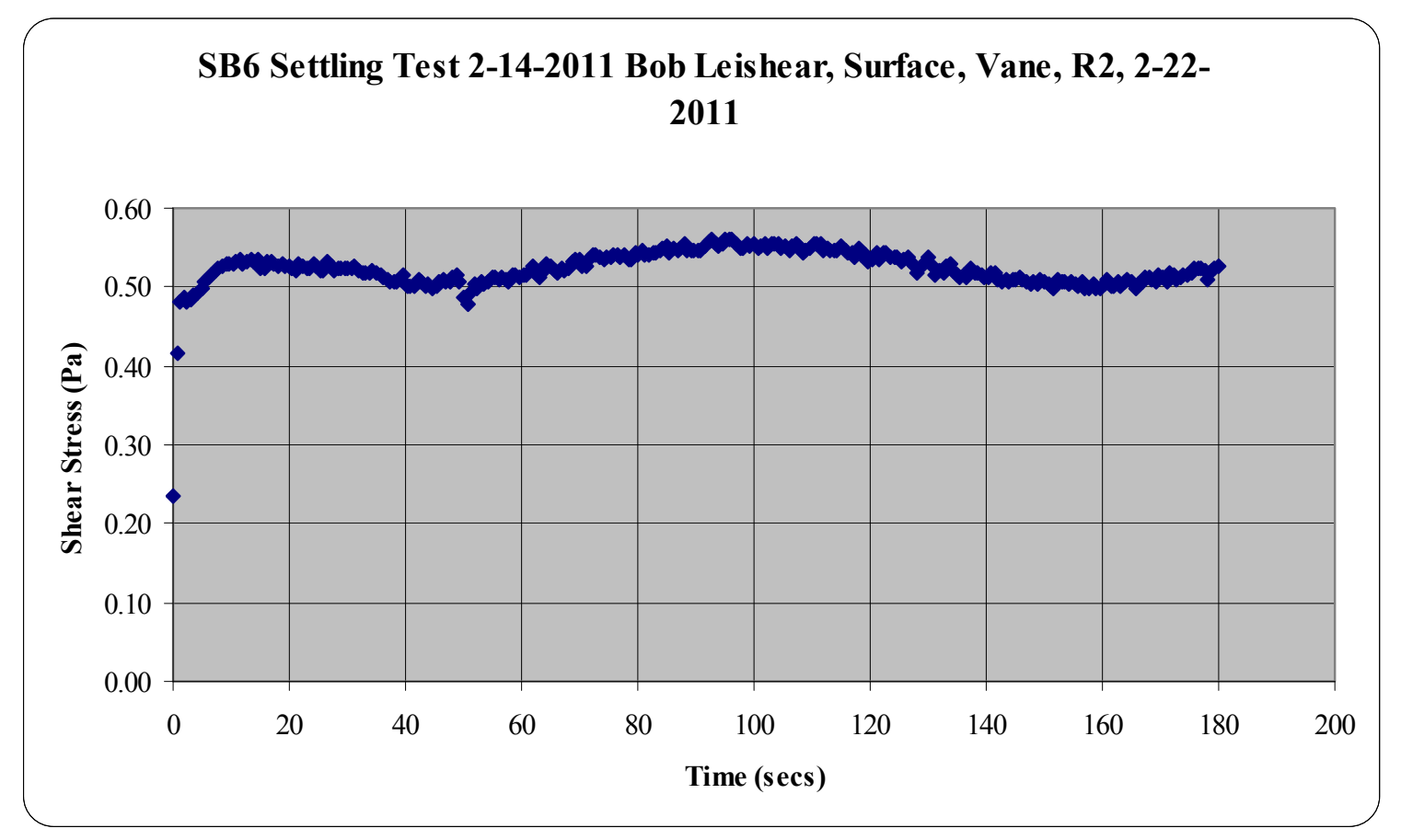

Figure 2-27: SB6 Simulant Rheology Data After Initial Blending of SB6 and $\mathrm{NaNO}_{2}$ Plus NaOH Using Modified Vane

\author{
(E. Hansen)
}

\title{
2.5.3.4 Summary of SB6 Simulant Particle Size and Yield Stress Changes
}

Even though particle size changed slightly during tests, the rheological properties of interest were conservatively affected. When the SB6 was first received it had a yield stress of 1.61 Pascals (Figure 2-15). After mixing with the salt solution, the yield stress decreased to 0.8 Pascals, and then further decreased to 0.65 Pascals throughout testing. The fact that the yield stress decreased during testing implies that the test results are conservative, since less flow was required to disturb the sludge as testing proceeded. In fact, the process of removing sludge from the tank bottom after settling may have affected the properties, since some of the larger particles were removed from the test fluid.

\subsubsection{Chemical Composition of SB6 Simulant}

The chemical composition of SB6 simulant was also tested to better understand the settling process during blending. Measurements of suspended solids during blending were compared to initial chemical constituents, as provided in Table 2-1, where the 1-sigma concentration uncertainty typically varies between $10-20 \%$. Also included in the table are the ratios of various metals with respect to aluminum. To understand the table, the method of obtaining samples requires discussion. One sample was obtained from the as-received SB6 after it was thoroughly mixed. The other two samples were obtained after removing sedimented sludge from the bottom of a tank, where the SB6 settled in a 2500 gallon tank for several weeks. Then, the sludge was removed from the bottom of the tank, and a layer of settled solids remained on the tank bottom after most sludge was removed. These residual sludge solids were later removed from the tank bottom, and sampled for chemical composition. The relative concentrations of metals with respect to aluminum were used for these comparisons, since the samples were different. Consider the iron in the residual sample (residue), where the ratio of aluminum to iron equals $\mathrm{Al} / \mathrm{Fe}$ 
$=3170 / 3350$. For the as-received SB6 simulant, $\mathrm{Al} / \mathrm{Fe}=17400 / 20200=0.86$. The residue had a higher concentration of iron with respect to aluminum for the residue than the as-received SB6. Similarly, all of the metals were of higher relative concentrations for the residue, and were of lower concentrations for the "after test" samples. That is, the "after test" samples provided longer settling times since more of the metals were settled into the residual simulant. These test results are of importance to full scale settling tests and other properties, since the "after test" simulant was used for full scale settling tests. Even so, settling rates are dependent not only on density, but on particle shape, which was not further investigated. The data suggests that settling is affected by density, but sufficient research to fully quantify this statement was not performed during this research. That is, there is a difference between the ratios of different metals to aluminum listed in the table, but the analytical uncertainty exceeds the observed measurements, and therefore a firm conclusion with respect to settling cannot be reached. To further understand relevant settling processes, evaluation of 30 foot settling column tests were performed to provide further insight into sludge settling characteristics (section 2.6).

\begin{tabular}{|l|r|r|r||}
\hline & & After test & \\
Component & As received & completion & Residue \\
\hline Al & 17400.0 & 8610.0 & 3170.0 \\
\hline $\mathrm{Ca}$ & 1460.0 & 851.0 & 454.0 \\
\hline $\mathrm{Ce}$ & 114.0 & 107.0 & 92.9 \\
\hline $\mathrm{Cu}$ & 96.5 & 49.2 & 27.1 \\
\hline $\mathrm{Fe}$ & 20200.0 & 11400.0 & 3350.0 \\
\hline $\mathrm{K}$ & 572.0 & 531.0 & 459.0 \\
\hline $\mathrm{La}$ & 68.4 & 39.3 & 19.3 \\
\hline $\mathrm{Mg}$ & 624.0 & 335.0 & 97.5 \\
\hline $\mathrm{Mn}$ & 6050.0 & 3270.0 & 999.0 \\
\hline $\mathrm{Mo}$ & 37.2 & 35.2 & 30.4 \\
\hline $\mathrm{Ni}$ & 2450.0 & 1340.0 & 396.0 \\
\hline $\mathrm{P}$ & 42.0 & 39.7 & 34.3 \\
\hline $\mathrm{S}$ & 693.0 & 160.0 & 138.0 \\
\hline $\mathrm{Si}$ & 2550.0 & 1520.0 & 421.0 \\
\hline $\mathrm{Sr}$ & 5.4 & 5.1 & 4.4 \\
\hline $\mathrm{Zn}$ & 68.0 & 37.5 & 17.7 \\
\hline$[\mathrm{Al}] /[\mathrm{Fe}]$ & 0.86 & 1.32 & 0.95 \\
\hline$[\mathrm{Al}] / \mathrm{Mn}]$ & 2.87 & 2.63 & 3.17 \\
\hline$[\mathrm{Al}] /[\mathrm{Ni}]$ & 7.10 & 6.42 & 8.00 \\
\hline$[\mathrm{Al}] / \mathrm{Mg}]$ & 27.88 & 25.70 & 32.51 \\
\hline$[\mathrm{Al}] /[\mathrm{S}]$ & 25.11 & 53.81 & 22.97 \\
\hline$[\mathrm{Al}] / \mathrm{Si}]$ & 6.82 & 5.66 & 7.53 \\
\hline$[\mathrm{Al}] /[\mathrm{Zn}]$ & 255.88 & 229.60 & 179.10 \\
\hline
\end{tabular}

Table 2-1: Percent Solids Concentrations $(\mu \mathrm{g} / \mathrm{g}$ : As-received and After Test Completion

\subsection{Full Scale Sludge Settling Test}

The purpose of full scale settling tests was to compare settled sludge conditions for full scale operations and pilot scale testing. For test results to be comparable, the settled sludge properties needed to be comparable. A settling time for pilot scale testing was obtained by observation of minimal sludge disturbance. A full scale settling time was required to obtain a settled sludge simulant with equivalent properties. A comparable SB6 sludge simulant sample was used for testing at both scales (section 2.5.3.5). 
Full scale settling tests were performed at SRNL using the slow settling Batch 1, SB6 sludge simulant shown in Figure 2-28. The falling bed height was visually observed and recorded in parallel to turbidity measurements, which were measured at two different levels in the settling column, as shown in Figure 2-29. Data analysis showed that a 32.14 day settling time ( $\approx 33$ days) is required for materials with properties similar to SB6 simulant. This recommendation was slightly longer than an initial estimate of 30 days. The initial estimate was obtained by multiplying the 66 hour time (see section 3.10) required between sludge tests to prevent sludge disturbance times the 10.85 scaling factor ( 66 hours $\cdot 10.85=29.84$ days). The recommended 33 day settling time was determined in a full scale settling test by allowing a known quantity of simulant to settle to a depth comparable to the settled depth observed in pilot scale testing. In pilot scale testing, 12.3 gallons ( 0.86 " deep) of simulant settled to $\approx 0.81 " \pm 0.13$ ". At pilot scale, this uncertainty equaled $16.7 \%$, as calculated from the data in Figure 2-30, which was compiled from 20 different pilot scale tests. This uncertainty was assumed to be applicable to full scale test results. For full scale testing a quantity of SB6 simulant was added to the settling column to provide a depth of 10.64 inches. Applying the $16.7 \%$ uncertainty to the data in Figure 2-29, the settling time was found to be slightly less than 33 days.

Fast settling of the denser metal compounds in the slurries was observed throughout testing. Monitoring turbidity with redundant probes, Figure 2-31 shows that two distinct material layers were present in the falling bed height, since marked changes in concentration occurred at two different times within the apparently opaque settling bed. This issue was not further investigated, and this consideration of settled sludge properties concludes a description of test equipment and measurement processes required to support pilot scale testing.

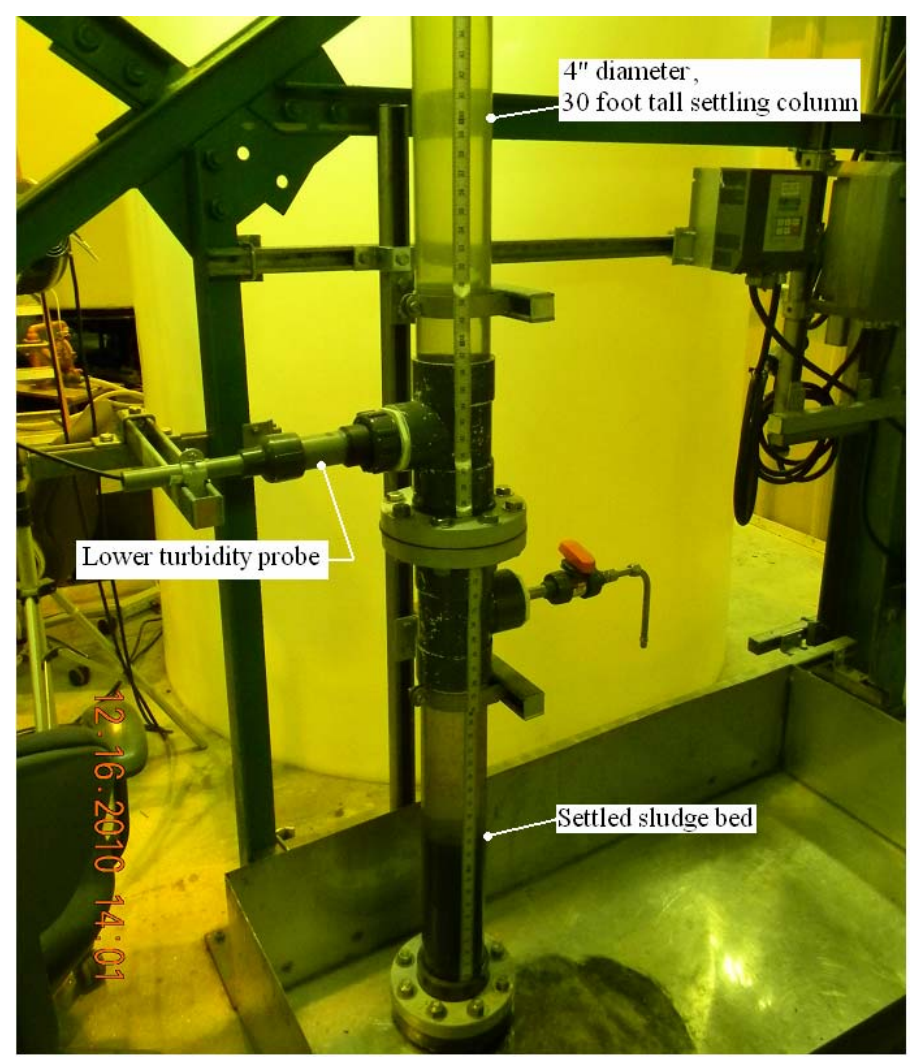

Figure 2-28: Full Scale, 30 Foot Settling Column 
SRNL-STI-2011-00151

5/26/11 Revision 0

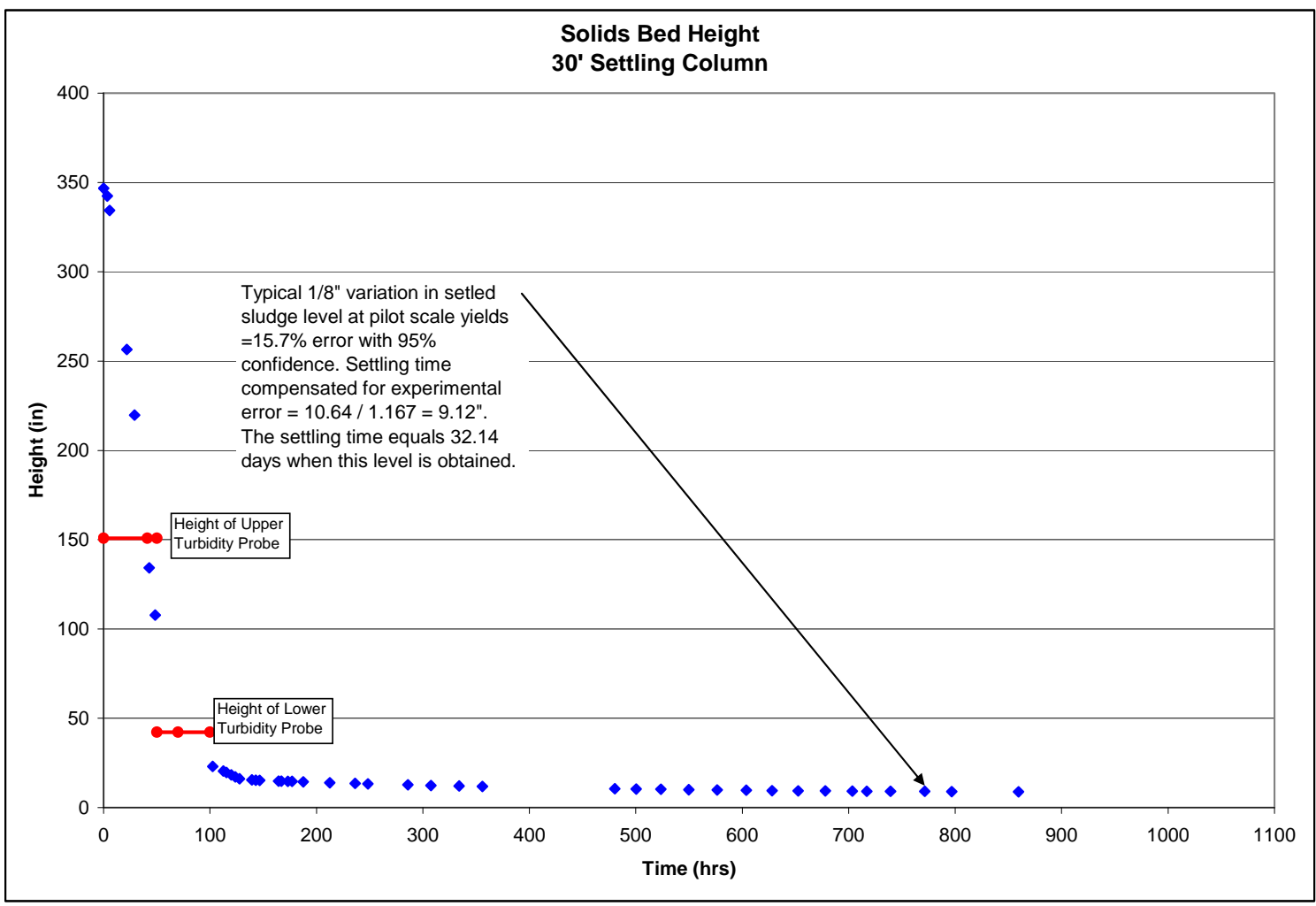

Figure 2-29: Settled Bed Height in Full Scale Settling Column Test

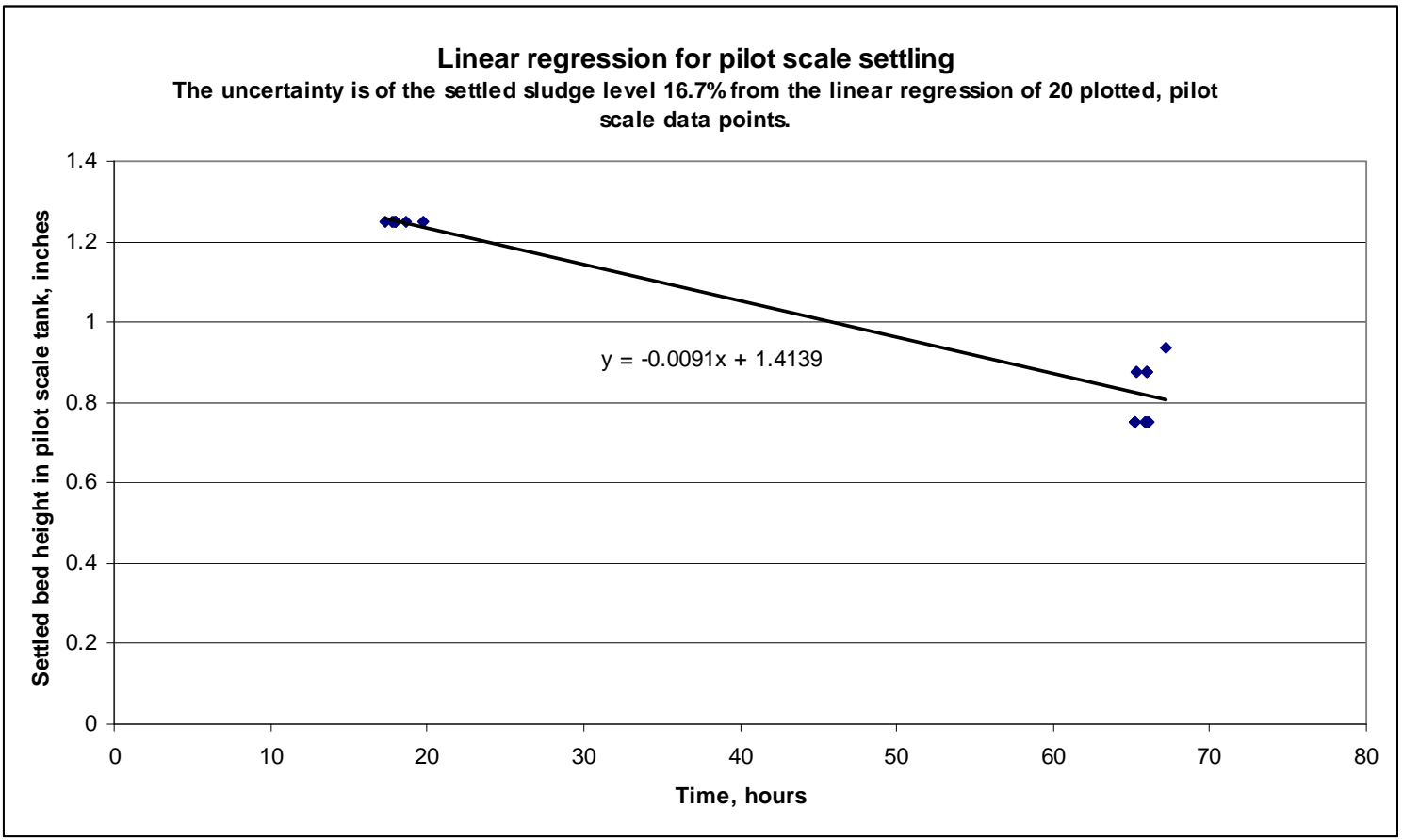

Figure 2-30: Pilot Scale Settling Times 


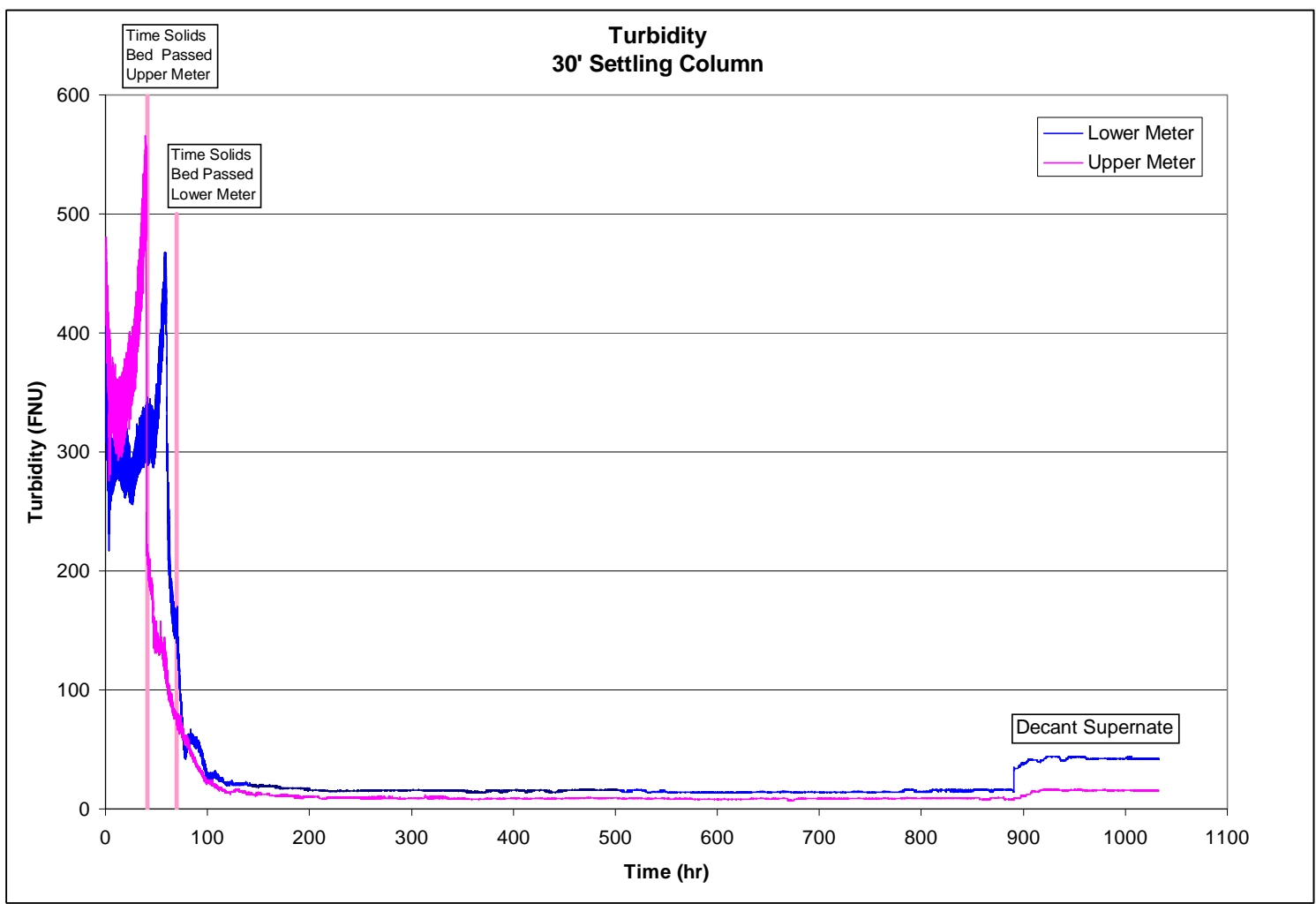

Figure 2-31: Settling Column, Turbidity Measurements

\subsection{Results and Discussion}

Blending time and sludge disturbance are the parameters to be scaled. CFD modeling is a primary method to accomplish scaling, and velocity measurements are required to determine the accuracy of these models.

\subsection{Turbulence Intensity and Average Velocity}

There are several fundamental aspects of velocity measurements (Figure 3-1). One is referred to as turbulence intensity (Warda, et al [15]), where turbulence intensity is a time averaged fluctuation of velocity around the mean velocity. Other aspects of velocity are the average, or mean value of the velocity, and the repeatability of those average measurements. Average velocities were the basis of recommendations provided here, and were evaluated using statistical uncertainty analysis (T. Edwards, Appendix A).

Recall from Figure 2-8 the location of the velocity probe, and consider typical measurements shown in Figure 3-1, Figure 3-2, and Figure 3-3. Each set of velocity measurements is identified by a boxed set of three dimensions, i.e., the angle from the jet, the height from the tank floor, and the distance from the tank wall. For example, consider the two shaded boxes at $40^{\circ}$ from the pump, 2 " off the floor, and 10 " from the wall. To obtain the resultant velocity, $V_{x y z}$, at a point at each time,

$$
\mathrm{V}_{\mathrm{xyz}}=\sqrt{\mathrm{V}_{\mathrm{x}}^{2}+\mathrm{V}_{\mathrm{y}}^{2}+\mathrm{V}_{\mathrm{z}}^{2}}
$$


SRNL-STI-2011-00151

5/26/11 Revision 0

A resultant velocity, $V_{x y}$, is obtained in the horizontal plane from the two-dimensional probe, such that

$$
\mathrm{V}_{\mathrm{xy}}=\sqrt{\mathrm{V}_{\mathrm{x}}^{2}+\mathrm{V}_{\mathrm{y}}^{2}}
$$

Equation 10

Turbulent intensity is defined as the variance of the velocity about the mean, and qualitative repeatability of this variance about the mean is readily observed, e.g., Figure 3-2. Additionally, relative turbulence intensity is defined as the ratio of the turbulent intensity divided by the average velocity magnitude (section 3.1.4.4). Turbulence intensity and relative turbulence intensity may be approximated, such that

$$
\begin{array}{cc}
V^{\prime}=\sqrt{\frac{\sum_{\mathbf{f}}=\mathbf{V}_{\mathbf{i}}-\mathbf{V}_{\mathbf{a v g}}}{\mathrm{n}\left(\mathrm{V}_{\mathrm{i}}-\mathrm{V}_{\mathrm{avg}}\right)^{2}}}=\sqrt{\frac{\sum_{\mathrm{i}=1}^{\mathrm{n}(\mathrm{n})}\left(\mathrm{V}_{\mathrm{f}}\right)^{2}}{(\mathrm{n})}} & \text { Equation 11 } \\
\mathrm{V}^{\prime} / \mathbf{V} \text { avg }=\text { relative turbulence intensity } & \text { Equation 12 }
\end{array}
$$

where $n$ is the number of velocity measurements at different times at a point, $V_{i}=$ instantaneous velocity, $V_{a v g}=$ average velocity with time, $V_{f}=$ instantaneous velocity fluctuation, and $V^{\prime}=$ average turbulence intensity.

Another aspect of turbulence is also noted in Figure 3-2, where the average velocity is frequently, but not always, the same for similar test conditions. The two measurements indicated by the shaded boxes were taken on the same day, in the same tank, using the same materials, but the average velocity is obviously different. This phenomenon was noted in several tests, and in some cases is even observed within a given test as shown in Figure 3-4. In that test, the average velocity can be observed to drop in magnitude as the test progresses. The variation in average velocity, as well as the turbulence intensity, demonstrates the chaotic, random nature of fluid velocity in the pilot scale tank. Given this chaotic fluid state, statistical data analyses were warranted to address the complexity of turbulent flow. Velocity plots are similar, and all velocity data is provided in Appendix B. 
SRNL-STI-2011-00151

5/26/11 Revision 0

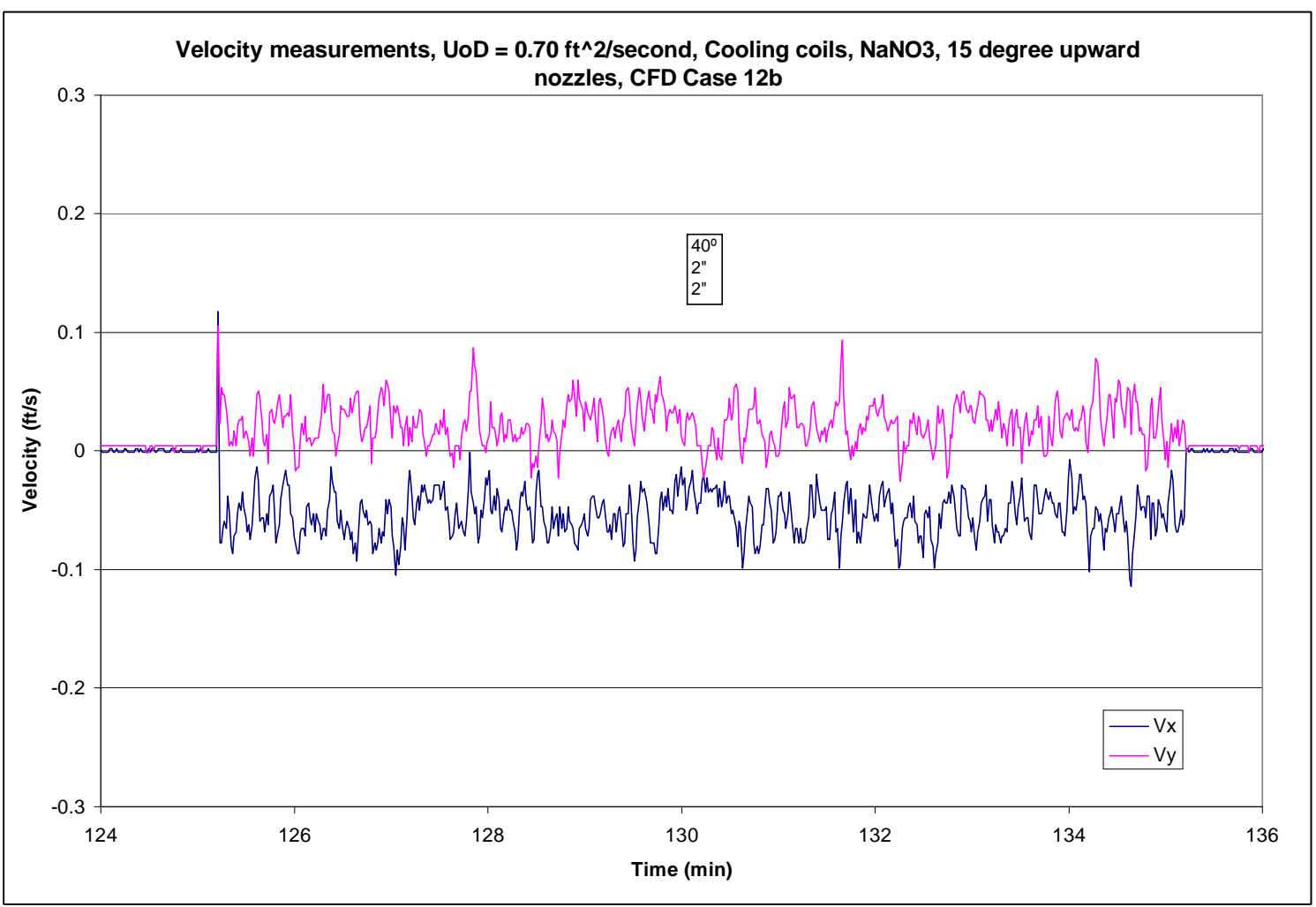

Figure 3-1: Typical Velocity Measurement

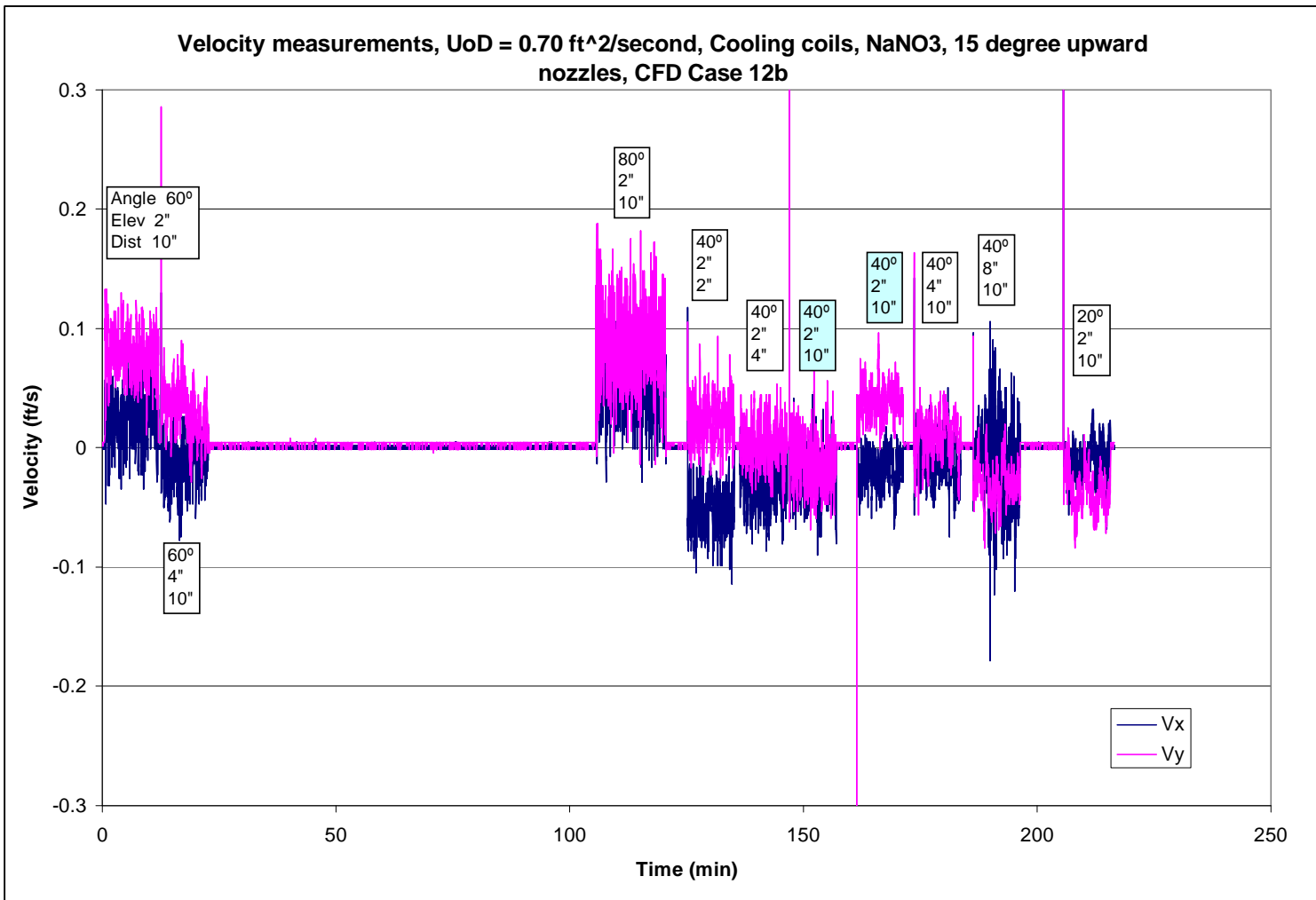

Figure 3-2: Typical Velocity Measurements With Coils 


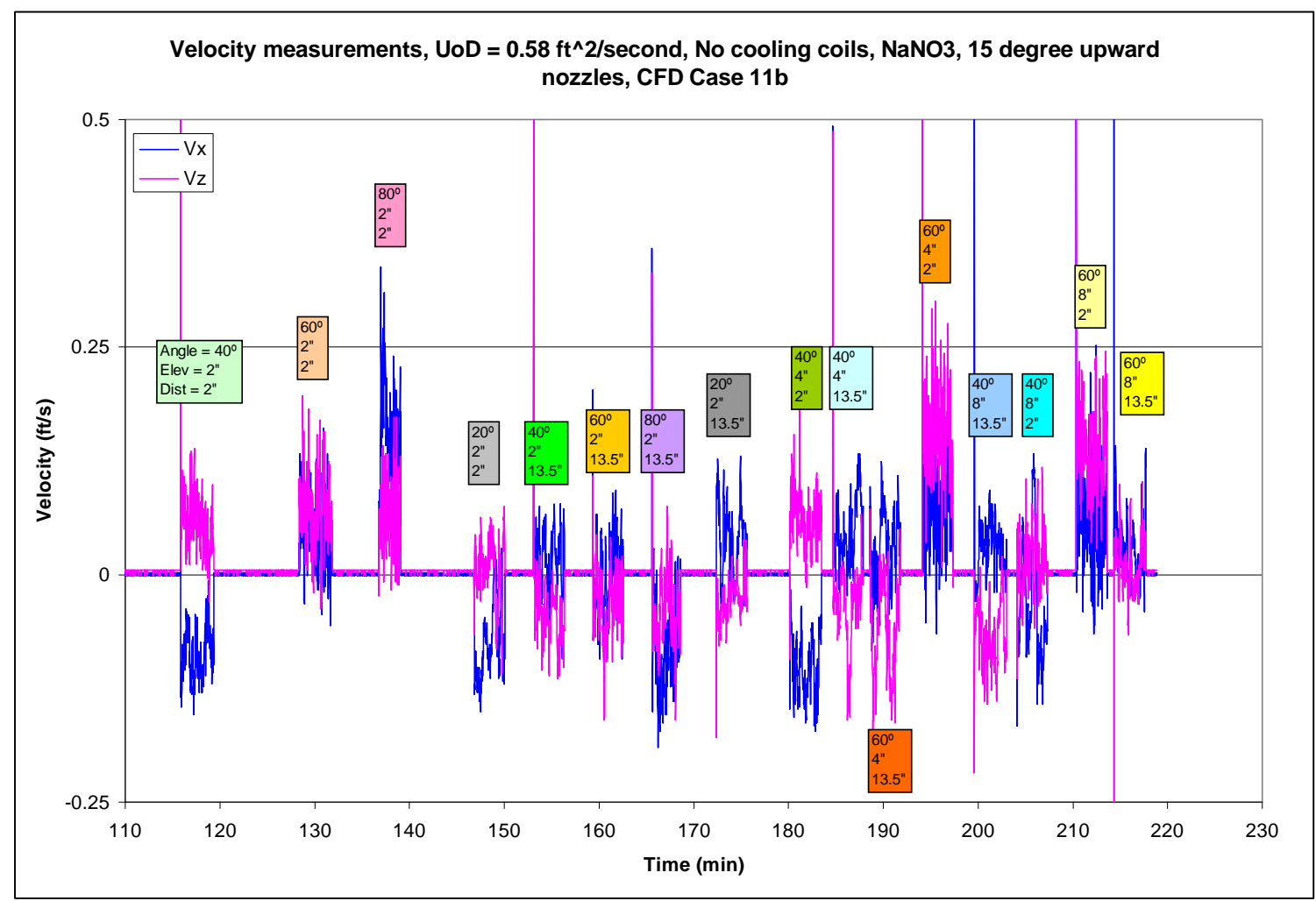

Figure 3-3: Typical Velocity Measurements Without Coils

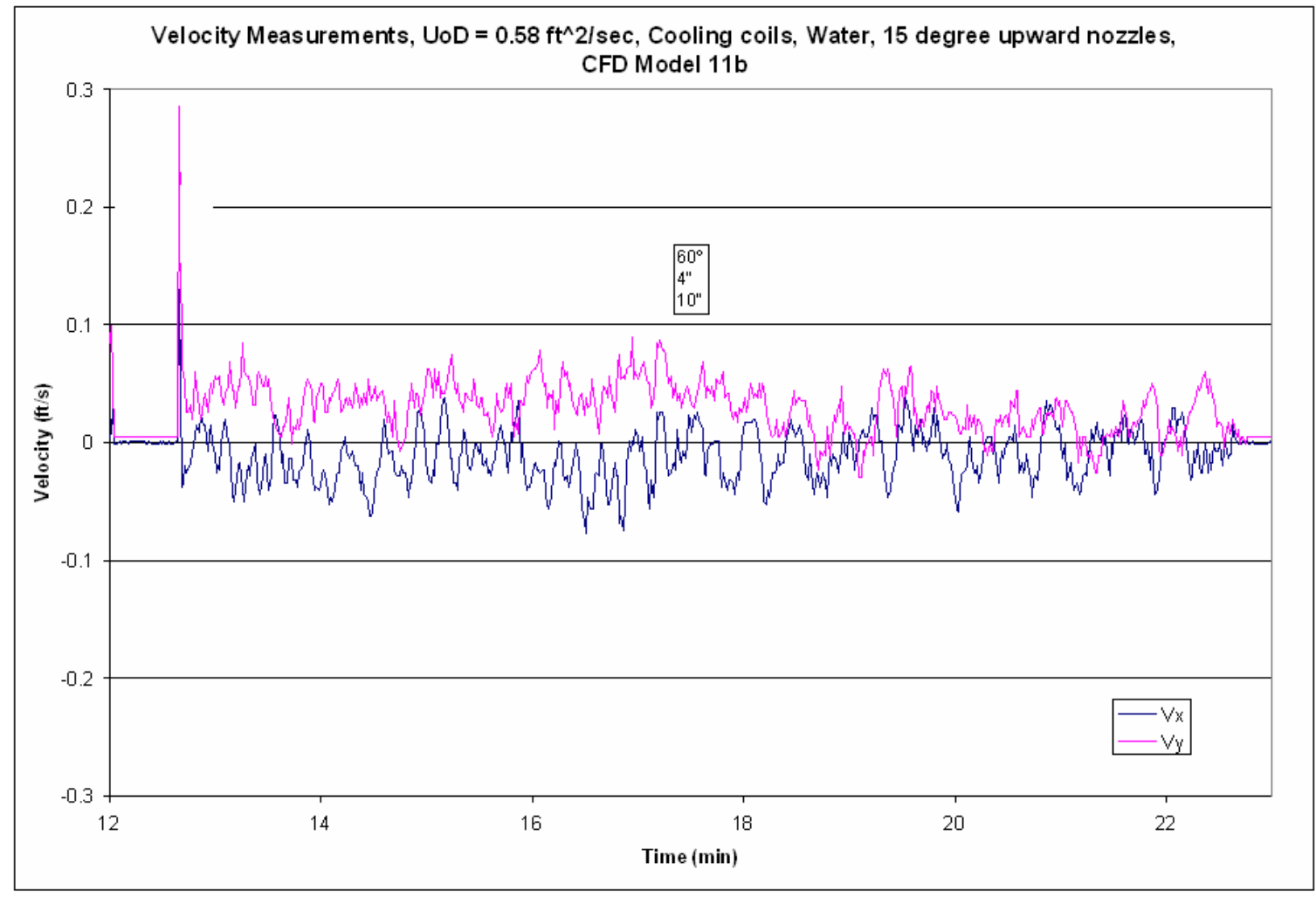

Figure 3-4: Variation of the Mean Velocity During a Test 
SRNL-STI-2011-00151

5/26/11 Revision 0

\subsubsection{Velocity Data and Comparison to CFD Models}

The average values of collected data were calculated and compared to the same locations in CFD models. Test data for pilot scale tests with and without cooling coils installed for both water and salt solutions were obtained in this research. All of the velocity probe location dimensions are listed in a companion CFD report (S. Lee [16]).

For pilot scale testing, several steps were taken to ensure that velocity probes were located within a $1 / 4$ inch of the locations specified in the CFD report. The tank perimeter was marked to establish the angle between the pump / tank center line and the required probe location. The rod holding the probe was then located by measuring with a tape measure from the inside tank wall to establish the correct radial location of the probe. Several extensions were attached to the end of the rod to ensure that the probe was located at the proper elevation. Once the probe was in position, the rod was visually inspected to ensure that it was plumb, and that the probe was rotated to ensure that the probe axes were properly aligned with the tank wall.

Also, full scale testing was required to understand turbulent effects. For the full scale ADMP testing discussed below, the probe locations were \pm 1.5 inches.

\subsubsection{Full Scale Test Data}

Previous testing provided some data at full scale for a much larger pump $(10,500 \mathrm{gpm})$ in an 85 foot diameter test tank. CFD modeling and experimental velocity measurements were used to successfully predict that sludge could be removed from Tank 18 (Leishear, Lee, and Stefanko [17]). That pump was referred to as the Advanced Design Mixer Pump (ADMP), and the test facility is partially shown in Figure 3-5. Operating at a 70 inch fluid level, velocity measurements were obtained at the locations shown in Figure 3-6, where a typical velocity measurement is shown in Figure 3-7. The average velocity measurements were predicted with CFD within about $25 \%$ for most locations away from the pump for locations of concern to this research (Figure 3-8). Velocity data from this research was available for review and was used during statistical analysis to establish a relationship between CFD and experimental results.

Another aspect of the ADMP research was the use of empirical equations to establish a velocity required to suspend sludge (Churnetski [18 and 19]). That equation is expressed as

$$
\mathrm{ECR}=\mathrm{K} \cdot \mathrm{U}_{0} \cdot \mathrm{D} \cdot \sqrt{\frac{\rho}{\tau}} \quad \text { Equation } 10
$$

where the effective cleaning radius $(E C R)$ equals the distance to which the pump can remove sludge (Figure 3-9), and $K$ is an experimentally determined constant. Note that at high velocities, sludge disturbance is related to both $U o D$ and material properties (Leishear, et al [20]). 


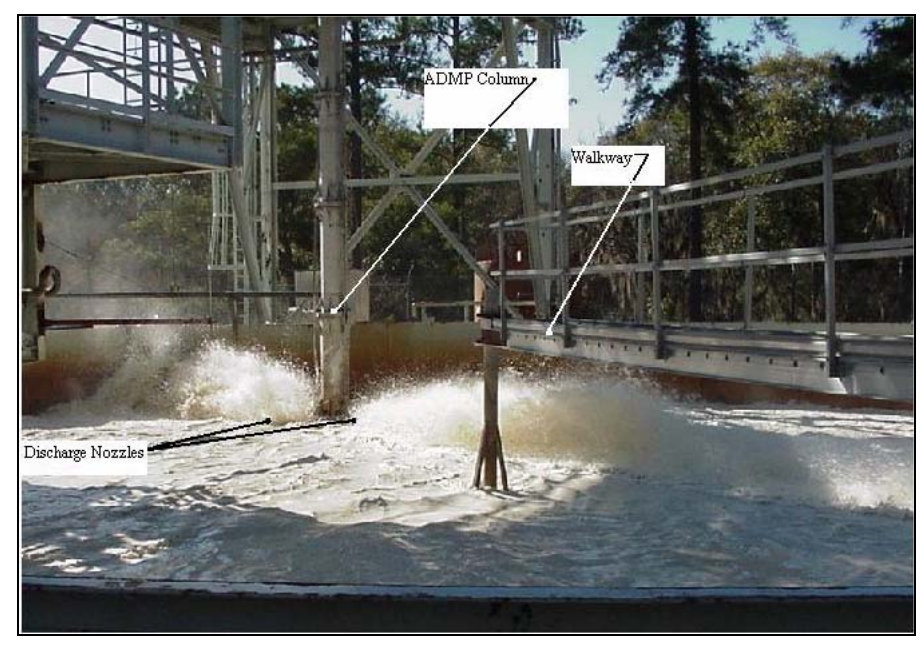

Figure 3-5: ADMP, Operating With the Water Level Near the Pump Discharge Centerline

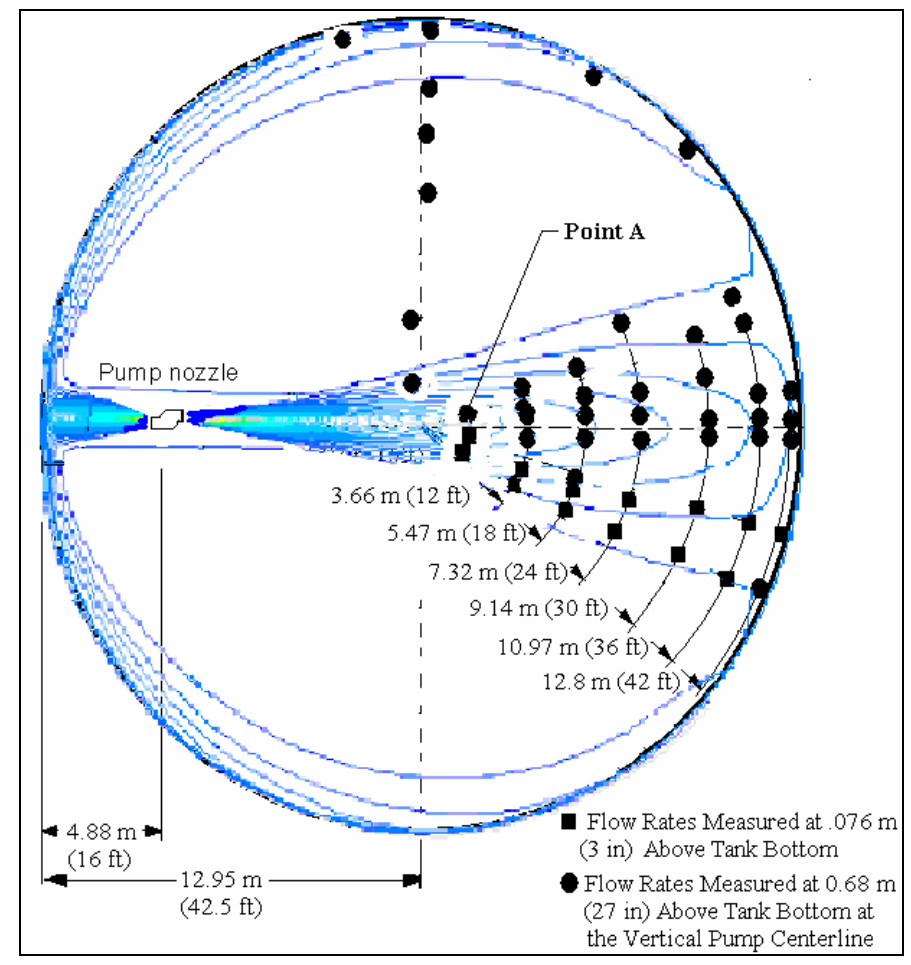

Figure 3-6: ADMP, Velocity Measurement Locations 


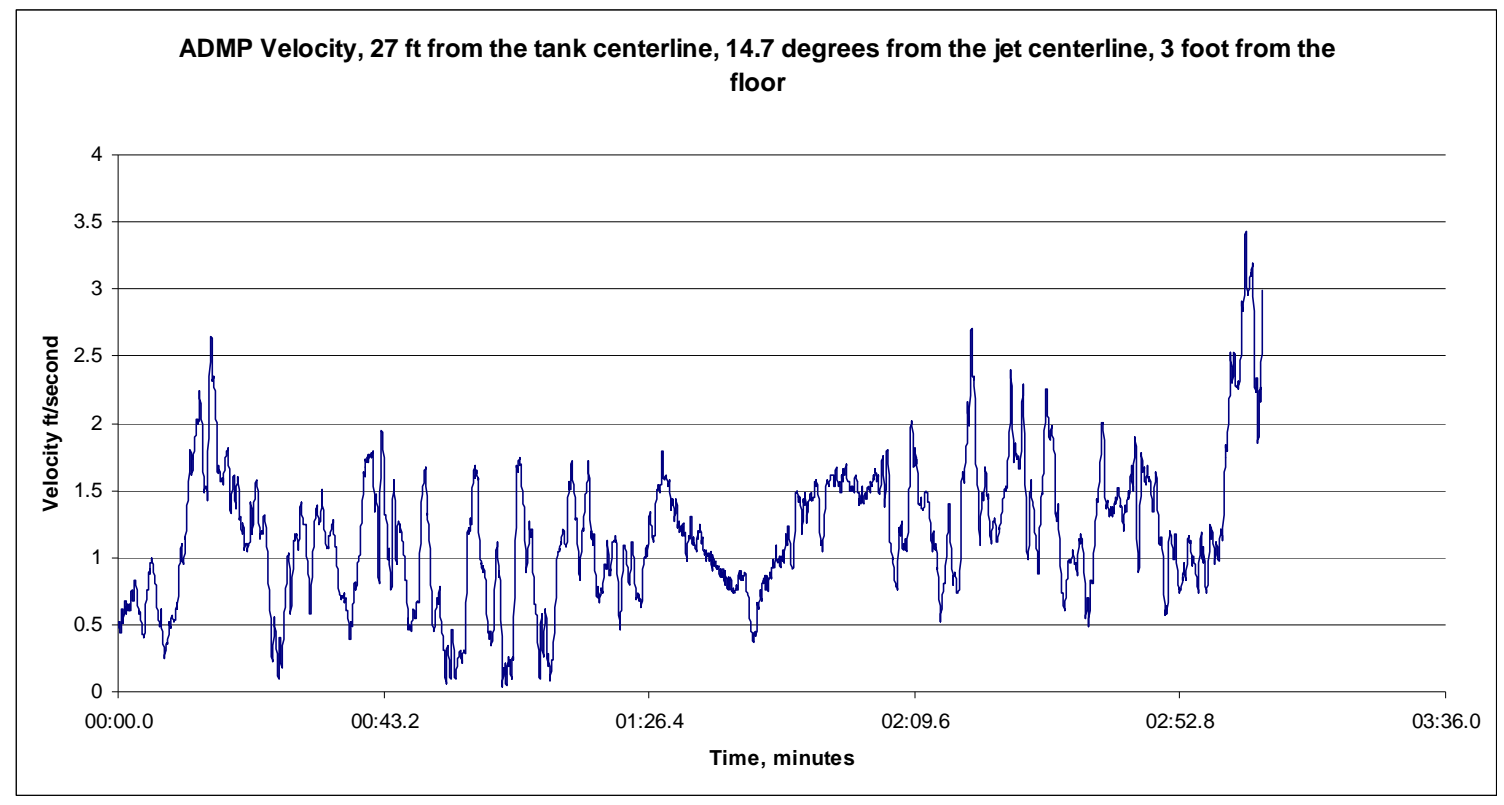

Figure 3-7: Typical ADMP Velocity Measurement

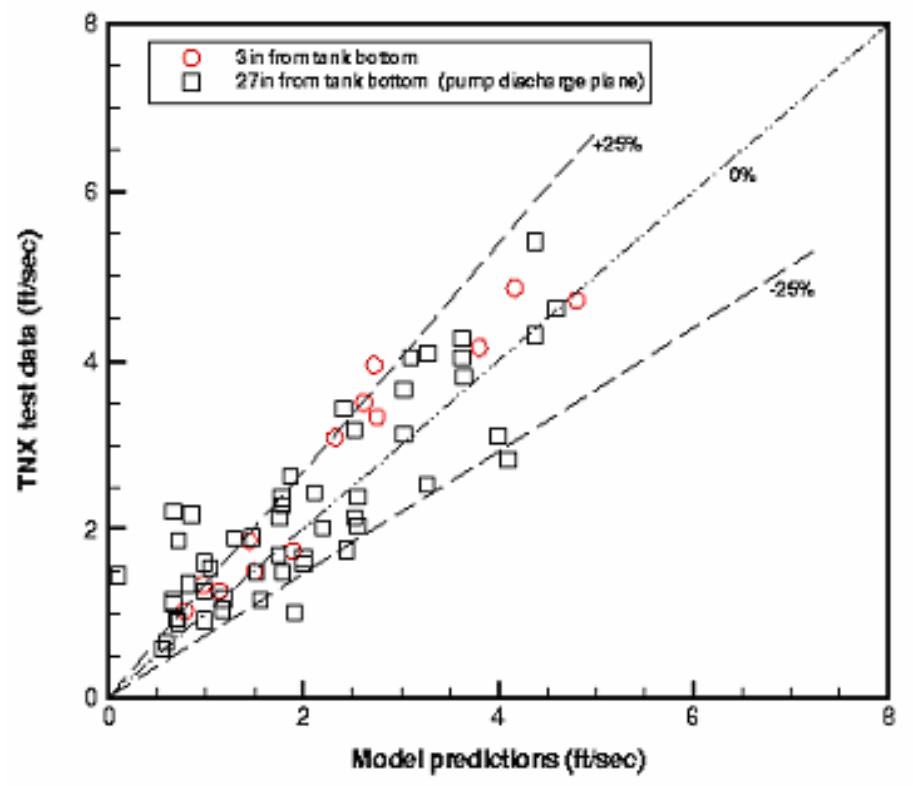

Figure 3-8: Comparison of ADMP Experimental Data to CFD Results 


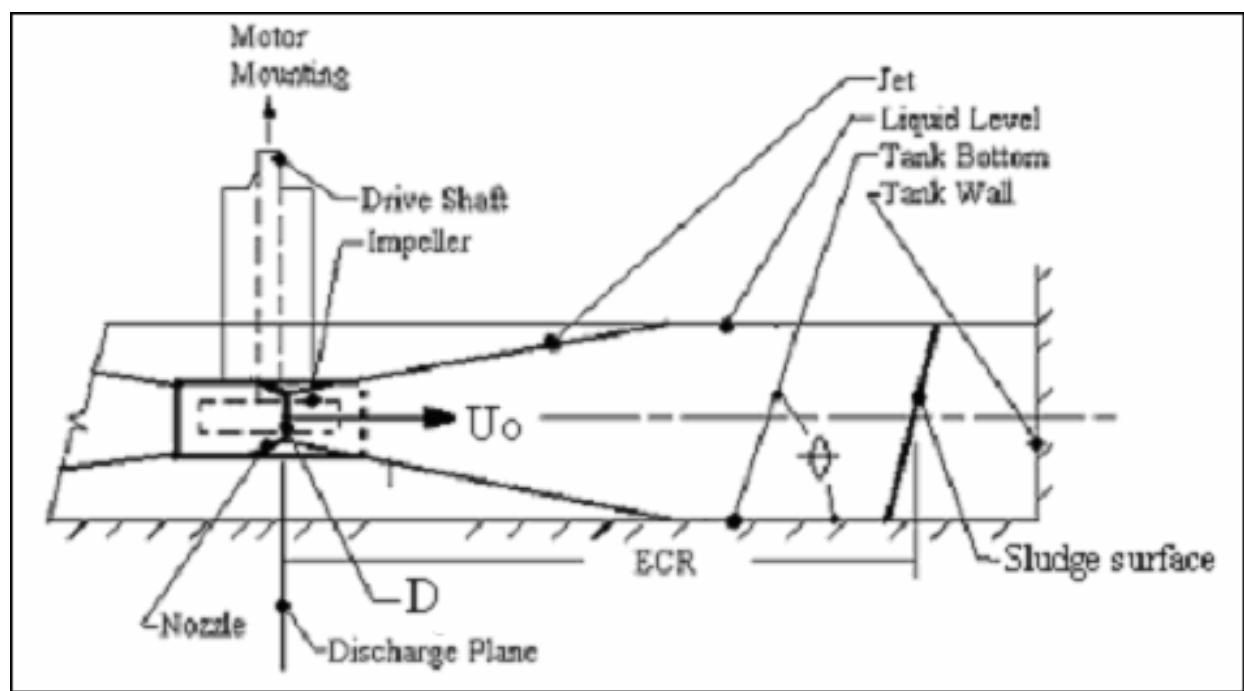

Figure 3-9: Sludge Mixing

\subsubsection{Statistical Velocity Data Analysis}

Using mean velocities, a velocity correction factor was established during this research, which can be applied to CFD model predictions for blending, sludge disturbance, and sludge entrainment during transfers. Velocity data was used in calculations to establish a relationship between CFD and experiment.

\subsubsection{Velocity Data}

Velocity data was available from the pilot scale tests performed during this research, and additional data was available from other previous full scale testing (Leishear, et.al. [17]). Although the full scale testing was performed with a pump of much higher flow rates, the concern here is not the flow rate, but the accuracy of CFD to model those flow rates at any point in a tank.

All pilot scale data is shown in Figure 3-10, and data used for analysis is shown in Figure 3-11. For blending analysis, velocities below $0.026 \mathrm{ft} / \mathrm{second}$ were discarded since they were below the range of interest, and velocities were also distinctly non-linear below 0.026. Presumably, instrumentation accuracy does not permit measurements at these low velocity levels, but instrument accuracy was not further investigated.

Essentially, full scale test results at 10,500 gpm in an 85 foot diameter tank and pilot scale test results at 9-16 gpm in an eight foot diameter tank were shown to be comparable. For this comparison, the mean variation warranted consideration. 
SRNL-STI-2011-00151

5/26/11 Revision 0

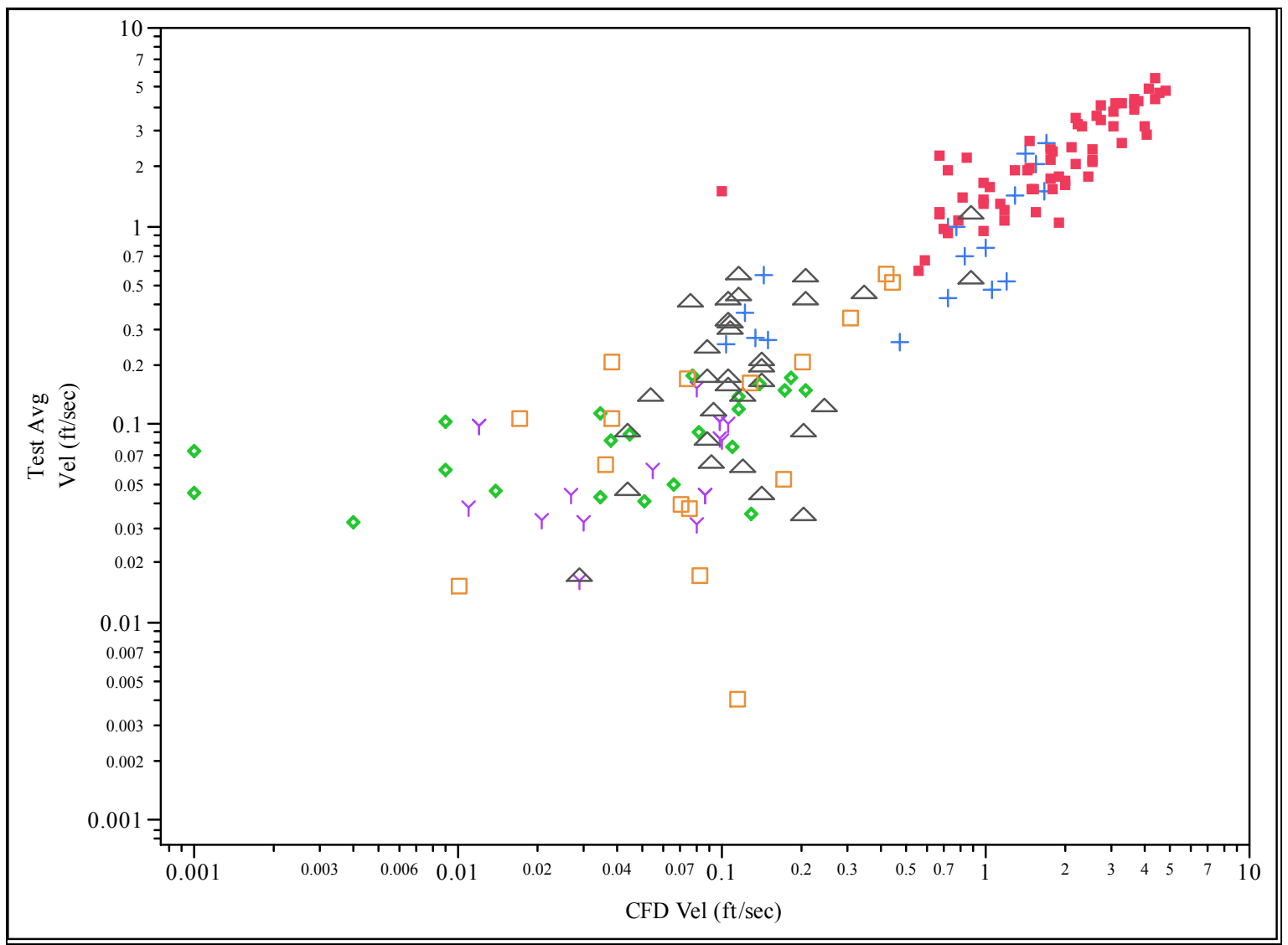

Figure 3-10: All Mean Velocity Data

(Appendix A) 


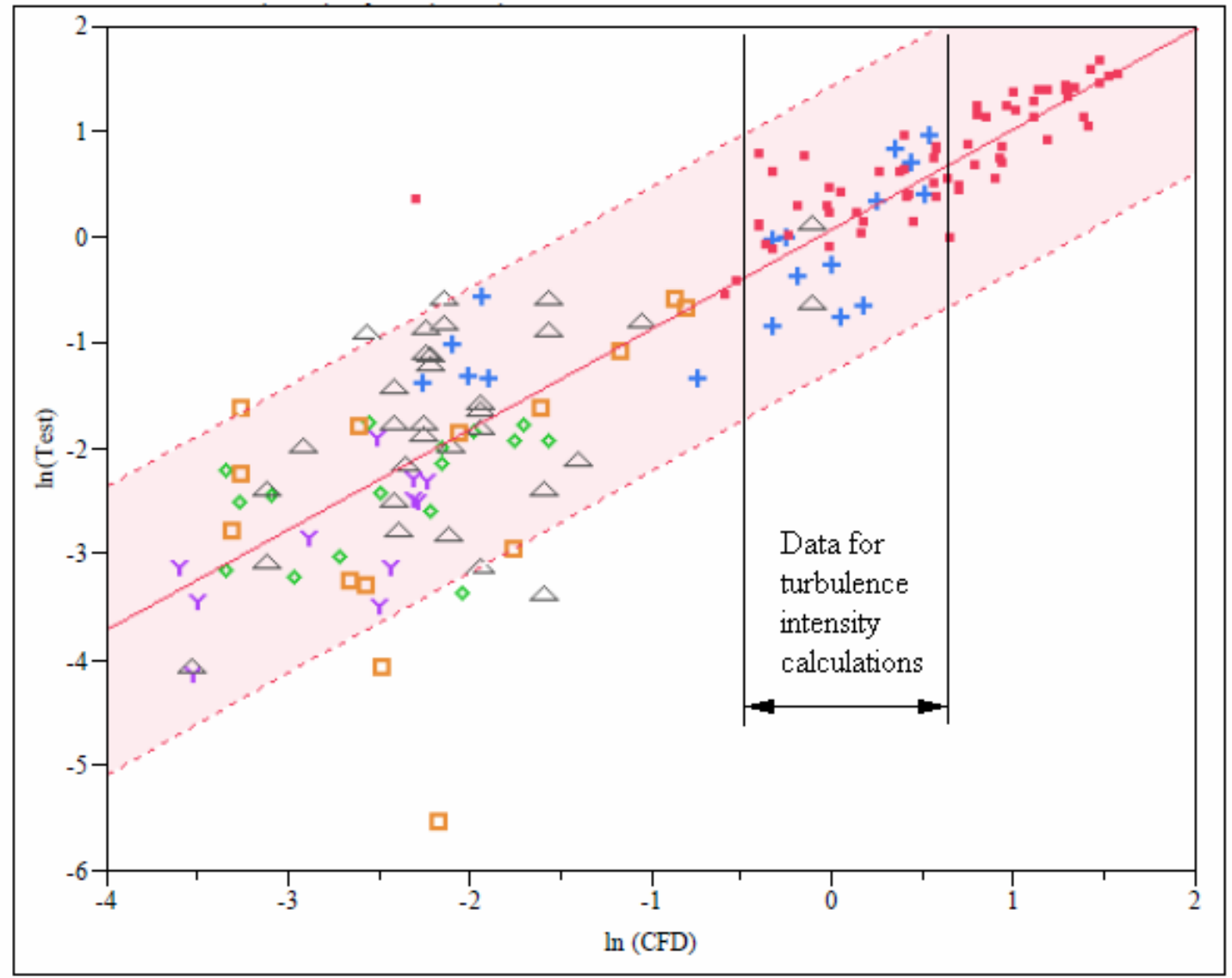

\begin{tabular}{|c|c|c|c|c|c|}
\hline$\theta$ & $\nabla$ & Test Description & Test Conditions & Scale & Type of Test \\
\hline - & 1 & Full Scale, No Coils & UoD $=29.4 \mathrm{ft}^{\wedge} 2 / \mathrm{sec}$; water; no coils & Full & ADMP \\
\hline $\mathbf{Y}$ & 2 & Pilot Scale, Coils & UoD $=0.70 \mathrm{ft}^{\wedge} 2 / \mathrm{sec} ;$ salt solution; coils; 15 degree upward nozz & Pilot & Case $12 \mathrm{a}$ \\
\hline$\diamond$ & 3 & Pilot Scale, No Coils & UoD $=0.58 \mathrm{ft}^{\prime} 2 / \mathrm{sec} ;$ salt solvtion; no coils; 15 degree upward & Pilot & Case 11a \\
\hline+ & 4 & Pilot Scale, No Coils & $\mathrm{UoD}=0.58 \mathrm{ft} \cdot 2 / \mathrm{sec} ;$ salt solvtion; no coils; 15 degree upward & Pilot & Case 11b \\
\hline$\Delta$ & 5 & Pilot Scale, No Coils & $\mathrm{UoD}=0.81 \mathrm{ft} \cdot 2 / \mathrm{sec} ;$ salt solution, no coils, tee nozzle & Pilot & Case 2 \\
\hline ㅁ & 6 & Pilot Scale, No Coils & UoD $=0.81 \mathrm{ft}^{\prime} 2 / \mathrm{sec}$; water; no coils; tee nozzle & Pilot & Case 1 \\
\hline
\end{tabular}

Figure 3-11: Mean Velocity for Full Scale and Pilot Scale Data

\section{(Appendix A)}

\subsubsection{First Approximation for Velocity Comparison of CFD to Experiment}

Experimentally measured velocities were compared to CFD models, and velocities were shown to be comparable throughout the range of test data. As a first approximation to compare CFD to experiment, both CFD predictions and experimental test results are shown in Figure 3-11. Each of the data points in the figure depicts the mean experimental velocity at a point for a discrete test. The solid line in the figure indicates predicted velocities obtained from CFD calculations. With 95\% confidence (Appendix A), the dotted lines provide a relationship between experimental velocities and CFD results. For a $95 \%$ confidence level of $95 \%$ blending times, the variation between CFD predictions and the full range of experimental blending times varied by a factor of 1.49 , where this large variance is consistent with observations. Although not investigated further, the variance seems to decrease at full scale where flow rates are considerably larger. A velocity correction factor of 1.49 could have been selected for design recommendations, but the correction 
factor was further refined using statistical analysis. To do so, the average experimental values for 95\% blending times at $95 \%$ confidence were compared to CFD results. CFD predicted blending times were not statistical blend times, but were, in fact, the time required for all points in the tank to reach the $95 \%$ blending criterion.

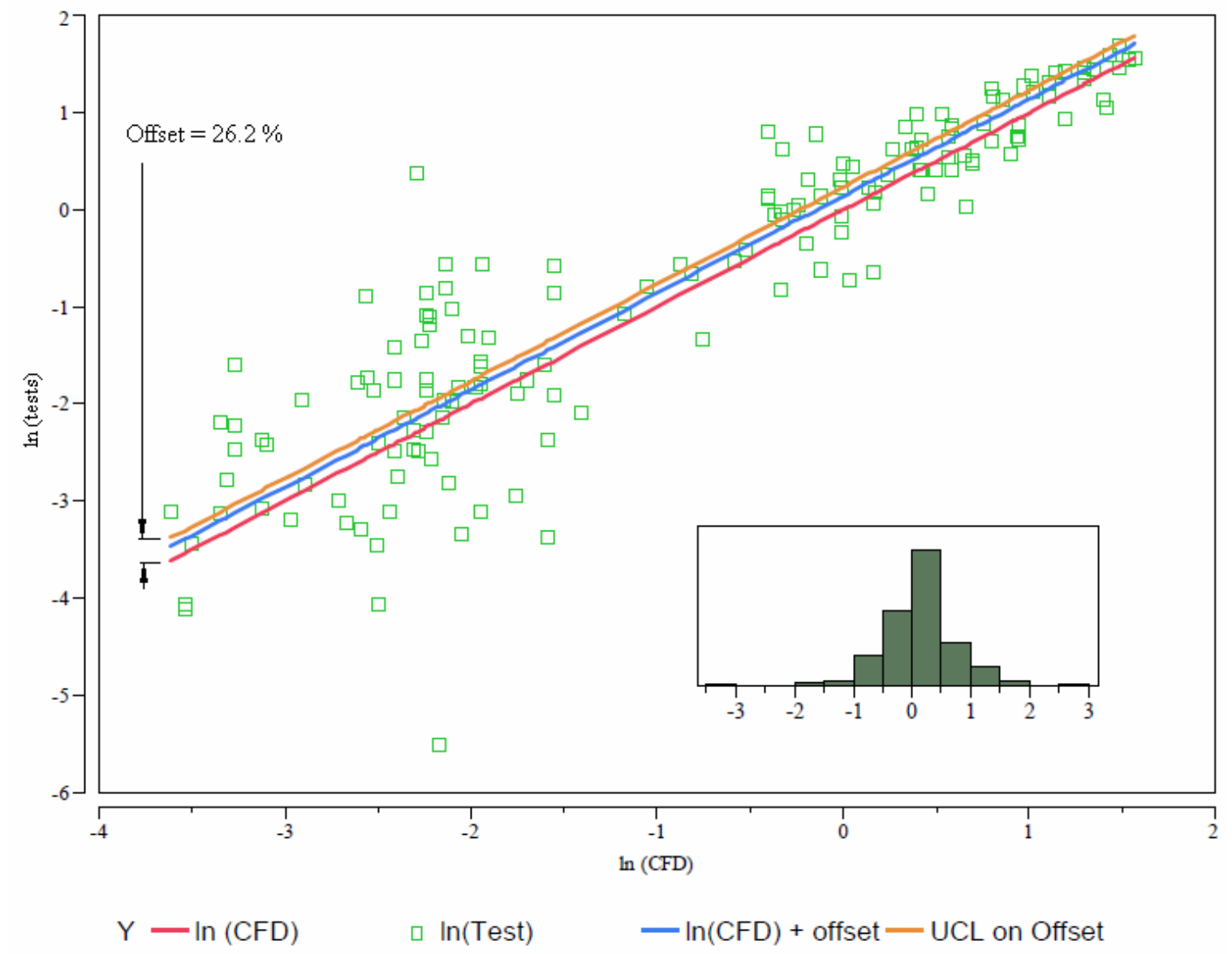

Figure 3-12: Variation of Experimental Mean Velocities Compared to CFD Velocities

(Appendix A)

\subsubsection{Velocity Comparison of CFD to Experiment}

Rather than comparing all of the mean velocities to the CFD results as in Figure 3-11, the average value of all experimental results was compared to CFD model results. That is, a straight line was obtained on a log-log graph to represent the average value of the mean velocities, as shown in Figure 3-12. By doing so, an average variation between experiment and CFD was obtained, where the CFD models provided the time at which all of the points in the tank were blended to 95\% mixing, or better. To compare the pilot scale results to these limiting CFD values, the average value of experimental data was selected. From the offset shown in Figure 3-12 (Appendix A), the ratio of the average test velocities to CFD predictions throughout the range of interest was 1.262 . This variation in velocity reflects a realistic velocity comparison between CFD and experiment. However, instrumentation errors also need compensation. The flow meter uncertainty was $4 \%$, per SRNL calibration standards. The velocity probe uncertainty was $4.3 \%$, where the Vendor Calibration Certificate specified tolerances in the $\mathrm{x}$ and $\mathrm{y}$ directions of \pm 0.01 $\mathrm{ft} /$ second for three different tests, which were performed at $2.00 \mathrm{ft} / \mathrm{second}$. The uncertainty at full range then equaled $4.303 \cdot 0.001=4.3 \mathrm{ft} /$ second $(2.15 \%)$ at full scale, where 4.303 is the student- $\mathrm{t}$ 
for a sample size of three (Coleman and Steele [14]). At a zero velocity, the uncertainty was determined from Figure 3-13 and Figure 3-14. Before the pump was operated, the uncertainty for $95 \%$ confidence was calculated to be $0.0046 \pm 0.002 \mathrm{ft} /$ second. Since the uncertainty at a zero velocity is a positive quantity, it conservatively predicts high velocities and was neglected for the purposes of this report. A minor uncertainty due to probe location was also evaluated. Using a $1 / 4$ inch variation on probe position, several points were evaluated using CFD models. Typical variations over this distance were $1.5 \%$, or less. For two points in the jet of the pilot scale pump nozzle, the uncertainty was $2-2.5 \%$. The $2.5 \%$ value conservatively bounds measured probe placement uncertainties at both full and pilot scale. At full scale, the probes were located within an inch of specified locations, and the uncertainty due to probe location was smaller than at pilot scale. Consequently, an uncertainty calculation for pilot scale bounds both scales. The total variation in the average velocity was obtained from $\pm \sqrt{0.262^{2}+0.04^{2}+0.0215^{2}+0.025^{2}}=$ 0.267 . That is, $\mathrm{a} \pm 26.7 \%$ uncertainty yields a correction factor of 1.267 . From this calculation, a velocity correction factor was determined to be 1.267 . To use this velocity correction factor, velocities calculated by CFD at pilot scale are multiplied by 1.267 to obtain the predicted velocity at full scale. Since this value was obtained from independent tests, different pump designs, and different scales, the factor is assumed to be pertinent to velocities obtained from different CFD results obtained using Fluent. Since Fluent was the base code for all CFD calculations for full and pilot scale modeling referenced in this research, the velocity correction factor may be applied as required to CFD results. Essentially, numerous CFD models were statistically compared to an average of all the mean velocities measured during a sequence of tests, i.e., an average of the average values, so to speak. From this comparison, a single velocity correction factor of 1.267 for CFD models was determined to be applicable for tanks with or without coils at either pilot scale or full scale.

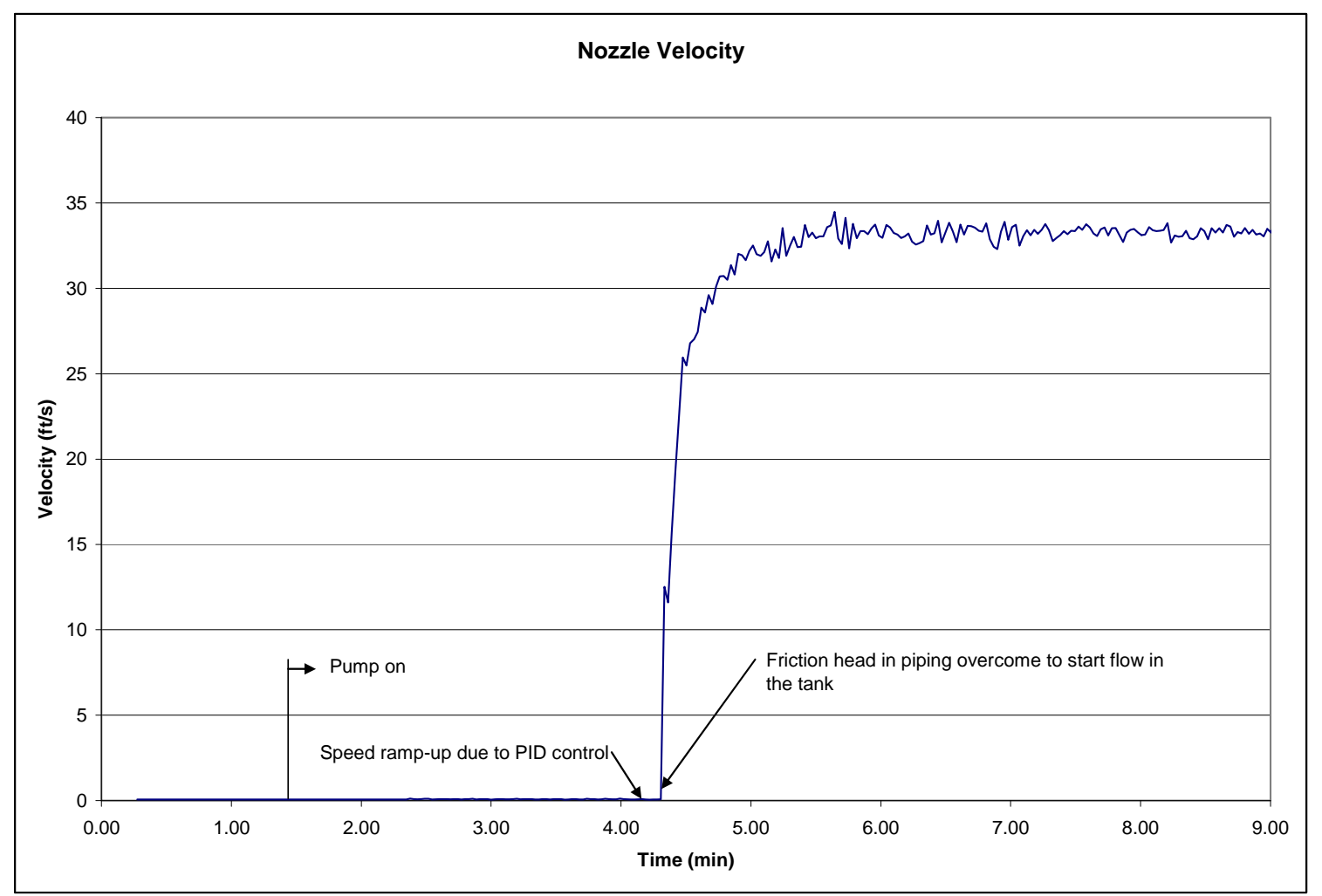

Figure 3-13: Flow Rates During Initial Testing 


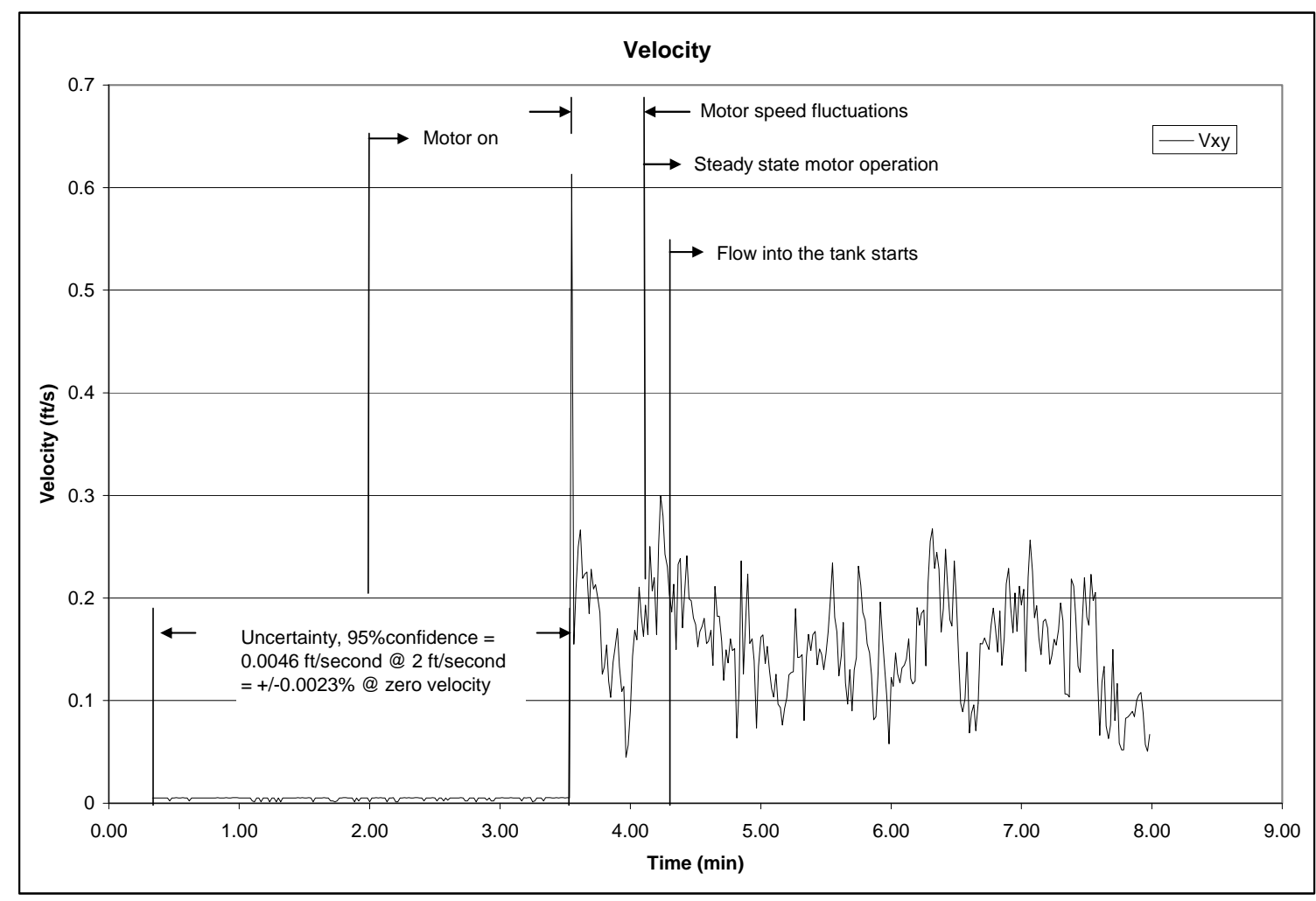

Figure 3-14: Velocity Measurements During Initial Testing ( $x-y$ plane)

\subsubsection{Turbulence Intensity}

Average velocities were used for statistical calculations in Appendix A where the effects of turbulence intensity were not calculated. This discussion provides a qualitative basis for that assumption. The goal of this research was not to investigate the complexities of turbulent intensity, but the observation of velocity fluctuations required consideration with respect to sludge disturbance. The conclusion here is that fluctuations observed at pilot scale are expected to be of the same magnitude, or a lower magnitude at full scale. Consequently, the effects of velocity fluctuations on sludge disturbance observed at pilot scale are expected to have similar or smaller effects at full scale.

Measurement of velocity fluctuations and the definition of turbulent intensity require further attention. When a velocity is measured there are many variables of concern. Some variables are related to instrumentation, and some are related to fluid mechanics. First, consider instrumentation. The same instrumentation was used for both pilot and full scale testing. The velocity instrument and positioning have an inherent error, as discussed in section 3.1.3.3. Additionally, electrical noise and mechanical vibrations can affect the indicated velocity. Inspection of Figure 3-14 concludes that the effects of electrical noise are negligible, since electrical influences were not observed as the power ramped up to turn the impeller. Mechanical vibrations were assumed to be negligible, since the small, three horsepower pump motor was located external to the tank and was connected to the tank through a PVC pipe (poly-vinyl chloride). Instrument response time also affects velocity indications, where lower values of velocity fluctuations may be recorded if the response is too slow. Since response times for the velocity probes were not fully evaluated, indicated velocity fluctuations may be lower than actual for both pilot and full scale testing. In short, the velocity fluctuations reported here have errors that were not fully quantified, and similar errors may occur at both pilot and full scale. 
Now consider the effects of fluid mechanics on velocity measurements. One aspect of fluid effects is the probe size and shape, which may have localized fluid flow effects that affect velocity indications. Another aspect of velocity fluctuation is related to the flow from the pump, which may in fact be the primary contributor to velocity fluctuations for the low flow rates into the tank. In Figure 3-14, fluctuations in velocity occur in the pilot scale tank before the flow rate changes in the tank. Velocity fluctuations initiated by the pump resulted in fluid oscillations of the entire tank contents. Even before flow into the tank commenced, the freewheeling impeller caused oscillations of the tank contents as the impeller speed fluctuated. As shown in Figure 3-15, the turbulence intensity is reasonably constant for different velocities throughout the tank at a constant pump flow rate, but when the speed is increased the turbulence intensity increases as shown in Figure 3-16. An inspection of the velocity plots in Appendix B shows that velocity fluctuations decrease throughout the tank when the nozzle velocities decrease. Velocity fluctuations are apparently related to the pump speed. That is, the tank fluid contents move at a high frequency vibration, which is superimposed on the overall fluid motions in the tank. One could effectively argue that these fluid oscillations due to a pump are not turbulence at all, but separating the effects of pump pulsations from turbulent flow effects is impractical for this research. Even so, similar phenomena are expected to occur during both pilot and full scale testing, where the pulsations are expected to be the same or smaller at full scale. Further investigation may be warranted but is outside the scope of this research.

To qualitatively consider turbulence intensity at both full scale and pilot scale, turbulence intensity values were considered, which were noted in the literature to be $30-35 \%$ for onedimensional axial turbulence intensity as reported by Warda, et al [15]. The probes used in this work provided only two-dimensional turbulence intensity data. Referring to Figure 3-11, note a range of values indicated as turbulence intensity data. These values were selected since they represent the only data points where full scale and pilot scale testing overlapped for this research. One inference is that the measured turbulence intensity is significantly affected by liquid velocity and pump pulsations. Some of the data for the ADMP research is provided in Appendix D. At full scale, the relative intensity seems to be more affected as the distance from the pump increases. Table 3-1 provides a comparison between the available pilot and full scale test results. The intensity values at both pilot and full scale were consistent with observed turbulence intensity noted by Warda. From the available data, the effects of turbulence intensity on sludge disturbance are assumed to be similar at either full scale or pilot scale. Again, further research is recommended to better understand turbulence intensity with respect to pump operations and pulsations. Specifically, higher frequency data is required to better measure the response of tank contents to pump induced oscillations. In short, the chaotic, random behavior of fluids during blending was simplified by using statistical analysis to establish correction factors for use in CFD modeling. 


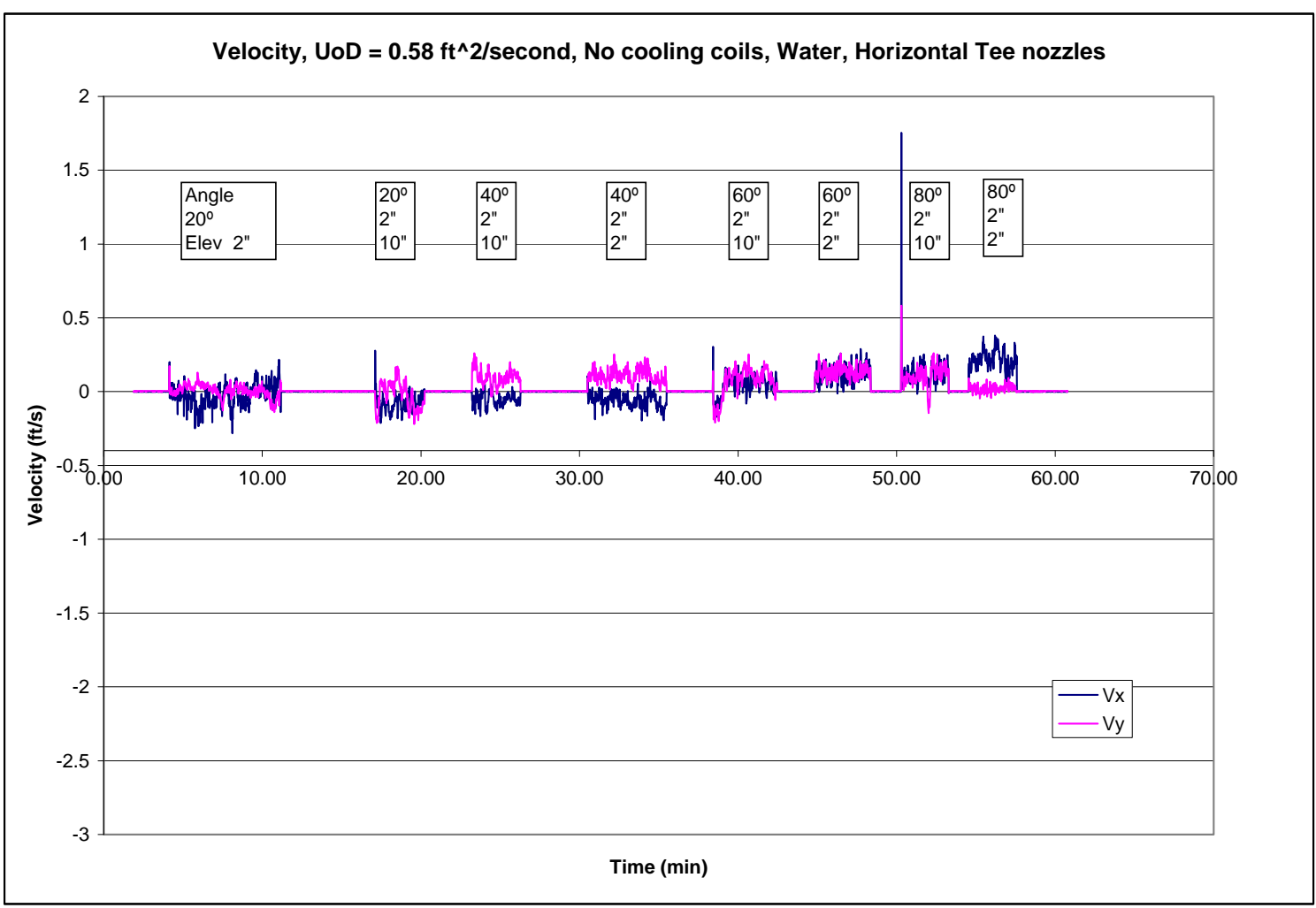

Figure 3-15: Turbulence Intensity at a Lower Pump Speed (x and y directions)

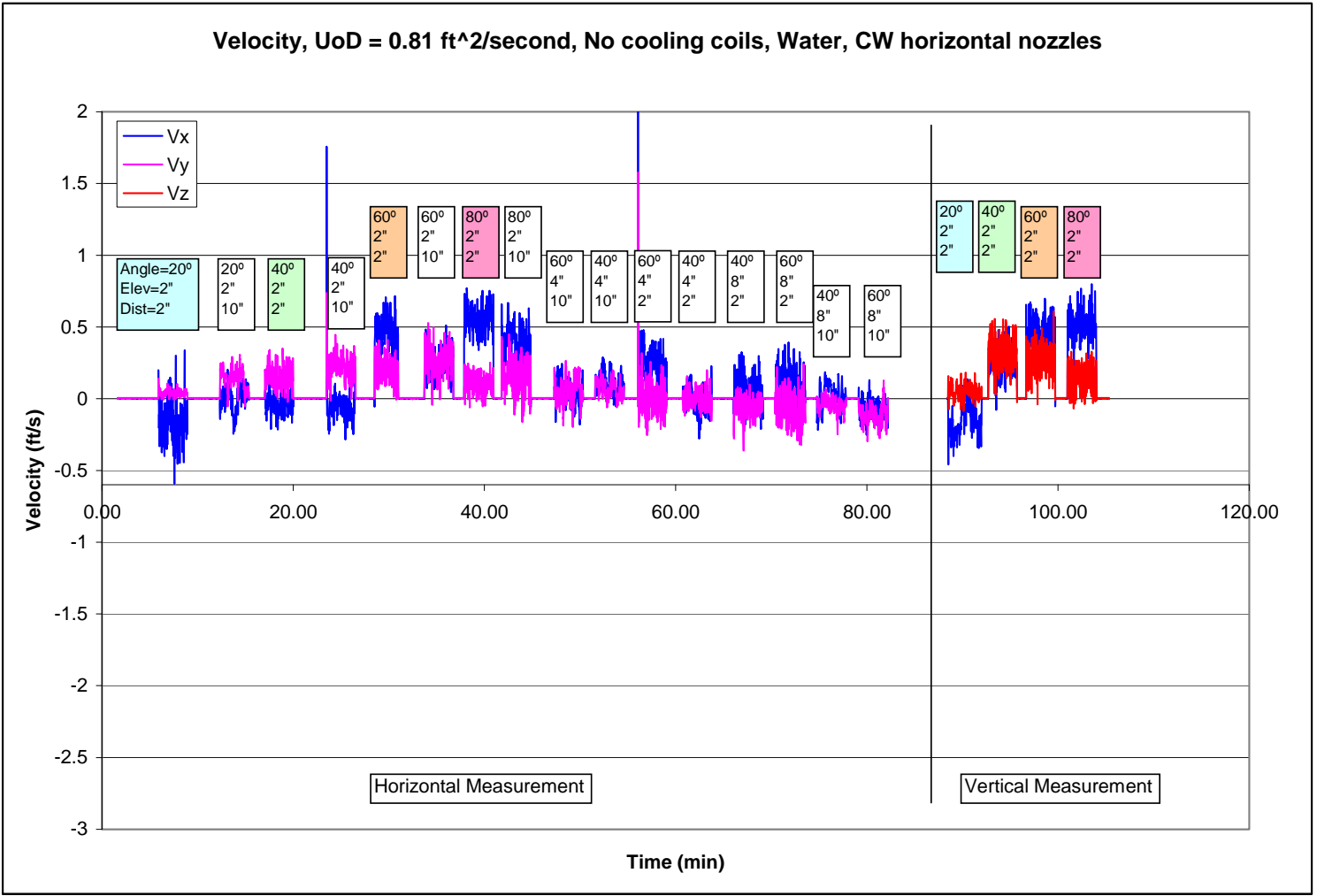

Figure 3-16: Turbulence Intensity at a Higher Pump Speed (x and y directions) 


\begin{tabular}{|c|c|c|c|}
\hline $\begin{array}{l}\text { ADMP Data, Appendix D, } \\
\text { Leishear, et.al. [16] }\end{array}$ & & $\begin{array}{l}\text { Pilot Scale Data, In and } \\
\text { around the jets, near the } \\
\text { pump nozzle, Lee and } \\
\text { Armstrong, Table } 11 \text { [15] }\end{array}$ & \\
\hline $\begin{array}{l}\text { Average velocity at a point, } \\
\text { Vxy }\end{array}$ & $\begin{array}{l}\text { Turbulence } \\
\text { intensity }\end{array}$ & $\begin{array}{l}\text { Average velocity at a point, } \\
\text { Vxy }\end{array}$ & $\begin{array}{l}\text { Turbulence } \\
\text { intensity }\end{array}$ \\
\hline 2.72 & 0.94 & 2.72 & 0.94 \\
\hline 3.73 & 1.24 & 2.7 & 1.02 \\
\hline 2.7 & 1.02 & 2.4 & 0.93 \\
\hline 3.08 & 1.14 & 1.14 & 0.66 \\
\hline 2.4 & 0.93 & 1.54 & 0.74 \\
\hline 3.18 & 0.93 & 1.89 & 1.03 \\
\hline 1.14 & 0.66 & 1.17 & 0.52 \\
\hline 1.54 & 0.74 & 0.95 & 0.6 \\
\hline 1.89 & 1.03 & 1.59 & 0.67 \\
\hline 1.17 & 0.52 & 2.64 & 1.02 \\
\hline 0.95 & 0.6 & 1.73 & 0.86 \\
\hline 1.59 & 0.67 & 0.96 & 0.47 \\
\hline 3.39 & 1.04 & 0.92 & 0.45 \\
\hline 4.08 & 1.24 & 2.37 & 0.96 \\
\hline 3.81 & 1.16 & 1.72 & 0.72 \\
\hline 3.44 & 1.03 & 1.17 & 0.52 \\
\hline 4.03 & 1.18 & 1.14 & 0.6 \\
\hline 2.64 & 1.02 & 1.11 & 0.58 \\
\hline 1.73 & 0.86 & & \\
\hline 0.96 & 0.47 & & \\
\hline 0.92 & 0.45 & & \\
\hline 2.37 & 0.96 & & \\
\hline 1.72 & 0.72 & & \\
\hline 1.17 & 0.52 & & \\
\hline 1.14 & 0.6 & & \\
\hline 1.11 & 0.58 & & \\
\hline Average of all velocities & $\begin{array}{l}\text { Average of all } \\
\text { turbulence } \\
\text { intensities }\end{array}$ & Average of all velocities & $\begin{array}{l}\text { Average of } \\
\text { all } \\
\text { turbulence } \\
\text { intensities }\end{array}$ \\
\hline 2.25 & 0.86 & 1.66 & 0.74 \\
\hline $\begin{array}{l}\text { Average Relative } \\
\text { Turbulence Intensity } \\
\text { Average }\end{array}$ & & $\begin{array}{l}\text { Average Relative } \\
\text { Turbulence Intensity } \\
\text { Average }\end{array}$ & \\
\hline 0.37 & & 0.44 & \\
\hline
\end{tabular}

Note: Turbulence intensities are the measured values from the velocity probe for resultant velocities.

Table 3-1: Turbulence Intensity at Pilot Scale and Full Scale 


\subsubsection{Jet Characteristics, Cavitation, and Pump Design}

The variability of the velocity was also evidenced by the instability of the jet as it exited the nozzles. The photo in Figure 2-6 shows some variation, or waviness, in the SBP jet, but the jet is very wavy as discerned from review of videos. That is, the shape of the jet fluctuates considerably with respect to time, which is consistent with the properties of a turbulent jet. This fluctuation affects turbulent flow measurements in the tank, and was captured by using statistical data analysis. There is also some minor fluctuation in flow through the nozzles as shown in Figure 3-17.

For the Phase 2 blending tests, the flow rates through the CW nozzles were reasonably constant at less than a $1 \%$ error with $95 \%$ confidence, as indicated by Figure 3-17. Pump flow characteristics were similar for other $\mathrm{CW}$ tests. A concern was raised that variability in blending times may be related to pump flow rate variability, but this small variability seems to an unlikely cause of the significant blending times observed during this testing.

During testing, cavitation bubbles were observed in the nozzle jets external to the pump. Bubbles exited the nozzles, and then collapsed as they entered solution within about a foot of the nozzles. At the operating nozzle velocity of $40.16 \mathrm{ft} / \mathrm{second}$, cavitation is a reasonable outcome, since cavitation occurs in pipe systems at flow rates as low as $6-8 \mathrm{ft} / \mathrm{second}$.

High internal pump velocities should be considered, since cavitation is a potential risk to pump reliability. Therefore, vibration analysis seems warranted before the pump is installed. After the fact, a premature pump failure cannot be repaired, and even troubleshooting the failure is complicated by the radioactive waste tank environment. However, if there is a pump cavitation problem, the design could be revised to include an inducer on the pump, which is essentially an in line propeller installed on the drive shaft in the pump suction. The CW pump is basically a new design for a waste tank, and the design should be very carefully reviewed while in design and fabrication. 
SRNL-STI-2011-00151

5/26/11 Revision 0

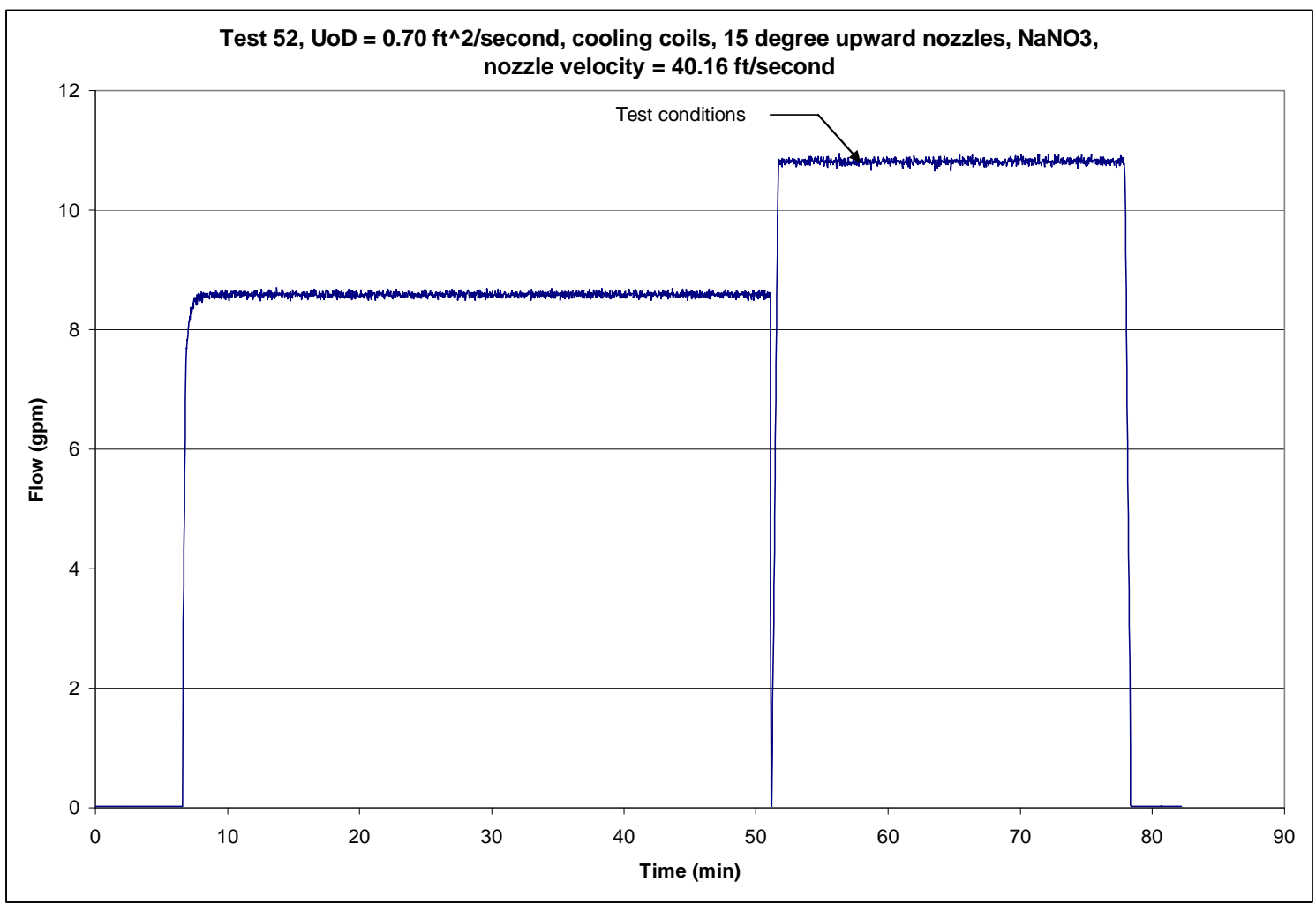

Figure 3-17: Typical Pump Flow Rates During a Phase 2 Blending Test

\subsection{Blending Times for Test Results of Similar Solutions}

All blending test results are similar to Figure 2-11, and although all graphs are not provided here, all important test results and test parameters for blending are listed in Table 3-2 and Table 3-3. Graphs and detailed discussions are provided for all Phase 1 tests in that report. 
SRNL-STI-2011-00151

5/26/11 Revision 0

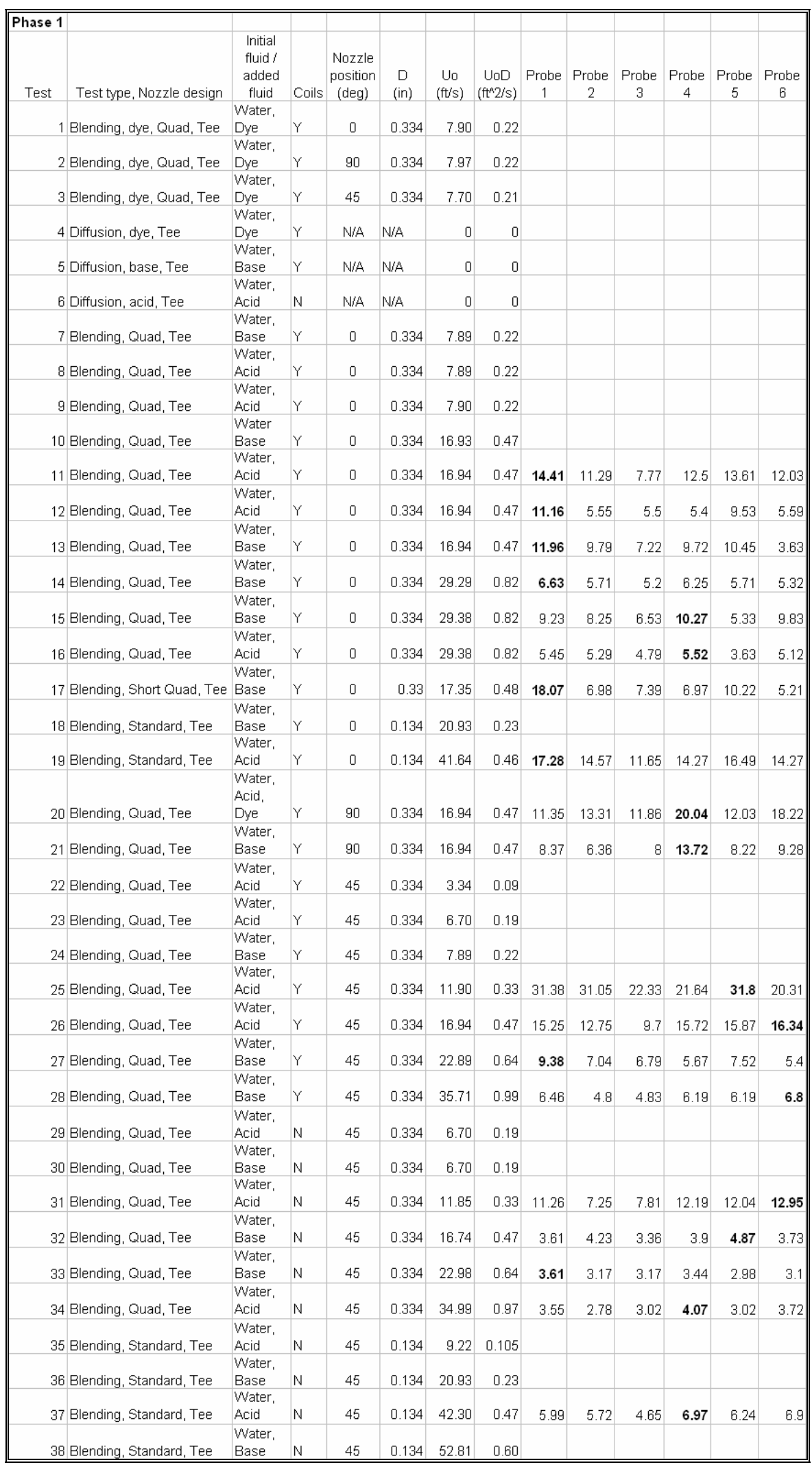

Note: Blending times not shown are below the recommended design conditions for $U o D$.

Table 3-2: Phase 1, Blending Test Results 


\begin{tabular}{|c|c|c|c|c|c|c|c|c|c|c|c|c|c|}
\hline \multicolumn{14}{|c|}{ Phase 2 } \\
\hline \multirow[t]{7}{*}{ Test } & Test type, Nozzle design & Fluids & Coils & $\begin{array}{l}\text { Nozzle } \\
\text { position } \\
\text { (deg) }\end{array}$ & $\begin{array}{l}D \\
\text { (in) }\end{array}$ & $\begin{array}{l}\text { Uo } \\
(\mathrm{ft} / \mathrm{s})\end{array}$ & $\begin{array}{l}\text { UoD } \\
\left(\mathrm{ft}^{\circ} 2 / \mathrm{s}\right)\end{array}$ & $\begin{array}{l}\text { Probe } \\
1\end{array}$ & $\begin{array}{l}\text { Probe } \\
2\end{array}$ & $\begin{array}{l}\text { Probe } \\
3\end{array}$ & $\begin{array}{l}\text { Probe } \\
4\end{array}$ & $\begin{array}{l}\text { Probe } \\
5\end{array}$ & $\begin{array}{l}\text { Probe } \\
6\end{array}$ \\
\hline & $\begin{array}{l}\text { Blending, Design, Tee, } \\
39 \text { Dye added to suction pipe }\end{array}$ & $\begin{array}{l}\text { NaNO3, } \\
\text { Dye }\end{array}$ & Y & 0 & 0.209 & 46.58 & 0.81 & N/A & N/A & N/A & N/A & N/A & N/A \\
\hline & $\begin{array}{l}\text { Blending, Design, Tee, } \\
40 \text { Dye added to suction pipe }\end{array}$ & $\begin{array}{l}\text { NaNO3, } \\
\text { Dye }\end{array}$ & Y & 0 & 0.209 & 46.58 & 0.81 & N/A & N/A & N/A & N/A & N/A & N/A \\
\hline & 41 Blending, Design, Tee & Water & Y & 0 & 0.209 & 46.58 & 0.81 & 9.17 & $\begin{array}{l}7 \quad 10.72 \\
\end{array}$ & 7.54 & 22.46 & N/A & 16.46 \\
\hline & 42 Blending, Design, Tee & Water & Y & 0 & 0.209 & 46.57 & 0.81 & 9.12 & 9.97 & 8.25 & $5 \quad 9.89$ & 9.98 & 10.47 \\
\hline & 43 Blending, Design, Tee & Water & Y & 0 & 0.209 & 46.58 & 0.81 & 7.74 & 6.03 & 5.47 & 4.41 & 6.52 & 1.80 \\
\hline & 44 Blending, Design, Tee & Water & Y & 0 & 0.209 & 46.58 & 0.81 & 8.08 & 8.94 & 7.90 & 9.31 & 9.10 & 8.90 \\
\hline & 45 Blending, $C W, 0$ degree & $\begin{array}{l}\mathrm{NaNO} 3 \\
6.4 \mathrm{M}\end{array}$ & Y & 0 & 0.205 & 47.40 & 0.81 & 6.15 & 6.78 & 8.31 & 8.54 & 8.40 & 9.31 \\
\hline & 46 Blending, $C W, 0$ degree & $\begin{array}{l}\mathrm{NaNO}_{3} \\
6.4 \mathrm{M}\end{array}$ & Y & 0 & 0.205 & 47.39 & 0.81 & 7.97 & \begin{tabular}{l|l|}
7 & 13.87
\end{tabular} & 7.77 & 7.37 & 8.51 & 9.65 \\
\hline & 47 Blending, CW, 0 degree & $\begin{array}{l}\mathrm{NaNO}, \\
6.4 \mathrm{M}\end{array}$ & Y & 0 & 0.205 & 47.39 & 0.81 & 5.41 & 6.18 & 6.95 & $\begin{array}{ll}5 & 8.28\end{array}$ & 7.55 & 6.81 \\
\hline & 48 Blending, CW, 15 degree & $\begin{array}{l}\text { NaNO3, } \\
6.4 \mathrm{M}\end{array}$ & $Y$ & 0 & 0.209 & 46.48 & 0.81 & 10.76 & $\begin{array}{l}5 \\
\end{array} 11.88$ & \begin{tabular}{l|l}
3 & 11.95 \\
\end{tabular} & 7.63 & 11.88 & 10.73 \\
\hline & 49 Blending, CW, 15 degree & $\begin{array}{l}\mathrm{NaNO} 3 \\
6.4 \mathrm{M}\end{array}$ & Y & 0 & 0.209 & 46.48 & 0.81 & 8.54 & 3.96 & 6.49 & 6.35 & 8.90 & 7.23 \\
\hline & 50 Blending, $\mathrm{CW}, 15$ degree & $\begin{array}{l}\text { NaNO3, } \\
6.4 \mathrm{M}\end{array}$ & Y & 0 & 0.209 & 46.47 & 0.81 & 11.73 & 9.48 & $\begin{array}{l}8 \quad 10.73 \\
\end{array}$ & $\begin{array}{l}3 \quad 10.51 \\
\end{array}$ & 11.76 & 11.19 \\
\hline & 51 Blending, CW, 15 degree & $\begin{array}{l}\mathrm{NaNO}_{3} \\
6.4 \mathrm{M}\end{array}$ & $Y$ & 0 & 0.209 & 46.46 & 0.81 & 17.20 & N/A & N/A & 8.14 & 8.40 & 9.77 \\
\hline & 52 Blending, $\mathrm{CW}, 15$ degree & $\begin{array}{l}\mathrm{NaNO}, \\
6.4 \mathrm{M}\end{array}$ & Y & 0 & 0.209 & 40.16 & 0.70 & 16.71 & $1 \mathrm{~N} / \mathrm{A}$ & N/A & 14.32 & 8.43 & 12.13 \\
\hline & 53 Blending, CW, 15 degree & $\begin{array}{l}\mathrm{NaNO} 3 \\
6.4 \mathrm{M}\end{array}$ & Y & 0 & 0.209 & 40.16 & 0.70 & 16.29 & $\begin{array}{l}96.51 \\
\end{array}$ & $1 \quad 13.24$ & + 14.58 & $\begin{array}{l}3.53 \\
\end{array}$ & 15.97 \\
\hline & 54 Blending, CW, 15 degree & $\begin{array}{l}\text { NaNO3, } \\
6.4 \mathrm{M}\end{array}$ & Y & 0 & 0.209 & 40.17 & 0.70 & 7.72 & 4.36 & 7.15 & 6.55 & 6.95 & 7.38 \\
\hline & 55 Blending, CW, 15 degree & $\begin{array}{l}\mathrm{NaNO}, \\
6.4 \mathrm{M}\end{array}$ & Y & 0 & 0.209 & 40.17 & 0.70 & 11.11 & 5.24 & $4 \quad 13.13$ & 7.69 & 11.99 & 13.41 \\
\hline & 56 Blending, $C W, 15$ degree & $\begin{array}{l}\text { NaNO3, } \\
6.4 \mathrm{M}\end{array}$ & Y & 0 & 0.209 & 40.16 & 0.70 & 14.52 & $2 \mathrm{~N} / \mathrm{A}$ & N/A & 10.65 & $5 \quad 10.73$ & 13.07 \\
\hline & 57 Blending, $\mathrm{CW}, 15$ degree & $\begin{array}{l}\mathrm{NaNO} 3 \\
6.4 \mathrm{M}\end{array}$ & Y & 0 & 0.209 & 40.16 & 0.70 & 5.32 & 4.53 & 2.68 & 2.51 & 5.92 & 2.28 \\
\hline & 58 Blending, $C W, 15$ degree & $\begin{array}{l}\mathrm{NaNO}, \\
6.4 \mathrm{M}\end{array}$ & Y & 0 & 0.209 & 40.17 & 0.70 & 5.81 & 8.34 & 9.48 & 8.71 & 8.48 & 9.79 \\
\hline & 59 Blending, CW, 15 degree & $\begin{array}{l}\mathrm{NaNO} 3 \\
6.4 \mathrm{M}\end{array}$ & Y & 0 & 0.209 & 40.16 & 0.70 & 2.82 & 2.48 & 1.79 & 1.45 & 1.11 & 2.08 \\
\hline & 30 Blending, $\mathrm{CW}, 15$ degree & $\begin{array}{l}\mathrm{NaNO}, \\
6.4 \mathrm{M}\end{array}$ & Y & 0 & 0.209 & 40.16 & 0.70 & 8.94 & 7.69 & 6.75 & 5.44 & 7.18 & 5.81 \\
\hline & 61 Blending, Design, Tee & $\begin{array}{l}\mathrm{NaNO} 3 \\
6.4 \mathrm{M}\end{array}$ & N & 0 & 0.209 & 40.16 & 0.81 & 3.19 & 3.19 & 3.25 & 2.99 & 7.43 & 3.02 \\
\hline & 22 Blending, Design, Tee & $\begin{array}{l}\mathrm{NaNO}, \\
6.4 \mathrm{M}\end{array}$ & N & 0 & 0.209 & 46.48 & 0.81 & 6.81 & 8.80 & 2.16 & 2.14 & 7.29 & 5.67 \\
\hline & 33 Blending, Design, Tee & $\begin{array}{l}\mathrm{NaNO}, \\
6.4 \mathrm{M}\end{array}$ & N & 0 & 0.209 & 46.47 & 0.81 & 2.79 & 4.41 & 2.68 & 3.22 & 7.83 & 3.07 \\
\hline & 34 Blending, $C W, 0$ degree & $\begin{array}{l}\text { NaNO3, } \\
6.4 \mathrm{M}\end{array}$ & N & 0 & 0.205 & 47.38 & 0.81 & 4.78 & 5.61 & 2.79 & 3.62 & 2.25 & 4.21 \\
\hline & 35 Blending, CW, 0 degree & $\begin{array}{l}\mathrm{NaNO} \\
6.4 \mathrm{M}\end{array}$ & N & 0 & 0.205 & 47.38 & 0.81 & 5.64 & 8.80 & 4.44 & 4.95 & 5.58 & 5.64 \\
\hline & 36 Blending, $\mathrm{CW}, 0$ degree & $\begin{array}{l}\mathrm{NaNO} 3 \\
6.4 \mathrm{M}\end{array}$ & N & 0 & 0.205 & 47.40 & 0.81 & 4.13 & 6.15 & 4.01 & 4.67 & 4.41 & 4.38 \\
\hline & 37 Blending, CW, 0 degree & $\begin{array}{l}\mathrm{NaNO}, \\
6.4 \mathrm{M}\end{array}$ & $\mathrm{N}$ & 0 & 0.205 & 47.40 & 0.81 & 1.65 & 1.91 & 1.42 & 2.02 & 1.68 & 0.74 \\
\hline & 68 Blending, $\mathrm{CW}, 0$ degree & $\begin{array}{l}\mathrm{NaNO} 3 \\
6.4 \mathrm{M}\end{array}$ & N & 0 & 0.205 & 47.38 & 0.81 & 2.99 & 2.93 & 3.27 & 4.41 & 3.79 & 3.39 \\
\hline & 69 Blending, $\mathrm{CW}, 15$ degree & $\begin{array}{l}\text { NaNO3, } \\
6.4 \mathrm{M}\end{array}$ & N & 0 & 0.209 & 46.48 & 0.81 & 6.12 & 7.83 & 6.63 & 6.81 & 5.44 & 5.01 \\
\hline & 70 Blending, CW, 15 degree & $\begin{array}{l}\mathrm{NaNO}_{3} \\
6.4 \mathrm{M}\end{array}$ & N & 0 & 0.209 & 46.48 & 0.81 & 4.90 & 6.15 & 3.56 & 3.05 & 3.87 & 4.44 \\
\hline & 71 Blending, $C W, 15$ degree & $\begin{array}{l}\mathrm{NaNO}, \\
6.4 \mathrm{M}\end{array}$ & N & 0 & 0.209 & 46.50 & 0.81 & 4.19 & $\begin{array}{l}9 \\
9\end{array} 4.98$ & 4.53 & 4.93 & 5.98 & 3.16 \\
\hline & 72 Blending, CW, 15 degree & $\begin{array}{l}\mathrm{NaNO}_{3} \\
6.4 \mathrm{M}\end{array}$ & N & 0 & 0.209 & 46.48 & 0.81 & 3.64 & 4.50 & 4.04 & 4.84 & 4.41 & 2.53 \\
\hline & 73 Blending, $C W, 15$ degree & $\begin{array}{l}\text { NaNO3, } \\
6.4 \mathrm{M}\end{array}$ & N & 0 & 0.209 & 46.48 & 0.81 & 3.19 & 3.76 & 2.99 & 2.93 & 2.79 & 2.96 \\
\hline & 74 Blending, CW, 15 degree & $\begin{array}{l}\mathrm{NaNO}, \\
6.4 \mathrm{M}\end{array}$ & N & 0 & 0.209 & 33.29 & 0.58 & 4.07 & 5.38 & 3.36 & 1.04 & 3.99 & 4.47 \\
\hline & 75 Blending, CW, 15 degree & $\begin{array}{l}\mathrm{NaNO} 3 \\
6.4 \mathrm{M}\end{array}$ & N & 0 & 0.209 & 33.29 & 0.58 & 7.52 & 8.60 & 4.87 & 5.69 & 6.01 & 6.15 \\
\hline & 76 Blending, $C W, 15$ degree & $\begin{array}{l}\mathrm{NaNO3}, \\
6.4 \mathrm{M}\end{array}$ & N & 0 & 0.209 & 33.29 & 0.58 & 3.45 & 4.36 & 3.10 & 3.42 & 4.53 & 3.56 \\
\hline & 77 Blending, $C W, 15$ degree & $\begin{array}{l}\text { NaNO3, } \\
6.4 \mathrm{M}\end{array}$ & N & 0 & 0.209 & 33.29 & 0.58 & 4.95 & 6.92 & 4.44 & 5.01 & 4.24 & 4.70 \\
\hline & 78 Blending, $C W, 15$ degree & $\begin{array}{l}\mathrm{NaNO}, \\
3.2 \mathrm{M}\end{array}$ & Y & 0 & 0.209 & 46.48 & 0.81 & 16.23 & $B$ N/A & N/A & 17.31 & 17.03 & 18.91 \\
\hline & 79 Blending, $\mathrm{CW}, 15$ degree & $\begin{array}{l}\mathrm{NaNO} 3 \\
3.2 \mathrm{M}\end{array}$ & Y & 0 & 0.209 & 46.49 & 0.81 & 8.57 & N/A & N/A & 5.38 & 1.96 & 4.02 \\
\hline & 30 Blending, CW, 15 degree & $\begin{array}{l}\mathrm{NaNO}, \\
3.2 \mathrm{M}\end{array}$ & Y & 0 & 0.209 & 46.48 & 0.81 & 14.64 & 4 N/A & N/A & 8.63 & 8.37 & 9.74 \\
\hline & 31 Blending, CW, 15 degree & $\begin{array}{l}\mathrm{NaNO}, \\
3.2 \mathrm{M}\end{array}$ & Y & 0 & 0.209 & 46.48 & 0.81 & 10.62 & $2 \mathrm{~N} / \mathrm{A}$ & N/A & 7.32 & 6.63 & 3.93 \\
\hline
\end{tabular}

Table 3-3: Phase 2, Blending Test Results 


\subsection{Blending Times for Similar Solutions}

Additional test data provided statistical insights into blending of similar solutions not previously available. In particular, blending with dual opposing nozzles was shown to be a quite random, chaotic process. Even though dye tests and other efforts were performed to identify the last place to blend in the tank, the last location to reach $95 \%$ blending varied from test to test. In Table 3-2 and Table 3-3, the probe where blending last occurred is shown in bold text. There was no consistent pattern among the $\mathrm{pH}$ probes regarding which probe location was the last to reach the $95 \%$ confidence $\mathrm{pH}$ range. As a result, blending times vary by $50 \%$ to more than $100 \%$ for seemingly identical tests. This finding is important with respect to blending, since a conclusion is obtained that all of the data, rather than only the highest valued blending time requires consideration in a statistical analysis. Grenville's research [8] concluded that the $95 \%$ confidence, blending time uncertainty was $23.7 \%$ for a tank without coils, which is much lower than the observed uncertainty for these tests. Another aspect of this blending research is the fact that the variation in test data is much higher as the flow rate diminishes. Although additional research is warranted to explain the physics of blending, observations of blue dye tests noted that the acids and bases slowly moved across the tank floor in what appeared to be laminar streamlines Even so, occasional random vortices were seen moving around the tank floor in other tests, as indicated by the motion of small particles in solution. These mechanisms are considered to contribute to the higher variability of blending times at lower flow rates, and require further research. In short, Phase 1 results were based on uncertainties of the largest blend times during sets of similar tests with similar $U o D$, and Phase 2 results are based on the uncertainty of blend times at all probes for similar test sets. That is, the technique of statistically analyzing the data was changed between Phase 1 and Phase 2 testing. For Phase 1, only the maximum blending time values were used in calculations. For Phase 2, all of the blending times from each probe were used in calculations. These findings were used as the basis for Phase 2 statistical uncertainty analyses (T. Edwards, Appendix A), where statistical analysis for Phase 1 blending is considered in detail in the Phase 1 report.

Another aspect of blending concerns the fluid addition location. Riser locations were changed from the $\mathrm{C} 1$ riser in Phase 1 to the B5 riser in Phase 2 (Figure 2-8). Experimental results showed that this change had a negligible impact on blending times. However, addition of a blue dye to the suction side of the blender pump decreased the blending time by a factor of $20-30$ (Tests 39 and 40, Table 3-3). This result was expected since the dye travels directly through the pipe to the pump, rather than across the tank floor to the pump. Blending by additions to the suction piping have little effect on the present design, since SRR plans to only add salt solutions through risers on the tank tops. Even so, this test provided some additional insight into blending processes, and transfers into a tank through the blender suction could greatly reduce blending times.

\subsubsection{Phase 1 Summary for Blending Tests}

An array of design parameters were investigated in Phase 1 to establish several of the basic design recommendations, and the reader is referred to the Phase 1 report for supporting discussion of test results. Those test results are summarized in Figure 3-18, where nozzle diameters and $U o D$ were varied and data was analyzed to establish the following relationships.

1. Pilot scale blending times were significantly affected by cooling coil installation. Blending times in a tank with coils were twice the blending times for a tank without coils, within the recommended range of operation. Below the recommended range of operation the basic fluid mechanics of blending is not understood, and blending times for a tank with coils was as much as seven times the blending time for a tank without coils. CFD models showed that coil affected blending times by a factor of 1.5 to 2 at full scale in the 
range of interest (S. Lee [16] and Figure 3-18), where CFD and experimental results are consistent.

2. Diffusion was very slow when compared to blending times, and consequently had a negligible effect on blending.

3. Pilot scale blending times in a tank with coils varied by more than $100 \%$ for the same nozzle design and $U o D$, but this variation was included in the statistical analysis of the data to provide a conservative blending time estimate.

4. For $p H$ tests, pilot scale blending times were independent of initial and final concentrations of acid or base. This observation validated the comparison of many different tests, which had different start and end $\mathrm{pH}$ conditions.

5. The $0^{\circ}$ nozzle position, parallel to the vertical tank wall was recommended.

6. Nozzle position and diameter had minor effects on blending times.

7. Nozzle diameter effects were not investigated outside the range of the Standard and Quad nozzle diameters (1-1/2" $-3-5 / 8$ " scaled down to 0.138 and 0.334 " respectively). At smaller diameters, conclusions with respect to $U_{0} D$ and blending times may not be valid.

8. A $95 \%$ blending time criteria was validated for use in test results, and a $99 \%$ blending time could not be obtained due to technical limitations of commercial equipment.

9. $p H$ measurements during testing were acceptable to describe normalized blending times near equilibrium, but were significantly in error during testing due to the buffering effects of carbonates formed in solution.

10. Instrument uncertainties for Phase 1 testing were shown to be negligible with respect to $U o D$. All variances in blend times were shown to be realistic expectations.

11. Visual indications using blue dye indicated much lower blending times than determined by using $p H$ measurements. This observation is consistent with Grenville's [8] observations on this topic.

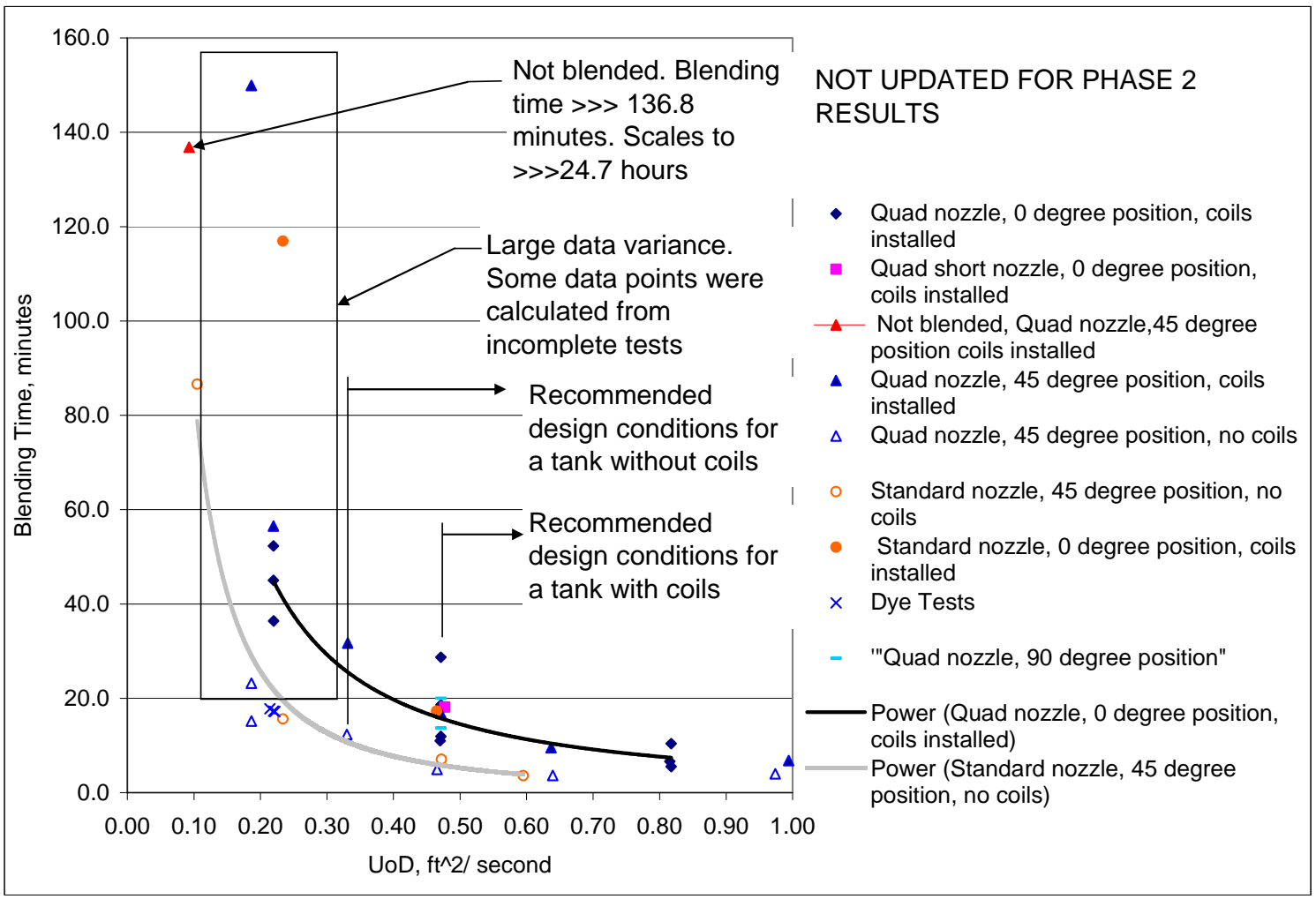

Figure 3-18: Phase 1, Blending Test Results 


\subsubsection{Phase 2, Pilot Scale Blending Results for Similar Solutions}

Phase 2 blending tests focused on final design requirements for the blending pump. All of the pertinent test results are displayed in Figure 3-19. Basically, Table 3-4 summarizes the design parameters and test groupings, which were investigated and statistically analyzed in Phase 2 research. This table, along with Figure 3-19 and Appendix A can be used to compare the effects of various parameters on blending times, where the average value of each set of tests is shown as a straight line for all of the probes in a related group of tests. Accordingly, the effects of any test parameter can be investigated, such as $U o D$, cooling coil installation, or type of fluid.

Additionally, some data sets were shown to be more influential on recommendations, and since that test data was critical to design recommendations, Figure 3-20, Figure 3-21, and Figure 3-22 show the details of those blending tests. Those data sets describe the variability of average experimental blending times with respect to CFD models, and provide blending times at the operating conditions where sludge disturbance was observed for testing with and without cooling coil models installed. Other Phase 2 blending test figures are left out of this report.

Significant conclusions from data analysis are that:

1. A negligible blending improvement is noted when nozzles were changed from a tee to the $\mathrm{CW}$ design (compare tests 64-68 to 61-63). This observation further demonstrated that $U o D$ is the primary factor with respect to pump design, rather than specific pump design details.

2. Changes in kinematic viscosity have a negligible effect on blending when coils are installed (compare tests 78-81 to 48-51).

3. From analysis of Figure 3-18, the recommended minimum pilot scale, pump design requirements are $U o D>0.33 \mathrm{ft}^{2} / \mathrm{sec}$ for a tank without coils, and $U o D>0.47 \mathrm{ft}^{2} / \mathrm{sec}$ for a tank with coils. Although blending can probably be performed at lower UoD's than recommended, there was insufficient available data at lower $U o D$ to extrapolate test results to full scale from test results and accompanying analysis.

4. Consistent with Phase 1 observations, the initial and final testing $p H$ had a negligible effect on blending times. For example, comparable blend times (11.0 and 11.9 minutes) were observed when the $\mathrm{pH}$ test range varied by either 5.86 or 1.52 (Tests 12 and 13 respectively).

5. A review of test data concluded that blending times varied considerably for the same design conditions. For example, Tests 52 and 58 had similar test conditions, i. e., $p H$ conditions (7.3-10.4 and 7.4-10.8), operating temperatures $\left(70^{\circ} \mathrm{F}\right.$ and $\left.71^{\circ} \mathrm{F}\right)$, fluids, procedures, and $U o D$. However, blending times varied by more than a factor of 2.3 , when maximum blending times were 18.25 and 7.94 minutes, respectively. This example is characteristic of blending time results, where there was a large variation in blending time for apparently identical conditions.

6. Measurements of sodium concentrations were performed for four successive tests under similar conditions to investigate the changes in concentration during blending. Changes in concentration varied significantly from test to test, and those results are presented in Appendix C. In those four tests, samples were taken at the same point in the tank at one minute intervals under similar test conditions. The differences in test results further exemplify the random nature of blending processes. 
SRNL-STI-2011-00151

5/26/11 Revision 0

\begin{tabular}{|c|c|c|c|c|c|}
\hline \multirow{2}{*}{$\begin{array}{l}\text { Test Grouping } \\
\text { Tests } 11-13,17,19\end{array}$} & \multicolumn{3}{|l|}{ Test Conditions } & \multicolumn{2}{|c|}{$\begin{array}{c}\text { CFD Blending Time, } \\
\text { minutes }\end{array}$} \\
\hline & UoD 0.47, Quads, & Coils, & $0^{\circ}$ to wall, water & Ac & 18.9 \\
\hline Tests $14-16$ & UoD 0.81, Quad, & Coils, & $0^{\circ}$ to wall, water & Ac & 10.73 \\
\hline Test 19 & $\mathrm{UoD}=0.47, \quad$ Std & Coils, & $0^{\circ}$ to wall, water & Ap & 18.9 \\
\hline Tests $20-21$ & $\mathrm{UoD}=0.47$, Quad, & Coils, & $90^{\circ}$ to wall, water & Ap & 18.9 \\
\hline Tests 32, & $\mathrm{UoD}=0.47$, Quad, & No coils, & $45^{\circ}$ to wall, water & Ap & 9.3 \\
\hline Test 37 & $\mathrm{UoD}=0.47, \quad \mathrm{Std}$ & No coils, & $45^{\circ}$ to wall, water & & \\
\hline Tests $41-44$ & UoD $=0.81$, Design Tee, & Coils, & $0^{\circ}$ to wall, water & Ap & 10.73 \\
\hline Tests $45-47$ & $\mathrm{UoD}=0.81, \quad \mathrm{CW}, 0^{\circ}$ upward nozzles, & Coils, & $0^{\circ}$ to wall, $6.4 \mathrm{M} \mathrm{NaNO}_{3}$ & Ac & 11.03 \\
\hline Tests 48-51 & $\mathrm{UoD}=0.81, \mathrm{CW}, 15^{\circ}$ upward nozzles, & Coils, & $0^{\circ}$ to wall, $6.4 \mathrm{M} \mathrm{NaNO}_{3}$ & & \\
\hline Tests $52-60$ & $\mathrm{UoD}=0.70, \mathrm{CW}, 15^{\circ}$ upward nozzles, & Coils, & $0^{\circ}$ to wall, $6.4 \mathrm{M} \mathrm{NaNO}_{3}$ & & 13.5 \\
\hline Tests $61-63$ & UoD $=0.81$, Design Tee, & No coils, & $0^{\circ}$ to wall, $6.4 \mathrm{M} \mathrm{NaNO}_{3}$ & Ap & 7.20 \\
\hline Tests $64-68$ & UoD $=0.81, \quad C W, 0^{\circ}$ upward. nozzles, & No coils, & $0^{\circ}$ to wall, $6.4 \mathrm{M} \mathrm{NaNO}_{3}$ & $\mathrm{Ac}$ & 7.20 \\
\hline Tests $69-73$ & $\mathrm{UoD}=0.81, \mathrm{CW}, 15^{\circ}$ upward nozzles, & No coils, & $0^{\circ}$ to wall, $6.4 \mathrm{M} \mathrm{NaNO}_{3}$ & & \\
\hline Tests $74-77$ & $\mathrm{UoD}=0.58, \mathrm{CW}, 15^{\circ}$ upward nozzles, & No coils, & $0^{\circ}$ to wall, $6.4 \mathrm{M} \mathrm{NaNO}_{3}$ & Ac & 7.4 \\
\hline Tests $78-81$ & UoD $=0.81, C W, 15^{\circ}$ upward nozzles, & Coils, & $0^{\circ}$ to wall, $3.2 \mathrm{M} \mathrm{NaNO}_{3}$ & & \\
\hline
\end{tabular}

Notes: Ac $=$ actual CFD model, $\mathrm{Ap}=$ experimental tests approximated from a similar CFD model.

Table 3-4: Pilot Scale Test Groupings for Comparison to CFD Models 
SRNL-STI-2011-00151

5/26/11 Revision 0

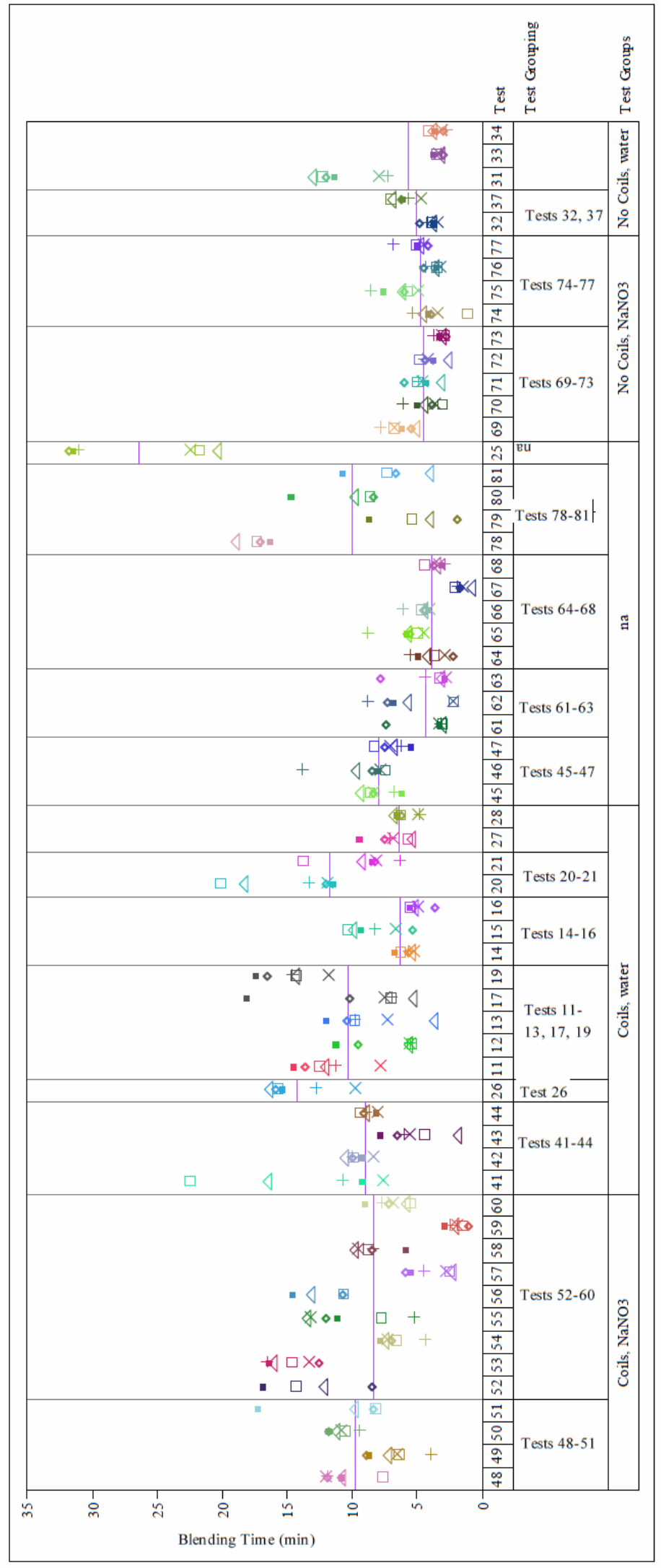

Figure 3-19: Phase 2, Blending Test Results 
SRNL-STI-2011-00151

5/26/11 Revision 0
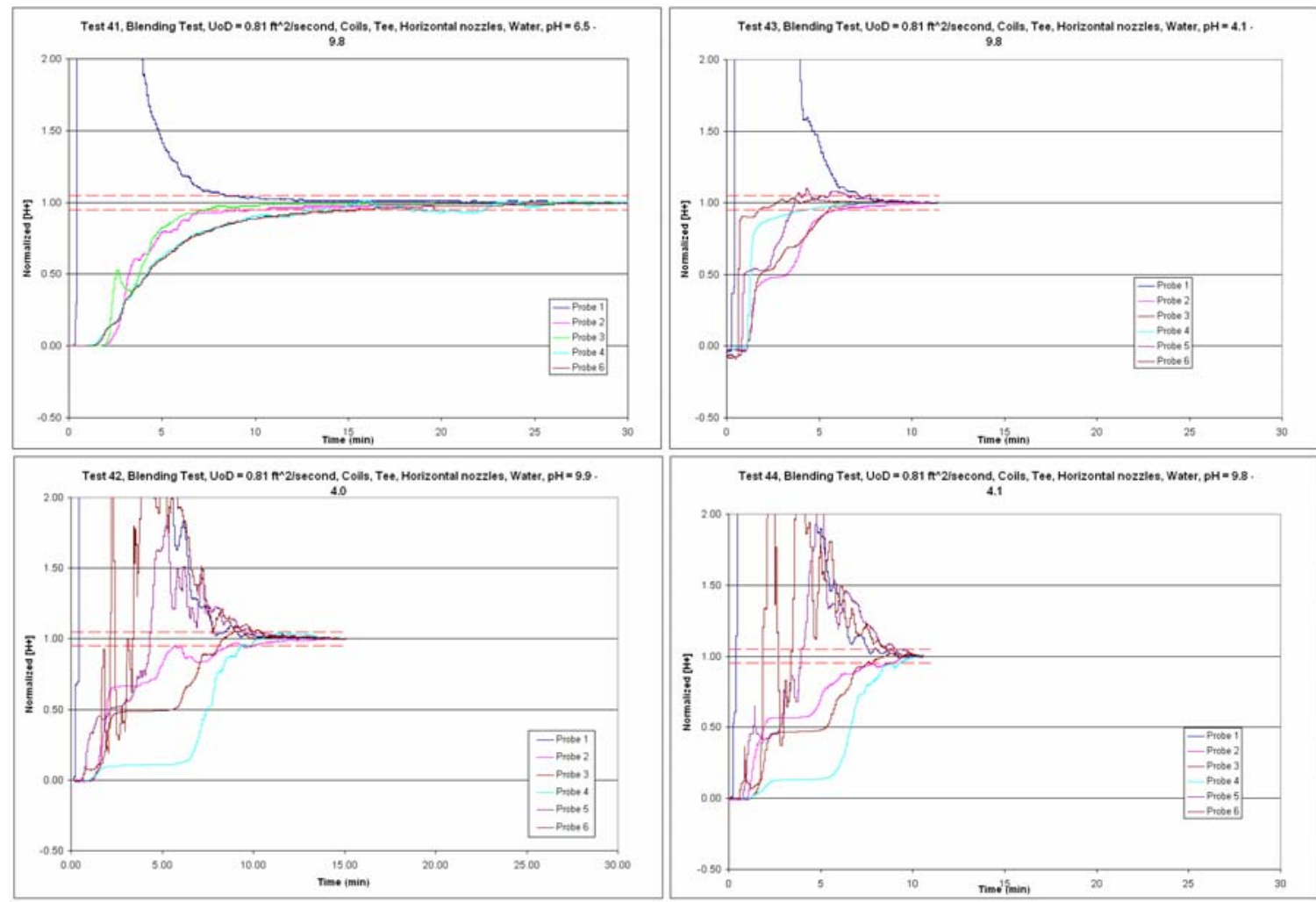

Figure 3-20: Blending Tests Used to Establish a Bounding CFD Correction Factor
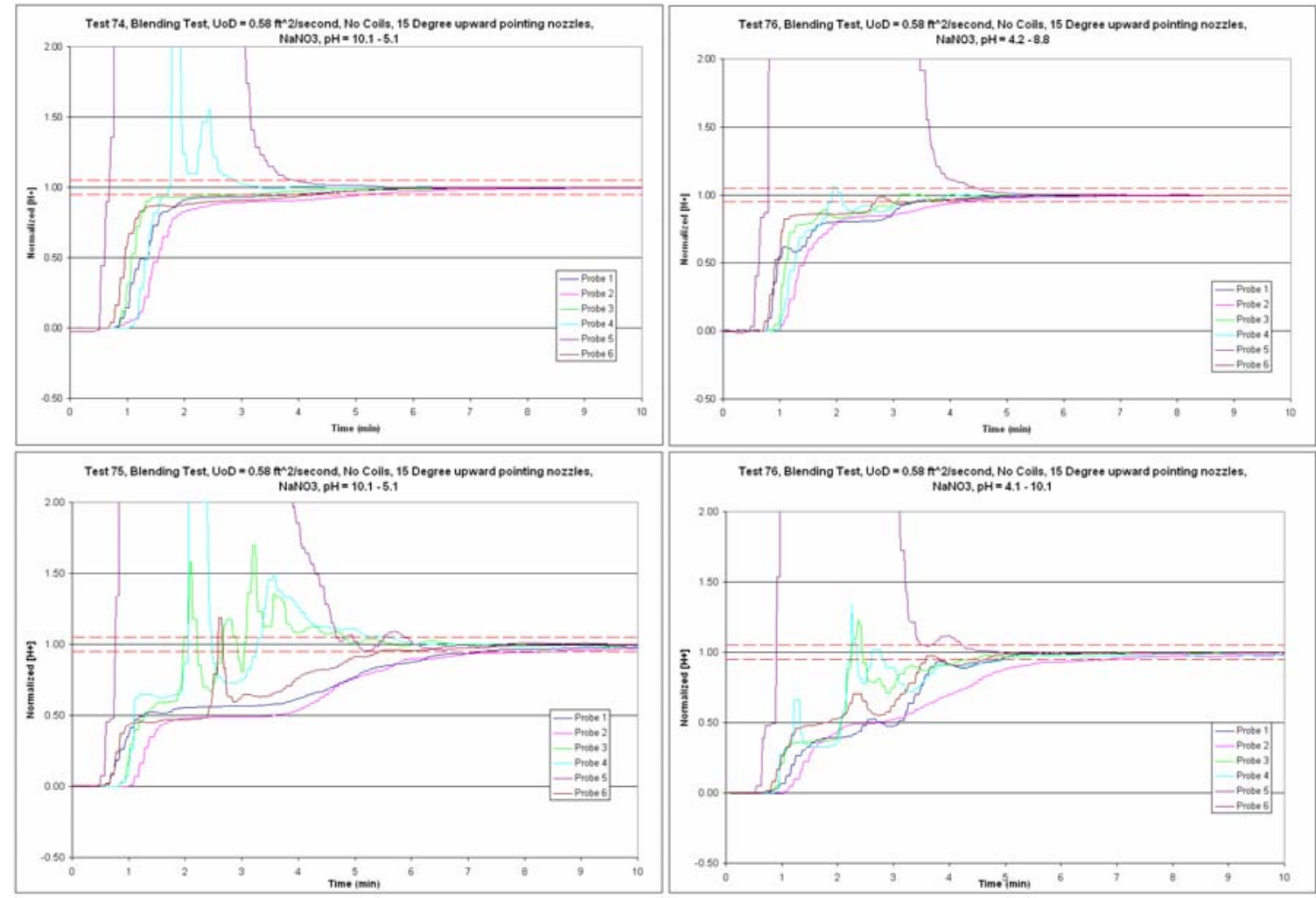

Figure 3-21: Blending Times for a Tank without Coils at the UoD Required to Disturb Sludge 
SRNL-STI-2011-00151

5/26/11 Revision 0

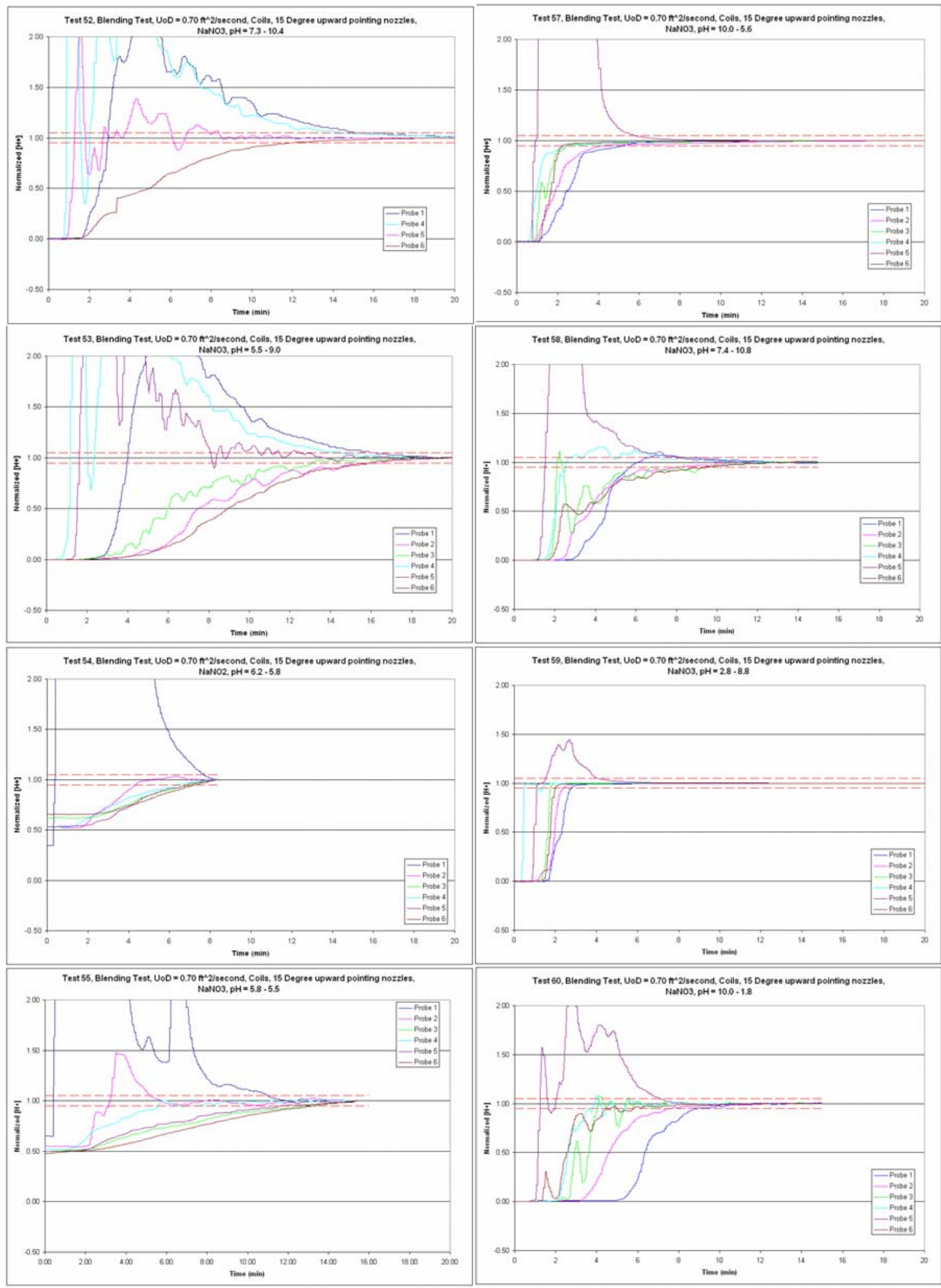

Figure 3-22: Blending Times for a Tank with Coils at the UoD Required to Disturb Sludge 


\subsubsection{Statistical Analysis and CFD Results for Blending of Similar Solutions}

To obtain a scaling factor for blending, the statistical discussion provided in Appendix A needs to be related to experimental data. To do so, Figure 3-23, provides two different variabilties for consideration, and one must be selected based on the nature of the tests performed. The typically larger variability (square symbol, UTL, upper tolerance limit for individual probes) provides the maximum value that would be obtained with $95 \%$ confidence if a single probe were installed in the tank to measure the blending time. This higher variability would only be used for evaluation of a single probe installed in a tank to measure a blending time. The typically lower variability (diamond symbol, UTL on mean blend time) provides the maximum value at $95 \%$ confidence for predicted blending times for a set of tests. This latter variability is appropriately applied to test groups. In short, predicted CFD values are within $20-80 \%$ of the average experimental values (cross symbol, grand average of blend times), but the predicted variation in blending times is even larger due to experimental variations in blending times.

To establish an experimental correction factor for CFD models, Figure 3-23 bears further scrutiny. Test sets $\{20,21\}$ and $\{32,37\}$ are discounted, since insufficient data points yielded questionable blending time predictions with very high resultant uncertainties. The rest of the data sets are pertinent to a correction factor.

Reviewing Table 3-5, the largest UTL data variance is shown to occur for test set $\{41-44\}$ for cases where CFD models were available for comparison. For this data set, the pilot scale blending correction factor equals UTL/CFD blend time $=28.33 / 10.73=2.64$, which is rather large but the 2.64 correction factor provides an estimate to correct CFD models at pilot scale. This correction factor is based on experimental variation in test data.

Blending data is unavailable at full scale for all cases of concern, and Equation 1 is reconsidered, along with the velocity correction factor of $26.7 \%$ (section 3.1.3). Since the blend time is inversely proportional with respect to velocity, the velocity correction should also be inversely proportional with respect to blend time. In that case, the correction factor at full scale equals 2.64 $\cdot 1.267=3.35$, and a scale-up CFD correction factor of 3.35 is justified for scale-up of CFD blending calculations by the analysis provided in Appendix A.

Two factors were combined to obtain a blending correction factor. The first factor, 2.64, was calculated from the experimental variation in blending times observed during numerous tests. This variation was compared to CFD predictions to obtain 2.64. At pilot scale, this value was experimentally validated to be a realistic variation in blending times. The underlying physical explanation of this wide scatter in data was not fully investigated, since hundreds of additional experiments would have been required. Even so, experiments were carefully conducted to ensure that experimental results were consistent from test to test. Statistical analysis of experimental data was used to describe the complexities of chaotic blending processes and obtain a correction factor to be applied to CFD models. One could, perhaps, argue that this 2.64 correction factor is adequate for scale-up. However, full scale blending data for a tank without coils is unavailable, but the overall agreement of CFD models with experiment at pilot scale implies that CFD is also acceptable at full scale. In Phase 1 testing, velocities were shown to be equivalent at different scales for any point in the tank. Therefore, velocity was used as a scale-up criterion for blending. Velocity was shown to vary by a correction factor of 1.267 throughout the range of interest. Consequently, the two factors were multiplied to obtain 3.35, which is the recommended factor to multiply calculated CFD blending times. That is, when a CFD model predicts a blending time, that blending time needs to be multiplied by 3.35 to obtain the probable ( $95 \%$ confidence) maximum blending time that may occur. This correction factor is not an experimental error, but is a factor required to account for expected variations in blending times. Further research may 
SRNL-STI-2011-00151

5/26/11 Revision 0

improve the prediction of this value for a correction factor, but the need for a correction factor has been clearly demonstrated. In fact, the correction factors developed from this research are a significant advance to blending theory.

\begin{tabular}{|c|c|c|c|c|c|c|c|}
\hline $\begin{array}{c}\text { Test } \\
\text { Grouping }\end{array}$ & $\begin{array}{c}\text { Number } \\
\text { of Test } \\
\text { Runs }\end{array}$ & $\begin{array}{c}\text { Average of } \\
\text { Average Blend } \\
\text { Times of Tests } \\
\text { mum. }\end{array}$ & $\begin{array}{c}\text { Variance } \\
\text { among } \\
\text { Tests }\end{array}$ & $\begin{array}{c}\text { Variance } \\
\text { among pH } \\
\text { Probes }\end{array}$ & $\begin{array}{c}\text { UTL on Mean } \\
\text { Blend Time for this } \\
\text { Type of Testing }\end{array}$ & $\begin{array}{c}\text { UTL 95/95 for } \\
\text { Ind Probes over } \\
\text { ALL tests }\end{array}$ & $\begin{array}{c}\text { CFD } \\
\text { Blending } \\
\text { Time } \\
\text { mum. }\end{array}$ \\
\hline $\begin{array}{c}\text { Tests 11-13, } \\
17,19\end{array}$ & 5 & 10.35 & 7.511 & 9.265 & 24.39 & 31.55 & 18.9 \\
\hline Tests 14-16 & 3 & 6.34 & 2.6364 & 1.5337 & 24.08 & 27.36 & 10.73 \\
\hline Tests 20-21 & 2 & 11.73 & 13.3259 & 10.0264 & 203.6 & 213.17 & 18.9 \\
\hline Tests 32,37 & 2 & 5.01 & 2.1797 & 0.5112 & 82.61 & 84.77 & 9.3 \\
\hline Tests 41-44 & 4 & 9.05 & 8.5305 & 9.2972 & 28.33 & 36.19 & 10.73 \\
\hline Tests 45-47 & 3 & 7.99 & 0.8954 & 2.7729 & 18.33 & 22.74 & 11.03 \\
\hline Tests 48-51 & 4 & 9.78 & 3.2583 & 4.8981 & 21.7 & 27.4 & \\
\hline Tests 52-60 & 9 & 8.4 & 17.7423 & 3.7893 & 22.82 & 27.08 & 13.5 \\
\hline Tests 61-63 & 3 & 4.44 & 0 & 4.8849 & 4.44 & 10.3 & 7.2 \\
\hline Tests 64-68 & 5 & 3.88 & 2.3106 & 1.0058 & 11.66 & 14.02 & 7.2 \\
\hline Tests 69-73 & 5 & 4.47 & 1.2473 & 0.7861 & 10.19 & 12.28 &. \\
\hline Tests 74-77 & 4 & 4.74 & 1.4969 & 1.3122 & 12.82 & 15.64 & 7.4 \\
\hline Tests 78-81 & 4 & 9.96 & 27.7221 & 6.2701 & 44.71 & 51.58 &. \\
\hline
\end{tabular}

Table 3-5: CFD and Statistical Data for Blending Tests

(Appendix A)

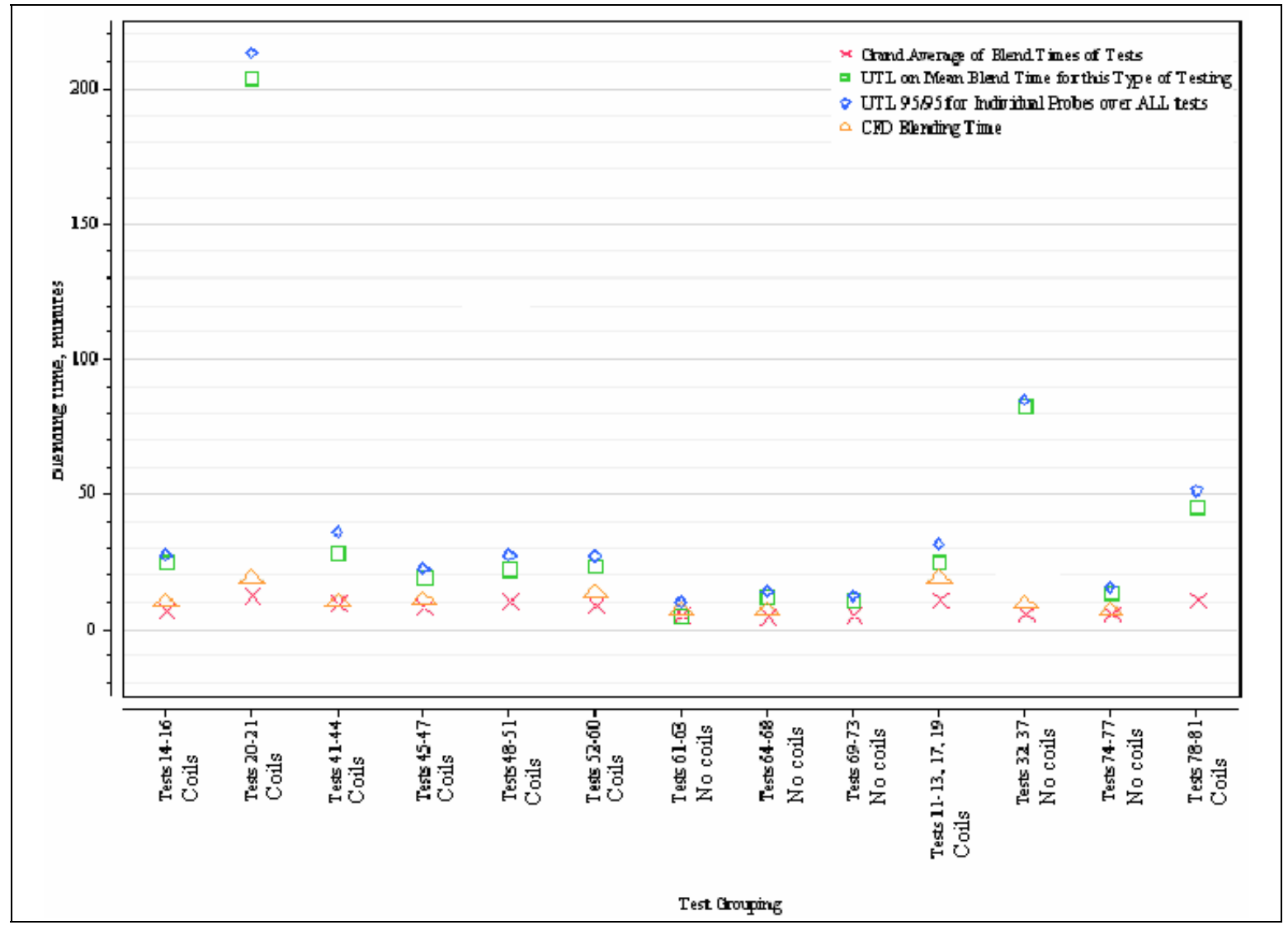

Figure 3-23: Statistical Data for Blending Tests

(Appendix A) 


\subsubsection{Comparison of Test Results to Published Results}

Correction factors and uncertainty calculations were used to compare experimental results to published results in the literature. The recommended correction factor provided from this research for blending times $(2.64 \cdot 1.267=3.35$, section 3.3 .3$)$ is considerably higher than the expected uncertainty listed in the literature for blending tank contents, where a single jet was angled upward from a bottom corner to blend the tank contents. Per Grenville, the 1-sigma uncertainty was $11 \%$. Then the approximate uncertainty for $95 \%$ confidence is $\approx 22 \%$, from which a correction factor of 1.22 is obtained. Certainly, the tests performed here were different than the tests considered by Grenville, but the correction factor recommended here nearly triples the value recommended for a single nozzle. This difference requires some consideration.

\subsubsection{Published Results}

First, consider Grenville's research [7] for blending with a single nozzle, which is summarized in Figure 3-24, where the correlation constant is obtained from Equation 1. Grenville calculated an $11 \%$, 1-sigma uncertainty (relative standard deviation) from the data in this figure for $\mathrm{C}=3.0$. The uncertainty for $\mathrm{C}$ is, in fact, the blending time uncertainty. Note that the variation in data varies by $25 \%$, or less, for any set of tests at a given Reynold's number. Below $\operatorname{Re}=100,000$ at the jet nozzle, the blending time variation is less than $10 \%$.

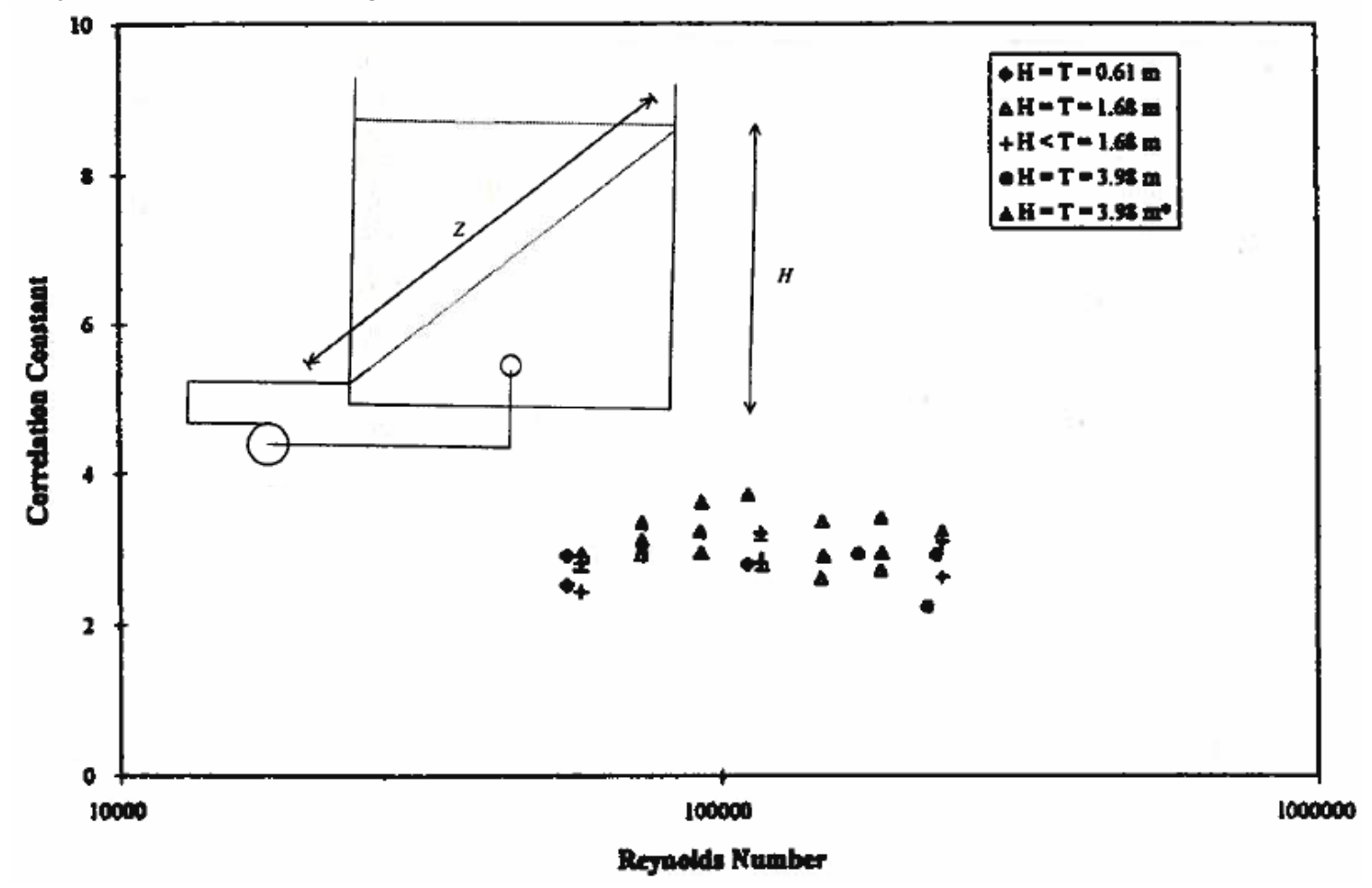

Figure 3-24: Blending With a Single Nozzle

\subsubsection{Test Results From This Research}

Second, consider the results from this research for nozzles located at the mid-height of the tank. Consider Figure 3-18, where test results are graphically shown both for a tank with and without coils.

For a tank without coils, the variation in data was comparable to the results obtained by Grenville. In fact, the blending time correction factor provided here could be reduced through further 
statistical analysis, if required. In that case, there would be two different correction factors, one for a tank with coils and one for a tank without coils.

For a tank with coils installed, the variability was considerably higher as noted in Figure 3-18 and Figure 3-19. Specifically, the blending times varied by magnitudes of up to more than a $100 \%$ for tests performed at $\operatorname{Re}=43,000-75,000$ at the jet nozzles $(U o D)=0.47-0.81 \mathrm{ft}^{2} /$ second, see Phase 1 report, Leishear, et.al. 1). That is, variations in blend times were consistently larger than expectations from Grenville's research. There were three different quantities that affected variability, which included the experimental variations, deviations from the CFD model, and velocity variations (section 3.3.3). The experimental and CFD variations yielded a 2.64 correction factor required for scale-up, and differences in velocity yielded a 1.267 correction factor, which may, or may not, be essential for scale-up. Together these quantities provided a conservative scale-up technique, which advances the application of CFD models for use in blending applications. Additional testing may further reduce the blending time correction factor by providing additional data, which would reduce the uncertainty of the blending time variability and the velocity variability that are the bases for the correction factor. Even so, the correction factor for a tank with coils installed would still be higher than for a tank without coils.

\subsection{Scale-up for Blending of Similar Solutions}

Recommendations result from blending tests and CFD models, as follows:

1. The recommended minimum, full scale, pump requirements are $U o D>10.85 \cdot 0.33=3.58$ $\mathrm{ft}^{2} / \mathrm{sec}$ for a tank without cooling coils (section 3.3.2).

2. The recommended minimum, full scale, pump requirements are $U o D>10.85 \cdot 0.47=5.10$ $\mathrm{ft}^{2} / \mathrm{sec}$ for a tank with cooling coils (section 3.3.2).

Different techniques can be used for scale-up to find maximum blending times:

For example, consider a full scale, 85 foot diameter tank without coils at $U o D=8.8 \mathrm{ft}^{2} /$ second (Phase $1, U o D=10.85 \cdot 0.81 \mathrm{ft}^{2} / \mathrm{sec}$ ),

Example 1: CFD predicts 64 minutes (Case 14, S. Lee [16]). Corrected, the maximum blending time equals

\section{$3.35 \cdot 64 \mathrm{~min} /(1$ hour $/ 60 \mathrm{~min})=3.57$ hours}

where 3.35 is a blending correction factor (section 3.3.3).

Example 2: Using Equation 1, and test set $\{41-44\}$, the correction factor equals 3.35 (section 3.3.3), and the average blending time equals

$$
\mathrm{t}(\text { theoretical })(\min )=3.35 \cdot \frac{\mathrm{C} \cdot \mathrm{T}^{2}}{\mathrm{U}_{0} \cdot \mathrm{D}}=3.35 \cdot \frac{3.72 \cdot\left(85_{-} \mathrm{ft}\right)^{2}}{8.8\left(\frac{\mathrm{ft}}{\mathrm{sec}}\right)(\mathrm{ft}) \cdot 60\left(\frac{\mathrm{sec}}{\mathrm{min}}\right) 60\left(\frac{\mathrm{min}}{\mathrm{hr}}\right)}=2.84_{-} \text {hours }
$$

The CFD estimate with a conservative correction factor provides a slightly longer (26\%), more conservative prediction, where the blending time is expected to vary between 1.07 and 3.57 hours. Note that this value is conservative, since the correction factor was based on results from Tests 41 -44 . 
SRNL-STI-2011-00151

5/26/11 Revision 0

For a tank with coils and horizontal nozzles at $U o D=7.6 \mathrm{ft}^{2} /$ second (pilot scale $U o D=0.70$ $\mathrm{ft}^{2} /$ second),

Example 3: CFD predicts 140 minutes (Case 14, S. Lee [16]). Corrected, the maximum blending time equals

$3.35 \cdot 140 \mathrm{~min} /(1$ hour $/ 60 \mathrm{~min})=\mathbf{7 . 8 2}$ hours.

This estimate of the blending time was based on all experimental blending time data and a $95 \%$ confidence level to find the maximum blending time.

Example 4: From Phase 1, the estimated blending time was $\mathbf{6 . 8}$ hours, which also included uncertainty considerations. This blending time was based on $95 \%$ a confidence level and the upper, limiting values of the blending times.

For this example, CFD predicted a slightly longer (15\%) maximum blending time (6.8 hours * $1.15=7.82$ hours).

Examples 3 and 4 provide strong inductive proof of scale-up techniques. Similar test conditions were used in two sets of tests to compare Phase 1 and Phase 2 blending time calculation techniques. Example 3 uses Phase 1 test results, and empirical equations, while Example 4 uses Phase 2 results and CFD models. Two independent sets of data supported by two independent calculation techniques yielded similar results, where a $15 \%$ difference in predicted blending times was reasonable. The scale-up techniques work well, but full scale blending tests are recommended for validation. This example is the crux for scale-up resulting from this research, since two completely different techniques yielded similar solutions.

\subsection{Aerosolization and Rooster Tailing}

Blending pump operation was evaluated for all tests at the mid-height of the tank liquid level, but mention of off-normal operating conditions seems warranted. Specifically, rooster tailing is shown in Figure 3-5, and is of concern when operating blending pumps in waste tanks, where a submerged jet breaks through the free liquid surface. Generated water vapor could saturate tank ventilation HEPA filters, causing them to pass radioactive contaminants outside the tank. Although outside the scope of this research, the potential for rooster tailing due to the upward angled SBP discharge nozzle design should be more fully evaluated prior to placing an SBP in radioactive service.

Limited pilot scale, aerosolization data was collected during testing, and is provided here for reference. For the pilot scale tank containing water, initial jet breakthrough at the liquid surface occurred at 3.76 inches above the horizontal pump centerline. At a liquid level of 2.3 inches above the pump centerline, some splashing on the tank wall from the jets was observed. Rooster tailing for tests with water occurred at a similar level, but additional splashing and spray was observed.

\subsection{Blending Due to Transfers Into A Tank}

Most testing was performed using the acid and base tracer addition technique, and this technique provided the design requirements for the pump with a limited number of tests. However, a better understanding of the actual salt solution blending processes was required, and a few tests were performed to evaluate limiting conditions for salt additions to a tank. These tests consisted of water additions to a salt solution, salt to water, and water to water. The results from these tests for 
bounding conditions provided some insight into the blending of inhomogeneous solutions, but were inadequate to fully assess the effects of adding one salt solution to another. The kinematic viscosity of salt solutions added to blend tanks are expected to vary from batch to batch, but differences in kinematic viscosity are not expected be as disparate as the kinematic viscosities of water and salt solutions. Expected kinematic viscosity and density differences for expected waste streams were not provided by SRR.

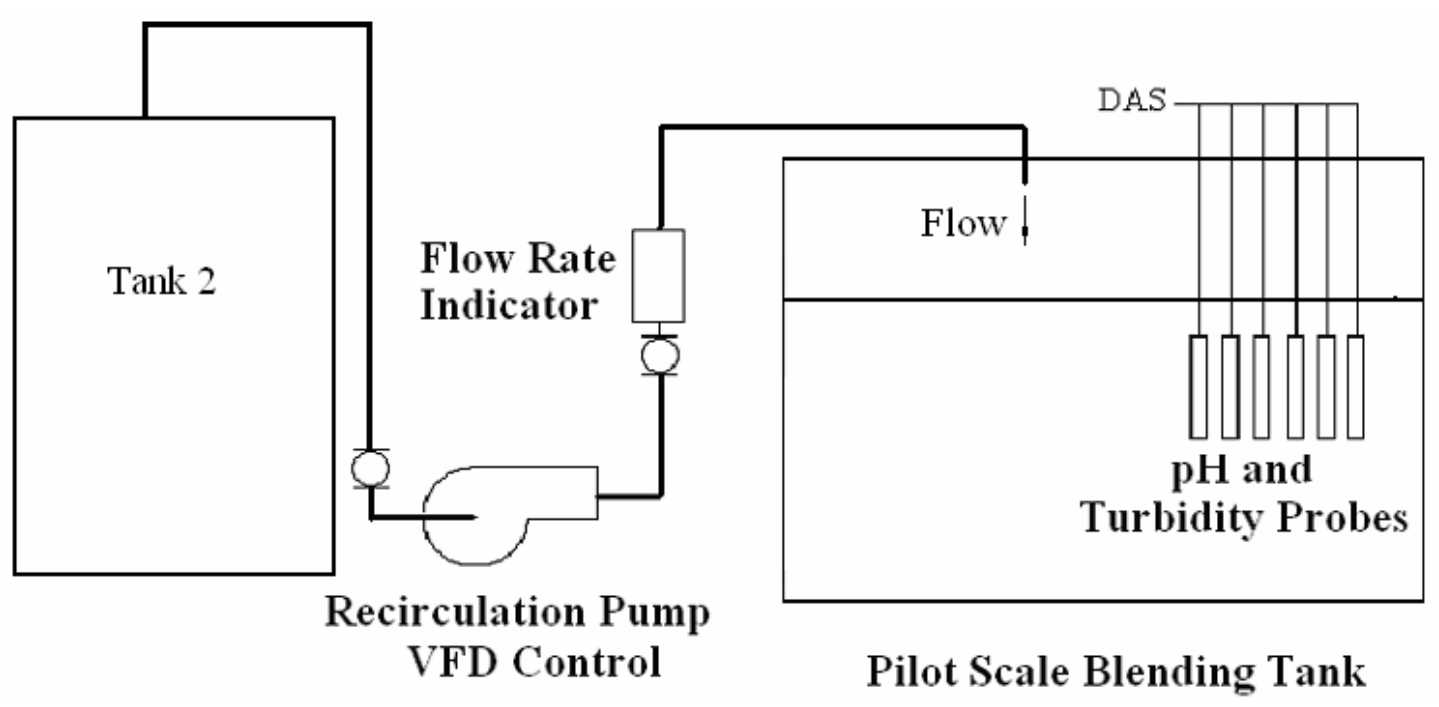

Figure 3-25: Simplified Schematic for Transfers Into the Pilot Scale Tank

Three tests were performed in the pilot scale tank to investigate blending effects due to transfers into a waste tank, using the equipment setup shown in Figure 3-25. The minimum full scale transfer flow rate for the facility was specified by SRR as $75 \mathrm{gpm}$, and the scaled flow rate was $0.61 \mathrm{gpm}$ at the pilot scale B5 riser location. A three inch Schedule 40 pipe $(0.285$ " ID) was scaled down, using commercially available 0.277 " ID tubing to drop fluid from above the waste level into the tank. The difference in tubing diameter was neglected given, since this test was primarily a scoping test. Final transfer piping design was unavailable, but the clearance of the incoming transfer pipe to the liquid level was scaled from P-PA-H-SK501 and P-PK-H-SK501.

As fluid flowed from the tube, the fluid above the free liquid surface flowed straight down without any expansion of the jet above the surface. In fact, the fluid jetting from the tubing looked almost like one of the cooling coils above the liquid level. When the flow struck the surface it expanded as a jet into solution, where trapped air bubbles in the jet could be observed to see the shape of the jet. However, the type of solution significantly affected the jet protrusion down into the supernate as assessed by the depth of observed bubbles jetting down into the fluid. The jet from the tube and supernate densities controlled bulk transfer blending.

Tests were performed by adding a 1/4 tank of one type of solution through the jet into a $3 / 4$ full tank containing another solution. To perform the tests, the two solutions to be blended were first prepared by adding acid to one solution and base to the other, yielding one solution of $p H=4$ and another solution of $p H=10$. The $p H$ probes were then placed at a level below the surface of the receipt fluid in the tank to monitor $p H$ changes as fluid was added to the pilot scale tank and the $p H$ then approached an equilibrium value. 
When a denser solution was added to a less dense solution $\left(\mathrm{NaNO}_{3}\right.$ to water), the air bubbles in the jet traveled to within six inches of the tank bottom. When adding a salt solution to a salt solution, the jet bubbles were within a foot of the tank bottom. When a less dense solution was added to a denser solution (water to $\mathrm{NaNO}_{3}$ ), the air bubbles in the jet only protruded about six inches into the supernate. That is, the blending process was altered by the fluid densities, where the depth of jet penetration was related to the overall blending of the tank contents. Inadequate testing was performed to quantify the relationship between fluid properties and blending for salt solutions. In fact, the term "similar" salt solution is used throughout this report without concise definition, due to this blending anomaly which requires further research.

\subsubsection{Blending During Transfers of Similar Solutions or Transfers of Denser into Less Dense Solutions}

When $\mathrm{NaNO}_{3}$ was added to water, the tank contents were completely blended without operating the blending pump. Blending was quantified by the use of $p H$ measurements, and as shown in Figure 3-26, pH values converged to equilibrium while blending occurred. That is, equilibrium conditions were met while the transfer was in progress, and additional blending was not required after transfer completion. When similar solutions were added together (transferred), complete blending also occurred without operating the blending pump, as shown in Figure 3-27. In both cases, blending was effectively performed solely by the transfer process into the tank.

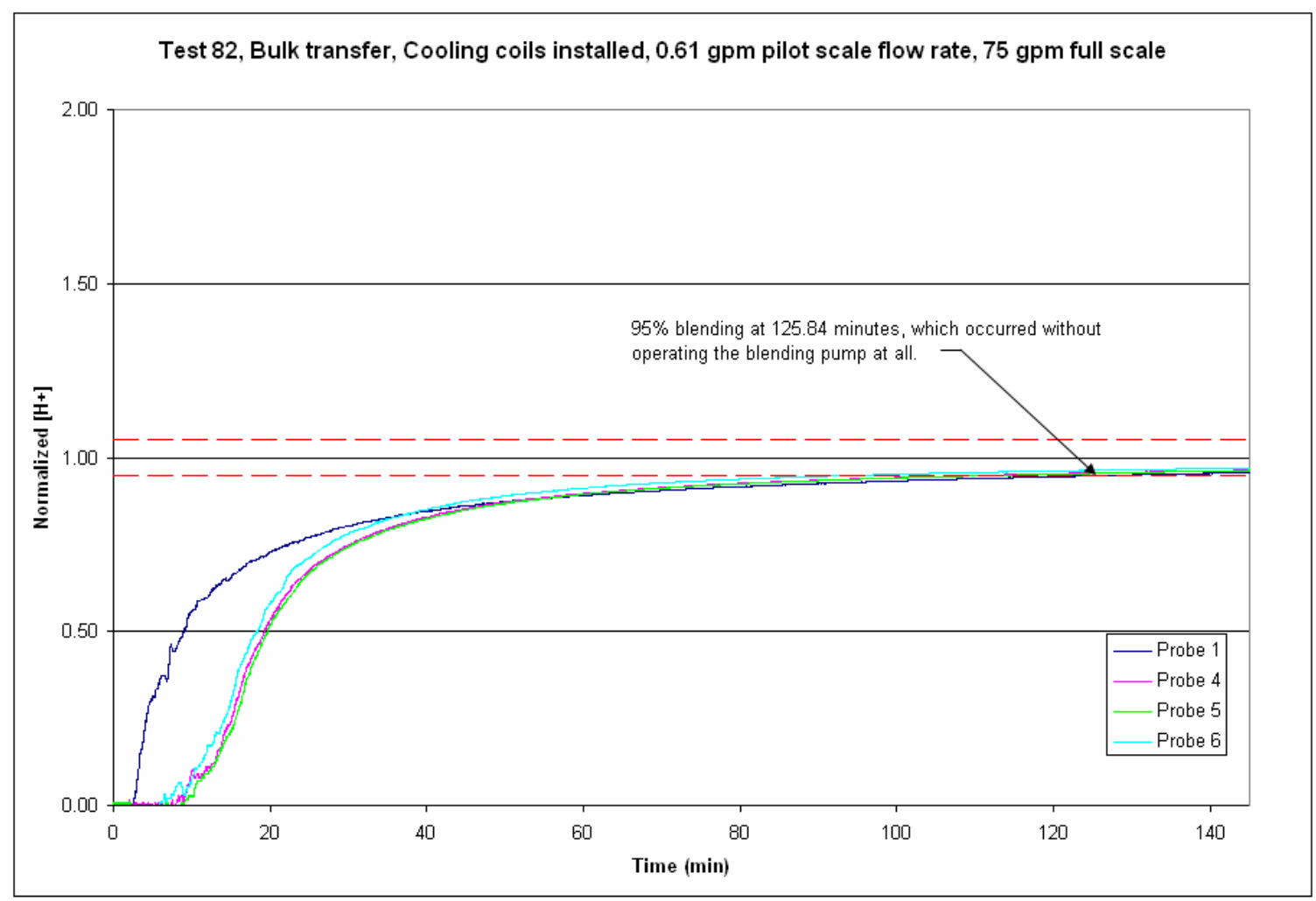

Figure 3-26: $p H$ Measurements for Transfer of $\mathrm{NaNO}_{3}$ to Water 


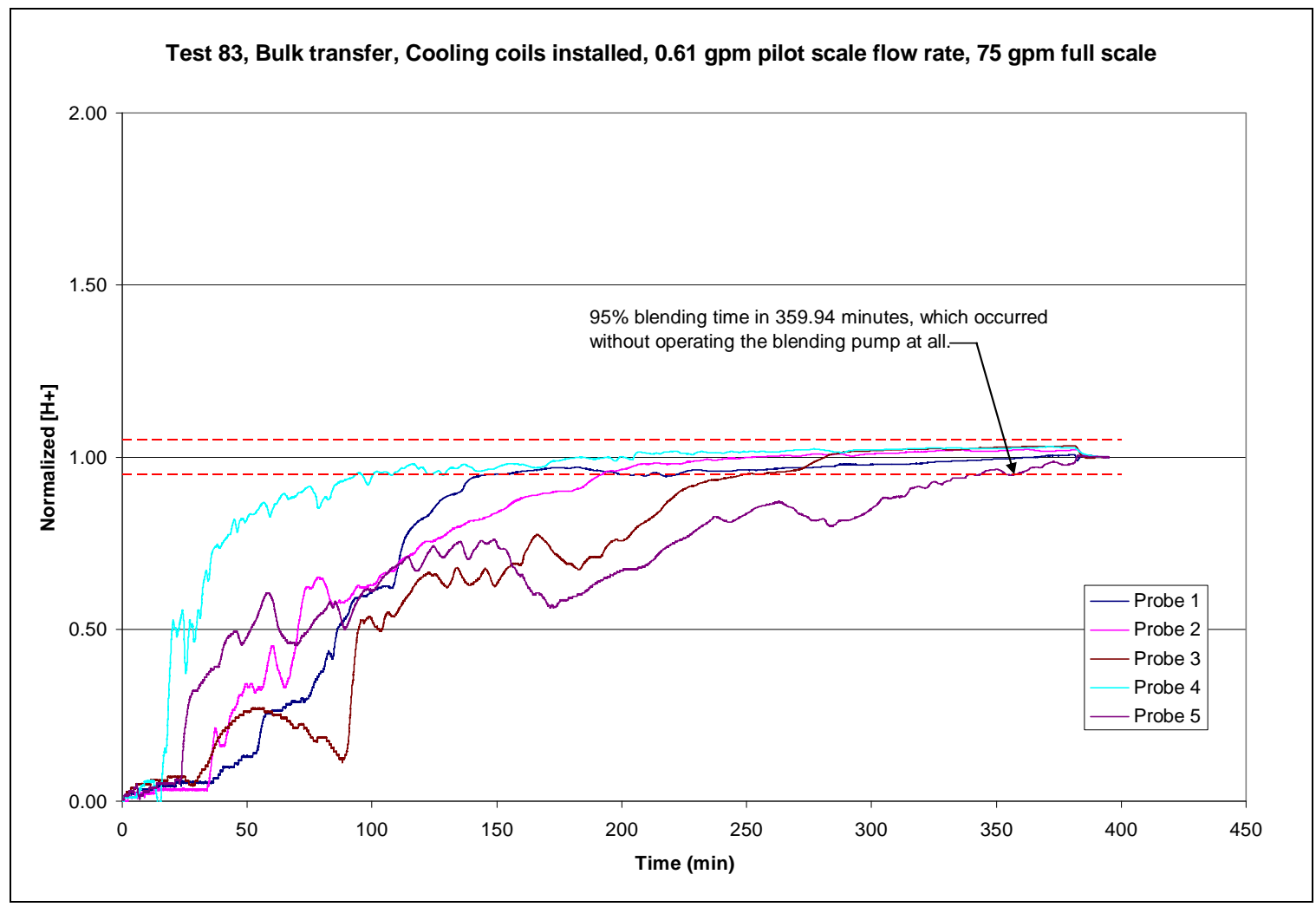

Figure 3-27: $p H$ Measurements for Transfer of $\mathrm{NaNO}_{3}$ to $\mathrm{NaNO}_{3}$

\subsubsection{Blending During Transfers of Less Dense Solutions into Denser Solutions}

When a less dense solution was added to a denser solution (water to $\mathrm{NaNO}_{3}$ ), the blending mechanism changed completely. For water addition to a supernate simulant, a stratified salt solution layer formed in the tank below a layer of water with dilute salt concentrations, and this layer gradually lowered as the blending pump jet impinged on the salt layer surface, as shown in Figure 3-28. Figure 3-29 shows the waves in the stratified salt solution surface due to the blending pump. This surface layer was quite evident at about one inch above the initial water level in the tank. That is, the $\mathrm{NaNO}_{3}$ level was initially 24.2 inches, water was added to bring the tank level up to 32.1 inches, a distinct layer was observed at 25 inches from the tank bottom, and then the blending pump was turned on. Minimal blending occurred prior to blending pump operation, and $\mathrm{pH}$ data provided some insight into this blending process.

Figure 3-30 demonstrates that thorough blending occurs above the salt layer surface, and little blending occurs below that surface. Note that $p H$ sharply increases as the layer drops past each probe. In short, during the mass transfer process the water from the jet removed salt solution at the wavy interface layer, and the level of the interface layer decreases with respect to time. Stratification effects negated analytical techniques that are used for blending of similar solutions, since theory is unavailable to explain this stratification process.

Although sufficient data is unavailable to accurately quantify scale-up, a rough estimate for the blending time at full scale can be determined from the 6.73 hour blending time in Figure 3-28, where an uncorrected blending time equals $10.85 \cdot 6.73$ hours $=3$ days for this specific example. This estimate is a reasonable lower bound for the blending time, since all blending mechanisms in this report were shown scale up linearly and required a correction factor for use. Since only a single test was performed, uncertainty data is unavailable. However, correction factors for 
velocity and blending times determined in this research varied from 1.27 to 3.35 respectively, and the correction factor for blending of stratified fluids is expected to be in this range, but probably near the lower limit. Then, the expected blending time is expected to be in the range of several days to a week, or more, when adding less dense solutions to denser solutions. Additional cases were not investigated, and blend times will vary depending on the relative solution concentrations and quantities during transfer. Further research or measured data from a full scale tank is required to validate blend times for inhomogeneous solutions.

The effect of stratification on sludge disturbance requires attention. Regardless of stratification, sludge disturbance is not expected to be affected by the stratification process. Sludge disturbance tests were performed using both water and salt solutions, where stratification was not present. For either case, the results were comparable since sludge was disturbed at the same $U o D$. In that case, only the additional wave motion at the salt solution boundary is a new variable with respect to sludge disturbance. Considering wave motion in stratified solutions, waves were of negligible magnitude as the salt interface approached the tank bottom, and the sludge layer approximated a solid surface with respect to sludge disturbance. Similarly, waves are expected to be negligible at the sludge surface as the salt interface lowers toward the sludge layer. Since the salt layer wave motion is not considered to be an issue with respect to sludge disturbance, sludge disturbance is expected to be the same when using either water or salt simulants. In other words, sludge disturbance is expected to be the same at similar flow rates regardless of stratification effects, and the recommended pump design flow rates $(U o D)$ are unaffected by stratification.

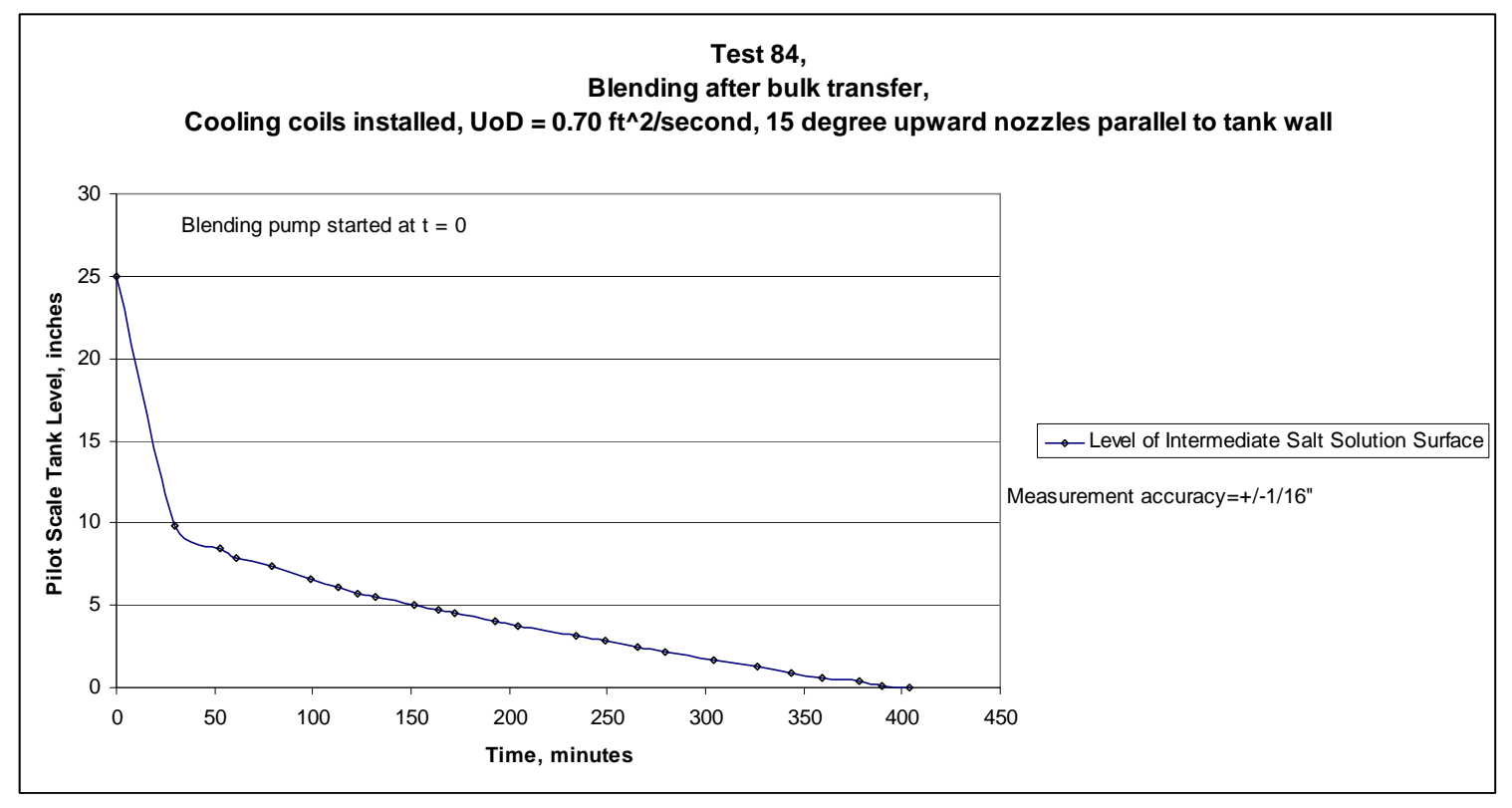

Figure 3-28: Interface Layer, Level Changes During Blending of a Stratified Salt Solution, Transfer of Water to $\mathrm{NaNO}_{3}$ 


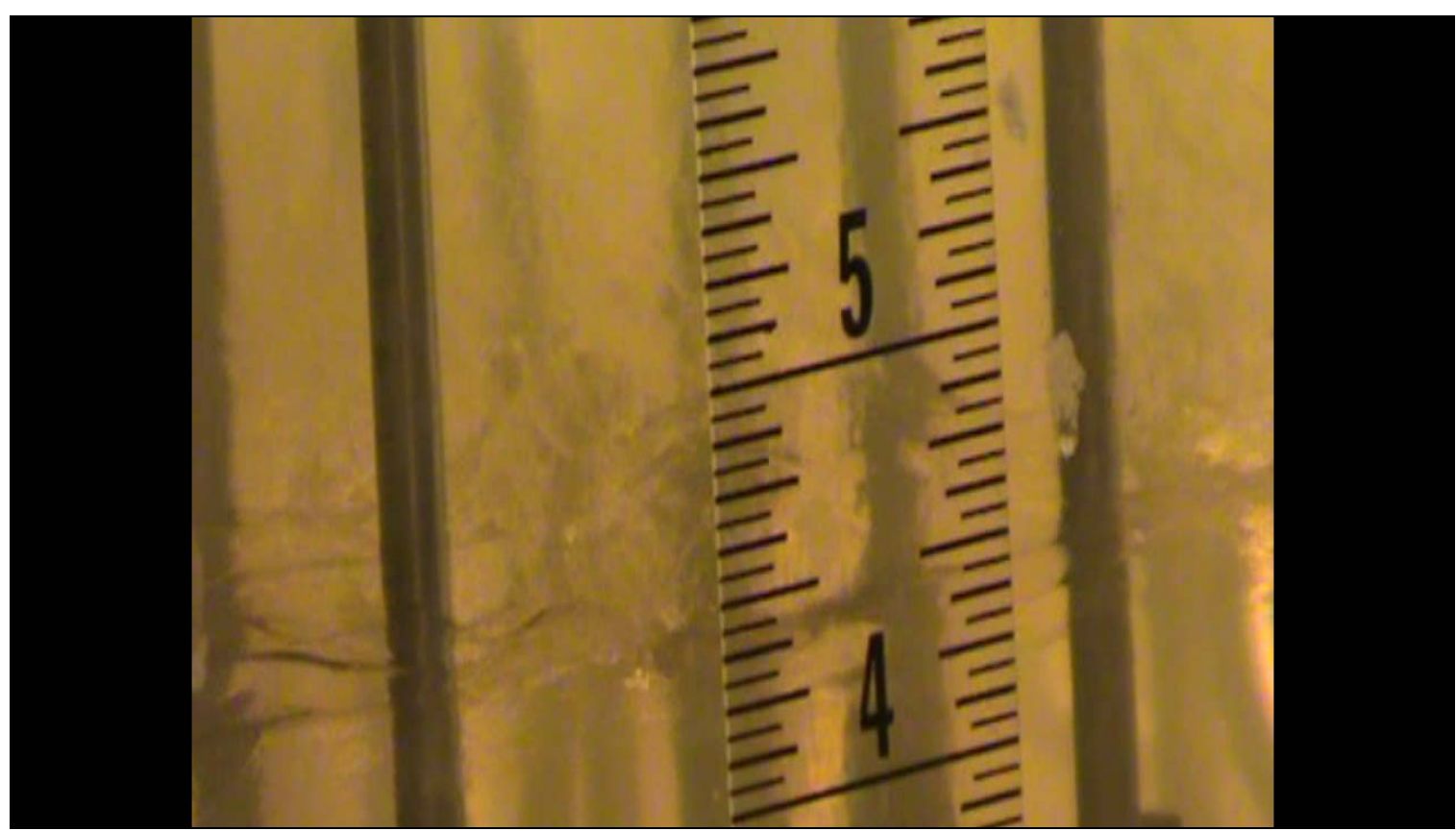

Figure 3-29: Interface Layer Between Water and Salt Solution Layers, Transfer of Water to $\mathrm{NaNO}_{3}$

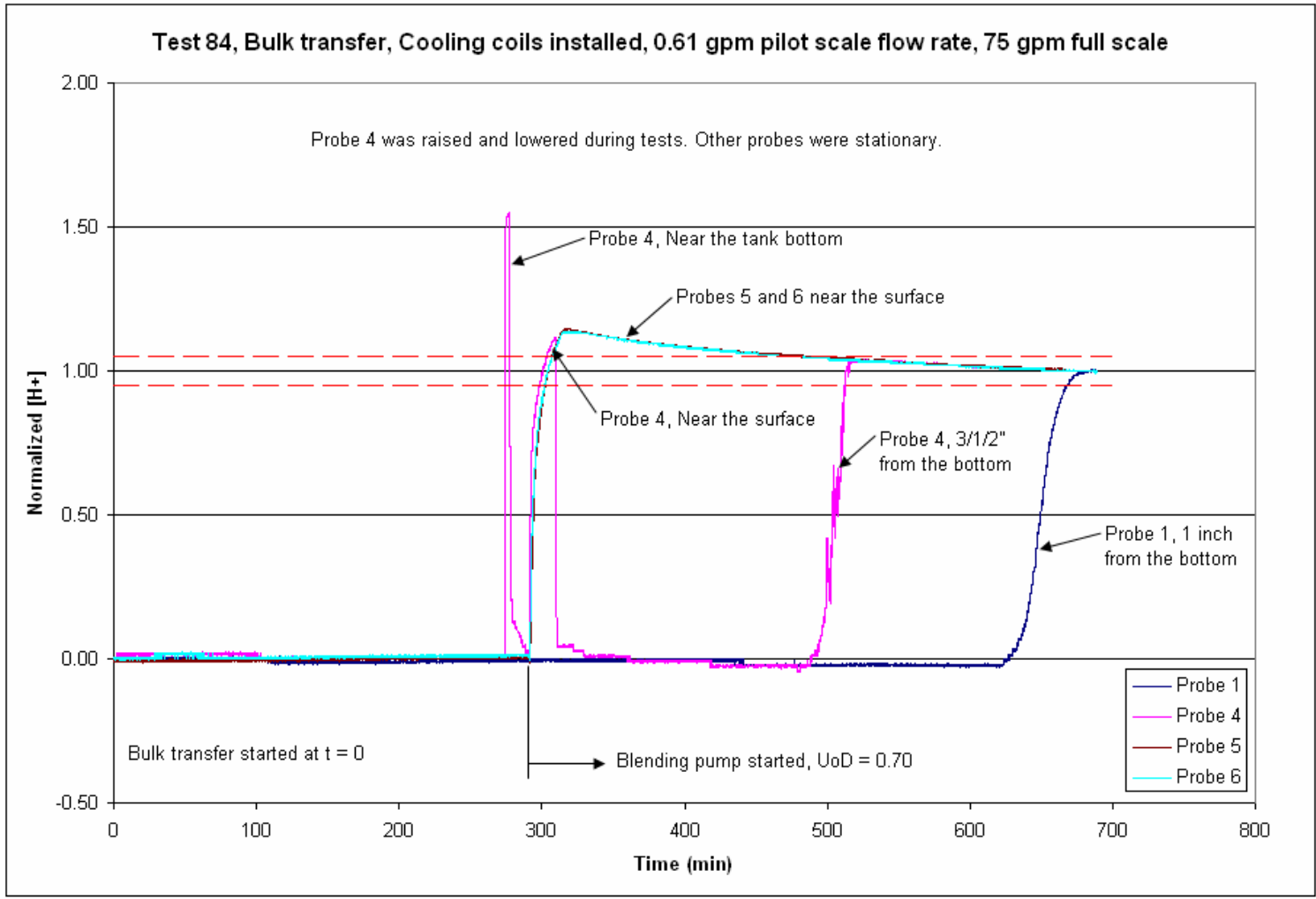

Figure 3-30: $p H$ Changes Due to Blending After Transfer of Water to $\mathrm{NaNO}_{3}$, Transfer of Water to $\mathrm{NaNO}_{3}$ 
SRNL-STI-2011-00151

5/26/11 Revision 0

\subsection{Sludge Disturbance}

Minimizing sludge disturbance during blender pump operations is important both to ensure that SWPF waste acceptance criteria are met, and to prevent a hydrogen release potential.

\subsubsection{Hydrogen Release}

One premise of this research is that if the sludge remains undisturbed by pump operations, and hydrogen will not be suddenly released. Although some sludge disturbance is permitted in the Tank Farm Safety Analysis and SRR is responsible for any evaluation with respect to sludge disturbance, the premise for this research was that testing would be performed to ensure that sludge was not significantly disturbed. If the sludge remains undisturbed, then hydrogen release is not expected.

Using Hanford sludge simulants, previous SRNL full scale testing demonstrated the assumption that sludge must be violently displaced to cause a sudden gas release. (Leishear, Restivo, Guerrero [21]). In that testing, a sludge simulant was saturated with oxygen to simulate hydrogen gas entrapment in sludge, and an air sparger was then used to suddenly release the trapped gas. Although gas was slowly released from a sludge simulant without agitation, sparger agitation was required for sudden gas release. Although gas release due to pump operation will vary in some respects, this testing clearly showed that significant agitation was required to suddenly release a gas from a Bingham fluid with a defined yield stress, which is typical of waste sludges.

\subsection{Sludge Disturbance Testing}

A series of 30 Sludge disturbance tests were performed. Tests were performed to establish:

1. Requirements for sludge settling times,

2. Sludge concentrations lifted into the supernate,

3. Pilot scale $U o D$ requirements for the blender pump.

4. Pump nozzle orientation.

SRNL recommendations are that a 33 day settling time is required at full scale (section 2.6). As discussed below, for a Tank 50 design with cooling coils the maximum $U o D=6.10 \mathrm{ft}^{2} / \mathrm{second}$, and for the same design without coils the maximum $U o D=4.85 \mathrm{ft}^{2} /$ second.

All CFD models displayed in this report to assess sludge disturbance were extracted from S. Lee's research [16]. Typically, a sludge plane is assumed to exist at $3 / 4$ inch from the tank bottom for pilot scale. On this sludge plane, a CFD modeling assumption was that a frictionless slip condition existed, which permitted calculations of velocities on the sludge plane. Minimal sludge disturbance was considered acceptable per SRR for this research (defined in section 3.9). When an acceptable test condition was determined at minimal sludge disturbance, the maximum velocity on the sludge plane was determined by CFD. This velocity was assumed to relate failure criteria at both pilot and full scales. Once a pilot scale velocity was determined using CFD, the 1.267 velocity correction factor (section 3.1.3.3) was applied to find the full scale velocity acceptance criterion. A discussion of the testing required to reach a recommendation follows.

\subsection{Initial Sludge Disturbance Testing}

Phase 1 blending tests specified a preferred nozzle parameter of $U o D=0.81 \mathrm{ft}^{2}$ second for $95 \%$, using a tee nozzle design parallel to both the tank wall and the tank floor. Sludge was disturbed symmetrically on both sides of the tank in an area roughly 40 inches along the tank circumference by 18 inches from the tank wall toward the center column. A CFD model (Figure 3-31) provided some insight into this phenomenon. Interestingly, the sludge disturbance behind the center 
column away from the pump was not noticed until after CFD modeling predicted it. For another test, concentration calculations provide insight into sludge disturbance, where concentrations are calculated using Figure 2-13, even though the concentrations exceed the limit recommended in this report for the use of the turbidity probes. Note also that the 0.16 weight percent concentration was measured (Figure 3-32), which exceeds the 0.09 weight percent limit, per the SWPF WAC. Since many of the test results are similar, only a few representative tests are presented.

The sludge disturbance process in the pilot scale was rather complex. The particles lifted into suspension were black in color, and when the pump speed was increased after testing to aid in remixing the tank contents, tan particles exited the jets, which indicated that a different material was not yet lifted into suspension during blending. Differential settling rates were assumed to cause different metal oxide particles concentrations through the sludge layer (see section 2.5), and a greater percentage of lighter metal oxide particles were expected to be lifted into suspension during blending (see section 2.5.3.5), but the process was not further investigated.

The terms significant sludge disturbance and acceptable, or minimal, sludge disturbance require definition. Significant sludge disturbance was bounded when the sludge was observed to be scoured 1/16 - 1/8 of an inch in 20 to 30 minutes due to the blending pump operation, where continued operation would have scoured the sludge even deeper. For initial sludge testing, the sludge was scoured to the tank bottom in minutes. Minimal sludge disturbance was described by the condition where some wisps of sludge were noted on the sludge surface. These wisps were blended into suspension to slightly increase the turbidity in the tank, but the sludge level was observed to remain constant over a 24 hour period. Tests were performed to find a sequence of two tests at increasing values of $U o D$, where one test provided minimal disturbance while the other test demonstrated the characteristic bounding sludge disturbance. The minimal disturbance test was selected as the $U o D$ design condition for the blending pump per SRR and SRNL Engineering.

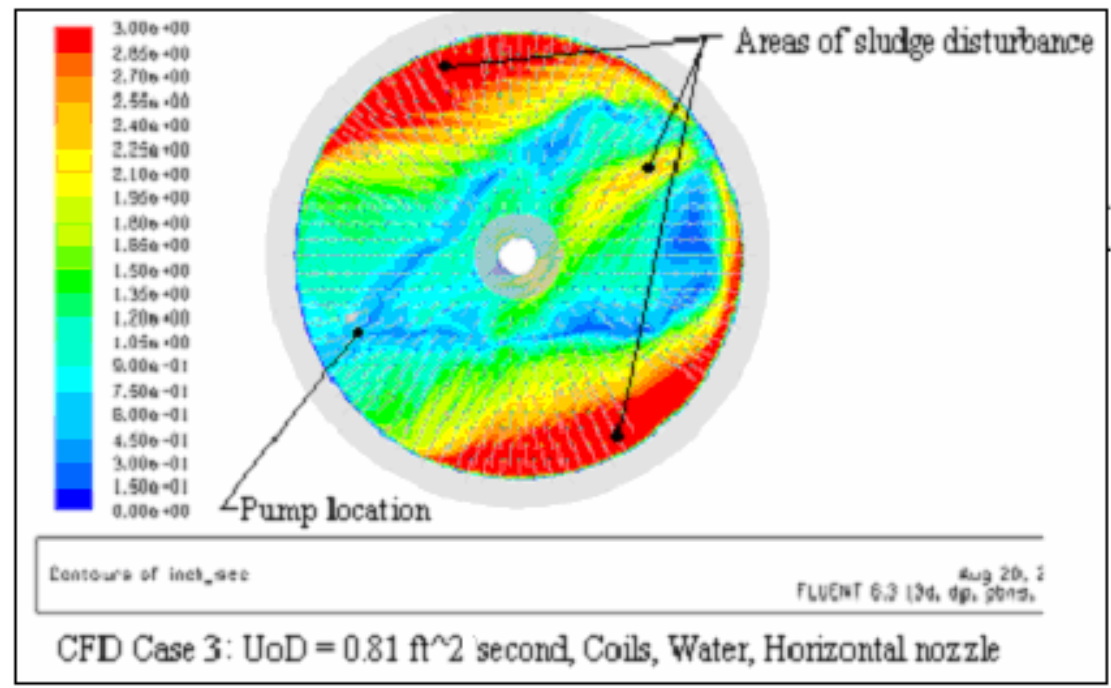

Figure 3-31: Example of Significant Sludge Disturbance, Velocities at the Sludge Plane 


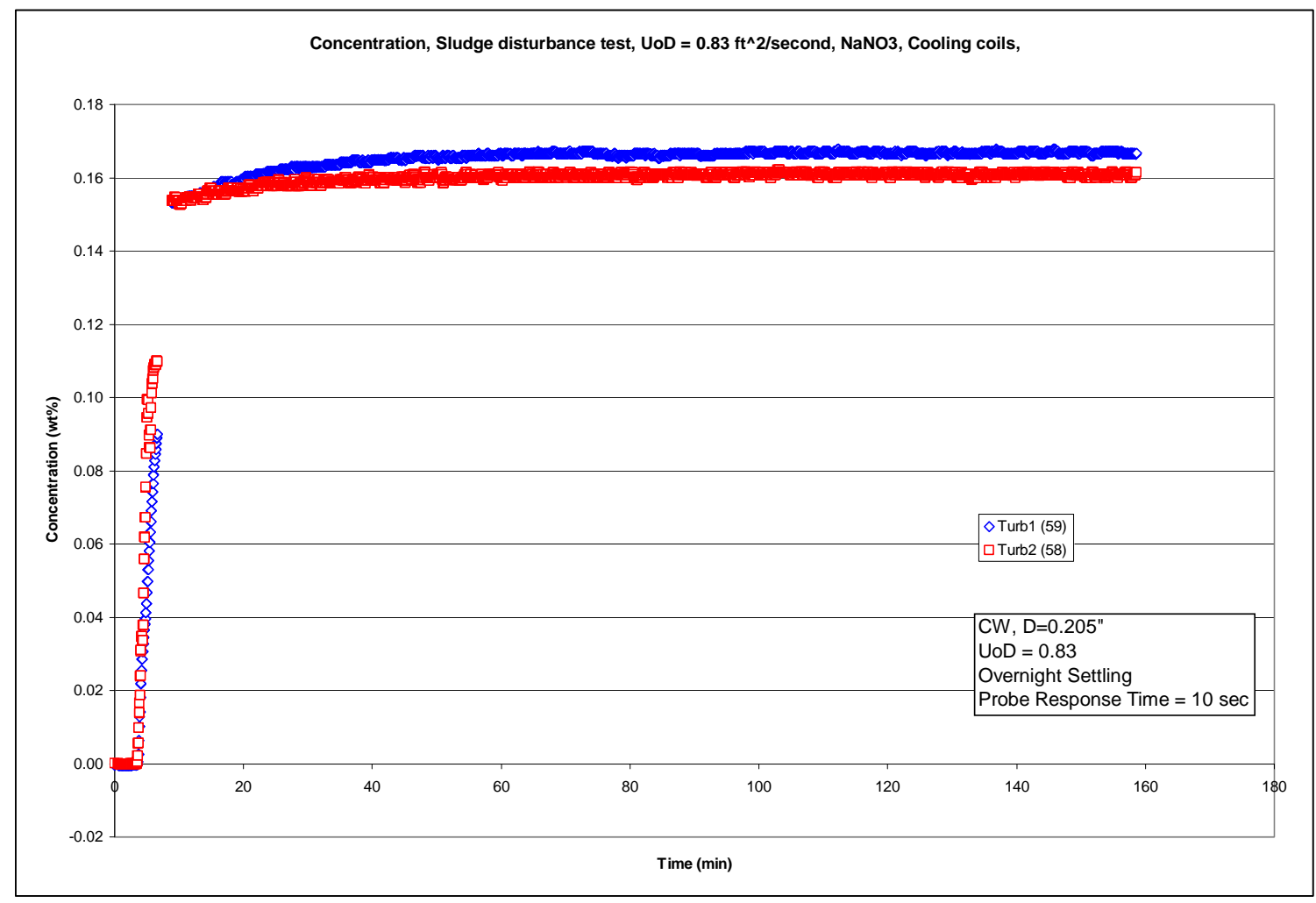

Figure 3-32: Example of Significant Sludge Disturbance, Concentrations Determined From Turbidity Probes

\subsection{Nozzle Selection}

Numerous different nozzle designs were used to investigate this problem, and the 15 degree upward nozzle was selected, as shown in Figure 2-6. Nozzle attachments were designed for the $\mathrm{CW}$ design, so that various nozzle angles could be investigated. Test were performed at $15^{\circ}$ upward, $30^{\circ}$ upward, $45^{\circ}$ inward, and $15^{\circ}$ upward but pitched $45^{\circ}$ toward the tank center. For over-night testing, all nozzles disturbed sludge. The $15^{\circ}$ upward design worked when the settling time was extended to 6.7 hours. Tank contents were initially settled overnight, and all nozzle designs that were tested significantly disturbed sludge, as evidenced by scouring of sludge down to the tank floor. The settling time for the sludge was then extended to 66 hours for remaining tests, where $15^{\circ}$ upward pointing nozzles were shown to negligibly disturb sludge. Although further testing may have shown that different nozzle designs may have provided better performance, success of the $15^{\circ}$ nozzles was sufficient to resume testing with that nozzle design.

\subsection{Sludge Disturbance in a Pilot Scale Tank Without Coils}

Using the $15^{\circ}$ nozzles, testing was first performed to find a recommended $U o D$ value for a tank without coils that would result in minor sludge disturbance. To find a recommended $U o D$, the $U o D$ was incrementally increased by changing the flow rate through the $\mathrm{CW}$ pump model for both water and salt supernate simulants. Then, additional tests were performed to validate that the selected $U o D$ resulted in a low sludge concentration. The acceptance criterion was that the sludge did not visually decrease in level over a 24 hour period. Even so, concentrations of sludge lifted into suspension remained below the SWPF WAC limit. 
SRNL-STI-2011-00151

5/26/11 Revision 0

\subsubsection{Pilot Scale UoD for a Tank Without Coils Containing $\mathrm{NaNO}_{2}$ Solution}

The test results for incrementally increasing $U o D$ for a tank without coils is shown in Figure 3-33. Unacceptable sludge disturbance occurred at $U o D=0.58 \mathrm{ft}^{2} / \mathrm{second}$. Note that the concentration is an order of magnitude below the SWPF WAC of 0.09 weight \%. Figure 3-34 demonstrates that the solids lifted into suspension decrease with respect to time, as visually observed by the fact that the sludge layer did not decrease during overnight testing at this design condition.

Since there were limited tests at $U o D=0.58 \mathrm{ft}^{2} /$ second, a $95 \%$ confidence value was calculated from available test results to obtain 0.055 weight percent, which is still below the SWPF WAC. Concentrations at full scale are expected to be much lower (approximately 0.004 weight percent). To obtain this value, sludge disturbance is assumed to be proportional to velocity, and a crude approximation is that velocities are approximately the same at both scales. Also, the sludge disturbed per unit area is blended into the entire tank volume. Then, the concentration in a full scale tank at $U o D=10.85 \cdot 0.58 \mathrm{ft}^{2} /$ second approximately equals:

$$
\begin{aligned}
& \text { full_scale_wt } \% \\
& \approx \text { pilot_scale_wt } \% \cdot \frac{\left(\text { full_scale_tan } \mathrm{k}_{-} \text {diameter }\right)^{2}}{\left(\text { pilot_scale } \tan \mathrm{k}_{-} \text {diameter }\right)^{2}} \cdot \frac{\left(\text { pilot_scale_tan } \mathrm{k}_{-} \text {volume }\right)}{\left(\text { full_scale_tan } \mathrm{k}_{-} \text {volume }\right)} \\
& =0.055_{-} \mathrm{wt} \_\% \cdot \frac{85^{2} \cdot 839 \text { _gal }}{8^{2} \cdot 1,225,000_{-} \text {gal }}=0.004_{-} \mathrm{wt}_{-} \%
\end{aligned}
$$

Note that the actual concentration will be slightly higher, since CFD modeling for a sludge plane in a tank without coils demonstrates that velocity scale-up is non-linear (section 3.11.5). Even though this estimate of sludge disturbance is provided, the acceptance criterion was the visual observation of negligible sludge disturbance. 
SRNL-STI-2011-00151

5/26/11 Revision 0

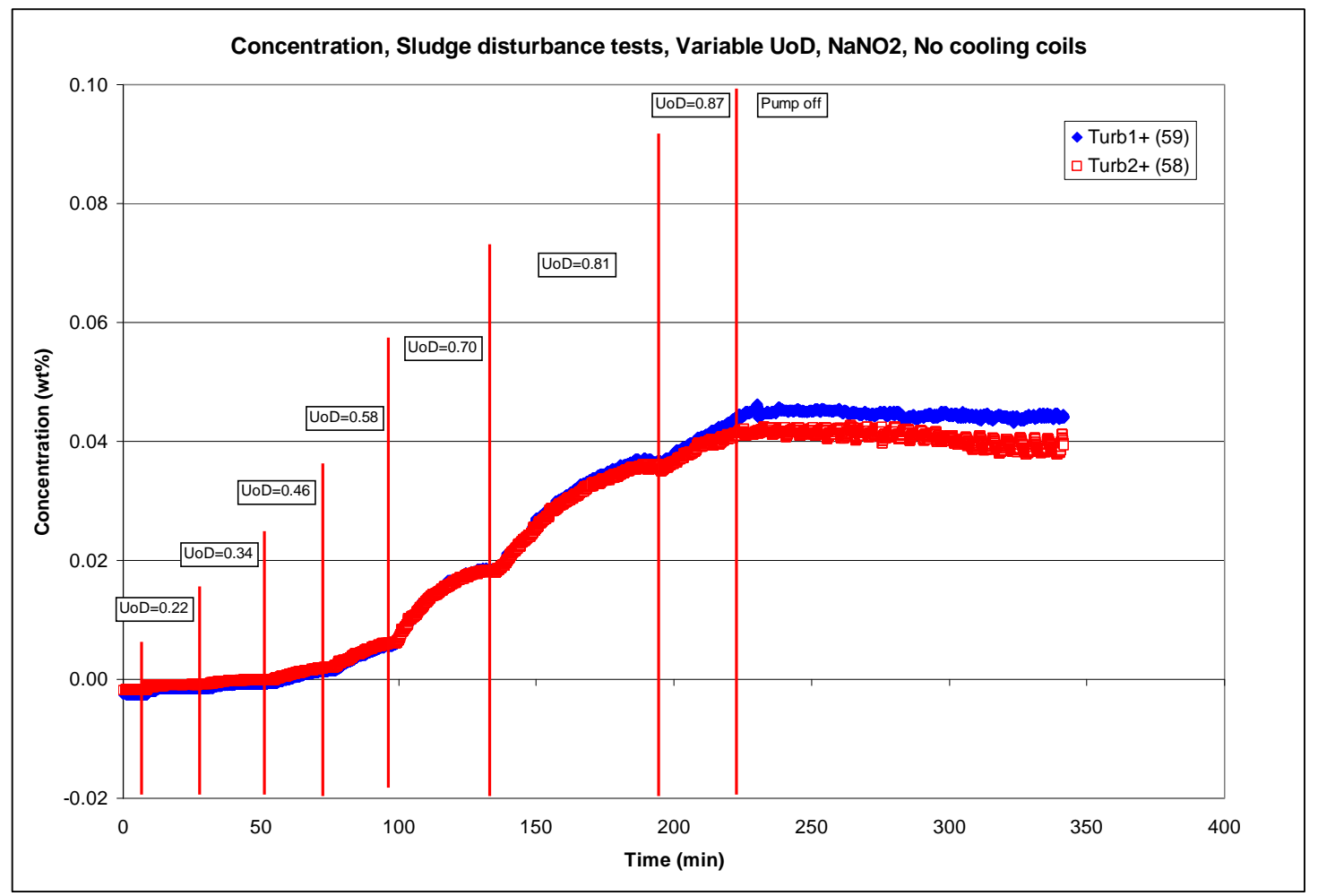

Figure 3-33: Concentrations Due to Incremental UoD Changes in a Tank Without Coils Filled With $\mathrm{NaNO}_{2}$ Solution

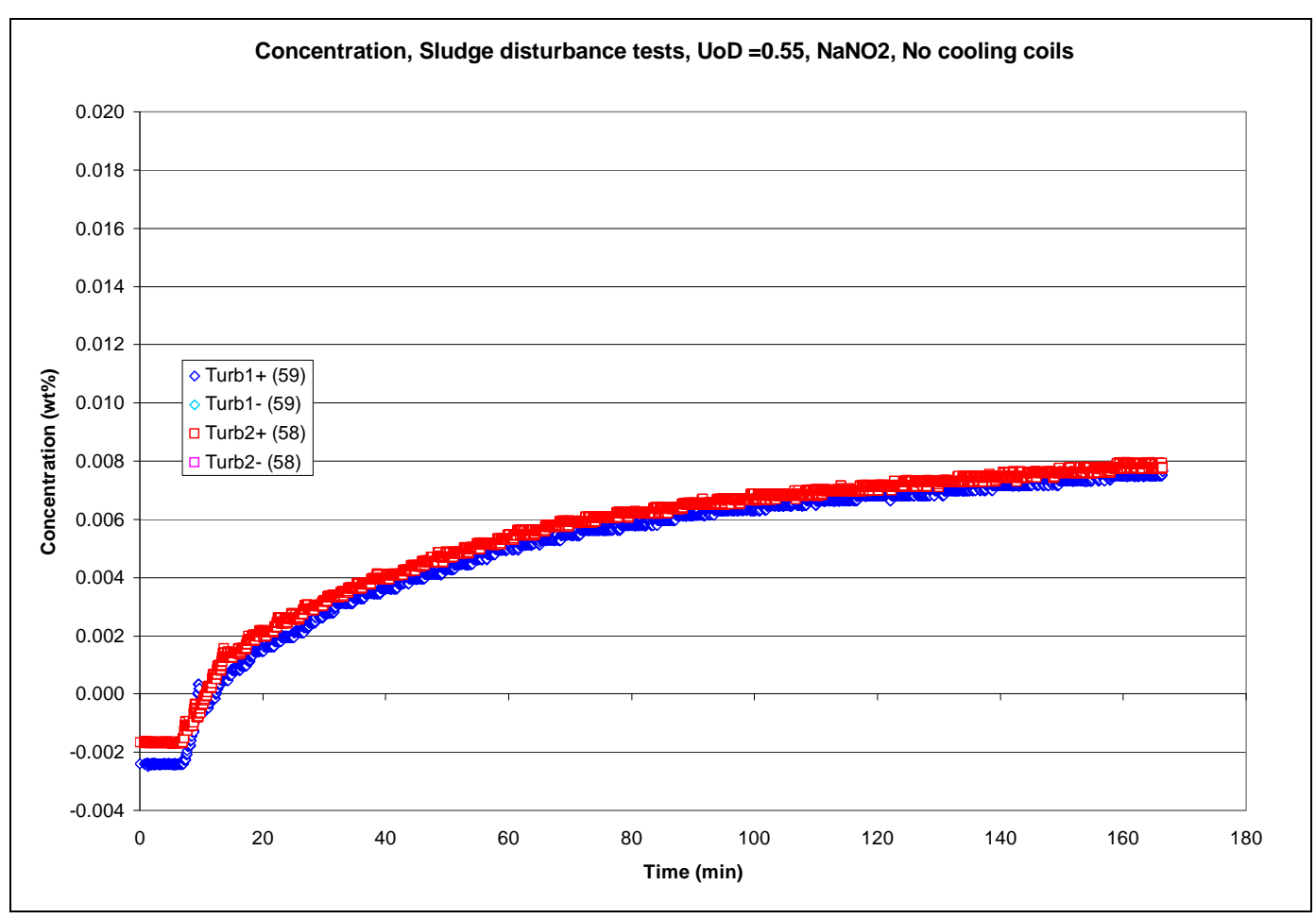

Figure 3-34: Concentrations at $U o D \approx 0.58 \mathrm{ft}^{2} /$ second in a Tank Without Coils Filled With $\mathrm{NaNO}_{2}$ Solution 


\subsubsection{Pilot Scale UoD for a Tank Without Coils Containing Water}

Tests were performed to determine the required $U o D$ to disturb sludge for both a water and salt supernate simulants in a tank without coils. For each simulant, tests were initially performed by incrementally increasing the $U o D$ to establish the required $U o D$ to disturb sludge. Once an optimal $U o D$ was determined, additional tests at that $U o D$ were performed to confirm the recommended $U o D$. Testing showed that the same $U o D$ was recommended for either supernate simulant, using the same sludge simulant with the same settling time requirements $(U o D=0.58$ $\mathrm{ft}^{2} /$ second). Since either simulant could be used for continued testing, the $\mathrm{NaNO}_{2}$ simulant was selected, where the salt simulant properties are more like actual waste supernate properties. Also, SB6 simulant settled slower when mixed with $\mathrm{NaNO}_{2}$ than when mixed with water (Figure 2-20), where slower settling sludge properties provided conservative settling time recommendations. These observations were the basis for using $\mathrm{NaNO}_{2}$ with the SB6 simulant for further sludge testing and full scale settling tests (section 2.6).

Test results for incrementally increasing $U o D$ for a tank without coils is shown in Figure 3-35. Acceptable sludge disturbance occurred at $U o D=0.58 \mathrm{ft}^{2} /$ second, and test results are shown in Figure 3-36. Note that sludge concentrations are well below the SWPF WAC after 24 hours. Suspended sludge concentration equals 0.014 weight percent at $95 \%$ confidence weight percent, or less, at full scale in a tank without coils for any sodium salt solution. Scale-up was estimated at 10.85 days to reach this concentration.

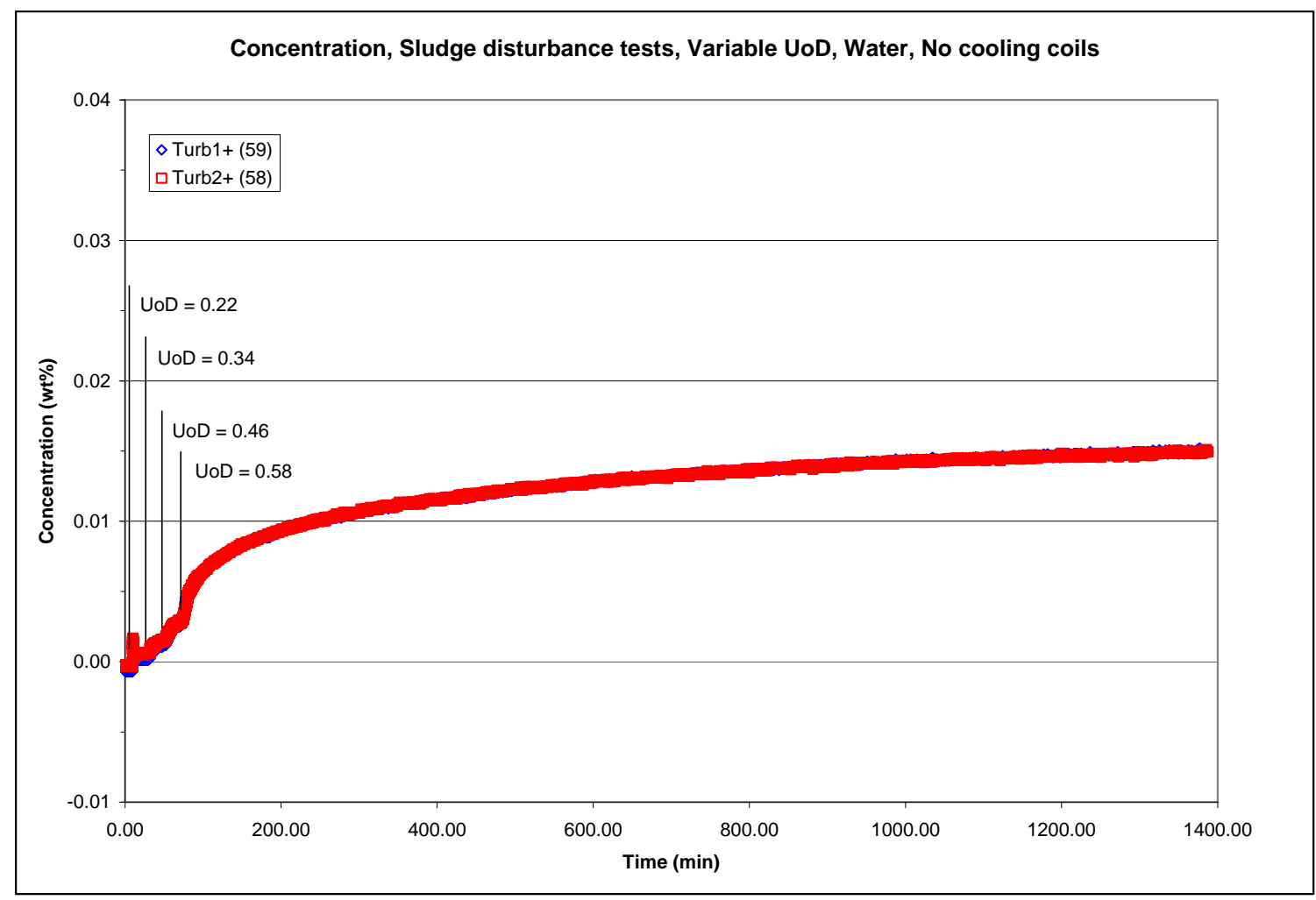

Figure 3-35: Concentrations Due to Incremental UoD Changes in a Tank Without Coils Filled With Water 


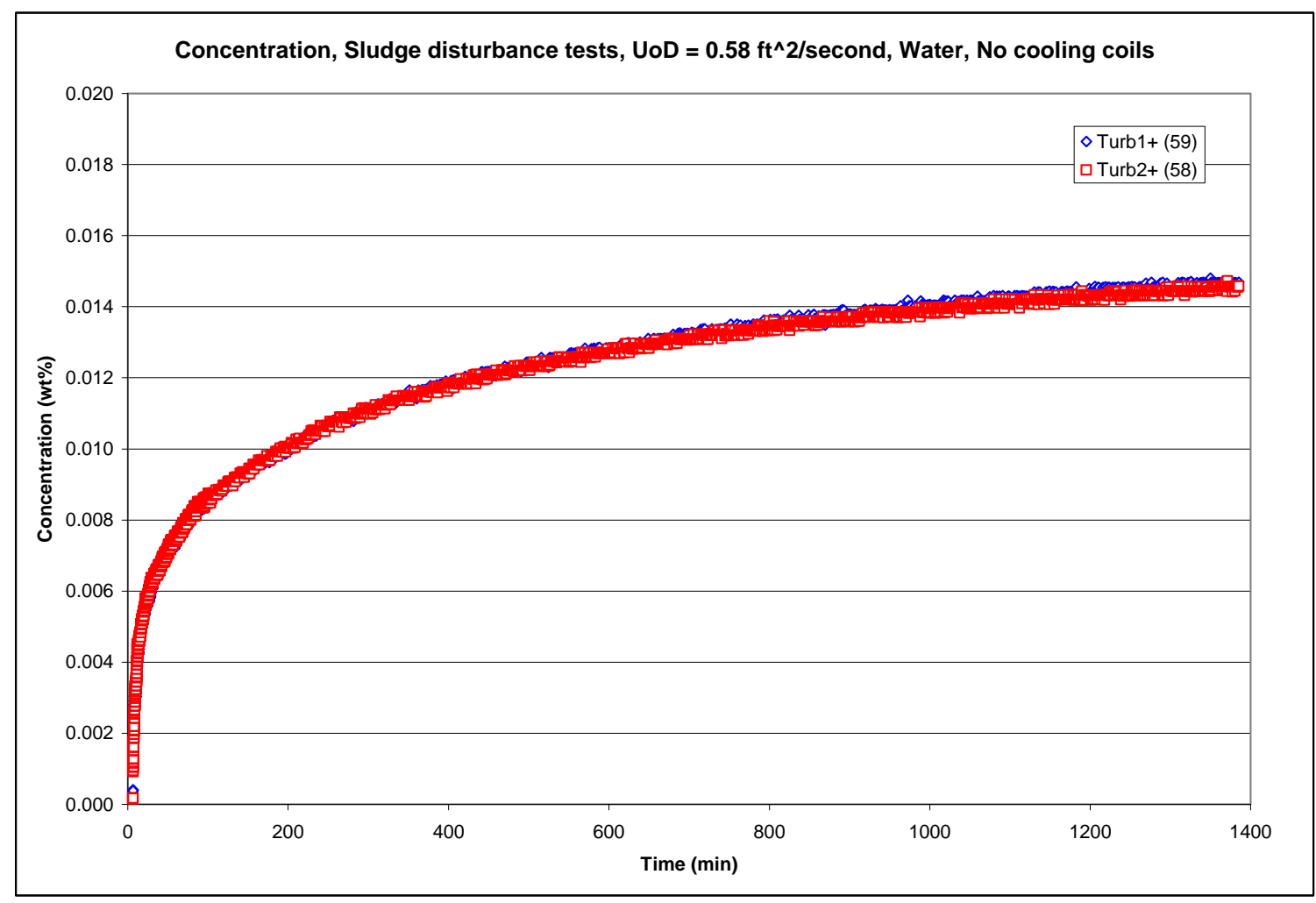

Figure 3-36: Concentrations at $U o D \approx 0.58 \mathrm{ft}^{2} /$ second in a Tank Without Coils Filled With Water

\subsubsection{Velocity Acceptance Criterion for a Tank Without Coils}

Using a CFD model for a tank containing $\mathrm{NaNO}_{2}$, the nominal velocity required to disturb sludge can be determined, which can then be corrected with the velocity correction factor. Two types of models are presented here. One is the slip plane model, where a plane is installed at the sludge layer position and velocity is directly calculated on the sludge plane. The other is a blending model, where fluid motion occurs down through the sludge layer to the tank bottom. For the blending model, velocities at the tank floor are equal to zero, and velocities were determined at the height of the sludge layer. The sludge layer was assumed at 15/16" to conservatively bound velocity predictions, rather than the $9 / 16$ " - 7/8" inch observed in pilot scale testing. From Figure 3-37 or Figure 3-38:, the maximum velocity on the sludge plane where sludge is disturbed equals $0.34-0.36 \mathrm{ft} / \mathrm{second}$. In other words, both models yield similar predicted velocities in the same region on the sludge layer. This predicted $0.34 \mathrm{ft} /$ second velocity is the theoretical maximum, CFD predicted velocity. However, velocity testing showed that there is significant variability in velocity, and this fact needs to be compensated. Using the 1.267 velocity correction factor to conservatively estimate a lower velocity limit, the velocity required to disturb sludge at full scale then equals $0.34 / 1.267=0.268 \mathrm{ft} / \mathrm{second}$. The velocity is reduced to correct calculated deviations of the measured average velocity from the average value predicted by CFD modeling. That is, application of the velocity correction factor is appropriate, since a realistic variation in velocity was experimentally determined (section 3.1.3.3). 
SRNL-STI-2011-00151

5/26/11 Revision 0

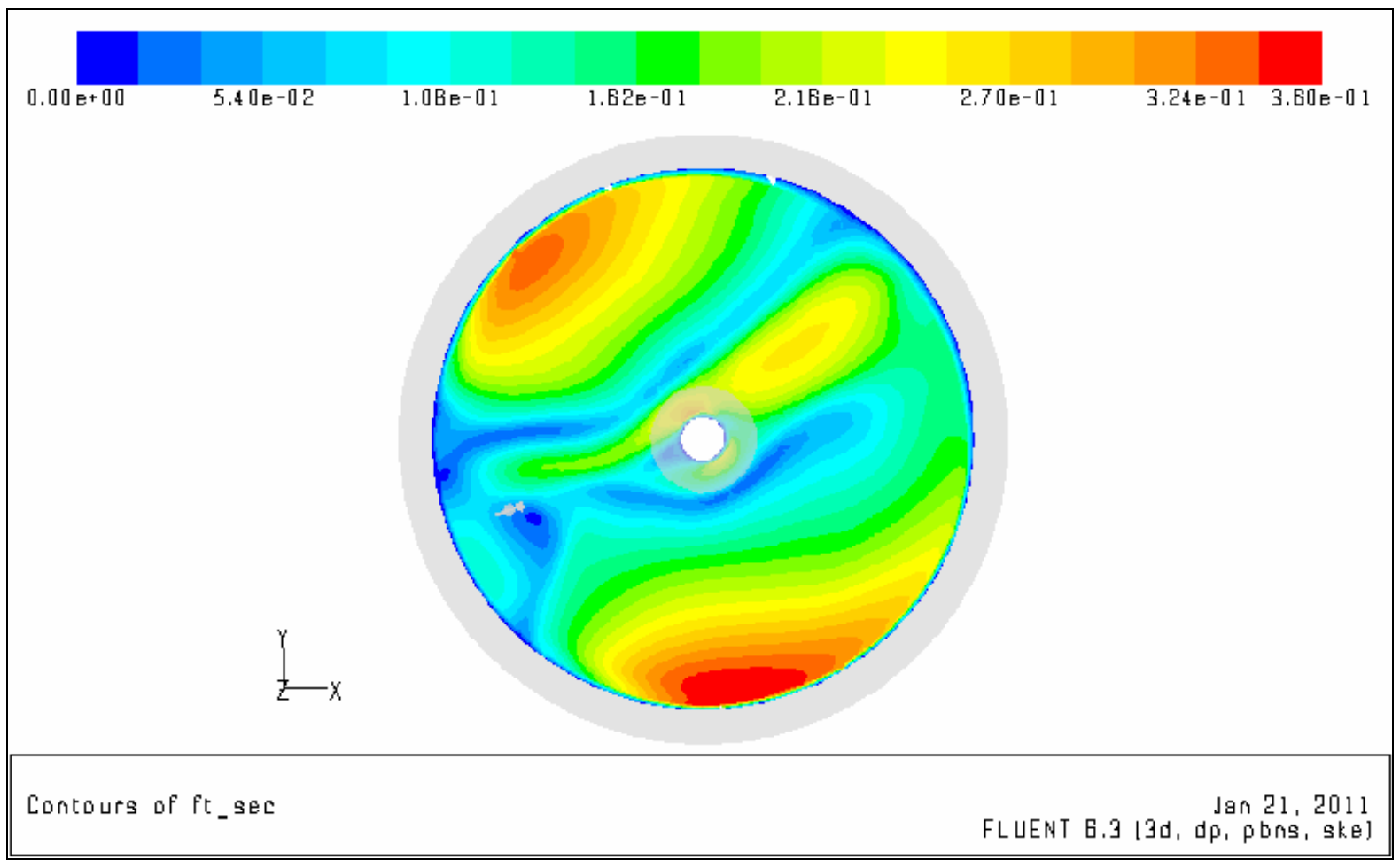

Figure 3-37: Velocities at the Sludge Layer for a Pilot Scale, Slip Plane Model, UoD = 0.58 $\mathrm{ft}^{2} /$ second (CFD Case 11a)

(CFD models by S. Lee)

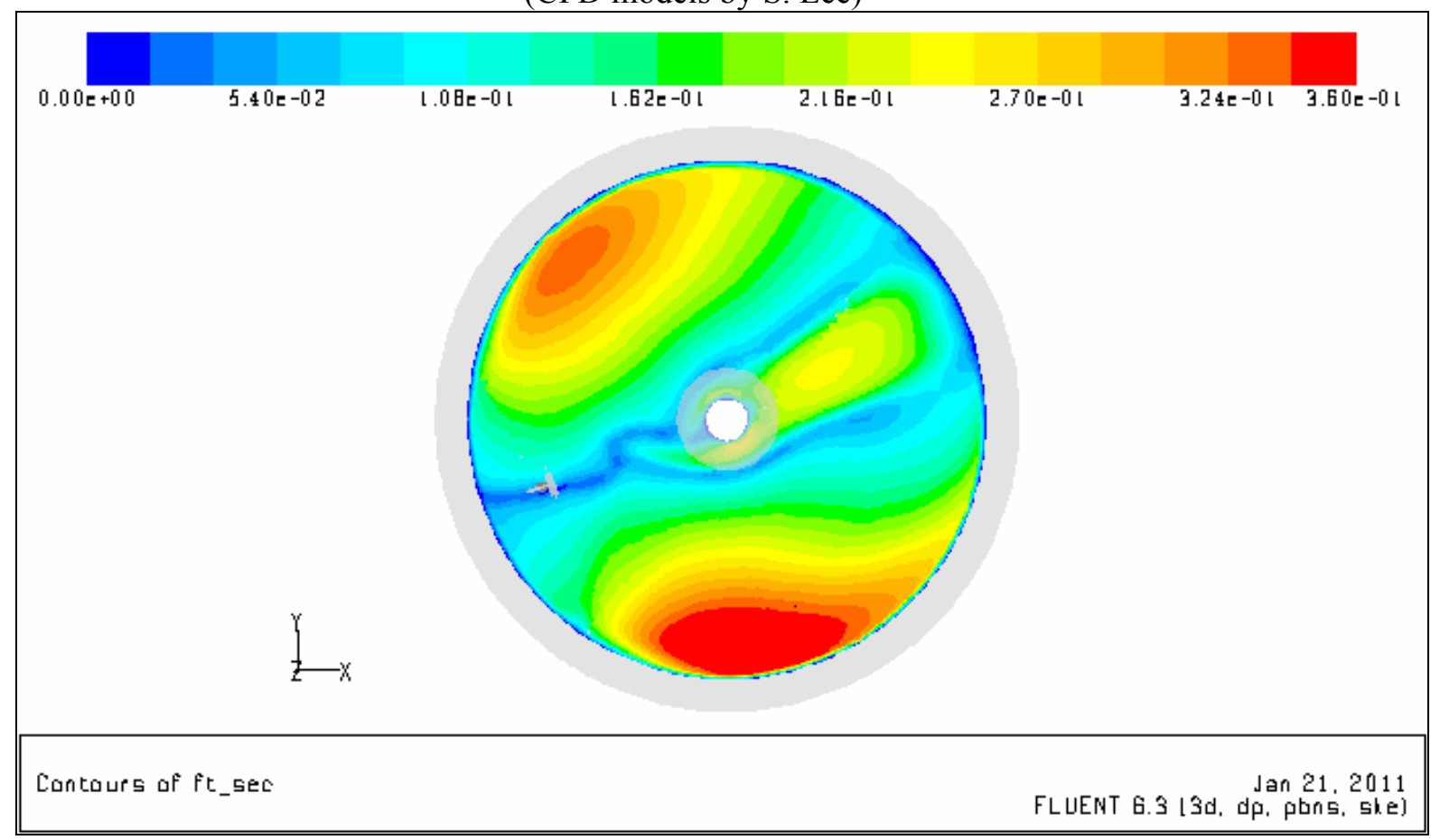

Figure 3-38: Velocities at the Sludge Layer Elevation for a Pilot Scale Blending Model, UoD $=0.58 \mathrm{ft}^{2} /$ second $($ CFD Case $11 \mathrm{~b})$ 


\subsubsection{Sludge Disturbance in a Full Scale Tank Without Coils}

Two different models were used to establish the $U o D$ design requirement for a tank without coils, which contained a center column. Both models provided results that were likely to disturb sludge, but the CFD results were used to extrapolate $U o D$ and the recommended blending time for that UoD.

The acceptance criterion is $0.268 \mathrm{ft} / \mathrm{second}$ (section 3.11.3) for the Case 13 full scale tank without coils (Figure 3-39). Linear scale-up at $U o D=0.58 \mathrm{ft}^{2} /$ second $\cdot 10.85=6.3 \mathrm{ft}^{2} /$ second, provided $0.420 \mathrm{ft} /$ second maximum velocity in the CFD model, which was well above the acceptance criterion and therefore unacceptable.

Another CFD case study was performed at a lower value of $U o D=5.1 \mathrm{ft}^{2} /$ second to address this problem. Case 20 (Figure 3-40) yielded a maximum velocity of $0.300 \mathrm{ft} / \mathrm{second}$, which was slightly above the required $0.268 \mathrm{ft} / \mathrm{second}$. Since there is only a small difference between 0.300 and 0.268 , a linear extrapolation is warranted. A linear fit of the two test results yielded $\mathrm{UoD}=-3.213 \cdot \mathrm{V}+0.93$

Solving for $U o D$ at $V=0.268, U o D=4.85 \mathrm{ft}^{2} /$ second.

Also of some interest, the same $U o D$ yielded a similar maximum velocity when the boundary conditions were changed in the CFD model. For one case, the fluid level in the tank was modeled down to the sludge layer and a slip plane was used at the sludge layer $(\tau=0$, Figure $3-40)$. For the other case, the liquid level was modeled down to the tank floor, and a wall plane was used as a boundary condition $(V=0)$. Similar maximum velocities were not noted for a tank with coils installed (see section 3.13)

\subsubsection{Blending Time in a Full Scale Tank Without Coils for Similar Fluids}

To find the blending time, a correction factor (3.35) is required from section 3.3.3, and a blend time is required from the CFD report ( 82.7 minutes at $U o D=5.10 \mathrm{ft}^{2} /$ second). Then, the blending time for a tank without coils at $U o D=4.85 \mathrm{ft}^{2} /$ second is

\section{$(5.1 / 4.85) \cdot 3.35 \cdot 82.7 / 60=4.86$ hours}

At $U o D=3.58 \mathrm{ft}^{2} /$ second, linear extrapolation provides a conservative prediction for the blending time for scale-down, such that $4.86 \cdot 4.85 / 3.58=6.58$ hours. The approximation is conservative, since scale-up was shown to exceed the expected velocities that would be obtained from a linear scale-up. 
SRNL-STI-2011-00151

5/26/11 Revision 0

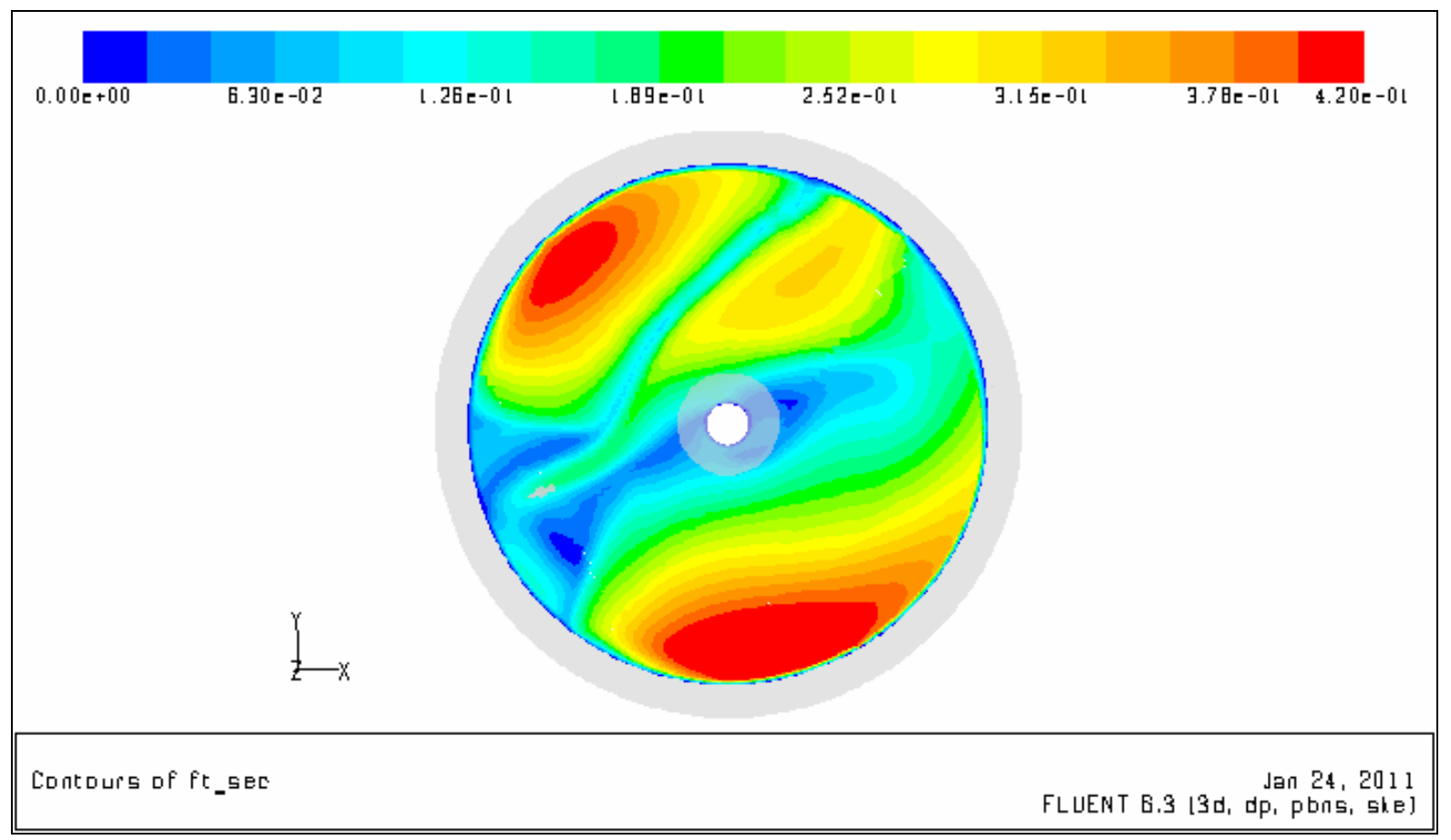

Figure 3-39: Velocities for a Full Scale Tank Without Coils, UoD $=6.3 \mathrm{ft}^{2} /$ second (CFD Case 13)

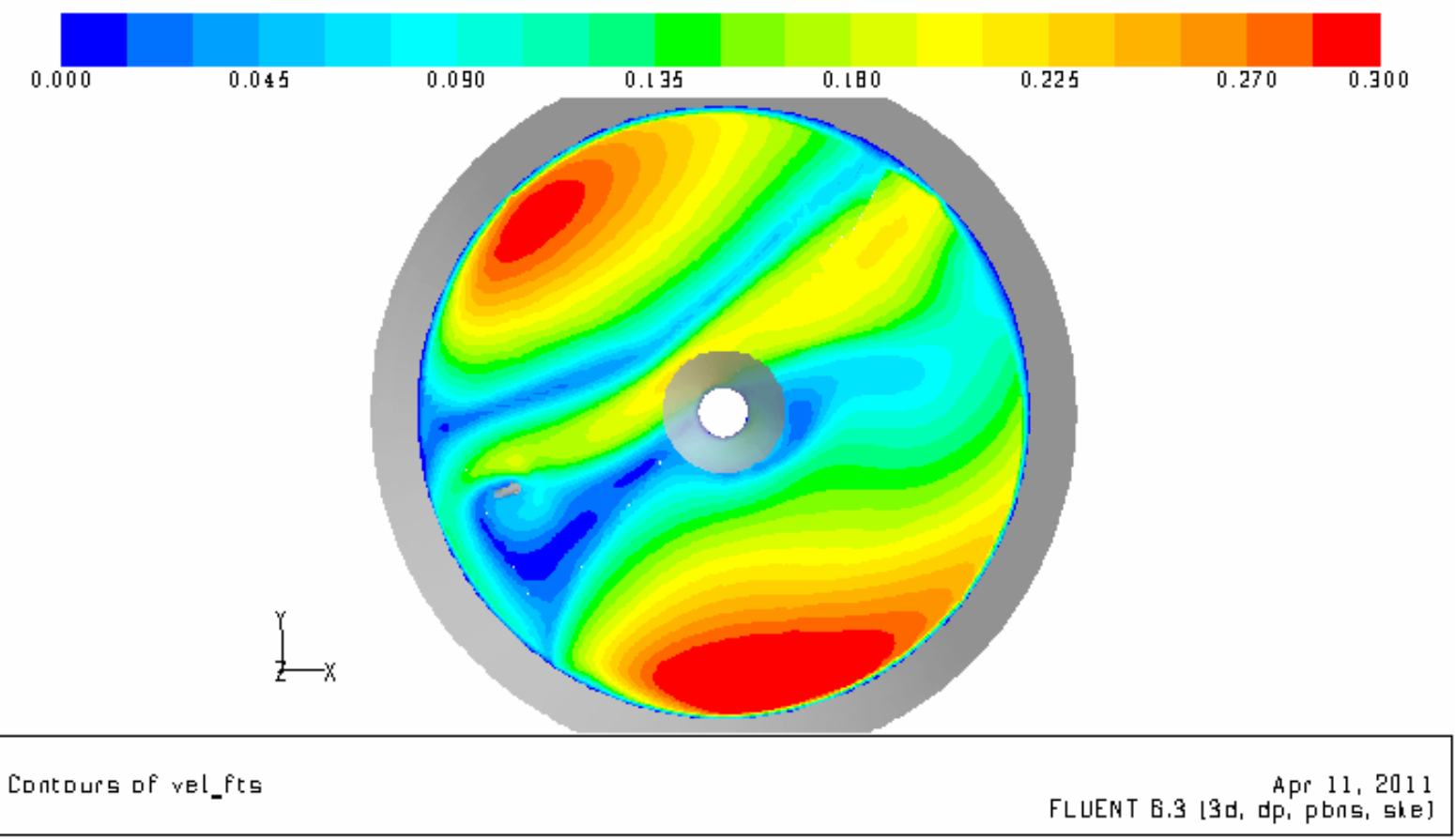

Figure 3-40: Velocities for a Full Scale Tank Without Coils, UoD $=5.1 \mathrm{ft}^{2} /$ second (CFD Case 20a, Slip Plane Sludge Model) 


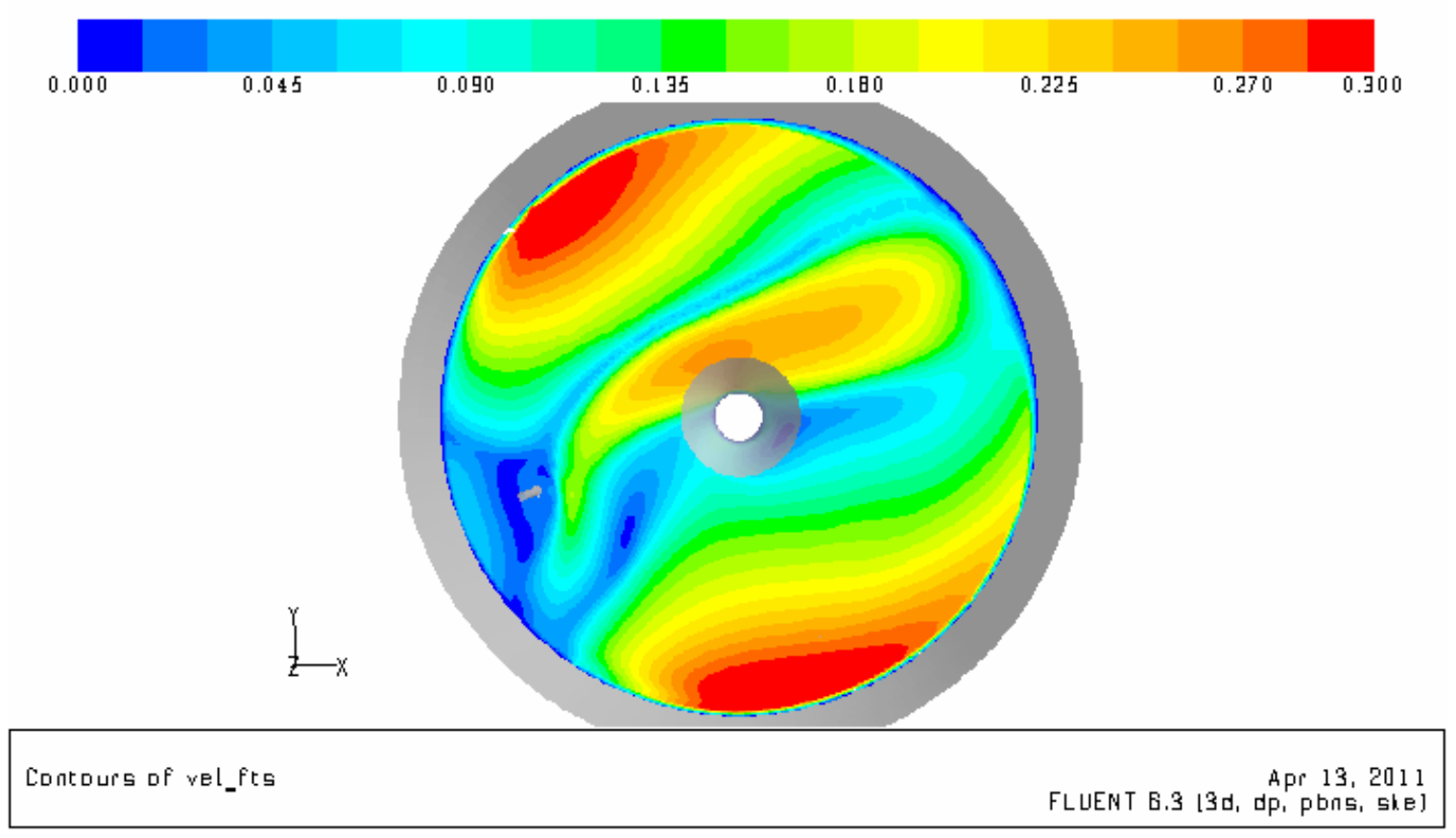

Figure 3-41: Velocities for a Full Scale Tank Without Coils, UoD $=5.1 \mathrm{ft}^{2} /$ second (CFD Case 20, Wall Plane Blending Model)

\subsection{Sludge Disturbance in a Tank With Cooling Coils}

The same techniques are used for a tank with or without coils. CFD models and velocity correction factors are used to determine full scale acceptance criteria for a tank with coils installed. Experimental tests were again performed by first incrementally increasing the $U o D$ to obtain a recommended $U o D$, and then performing several tests to validate that recommendation. The SRNL recommendation is $U o D=0.70 \mathrm{ft}^{2} /$ second for the case of a pilot scale tank with cooling coils and $15^{\circ}$ upward pointing nozzle installed, using $\mathrm{NaNO}_{2}$ supernate simulant and SB6 sludge simulant.

\subsubsection{Velocity Acceptance Criterion for a Tank With Coils}

Test results for a tank containing cooling coils and $\mathrm{NaNO}_{2}$ are shown in Figure 3-42, where UoD $=0.70 \mathrm{ft}^{2} /$ second is the value required for minimal sludge disturbance. Tests were performed in incremental steps of $0.17 \mathrm{ft}^{2} /$ second to determine this value. Some higher velocities, as high as $0.453 \mathrm{ft} / \mathrm{second}$, are noted behind the column away from the pump, but the acceptance criterion is $0.34 \mathrm{ft} /$ second along the wall, where the most significant sludge disturbance occurred. The swirling action of the jet flow down the tank wall in this zone may affect mixing characteristics of the sludge. The nominal velocity is then $0.34 \mathrm{ft} / \mathrm{second}$, which is close to the nominal value determined for a tank without coils as expected. Applying the 1.267 velocity correction factor, $V$ $=0.268 \mathrm{ft} /$ second. Application of the velocity correction factor is appropriate, since a realistic variation in velocity was experimentally determined (section 3.1.3.3). 


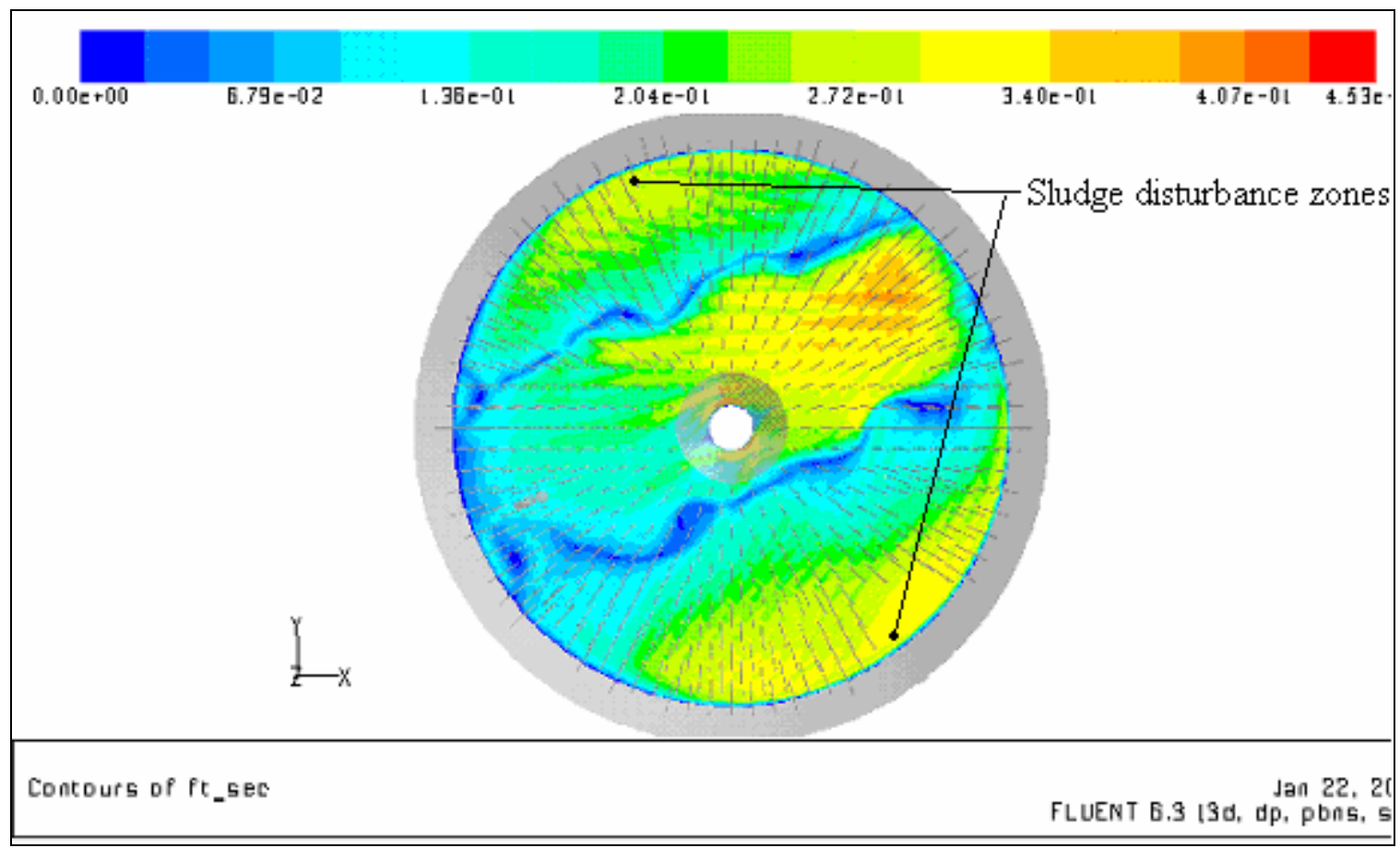

Figure 3-42: Velocities at the Sludge Layer for the Pilot Scale, Slip Plane Model, UoD = 0.70 $\mathrm{ft}^{2} /$ second (CFD Case 12b)

\subsubsection{Sludge Disturbance in a Full Scale Tank With Coils}

Although the cooling coil cases scale-up in a nearly linear fashion as seen by comparing Figure 3-42 to Figure 3-43, the velocity correction factor demonstrates that the $U o D$ needs to be reduced. To correct this problem, a CFD model was performed at $U o D=6.1 \mathrm{ft}^{2} /$ second, which is shown in both Figure 3-44 and Figure 3-45. Note again, that the two different CFD model techniques present nearly the same results for velocities on the sludge plane, where one model considered a solid plane at the sludge layer, and the other model assumed a solid plane below the sludge layer at the wall, and the boundary conditions were changed accordingly. However, the slip plane sludge layer provides a higher, 0.268 velocity along the tank wall, and the $6.1 \mathrm{ft}^{2} /$ second model is shown to be the limiting design case to prevent sludge disturbance in a tank with cooling coils and conservative sludge. The sludge disturbance on the other side of the column away from the pump is comparable, when Figure 3-42 is compared to Figure 3-45. The recommended maximum $U o D=6.1 \mathrm{ft}^{2} /$ second.

\subsubsection{Blending Time in a Full Scale Tank With Coils for Similar Fluids}

From the CFD report, the blending time equals 159.2 minutes, and from section 3.3.3 the correction factor equals 3.35. Then the recommended blending time at $U o D=6.1 \mathrm{ft}^{2} /$ second equals $3.35 \cdot 159.2$ minutes $=8.89$ hours. At $U o D=5.1 \mathrm{ft}^{2} /$ second, the maximum blending time equals 8.89 hours $\cdot 6.1 / 5.1=10.63$ hours.

\subsection{Summary of Blending Times and CFD Results}

Note that all of the recommended maximum blending times incorporate a 3.35 correction factor, which implies that the average value of the blending time may be lowered by nearly $1 / 3.35=$ $70.1 \%$ from the maximum value. Note also, that these average blending times are near the CFD model predictions as discussed in the CFD report. 
SRNL-STI-2011-00151

5/26/11 Revision 0

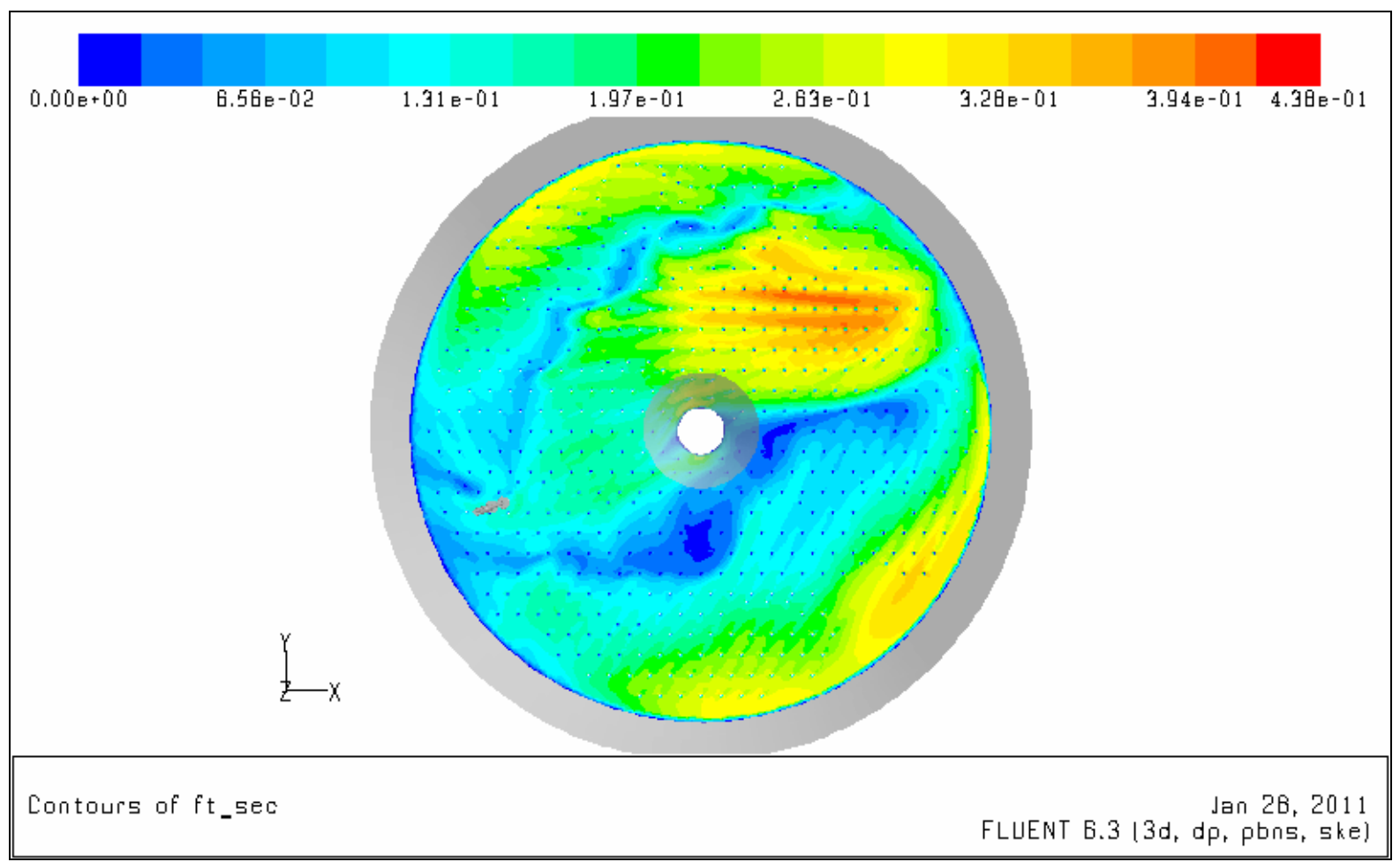

Figure 3-43: Velocities at the Sludge Layer for the Full Scale, Slip Plane Model, UoD = 7.3 $\mathrm{ft}^{2} /$ second (CFD Case 14)

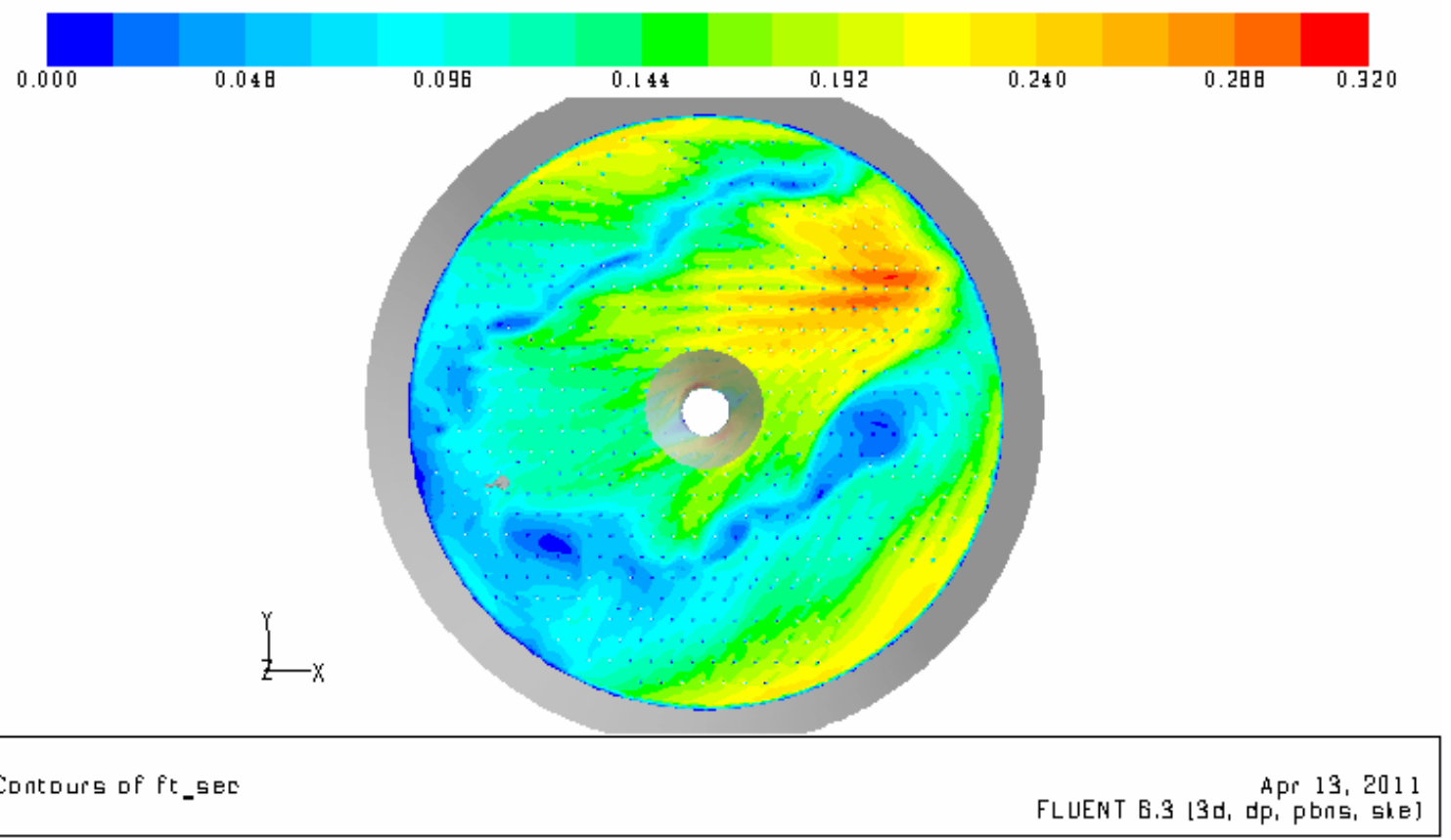

Figure 3-44: Velocities at the Sludge Layer for the Full Scale, Blending Model, UoD $=6.1$ $\mathrm{ft}^{2} /$ second (CFD Case 19) 
SRNL-STI-2011-00151

5/26/11 Revision 0

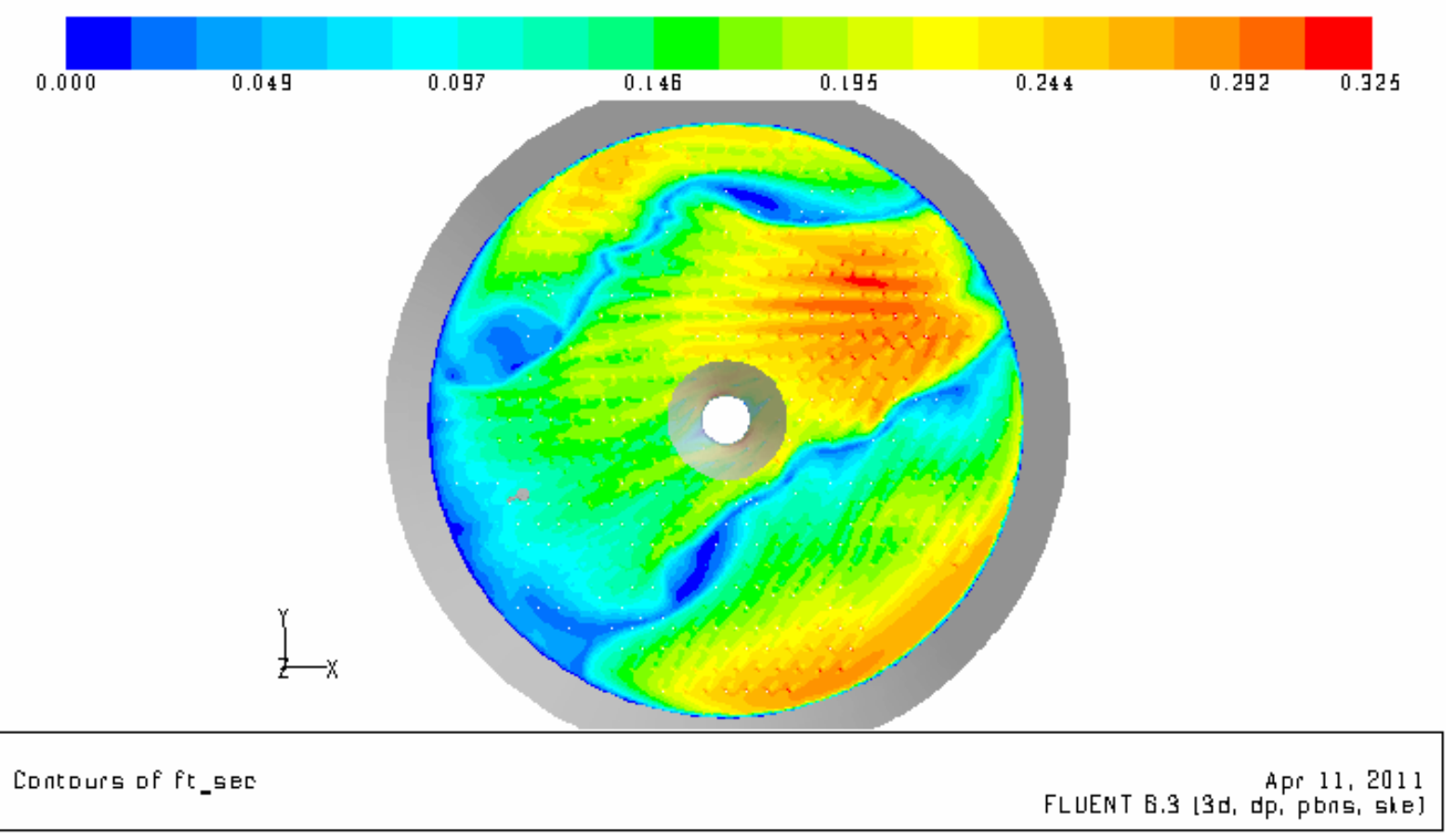

Figure 3-45: Velocities at the Sludge Layer for the Full Scale, Slip Plane Model, UoD =6.1 $\mathrm{ft}^{2} /$ second (CFD Case 19a)

\subsection{Material Property Effects on Sludge Disturbance During Blending}

For high yield stress sludge, or sludge simulants theory is available to describe sludge disturbance, but data is unavailable in the literature to understand sludge disturbance for low yield stress Bingham plastic fluids. Phase 2 Research performed some limited investigation, but results provided insight into the sludge disturbance process at low velocities.

Data for low yield stress sludge simulant obtained during this research is shown in Figure 3-46, where points $\mathrm{A}$ and $\mathrm{B}$ present bench scale material properties for sludge tests performed with either $\mathrm{NaNO}_{2}$ or water. Note that the yield stresses vary by a factor of nearly two. Pilot scale tests without coils installed showed that the $U o D$ required to disturb sludge for these two different yield stress sludge simulants was the same. In other words, yield stress was not a predominant factor in sludge disturbance during these tests. This conclusion is decidedly different than classic sludge mixing calculations, where sludge disturbance is directly related to yield stress (section 3.1.2). In short, these tests have shown that sludge disturbance at low values of $U o D$ for low yield stress sludge is a function of velocity, rather than yield stress. Further research is recommended. 


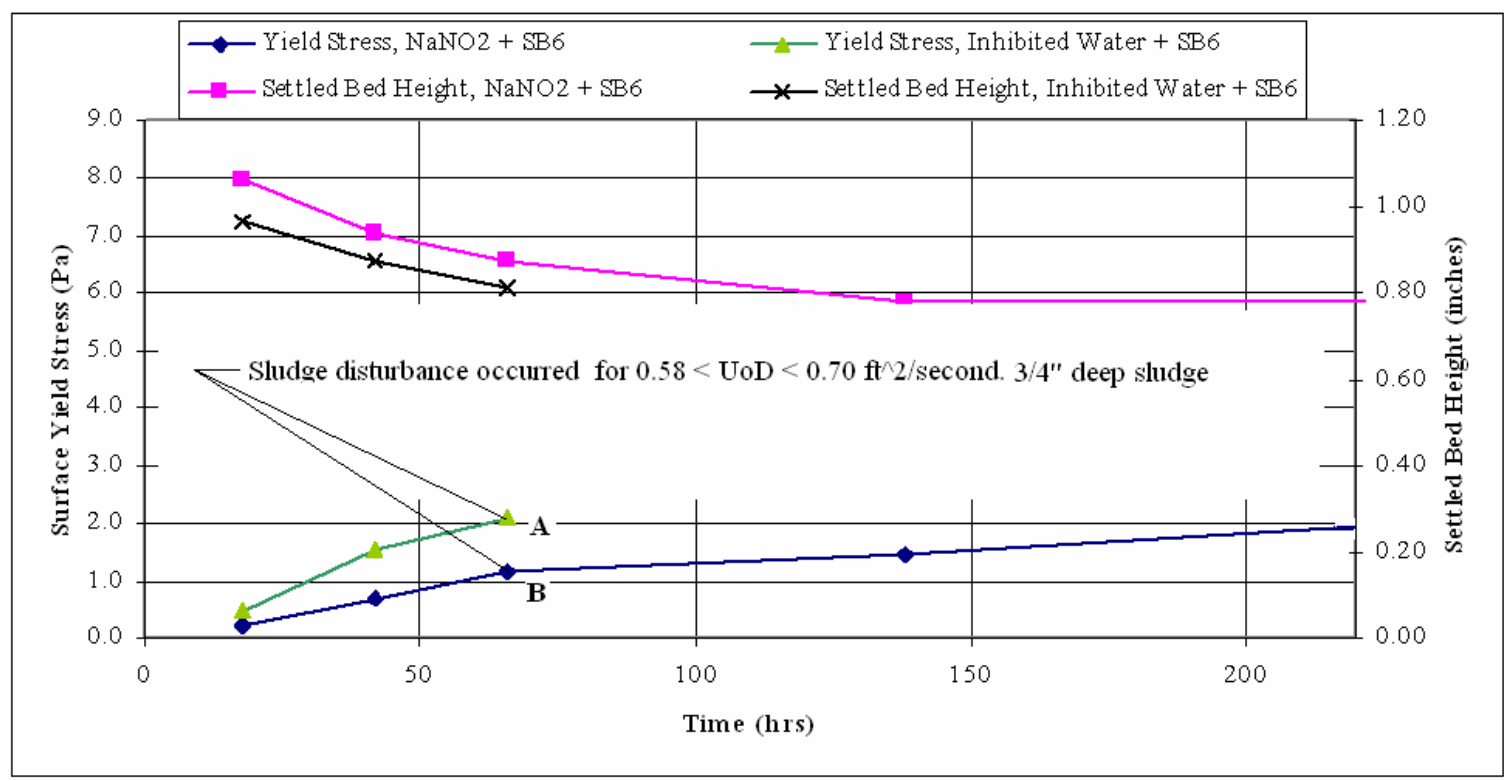

Figure 3-46: Material Effects on Sludge Disturbance

\subsection{Pilot Scale Transfer Pump Tests}

Sludge entrainment tests were also performed for two different transfer pump models (section 2.1.4), operating at $1.1 \mathrm{gpm}$, which was scaled from an SRR specified $130 \mathrm{gpm}$ upper limit for facility transfer flow rates.

1. A pump was modeled without a bottom plate, as a straight tube with an orifice plate on the bottom of the tube.

2. A pump was modeled with a bottom plate to divert flow through the suction screen. The suction screen was not modeled. The experimental pump with a bottom plate was scaled down from a 4" vertical opening where a screen would typically be installed on a full scale transfer pump.

In all transfer tests, the pumps were lowered to different elevations above the pilot scale tank floors to determine the elevation at which sludge disturbance occurred.

The acceptance criterion can be selected as either no sludge entrainment (disturbance) to prevent any possible hydrogen release, or the SWPF WAC limit can be used. The two conditions result in very different acceptance criteria, and no sludge entrainment (disturbance) was the criterion was selected, since a limited number of tests were planned, and sufficient data to scale up the sludge entrainment results were not obtained. Consequently, recommendations are conservative, and the magnitude of that conservatism was not quantified. As sludge is transferred through the suction pipe, the concentrations are measured, and the amount of sludge transferred at pilot scale could be estimated from flow rates and concentrations. However, a scale-up concern still remains. What is the velocity required to disturb sludge sufficiently to release sludge into suspension? For blending tests, a visual observation was used and a velocity was selected based on this observation and supporting calculations $(0.268 \mathrm{ft} / \mathrm{second})$, but that visual observation could not be quantified for transfer tests. During transfer testing, sludge simulant was observed in a transparent section of the transfer piping during transfers. However, an acceptable amount of sludge observed in the pipe was not quantified for scale-up. That is, sufficient tests to scale-up the test data were not performed. Also, sludge entrainment at the transfer pump suction could not be observed, due to distance of the pump suction from the tank wall. Velocities to disturb sludge $(0.022 \mathrm{ft} / \mathrm{second}$, section 3.15.3) are an order of magnitude less than recommendations to disturb sludge during 
blending pump operation. Why is there such a significant difference? Determination of the velocity required for no sludge disturbance was not fully investigated for blending, but the velocity required for zero sludge entrainment due during transfers is much lower than the 0.268 $\mathrm{ft} /$ second blending value. That is, the acceptance criterion is decidedly different for blending versus transfers. Not only were the acceptance criteria different, but the behavior of the sludge was different. Specifically, the concentration in the transfer pipe spiked and then dropped. Consequently, a significantly higher value is perhaps acceptable for transfers, but the lower conservative value of $0.022 \mathrm{ft} / \mathrm{second}$ value was conservatively selected to minimize testing, and this value was based on no disturbance ( $0 \%$ entrainment) during tests and supporting calculations as follows.

\subsubsection{Sludge Transfer for a Pump Without a Bottom Plate}

For a transfer pump without a bottom plate, Figure 3-47 provides all test results for a specific set of tests where the pump was gradually lowered. When the pump was initially turned on at a 23$5 / 16$ " elevation, there was spike in concentration due to settled solids in the transfer pipe. Once the piping was cleared, an equilibrium condition was reached for tests at pump elevations between 5-5/16"down to 2-15/16". When the pump was further lowered to a 2-3/8" sludge clearance, sludge minor, incipient sludge disturbance was observed. Since no sludge disturbance is the acceptance criterion, no sludge entrainment at full-scale is expected to occur when the sludge clearance $>25.78 "=2-3 / 8 " \cdot 10.85$. Additional CFD models at a 2-3/8" clearance are expected to provide a lower velocity to be used as an acceptance criterion. The same test results are shown on a different scale in Figure 3-48 to better clarify the findings.

More sludge disturbance was measured when the pump was lowered to $9 / 16$ ". Sludge disturbance at the pump could not be observed, since the transfer pump was located away from the tank wall, but some sludge simulant was observed in the transfer pipe during this transfer. When the pump height was located at a 9/16" sludge clearance at pilot scale, the sludge concentration was below the SWPF WAC. A CFD model was performed for this case (Figure 3-49), and the maximum velocity at the sludge surface equaled $0.142 \mathrm{ft} / \mathrm{second}$. The corrected velocity equaled 0.112 $\mathrm{ft} /$ second $(0.142 / 1.267=0.112$, section 3.1.3.3).

The design for a pump without a bottom plate was not further evaluated, since significant improvements can be obtained when a plate is mounted below the pump suction to deflect the flow direction away from the sludge, and minimize sludge disturbance. A pump with a bottom plate was selected by SRR for design based on these preliminary findings. 


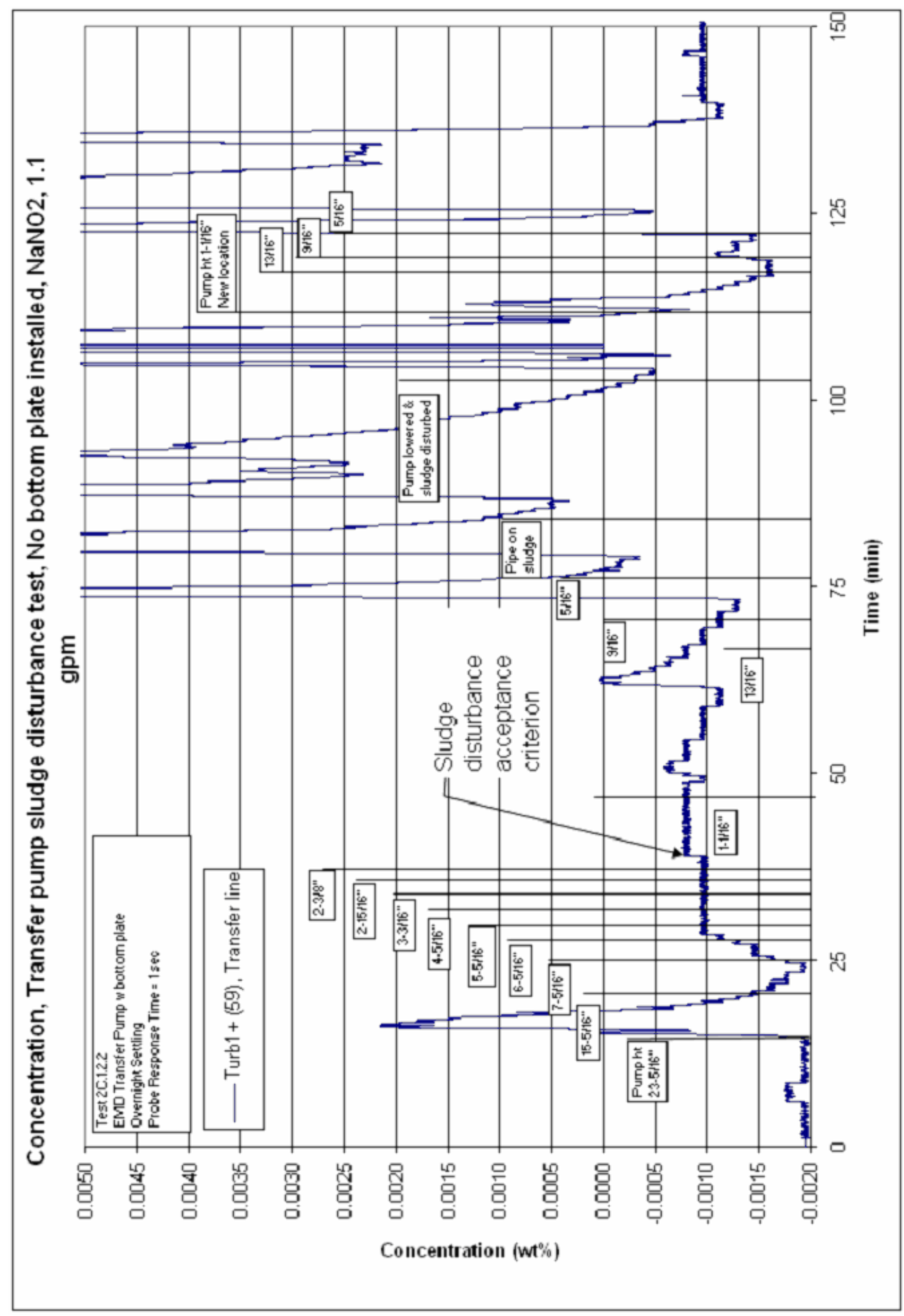

Figure 3-47: Initial Sludge Disturbance for a Transfer Pump Without a Bottom Plate 
SRNL-STI-2011-00151

5/26/11 Revision 0

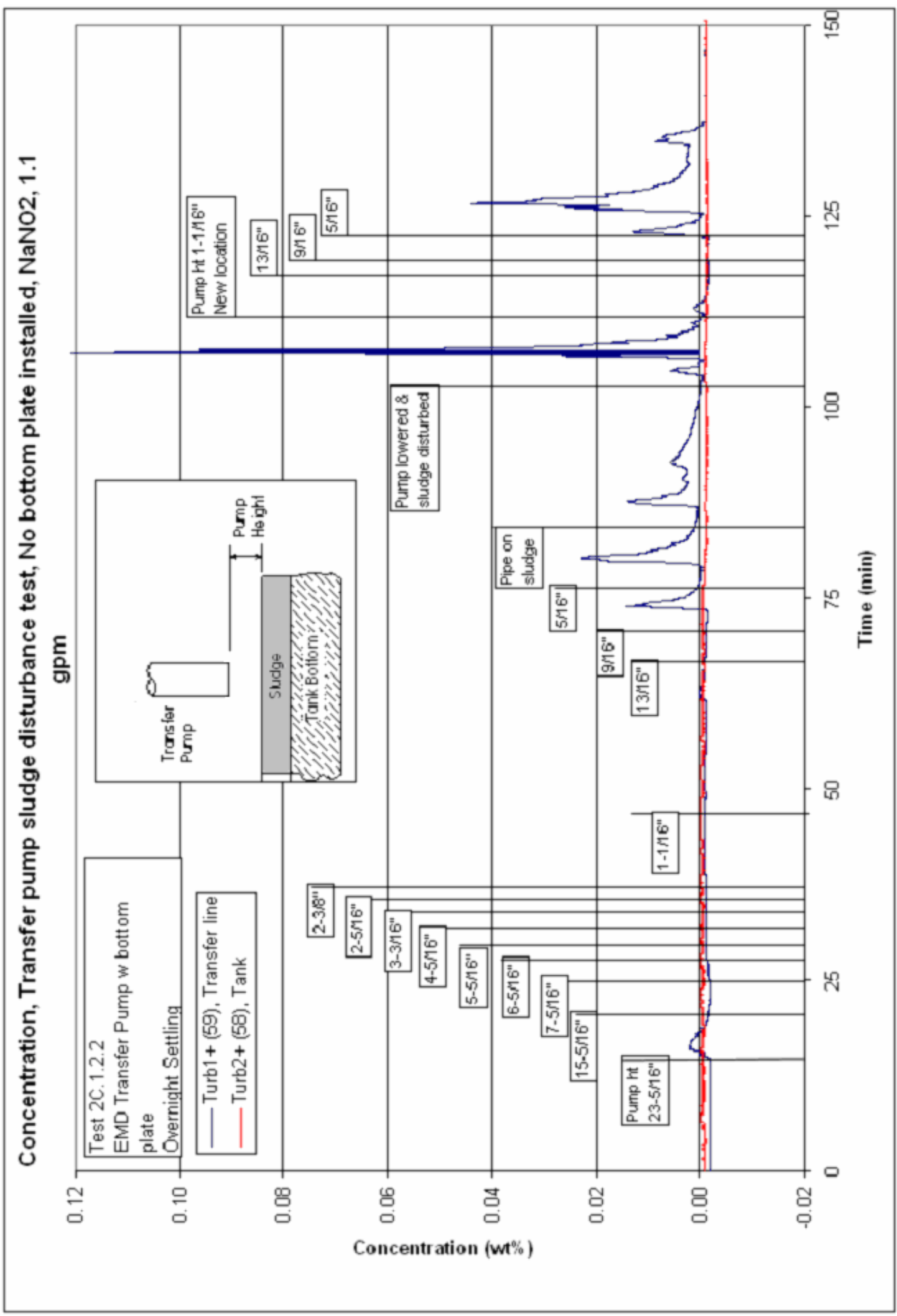

Figure 3-48: Transfer Pump Sludge Disturbance Test Without a Bottom Plate Installed 


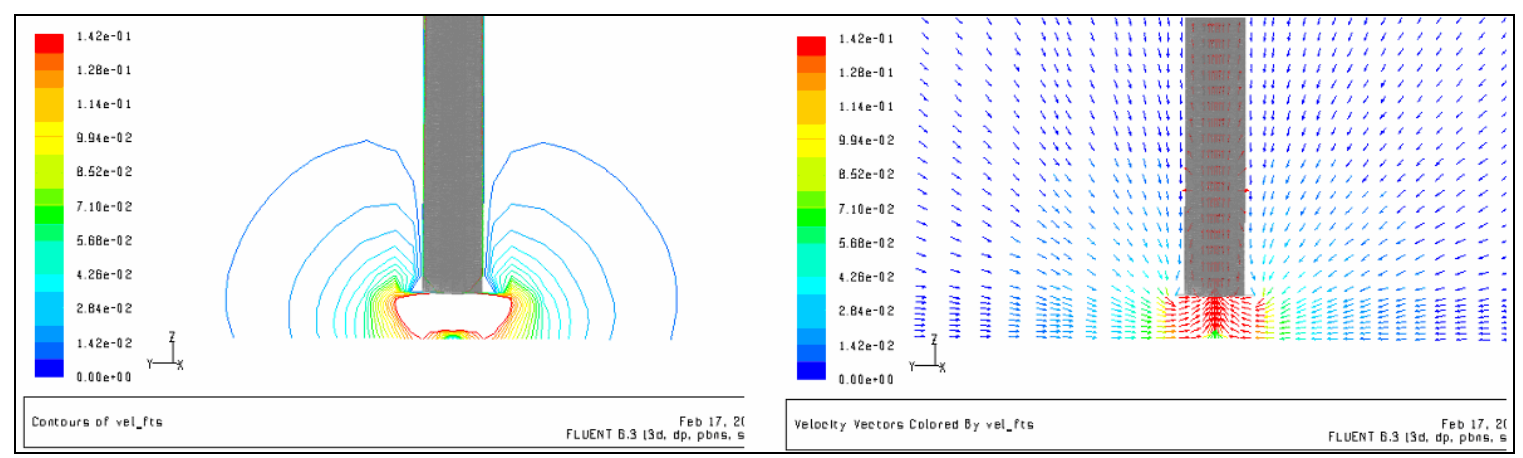

Figure 3-49: Velocities When the Transfer Pump is 9/16" Above the Sludge Layer, No Bottom Plate Installed, $\mathrm{NaNO}_{2}, 1.1 \mathrm{gpm}$, Elevation (CFD Case 15)

\subsubsection{Pilot Scale Sludge Transfer Tests for a Pump With a Bottom Plate Installed}

For a pilot scale transfer pump with a scaled down 4" screen and a flat, bottom plate attached, the pump can be moved to within $3 / 8$ inch of the sludge without entraining the sludge. Several pilot scale tests are discussed below to support this conclusion.

First, a series of tests were performed at different pump clearances to the sludge layer to determine a recommended pump height. Shown in Figure 3-50 these tests show that an increase in concentration occurred when the pump was lowered to $1 / 4$ inch, or less, and above that level no sludge was entrained. Note that the sludge concentrations are well below the SWPF WAC at a $1 / 4$ inch pump level. A $3 / 8$ " clearance is endorsed to ensure that no sludge is disturbed. The Excel ${ }^{\circledR}$ conversion equation results in negative concentrations at these low values (Figure 2-13), since the concentration is not set equal to zero when the turbidity equals zero. However, the relative concentration change is accurate.

Secondly, another set of tests were performed to better describe sludge disturbance when the pump was installed on the surface sludge or located at a $1 / 4$ inch clearance to the sludge. These results are shown in Figure 3-51, where installing the pump on the surface entrains the sludge to near, but not over, the SWPF WAC limit of 0.09 weight percent. At the $1 / 4$ inch clearance, sludge disturbance concentration was well within the SWPF WAC. However, additional replicate data are needed to statistically investigate and quantify scale-up.

Additional tests were performed at a sludge clearance of $3 / 8$ inch, and sludge was not entrained, as shown in Figure 3-52. CFD modeling was then performed to investigate sludge entrainment at full scale. 


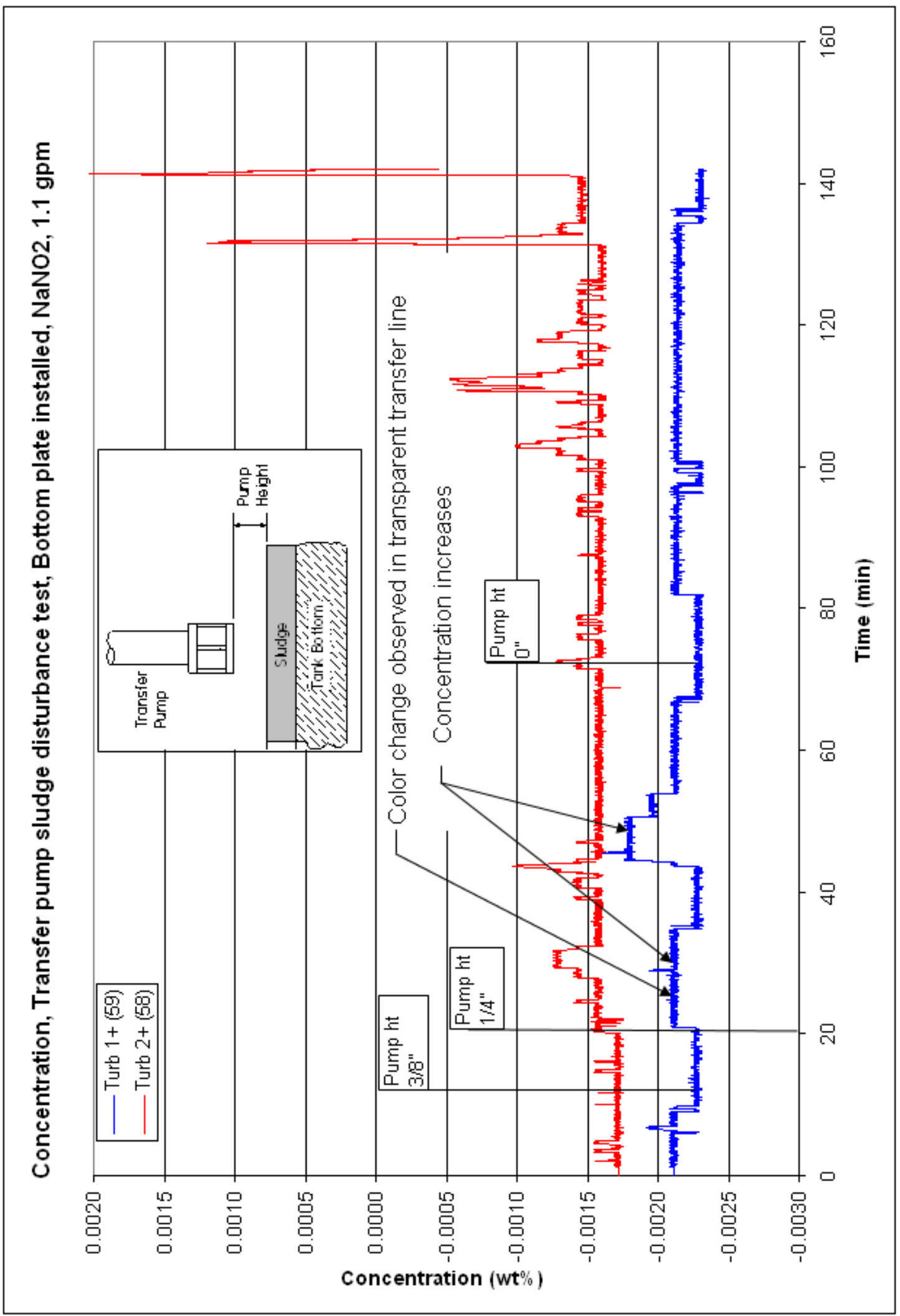

Figure 3-50: Variable Height Transfer Pump Sludge Disturbance Tests With a Bottom Plate Installed, Acceptance Criterion 


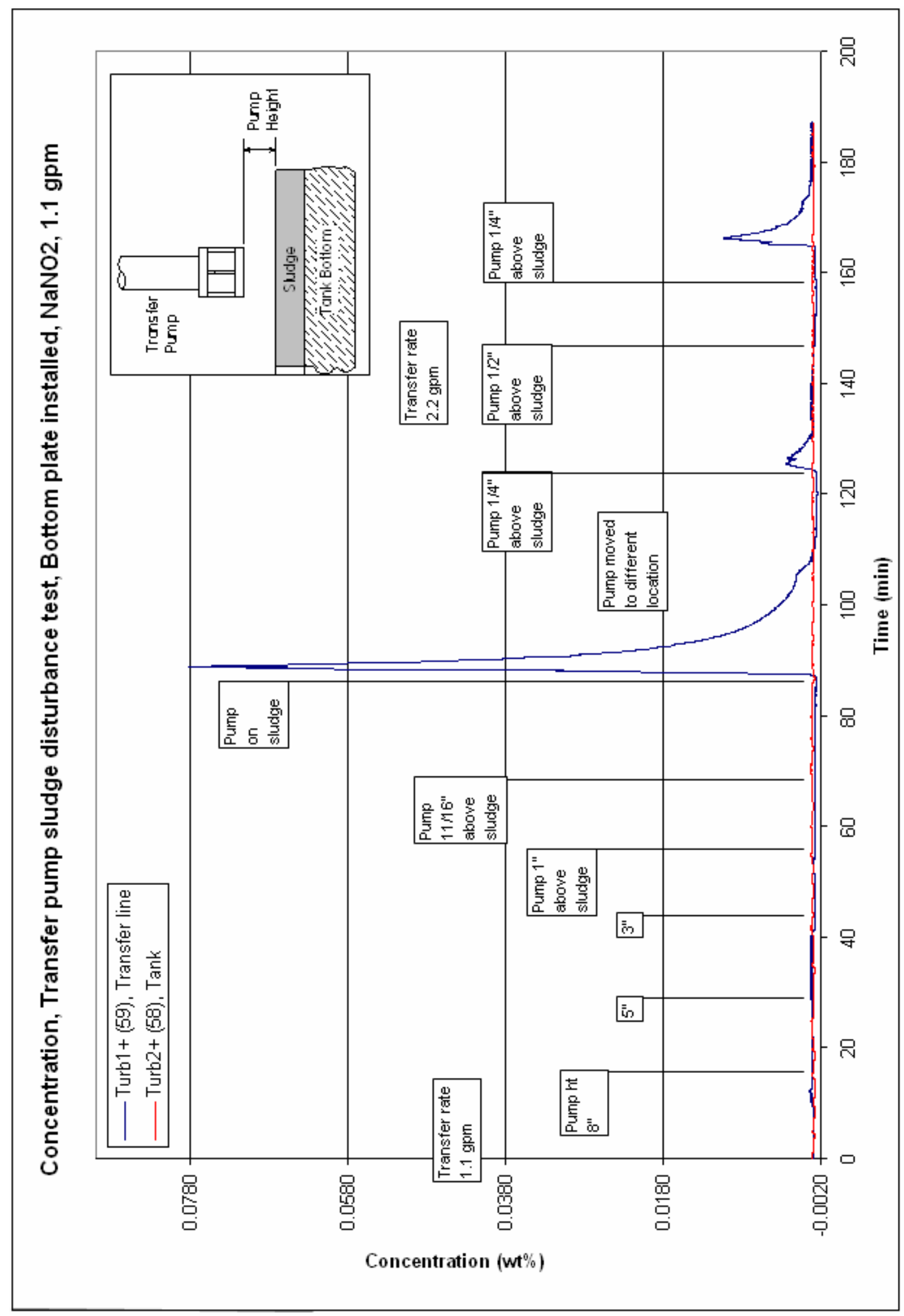

Figure 3-51: Sludge Disturbance When a Pump with a Bottom Plate is Installed Near or On the Sludge Surface 

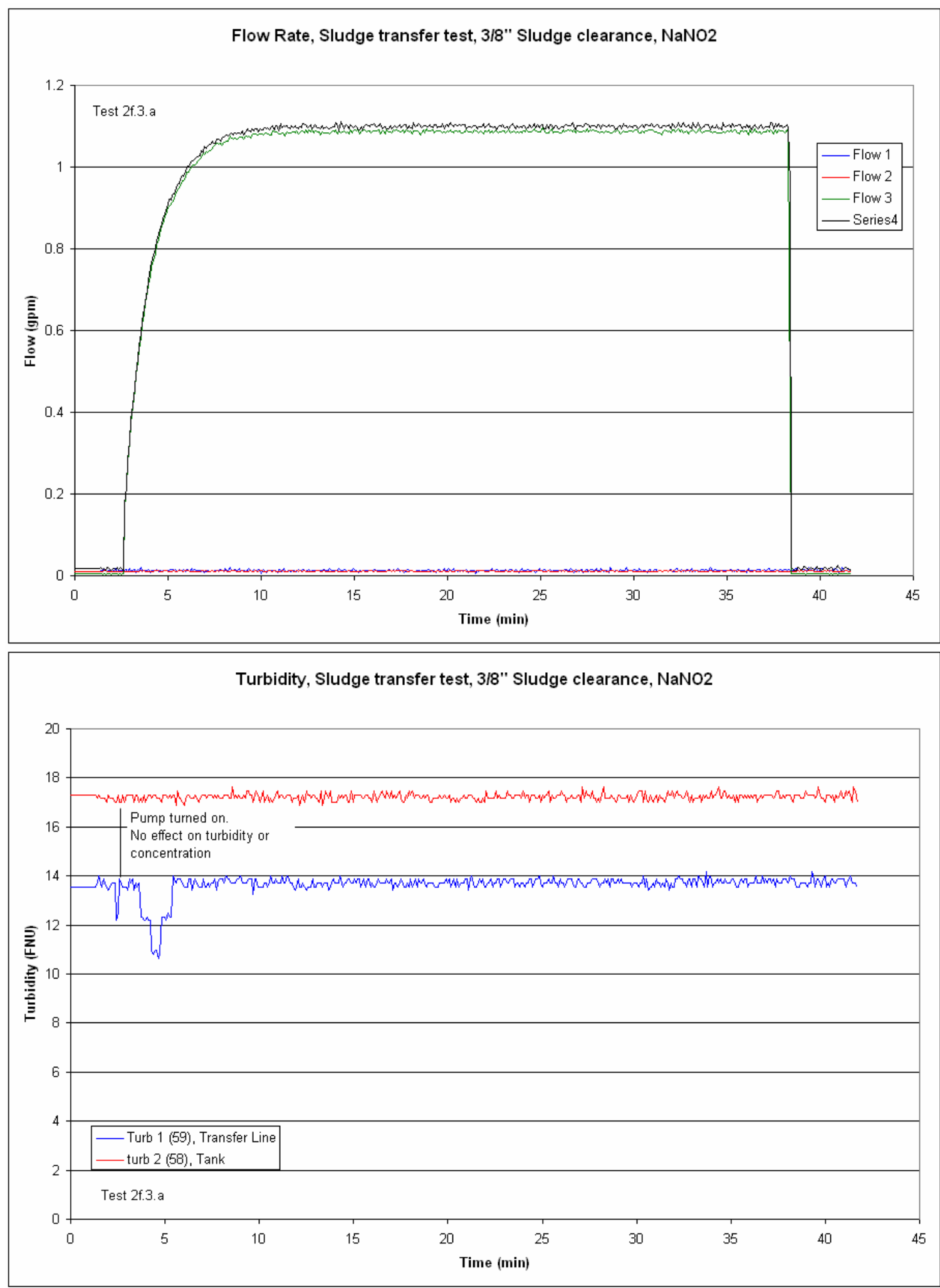

Figure 3-52: Transfer Pump Tests at a 3/8" Sludge Clearance for a Pump with a Bottom Plate, $\mathrm{NaNO}_{2}$ 


\subsubsection{CFD Models for a Transfer Pump With a Bottom Plate Installed}

CFD models for the case of no sludge entrainment are shown in Figure 3-53. The maximum velocity on the sludge plane for no sludge entrainment is then $0.028 \mathrm{ft} / \mathrm{second}$. The corrected velocity equals $0.022 \mathrm{ft} /$ second $(.028 / 1.267=0.022 \mathrm{ft} /$ second, section 3.1.3.1), and this value is endorsed by SRNL. Note again (section 3.15), that this value is an order of magnitude less than the acceptance criteria for blending sludge disturbance.

The lower predicted velocity may be influenced by different factors. The sludge entrainment mechanism may be different for a transfer pump than a blending pump. For a blending pump, the flow moves across an open surface, while for the transfer pump the flow is confined to the immediate area surrounding the pump. Additionally, the performed tests may have had some fluid transient anomalies. For example, a backflow problem was observed by a cloud of sludge near the transfer pump when the first tests were performed. Procedures were modified to correct this problem to ensure that backflow through the piping did not occur when the transfer pump was started, and sludge clouds were not observed in subsequent tests. However, there may have been slight, unobserved backflow, or shock waves due to valve opening that occurred at test start-up, which may have suspended some solids. Even so, similar transients would be expected during a full scale transfer interruption during operations, when the pump would be started and re-started. Transfers are suspended occasionally during Tank Farm operations. Then start-up at pilot scale and re-start at full scale are similar with respect to start-up and shut-down, although transient effects would be lessened at full scale. Transient effects would be reduced at full scale, since frictional and wave speed effects are both reduced in larger diameter pipes. Consequently, pilot scale transients and full scale transients would be similar, and CFD models are comparable at either scale. The velocity required to suspend sludge at the transfer pump is between 0.022 $\mathrm{ft} / \mathrm{second}$ and $0.34 \mathrm{ft} / \mathrm{second}$. In short, inadequate data is available to fully address all technical issues with respect to fluid mechanics at the transfer pump suction inlet, but the recommended velocity offers a conservative velocity estimate for CFD scale-up. This conclusion provides appropriate scale-up estimates with respect to sludge suspension. Additional tests can be performed to further evaluate this issue, as required.

Using the $0.022 \mathrm{ft} /$ second velocity and CFD models, transfer pumps designed with a flat plate at the bottom of the inlet screen may be installed for the following conditions.

- CFD Case 17b: A 9.5 inch pump height above a settled sludge layer for a 2" screen is recommended, since the CFD models provided $0.021 \mathrm{ft} / \mathrm{second}$, which is less than $0.022 \mathrm{ft} / \mathrm{second}$ acceptance criterion. A 2" screen can be placed somewhat lower, but a CFD model was not performed to evaluate lower sludge clearances.

- CFD Case 17c: A 5.43 inch pump height above a settled sludge layer for a 4" screen is not recommended, since the CFD models provided $0.026 \mathrm{ft} / \mathrm{second}$, which is greater than $0.022 \mathrm{ft} / \mathrm{second}$. The pump height needs to be increased for this case.

- CFD Case 17a: A 5.43 inch pump height above a settled sludge layer for a 6" screen is recommended, since the CFD models provided $0.021 \mathrm{ft} / \mathrm{second}$, which is less than $0.022 \mathrm{ft} /$ second. 


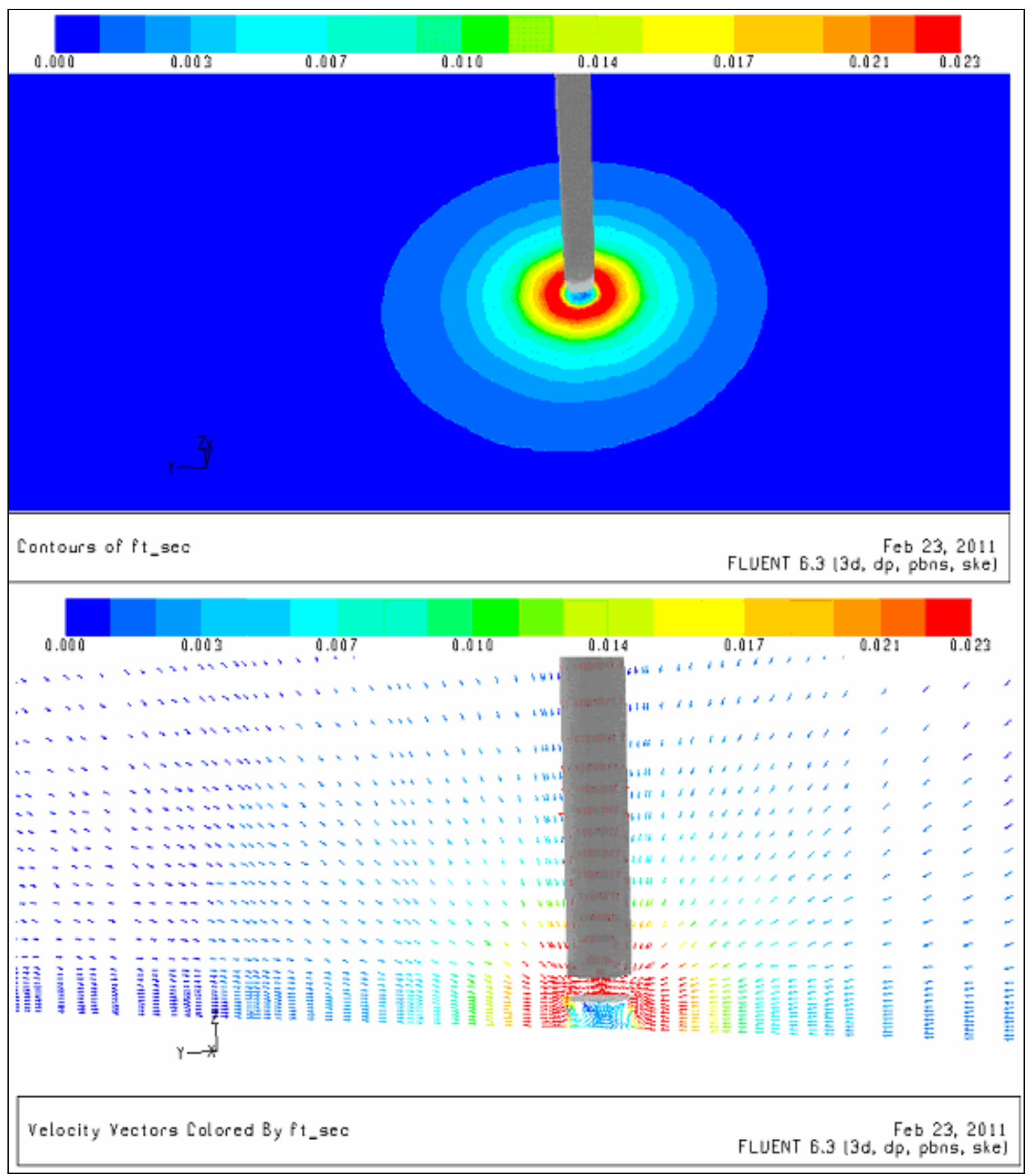

Figure 3-53: Sludge Disturbance Tests when the Transfer Pump is 3/8" Above the Sludge Layer, $\mathrm{NaNO}_{2}, 1.1 \mathrm{gpm}$ (CFD Case 16a, $0.028 \mathrm{ft} /$ second Maximum Velocity at the Surface)

(S. Lee [16]) 
SRNL-STI-2011-00151

5/26/11 Revision 0

\subsection{Conclusions and Recommendations}

As a result of testing, major innovative, technological advances have been achieved in the areas of sludge mixing and salt solution blending in liquid radioactive waste storage tanks. Based on these discoveries, safe and effective design recommendations were determined for blending and transfer pump design, installation, and operations.

For blending of similar salt solutions, the controlling factor, or design parameter, for blending is expressed as $U_{0} D$ (feet ${ }^{2} /$ second), where $U_{0}$ is the discharge velocity of blending pump nozzles, and $D$ is the inside diameter of those nozzles. During tests, the $U_{0} D$ and pump orientation were varied, but the liquid level and pump elevation were constant. Pilot scale blending was determined using a commercial $95 \%$ blending criteria, where blending was complete when the final normalized concentration was within $5 \%$ of the change in concentration between test start and completion. To evaluate this criterion, tracer chemicals were added to the tank, and the $p H$ was monitored throughout the tank to monitor blending times. To select a blending time, sludge disturbance required analysis.

In short, a single blending pump can blend salt contents for a Tank 50 design if the pump UoD equals 3.6 to $6.1 \mathrm{ft}^{2} /$ second. Many operating parameters were considered and analytical methods were proven to permit investigation of other operating parameters. For the 2.25 inch diameter nozzles designed in the $\mathrm{CW}$ design, the recommended total flow rates through both nozzles are $473-806$ gpm.

Sludge disturbance during blending was assessed by operating the blender pump at different values of $U_{0} D$ to determine when sludge was disturbed. $\mathrm{A} \approx 3 / 4$ inch deep, pourable sludge simulant was used below a 31.35 inch salt supernate simulant layer (total level $=32.1$ inches). The selected simulant was considered to be conservative for the purposes of this research, where the simulant had a negligible yield stress. The blending requirements are likened to mixing a layer of water over a layer of syrup without disturbing the syrup, since the sludge simulant was as thin as a light syrup. The higher the $U_{0} D$, the faster the blending occurred. The lower the $U_{0} D$, the less likely that sludge was disturbed. An operating range was experimentally shown to meet these conditions at pilot scale.

A few blending tests were also performed by transferring supernate simulants to the pilot scale tank. One quarter of the total test volume was added to the tank, which initially contained $3 / 4$ of a tank of supernate. Solutions were added at a flow rate scaled down from a $75 \mathrm{gpm}$ minimum facility transfer flow rate. When the added solution was of equal or higher density than the tank solution, the tank was completely blended by addition of the added fluid. That is, when a 5.8 molar salt solution was added to a tank containing salt solution or water, the tank contents were blended without turning on the blending pump at all. Blending may not be required for some cases, but for other cases blending is required. Sufficient testing was not performed to determine when blending is, or is not, required when denser solutions are added to a tank. Also, when a half tank of water was added to 5.8 molar salt solution, blending performance changed, a lower stratified salt layer formed which slowly lowered, and the scaled up blending time equaled between three days and a week, or more. Intermediate density solutions were not investigated, but lower density fluid additions may significantly increase blending times.

Pilot scale transfer tests from the tank were performed to investigate sludge entrainment, during transfers to SWPF. Transfers were performed at a rate scaled down from a 130 gpm maximum facility transfer flow rate, using the same pilot scale tank and equipment. The waste acceptance 
criterion is 0.09 weight percent for transfer to the SWPF. This concentration was not accurately measurable using commercial density meters, and SRNL consequently developed techniques to use turbidity probes to measure low concentrations in the transfer lines. The probes emit infrared light, and the reflected light is measured to determine solids concentration in solution. Overall, experimentation and CFD modeling showed that a preliminary transfer pump design with an attached, flat bottom plate can be lowered to as close as 9-1/2 inches from the sludge layer without disturbing the sludge at all. Models of the final transfer pump design are required for validation of this clearance.

Parallel to pilot scale tests, CFD validation for scale-up to Tank 50 was required. To perform this validation, velocities at numerous locations and elevations in pilot scale and full scale tanks were used for comparison to CFD models. Statistical evaluations of experimental velocity and blend time data were combined with CFD results and visual observations to establish the required $U_{0} D$ range required to meet full scale blending time, and establish transfer pump requirements to prevent sludge entrainment. This validation provided validation of pilot scale CFD modeling with experimental results. CFD modeling was then used to predict full scale performance during pump operations.

In other words, the primary goals of this research were to provide pump design recommendations, and validate CFD methods to support future calculations for system operation. Those goals were met, and are summarized by the research accomplishments listed below.

\subsection{Summary of Advances in Research}

1. For a tank without cooling coils, scale-up blending times were nearly identical for two independent calculation techniques. One set of experimental results were used along with empirical equations from the literature, while another set of experimental results was used along CFD models. Both the experimental data and the calculation techniques were independent. Statistical analyses of each set of results yielded nearly the same blending times, which provides strong defense for the use of CFD to calculate blending times.

2. Salt solution blending and sludge disturbance may be evaluated for other waste tank designs using CFD. However, materials with different sludge properties or significant differences in supernate, salt batch properties require further experimental investigation before application of CFD modeling.

3. Blending times can also be calculated for a tank without coils using equations presented here. Equations were not developed for a tank with coils.

4. Nozzle position with respect to the tank wall and nozzle diameter had minor effects on blending times.

5. The $0^{\circ}$ nozzle position, parallel to the vertical tank wall was recommended for blending. However, only minor differences in blending times were observed between different nozzle positions in a horizontal plane. The $0^{\circ}$ nozzle position is also recommended to minimize sludge disturbance.

6. UoD was shown to be the controlling factor during blending, where the pump design only had a minor effect on blending. Then, the pump design is considered to be minor factor for CFD modeling.

7. Pilot scale blending times varied by more than $100 \%$ for apparently comparable conditions, where blending times were based on reaching a final concentration near equilibrium after adding tracer quantities of acid or base to salt solutions. The initial and final, acid or base, concentrations in the pilot scale tank did not affect blending times.

8. Cooling coils in waste tanks significantly affect blending times by a factor of 1.5 to 2.0 in the recommended operating range. As $U o D$ was lowered, cooling coils increased the blending time by a factor of as much as 7 times, before blending was not completed at all. 
9. Statistical analysis was used to simplify the complexities of turbulence to provide techniques for comparisons of experiments to CFD models and for the use of CFD models for scale-up.

10. Not only was there a significant variation in blending times between tests, but the last point at which complete blending occurred changed from test to test for comparable conditions. This observation is contrary to opinions that have long been published in the engineering literature that assume that the same point mixes last in repeated tests. In other words, blending processes are extremely chaotic, and this chaotic property of blending was quantified for the first time in this research.

11. When using CFD models to determine blending times, a blending factor of 3.35 is recommended. Different blending factors were determined for different sets of tests, and the most conservative of all tests was selected for use. To use the factor, a blending time for other full scale tank designs may be calculated using CFD, and those calculated blending times should be multiplied by the 3.35 correction factor to obtain recommended blending times for facility operations. This finding is markedly different than the $23 \%$ variation (1.23 blending factor) in blending times for tanks without coils cited in the engineering literature.

12. Diffusion was very slow when compared to blending times, and has a negligible effect on blending times.

13. When using velocities in CFD models to evaluate sludge disturbance or blending, a 1.267 velocity correction factor is recommended, which was determined by comparing measured velocities to CFD calculated velocities. That is, an experimental variability in the average fluid velocity of $26.7 \%$ was calculated between CFD predictions and experiment, for both pilot and full scale testing. Attesting to the chaotic nature of blending, different average velocities were measured at the same locations at different times for comparable conditions.

14. Pump nozzles installed parallel to the tank floor disturbed sludge at pilot scale for recommended pump flow rates, and the amount of disturbed sludge scaled up to $3000-$ 4000 gallons for an 8 inch deep sludge layer. However, sludge disturbance was controlled for design flow rates, using dual, opposing, $15^{\circ}$, upward pointing nozzles installed parallel to the tank wall.

15. Distribution of settled metals in the sludge layer was inhomogeneous. When sludge is mixed into suspension, higher concentrations of denser metals were observed near the bottom of the sludge layer, and higher concentrations of lighter metals were observed near the surface of the sludge layer.

16. Sludge properties were a significant conservatism for this research. A sludge was selected that would be representative of a sludge that was recently mixed, or transported into the tank. As sludges settle, the yield stresses increase, and the ability to disturb sludge decreases. In other words, the test results provided here become more conservative over time as sludge settles.

17. A conservative velocity to disturb sludge at all was established for transfer pumps, since inadequate experimental data was obtained to quantify the concentration of sludge lifted into a transfer pump during pilot scale operations.

18. A $95 \%$ blending time criteria was validated for use in test results, and a $99 \%$ blending time could not be obtained due to technical limitations of commercial equipment. $p H$ measurements during testing were acceptable to describe normalized blending times near equilibrium, but were significantly in error during testing due to the buffering effects of carbonates formed in solution.

19. At pilot scale, velocity fluctuations are significantly affected by pump speeds. This effect is less pronounced at full scale. 
20. Variability in the blending time for a tank with cooling coils is considerably higher than for a tank without coils. In fact, a lower blending time correction factor can be calculated with available data for a tank without coils.

\subsection{Recommendations for Future Work}

Numerous recommendations for potential future work stem from this research.

1. Validate blending times in a full scale tank.

2. Validate that sludge remains undisturbed in a full scale tank during blending.

3. Sample sludge as it accumulates in blend and feed tanks, and measure rheological properties to validate sludge assumptions.

4. Investigate bulk transfer effects on sludge disturbance, since the currently planned $45^{\circ}, 3$ inch diameter transfer pipe will introduce higher velocity flows down into the tank than previous downcomer designs.

5. Perform full scale testing or measurements at the tank to validate minimal sludge disturbance due to transfer pump operations.

6. Evaluate blend time effects when adding less dense solutions to denser solutions, using further pilot scale research or measured data from a full scale tank.

7. Perform additional CFD models if blend times are required at the lower operating limits, since blending times were recommended for the upper operating limit only.

8. Perform additional CFD models to increase the recommended $U o D$, if longer settling times are permissible

9. Perform additional CFD models for a Type IV tank if this pump design is used in that type of tank.

10. Perform additional CFD blending and sludge disturbance models for sludge layers other than 8.1 inches at full scale, as required.

11. Perform additional CFD models to establish the clearance to prevent sludge disturbance for a transfer pump without a bottom plate for a conservative sludge simulant.

12. Perform full scale testing for aerosolization (rooster tailing) for upward pointing nozzles.

13. Perform additional CFD models at different pump elevations and liquid levels, if required for operations.

14. Evaluate potential for cavitation damage in CW pump design and ensure longer pump life, using vibration analysis. An SRNL peer review of the final pump designs is also recommended.

15. Perform CFD models for the actual transfer pump suction for sludge disturbance.

16. Experimentally investigate sludge disturbance for higher yield stress sludges.

17. Perform additional testing or CFD modeling to determine if transfer pumps can be lowered closer to the sludge layer, if required by SRR. Full scale testing using Kaolin clay can also be considered to investigate sludge entrainment when the transfer pump is lowered to the sludge surface.

18. The CFD modeling techniques for blending and sludge disturbance developed during this research are also applicable to Type I and II tanks or other Type III or IIIA tanks, if required. Complex tube bundle shapes may require further evaluation.

19. Sludge disturbance and gas release may also be investigated at pilot scale.

20. After pump operations are in process, an SRNL review of performance data is recommended to validate recommendations from this report for future CFD applications.

21. Perform additional testing at pilot scale and collect full scale test data to reduce blending time correction factors.

22. Investigate the effects of pump pulsations on turbulence intensity. 
SRNL-STI-2011-00151

5/26/11 Revision 0

\subsection{References}

1. Leishear, R. A., Fowley, M. D., and Poirier, M. R., "SDI, Blend and Feed Blending Pump Design, Phase 1”, Savannah River National Laboratory, SRNL-STI-2010-00054.

2. Leishear, R. A., Fowley, M. D., and Poirier, M. R., "Task Technical and Quality Assurance Plan for SDI Blend and feed Study, Phase 2", Savannah River National Laboratory, SRNL-RP-2010,019007.

3. Leishear, R., Folwey, M., Poirier, M., Steeper,T., 2010,“Cooling Coil Effects On Blending in a Pilot Scale Tank", AIChE Annual Conference, New York, New York

4. Leishear, R. A., Fowley, M. D., Poirier, M. R., Lee, S. Y., Parkinson, K. S., and Steeper, T. J., 2011, "Incipient Sludge Mixing in Nuclear Waste Tanks During Salt Blending “, Waste Management 2011 Conference, 2011, Phoenix, AZ, Paper No. 11086.

5. Poirier, M. R., Qureshi, Z. H., "Scaling Solid Resuspension and Sorption for the Small Column Ion Exchange (SCIX) Processing Tank", Savannah River National Laboratory, SRNL-STI-2010-00792.

6. Paul, E. L., Atieno-Oberg, V. A., Kresta, S. M., Eds., 2004, "Handbook of Industrial Mixing", Brown, D. A. R., Jones, P. N., Middleton, J. C., "Experimental Methods", Hoboken, John Wiley and Sons, New Jersey.

7. Grenville, R., Tilton, J., 1996, "A New Theory Improves the Correlation of Blend Time Data from Turbulent Jet Mixed Vessels", Trans. Inst. of Chem. Eng., Vol. 74.

8. Grenville, R., Tilton, J., 1997, "Turbulence or Flow as a Predictor of Blend Time in Turbulent Jet Mixed Vessels", Proceedings of the North European Conference on Mixing.

9. R. A. Dimenna, S. Y. Lee, and D. A. Tamburello, 2011, "Advanced Mixing Models", SRNL-STI-2011-00026, Savannah River National Laboratory.

10. Herman, D. T., Poirier, M. R., 2009, "Recipe for Simulated Sludge Batch 6-DS for Rotary Filter Testing", SRNL-TR-2009-00111.

11. Stone, J. A., Kelley, J. A., McMillan, T. S., 1976, "Sampling and Analyses of SRP High Level Waste Sludges”, DP-1399, Westinghouse Savannah River Corporation, S.C., p. 15.

12. Hamm, B. A. Ebra, B. A., 1984, "High Level Caves Rheological Studies of Tanks 15H, 42H, and 8F Sludge / Slurries," DPST-84-439, Westinghouse Savannah River Corporation, S.C., pp. $1-27$.

13. Poirier, M. R.; Herman, D. T.; Fondeur, F. F.; Hansen, E.; and Fink, S. D., 2003 "MST/Sludge Agitation Studies for Actinide Removal Process and DWPF", WSRC TR-2003-00471.

14. Coleman, H. W., Steele, W. G., 1989, "Experimentation and Uncertainty Analysis for Engineers", John Wiley and Sons, New York, New York.

15. Warda, H. A., Kassab, S. Z., Elshorbagy E. A., Esaadawy, E. A., 1999, “An Experimental Investigation of the Near Field Region of Free Turbulent Round Central and Annular Jets", Flow Measurement and Instrumentation, Elsevier Publishing.

16. Lee, S., Armstrong, B., "SDI CFD Modeling Analysis", Savannah River National Laboratory, SRNL-STI-2011-00025. 
17. R. A. Leishear, M. J. Augeri, M. Hubbard, J. L. Thomas, S. Lee, R. A. Dimenna, D. B. Stefanko, "ADMP Mixing of Tank 18F Sludge: History, Modeling, Testing, and Results", WSRC-TR-2004-00036.

18. Churnetski, B. V., 1981, "Effective Cleaning Radius Studies," DPST-81-282, Westinghouse Savannah River Corporation, S.C., pp. $1-22$.

19. Churnetski, B. V., 1982, "Prediction of Centrifugal Pump Cleaning Ability in Waste Sludge," Nuclear and Chemical Waste Management, Pergamon Press Ltd., Vol. 3, pp. 199-203.

20. Leishear, R. A., Stefanko, D. B., 2005, "Relationship Between Vibrations and Mechanical Seal Failures in Centrifugal Pumps", International Mechanical Engineering Conference and Exposition.

21. Leishear, R., Restivo, M., Sherwood, D., Guerrero, H., 2010, "Mass Transfer Coefficients for a Non-Newtonian Fluid and Water With and Without Ant-foam Agents", Vol. 132, ASME, Journal of Fluids Engineering. 
SRNL-STI-2011-00151

5/26/11 Revision 0

Appendix A: Statistical Analysis 
SRNL-STI-2011-00151

5/26/11 Revision 0

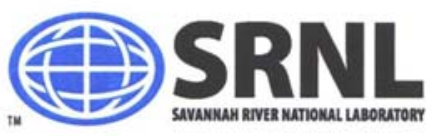

\section{INTER-OFFICE MEMORANDUM}

March 17, 2011

To:

R. A. Leishear, 786-5A

cc:

P. L. Lee, 703-41A

S. Y. Lee, 703-41A

E. P. Shine, $703-41 \mathrm{~A}$

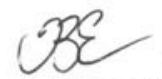

T. B. Edwards, 999-W (819-8464)

Applied Computational Engineering and

Statistics

E. P. Shine, Technical Reviewer

$\frac{4-19-2011}{\text { Date }}$

P. L L Lee, Manager

$\frac{4-19-2011}{\text { Date }}$

Applied Computational Engineering and

Statistics

\section{Statistical Support for EDL and CFD Research for SRR's SDI Project}


SRNL-STI-2011-00151

5/26/11 Revision 0

SRNL-L4221-2011-00005

March 17, 2011

Page 2 of 33

\subsection{INTRODUCTION}

The Savannah River National Laboratory (SRNL) is conducting tests at its Engineering Development Laboratory (EDL) to investigate blending times and sludge disturbance for the Salt Disposition Integration (SDI) Project for Savannah River Remediation, LLC (SRR). The experimental setup at EDL provides results for a pilot scale (1:10.85) model of the full-scale tank operation. A computational fluid dynamics (CFD) model is available for estimating both fullscale and pilot-scale operational parameters. One of the objectives of the SRNL study is the development of a solid understanding of the scaling required for the CFD models. To facilitate this investigation, computerized runs of the CFD system have been conducted for the experimental conditions utilized during EDL's pilot-scale testing. The purpose of this document is to provide a statistical review and comparison of the EDL and CFD results.

\subsection{DISCUSSION}

Two parameters of the SDI operation that are of interest in this study are blending times and velocities required to disturb sludge, which consists of settled solids on the floor of liquid radioactive waste storage tanks. Measurements from EDL's tests and from the CFD runs for these parameters are presented and discussed in this section. JMP Version 7.0.2 [1] was used to support this investigation.

\section{$2.1 \quad$ Blending Times}

The blending times determined for the EDL testing are provided in Table A1 in Appendix A. A plot of the blending times by various groupings is provided in Exhibit A1 of Appendix A. Tests conducted under similar settings were grouped as these exhibits were prepared. Exhibit A2 in Appendix A provides an analysis of variance (ANOVA) of the blending measurements for each of the test groupings. The ANOVA estimates the variances for two sources of variation in the measurements for each test grouping: test to test variation and probe to probe variation. The former quantifies the variation in blending times among a specified set of tests, and the latter estimates the variation in blending times that is expected among the probes during a single test run. The estimates of these variances are to be used to bound a high percentage of the test to test differences and the probe to probe differences, respectively. That is, based upon an assumption of normality for the test to test differences in blend times and an assumption of normality for the probe to probe differences, upper bounds on $95 \%$ of the possible test average blend times and $95 \%$ of the possible probe blend times were computed. Both of these calculations were performed at the $97.5 \%$ confidence level, which provides an overall $95 \%$ confidence in the results from these calculations. Both of these contributions to the variation in blend times for a test are assumed to be normally distributed with a mean of 0 and a variance estimated by the ANOVA results of Exhibit A2.

As a justification for the analysis performed in Exhibit A2, consider a set of blending tests conducted by EDL under the same conditions. The averages of the blending times for each of the tests in the set vary around the grand average for the set of tests. This variation around the grand average is due to test to test variation that is estimated by the between test variance indicated by "Test\&Random" in the ANOVA results of Exhibit A2. In addition, the probe to probe variation around an individual test average during the EDL experimentation is estimated by the "Residual" variance for a test grouping in Exhibit A2. In attempting to bound the experimental blending times for EDL testing conducted under the same conditions, each of the sources of variation in blending times around the grand average for the given test conditions is assumed to follow a normal distribution, with a mean of zero and with a variance estimated by the ANOVA of Exhibit A2. Thus, in a random sample of $n$ experimental tests conducted by EDL under the same 
SRNL-STI-2011-00151

5/26/11 Revision 0

conditions, let the grand mean of the resulting blend times be represented by $\bar{x}_{T}$ and the estimated test to test variance (denoted by "Test\&Random" in Exhibit A2) be $\mathrm{s}_{\mathrm{T}}^{2}$, then the results for the $\mathrm{n}$ tests may be used to determine an upper $100(1-\alpha) \%$ tolerance bound for the distribution of average blend times for tests conducted under these conditions with $100(1-\gamma / 2) \%$ confidence as follows:

$$
\overline{\mathrm{x}}_{\mathrm{T}}+\mathrm{k}_{\mathrm{T}} \cdot \mathrm{s}_{\mathrm{T}}
$$

where the equation for $\mathrm{k}$ involves the noncentral Student $\mathrm{t}$ distribution and is given by:

$$
\mathrm{k}_{\mathrm{T}}=\frac{\mathrm{t}\left(\gamma / 2, \mathrm{n}-1, \sqrt{\mathrm{n}} \cdot \mathrm{z}_{1-\alpha}\right)}{\sqrt{\mathrm{n}}}
$$

where $\mathrm{t}(\cdot)$ represents the upper- $\gamma / 2$ tail of the non-central Student $t$ distribution with $\mathrm{n}-1$ degrees of freedom and noncentrality parameter given by $\sqrt{n} \cdot z_{1-\alpha}$, where $z_{1-\alpha}$ is the $(1-\alpha) 100 \%$ - tile of the standard normal distribution (see [2]).

If the blending times determined at each of the $\mathrm{m}$ (typically, $\mathrm{m}$ is equal to 6) probes monitored during a test run are assumed to be a random sample of $m$ times from the population of possible blend times that could have been selected and if the blending times are normally distributed around the average for the given test, then the variation in these times is estimated by the "Residual" variance of Exhibit A2. Also, using the individual test mean, $\bar{x}_{t}$, and the "Residual" variance from Exhibit A2, denoted by $s_{\mathrm{P}}^{2}$, then an upper tolerance limit (UTL) for $100(1-\alpha) \%$ of the population of blend times at possible probe locations for a given test conducted under these conditions with $100(1-\gamma / 2) \%$ confidence as follows:

$$
\overline{\mathrm{x}}_{\mathrm{t}}+\mathrm{k}_{\mathrm{P}} \cdot \mathrm{sp}_{\mathrm{P}}
$$

where the equation for $\mathrm{k}$ involves the noncentral Student $\mathrm{t}$ distribution and is given by:

$$
\mathrm{k}_{\mathrm{P}}=\frac{\mathrm{t}\left(\gamma / 2, \mathrm{~m}-1, \sqrt{\mathrm{m}} \cdot \mathrm{z}_{1-\alpha}\right)}{\sqrt{\mathrm{m}}}
$$

where $t(\cdot)$ represents the upper- $\gamma / 2$ tail of the non-central Student $t$ distribution with $n-1$ degrees of freedom and noncentrality parameter given by $\sqrt{\mathrm{m}} \cdot \mathrm{z}_{1-\alpha}$, where $\mathrm{z}_{1-\alpha}$ is the $(1-\alpha) 100 \%$ - tile of the standard normal distribution.

Since each of these two tolerance limits is determined with (1- $\gamma / 2) 100 \%$ confidence, then with (1- $\gamma) 100 \%$ confidence an upper limit on $100(1-\alpha) \%$ of the possible blending times for randomly placed probes in $100(1-\alpha) \%$ of the tests that EDL might conduct for a given set of conditions is given by

$$
\overline{\mathrm{x}}_{\mathrm{T}}+\mathrm{k}_{\mathrm{T}} \cdot \mathrm{s}_{\mathrm{T}}+\mathrm{k}_{\mathrm{P}} \cdot \mathrm{s}_{\mathrm{P}}
$$

Table A2 in Appendix A provides the UTLs determined with $97.5 \%$ confidence for $95 \%$ of the tests and with $97.5 \%$ confidence for $95 \%$ of the probes for each of the various test conditions 
SRNL-STI-2011-00151

5/26/11 Revision 0

SRNL-L4221-2011-00005

March 17, 2011

Page 4 of 33

explored by EDL during these experiments. The table also includes the CDF results for each of these test conditions as well. A plot of these results is provided in Exhibit A3. In looking to these data to determine a scaling factor or an offset that may be applied to the CFD blending times to obtain an appropriate time for blending, note that for groupings involving only 2 tests, specifically the group of Tests 20 and 21 and the group of Tests 32 and 37, there is only 1 degree of freedom associated the estimated variance for test to test differences. Having only one degree of freedom leads to a very large $\mathrm{k}_{\mathrm{T}}$ value in determining the UTL for these situations, and as a result, the UTLs for these two groups should be used with caution.

\section{$2.2 \quad$ Velocities}

The velocities determined at various locations and test conditions during the EDL tests and the corresponding values generated by the CFD analyses for the velocities at these locations under these conditions are provided in Table A3 in Appendix A. The information in this table reveals that these velocities were associated with full-scale as well as pilot-scale tests. One of the parameters of this testing is the product $\mathrm{UoD}$, where Uo is the nozzle velocity for a single nozzle of the pump used during a particular test and $\mathrm{D}$ is the nozzle diameter. The UoD values for this testing are given in Table A3, and they range from a high of $29.4 \mathrm{ft}^{2} / \mathrm{sec}$ to a low of $0.58 \mathrm{ft}^{2} / \mathrm{sec}$ with all of the pilot scale testing being conducted at UoD of no more than $0.81 \mathrm{ft}^{2} / \mathrm{sec}$. Scatterplots of the test velocities versus those generated by the CFD analyses for locations and test conditions investigated are provided in Exhibit A4 in Appendix A. The legend for these plots appears at the bottom of Exhibit A4. The $\mathrm{x}$ - and y-axes in the top scatterplot are in $\mathrm{ft}$ per second while for the lower graphic the common logarithms of the test versus CFD velocities are plotted.

A primary objective of the investigation into these velocities is the determination of the relationship between these pairs of test velocities and CFD velocities, and one of the questions of interest is: Does the scale of the testing have a significant impact on that relationship? The lower plot of Exhibit A4 suggests that these two values for velocity are reasonably well correlated for most test conditions, except for those at the very low end (less than $0.026 \mathrm{ft} / \mathrm{sec}$ ) of the CFD values. Exhibit A5 in Appendix A provides a linear fit of the natural logarithms of the test velocities to the natural logarithms of the CFD velocities. The fitted line is shown as the solid red line in the plot of Exhibit A5. The dotted red lines form a $95 \%$ confidence interval for an individual test velocity that might be seen at a location in the tank for a test condition with a specific CFD velocity as indicated on the $\mathrm{x}$-axis. The estimated intercept for the fitted equation is not statistically different from zero and the $95 \%$ confidence interval for the estimated slope includes 1 .

These results suggest that it is possible to determine an offset that could be applied to the CFD values. That is, it is possible to express the relationship between the pairs of values for velocity as:

$$
\text { Average Test Velocity }=\text { CFD Velocity } \times \text { Offset Value }
$$

where the Average Test Velocity represents the average of all velocities that are measured experimentally for various test locations and test conditions with the same CFD velocity as indicated on the $x$-axis. The scatter in the experimental velocities that is evident in the measurements of Exhibit A5 is attributed to random effects due to turbulence, and it is the average of these velocities that is of interest in this experimentation since the CFD modeling does not account for effects due to turbulence.

If equation (6) is transformed by taking the natural logarithm of both sides of the equation, then the offset may be estimated using a special fitting option in JMP's Fit $Y$ by $\mathrm{X}$ modeling platform. The JMP output from this fit with the slope constrained to 1 is provided in the left panel of 
SRNL-STI-2011-00151

5/26/11 Revision 0

Exhibit A6 in Appendix A. The intercept in this exhibit estimates the offset as a natural logarithm. That value is 0.142592 . JMP was used to estimate an upper $95 \%$ confidence limit on this offset. That analysis is provided in the right panel of Exhibit A6 and the upper bound (in natural logarithms) is 0.232724 . Taking the antilog of these values allows for the estimation of an adjustment for the CFD velocity of 1.153 and of an upper bound for the adjustment of 1.262 , and for the re-expression of equation 6 (with $95 \%$ confidence):

Average Test Velocity $\leq$ CFD Velocity $\times 1.262$

The natural logarithms of these values are plotted in Exhibit A7 of Appendix A.

\subsection{SUMMARY AND CONCLUSIONS}

This document provides analyses and comparisons of EDL and CFD values for blending times and slurry velocities. Times needed to successfully blend the tank contents for the various conditions tested were statistically estimated and compared to those provided by the CFD model. In addition, the testing velocity measurements at various positions and the CFD velocity values for these positions were utilized to provide an offset that may be applied to CFD velocity values to estimate corresponding operational average velocities.

\subsection{REFERENCES}

[1] JMP Version 7.0.2, SAS Institute, Inc., Cary NC, 1989-2007.

[2] Odeh, R. E. and D. B. Owen, Tables for Normal Tolerance Limits, Sampling Plans, and Screening, Marcel Dekker, Inc., New York 1980. 
SRNL-STI-2011-00151

5/26/11 Revision 0

SRNL-L4221-2011-00005

March 17, 2011

Page 6 of 33

\subsection{APPENDIX A}

\section{Supplemental Tables and Exhibits}


SRNL-STI-2011-00151

5/26/11 Revision 0

SRNL-L4221-2011-00005

March 17, 2011

Page 7 of 33

Table Al. Blending Times for EDL Tests

\begin{tabular}{|c|c|c|c|c|c|}
\hline $\begin{array}{c}\text { Test } \\
\text { Groups }\end{array}$ & $\begin{array}{c}\text { Test } \\
\text { Grouping }\end{array}$ & $\begin{array}{c}\mathrm{UoD} \\
\left(\mathrm{ft}^{\wedge} \mathbf{2} / \mathrm{sec}\right)\end{array}$ & Test & Probe & $\begin{array}{l}\text { Blending } \\
\text { Time (min) }\end{array}$ \\
\hline Coils, water & Tests $11-13,17,19$ & 0.47 & 11 & pH Probe 1 & 14.41 \\
\hline Coils, water & Tests $11-13,17,19$ & 0.47 & 11 & pH Probe 2 & 11.29 \\
\hline Coils, water & Tests $11-13,17,19$ & 0.47 & 11 & pH Probe 3 & 7.77 \\
\hline Coils, water & Tests $11-13,17,19$ & 0.47 & 11 & pH Probe 4 & 12.5 \\
\hline Coils, water & Tests $11-13,17,19$ & 0.47 & 11 & pH Probe 5 & 13.61 \\
\hline Coils, water & Tests $11-13,17,19$ & 0.47 & 11 & pH Probe 6 & 12.03 \\
\hline Coils, water & Tests $11-13,17,19$ & 0.47 & 12 & pH Probe 1 & 11.16 \\
\hline Coils, water & Tests $11-13,17,19$ & 0.47 & 12 & pH Probe 2 & 5.55 \\
\hline Coils, water & Tests $11-13,17,19$ & 0.47 & 12 & pH Probe 3 & 5.5 \\
\hline Coils, water & Tests $11-13,17,19$ & 0.47 & 12 & pH Probe 4 & 5.4 \\
\hline Coils, water & Tests $11-13,17,19$ & 0.47 & 12 & pH Probe 5 & 9.53 \\
\hline Coils, water & Tests $11-13,17,19$ & 0.47 & 12 & pH Probe 6 & 5.59 \\
\hline Coils, water & Tests $11-13,17,19$ & 0.47 & 13 & pH Probe 1 & 11.96 \\
\hline Coils, water & Tests $11-13,17,19$ & 0.47 & 13 & $\mathrm{pH}$ Probe 2 & 9.79 \\
\hline Coils, water & Tests $11-13,17,19$ & 0.47 & 13 & pH Probe 3 & 7.22 \\
\hline Coils, water & Tests $11-13,17,19$ & 0.47 & 13 & pH Probe 4 & 9.72 \\
\hline Coils, water & Tests $11-13,17,19$ & 0.47 & 13 & pH Probe 5 & 10.45 \\
\hline Coils, water & Tests $11-13,17,19$ & 0.47 & 13 & pH Probe 6 & 3.63 \\
\hline Coils, water & Tests $14-16$ & 0.82 & 14 & pH Probe 1 & 6.63 \\
\hline Coils, water & Tests 14-16 & 0.82 & 14 & pH Probe 2 & 5.71 \\
\hline Coils, water & Tests 14-16 & 0.82 & 14 & pH Probe 3 & 5.2 \\
\hline Coils, water & Tests 14-16 & 0.82 & 14 & pH Probe 4 & 6.25 \\
\hline Coils, water & Tests 14-16 & 0.82 & 14 & pH Probe 5 & 5.71 \\
\hline Coils, water & Tests 14-16 & 0.82 & 14 & pH Probe 6 & 5.32 \\
\hline Coils, water & Tests 14-16 & 0.82 & 15 & pH Probe 1 & 9.23 \\
\hline Coils, water & Tests 14-16 & 0.82 & 15 & $\mathrm{pH}$ Probe 2 & 8.25 \\
\hline Coils, water & Tests 14-16 & 0.82 & 15 & pH Probe 3 & 6.53 \\
\hline Coils, water & Tests 14-16 & 0.82 & 15 & pH Probe 4 & 10.27 \\
\hline Coils, water & Tests 14-16 & 0.82 & 15 & pH Probe 5 & 5.33 \\
\hline Coils, water & Tests 14-16 & 0.82 & 15 & pH Probe 6 & 9.83 \\
\hline Coils, water & Tests 14-16 & 0.82 & 16 & $\mathrm{pH}$ Probe 1 & 5.45 \\
\hline Coils, water & Tests 14-16 & 0.82 & 16 & pH Probe 2 & 5.29 \\
\hline Coils, water & Tests 14-16 & 0.82 & 16 & pH Probe 3 & 4.79 \\
\hline Coils, water & Tests 14-16 & 0.82 & 16 & pH Probe 4 & 5.52 \\
\hline Coils, water & Tests 14-16 & 0.82 & 16 & pH Probe 5 & 3.63 \\
\hline Coils, water & Tests 14-16 & 0.82 & 16 & pH Probe 6 & 5.12 \\
\hline Coils, water & Tests $11-13,17,19$ & 0.48 & 17 & $\mathrm{pH}$ Probe 1 & 18.07 \\
\hline Coils, water & Tests $11-13,17,19$ & 0.48 & 17 & pH Probe 2 & 6.98 \\
\hline Coils, water & Tests $11-13,17,19$ & 0.48 & 17 & pH Probe 3 & 7.39 \\
\hline Coils, water & Tests $11-13,17,19$ & 0.48 & 17 & pH Probe 4 & 6.97 \\
\hline Coils, water & Tests $11-13,17,19$ & 0.48 & 17 & pH Probe 5 & 10.22 \\
\hline Coils, water & Tests $11-13,17,19$ & 0.48 & 17 & pH Probe 6 & 5.21 \\
\hline Coils, water & Tests $11-13,17,19$ & 0.47 & 19 & pH Probe 1 & 17.28 \\
\hline Coils, water & Tests $11-13,17,19$ & 0.47 & 19 & pH Probe 2 & 14.57 \\
\hline Coils, water & Tests $11-13,17,19$ & 0.47 & 19 & pH Probe 3 & 11.65 \\
\hline Coils, water & Tests $11-13,17,19$ & 0.47 & 19 & pH Probe 4 & 14.27 \\
\hline Coils, water & Tests $11-13,17,19$ & 0.47 & 19 & pH Probe 5 & 16.49 \\
\hline Coils, water & Tests $11-13,17,19$ & 0.47 & 19 & pH Probe 6 & 14.27 \\
\hline Coils, water & Tests $20-21$ & 0.47 & 20 & pH Probe 1 & 11.35 \\
\hline Coils, water & Tests 20-21 & 0.47 & 20 & pH Probe 2 & 13.31 \\
\hline Coils, water & Tests 20-21 & 0.47 & 20 & pH Probe 3 & 11.86 \\
\hline Coils, water & Tests 20-21 & 0.47 & 20 & pH Probe 4 & 20.04 \\
\hline Coils, water & Tests $20-21$ & 0.47 & 20 & pH Probe 5 & 12.03 \\
\hline Coils, water & Tests 20-21 & 0.47 & 20 & pH Probe 6 & 18.22 \\
\hline Coils, water & Tests $20-21$ & 0.47 & 21 & pH Probe 1 & 8.37 \\
\hline Coils, water & Tests 20-21 & 0.47 & 21 & pH Probe 2 & 6.36 \\
\hline Coils, water & Tests 20-21 & 0.47 & 21 & pH Probe 3 & 8 \\
\hline Coils, water & Tests 20-21 & 0.47 & 21 & pH Probe 4 & 13.72 \\
\hline Coils, water & Tests 20-21 & 0.47 & 21 & pH Probe 5 & 8.22 \\
\hline Coils, water & Tests 20-21 & 0.47 & 21 & pH Probe 6 & 9.28 \\
\hline na & $\mathrm{na}$ & 0.33 & 25 & pH Probe 1 & 31.38 \\
\hline na & na & 0.33 & 25 & pH Probe 2 & 31.05 \\
\hline na & na & 0.33 & 25 & pH Probe 3 & 22.33 \\
\hline
\end{tabular}


SRNL-STI-2011-00151

5/26/11 Revision 0

SRNL-L4221-2011-00005

March 17, 2011

Page 8 of 33

Table Al. Blending Times for EDL Tests

\begin{tabular}{|c|c|c|c|c|c|}
\hline $\begin{array}{c}\text { Test } \\
\text { Groups }\end{array}$ & $\begin{array}{c}\text { Test } \\
\text { Grouping }\end{array}$ & $\begin{array}{c}\text { UoD } \\
\left(\mathrm{ft}^{\wedge} 2 / \sec \right)\end{array}$ & Test & Probe & $\begin{array}{c}\text { Blending } \\
\text { Time (min) }\end{array}$ \\
\hline na & na & 0.33 & 25 & pH Probe 4 & 21.64 \\
\hline na & na & 0.33 & 25 & pH Probe 5 & 31.8 \\
\hline na & na & 0.33 & 25 & pH Probe 6 & 20.31 \\
\hline Coils, water & Test 26 & 0.47 & 26 & pH Probe 1 & 15.25 \\
\hline Coils, water & Test 26 & 0.47 & 26 & pH Probe 2 & 12.75 \\
\hline Coils, water & Test 26 & 0.47 & 26 & pH Probe 3 & 9.7 \\
\hline Coils, water & Test 26 & 0.47 & 26 & pH Probe 4 & 15.72 \\
\hline Coils, water & Test 26 & 0.47 & 26 & pH Probe 5 & 15.87 \\
\hline Coils, water & Test 26 & 0.47 & 26 & pH Probe 6 & 16.34 \\
\hline Coils, water & na & 0.64 & 27 & pH Probe 1 & 9.38 \\
\hline Coils, water & na & 0.64 & 27 & pH Probe 2 & 7.04 \\
\hline Coils, water & na & 0.64 & 27 & $\mathrm{pH}$ Probe 3 & 6.79 \\
\hline Coils, water & na & 0.64 & 27 & pH Probe 4 & 5.67 \\
\hline Coils, water & na & 0.64 & 27 & pH Probe 5 & 7.52 \\
\hline Coils, water & na & 0.64 & 27 & pH Probe 6 & 5.4 \\
\hline Coils, water & na & 0.99 & 28 & pH Probe 1 & 6.46 \\
\hline Coils, water & na & 0.99 & 28 & pH Probe 2 & 4.8 \\
\hline Coils, water & na & 0.99 & 28 & pH Probe 3 & 4.83 \\
\hline Coils, water & na & 0.99 & 28 & pH Probe 4 & 6.19 \\
\hline Coils, water & na & 0.99 & 28 & pH Probe 5 & 6.19 \\
\hline Coils, water & na & 0.99 & 28 & pH Probe 6 & 6.8 \\
\hline No Coils, water & na & 0.33 & 31 & pH Probe 1 & 11.26 \\
\hline No Coils, water & na & 0.33 & 31 & pH Probe 2 & 7.25 \\
\hline No Coils, water & na & 0.33 & 31 & pH Probe 3 & 7.81 \\
\hline No Coils, water & na & 0.33 & 31 & pH Probe 4 & 12.19 \\
\hline No Coils, water & na & 0.33 & 31 & pH Probe 5 & 12.04 \\
\hline No Coils, water & na & 0.33 & 31 & pH Probe 6 & 12.95 \\
\hline No Coils, water & Tests 32,37 & 0.47 & 32 & pH Probe 1 & 3.61 \\
\hline No Coils, water & Tests 32,37 & 0.47 & 32 & $\mathrm{pH}$ Probe 2 & 4.23 \\
\hline No Coils, water & Tests 32,37 & 0.47 & 32 & pH Probe 3 & 3.36 \\
\hline No Coils, water & Tests 32,37 & 0.47 & 32 & pH Probe 4 & 3.9 \\
\hline No Coils, water & Tests 32,37 & 0.47 & 32 & pH Probe 5 & 4.87 \\
\hline No Coils, water & Tests 32,37 & 0.47 & 32 & pH Probe 6 & 3.73 \\
\hline No Coils, water & na & 0.64 & 33 & pH Probe 1 & 3.61 \\
\hline No Coils, water & na & 0.64 & 33 & pH Probe 2 & 3.17 \\
\hline No Coils, water & na & 0.64 & 33 & pH Probe 3 & 3.17 \\
\hline No Coils, water & na & 0.64 & 33 & pH Probe 4 & 3.44 \\
\hline No Coils, water & na & 0.64 & 33 & pH Probe 5 & 2.98 \\
\hline No Coils, water & na & 0.64 & 33 & pH Probe 6 & 3.1 \\
\hline No Coils, water & na & 0.97 & 34 & pH Probe 1 & 3.55 \\
\hline No Coils, water & na & 0.97 & 34 & pH Probe 2 & 2.78 \\
\hline No Coils, water & na & 0.97 & 34 & $\mathrm{pH}$ Probe 3 & 3.02 \\
\hline No Coils, water & na & 0.97 & 34 & $\mathrm{pH}$ Probe 4 & 4.07 \\
\hline No Coils, water & na & 0.97 & 34 & pH Probe 5 & 3.02 \\
\hline No Coils, water & na & 0.97 & 34 & pH Probe 6 & 3.72 \\
\hline No Coils, water & Tests 32,37 & 0.47 & 37 & pH Probe 1 & 5.99 \\
\hline No Coils, water & Tests 32,37 & 0.47 & 37 & pH Probe 2 & 5.72 \\
\hline No Coils, water & Tests 32,37 & 0.47 & 37 & pH Probe 3 & 4.65 \\
\hline No Coils, water & Tests 32,37 & 0.47 & 37 & pH Probe 4 & 6.97 \\
\hline No Coils, water & Tests 32,37 & 0.47 & 37 & pH Probe 5 & 6.24 \\
\hline No Coils, water & Tests 32,37 & 0.47 & 37 & pH Probe 6 & 6.9 \\
\hline Coils, water & Tests $41-44$ & 0.81 & 41 & pH Probe 1 & 9.17 \\
\hline Coils, water & Tests $41-44$ & 0.81 & 41 & pH Probe 2 & 10.72 \\
\hline Coils, water & Tests $41-44$ & 0.81 & 41 & pH Probe 3 & 7.54 \\
\hline Coils, water & Tests $41-44$ & 0.81 & 41 & pH Probe 4 & 22.46 \\
\hline Coils, water & Tests $41-44$ & 0.81 & 41 & pH Probe 5 & . \\
\hline Coils, water & Tests $41-44$ & 0.81 & 41 & pH Probe 6 & 16.46 \\
\hline Coils, water & Tests $41-44$ & 0.81 & 42 & pH Probe 1 & 9.12 \\
\hline Coils, water & Tests $41-44$ & 0.81 & 42 & pH Probe 2 & 9.97 \\
\hline Coils, water & Tests $41-44$ & 0.81 & 42 & pH Probe 3 & 8.25 \\
\hline Coils, water & Tests $41-44$ & 0.81 & 42 & pH Probe 4 & 9.89 \\
\hline Coils, water & Tests $41-44$ & 0.81 & 42 & pH Probe 5 & 9.98 \\
\hline Coils, water & Tests $41-44$ & 0.81 & 42 & pH Probe 6 & 10.47 \\
\hline
\end{tabular}


SRNL-STI-2011-00151

5/26/11 Revision 0

SRNL-L4221-2011-00005

March 17, 2011

Page 9 of 33

Table Al. Blending Times for EDL Tests

\begin{tabular}{|c|c|c|c|c|c|}
\hline $\begin{array}{c}\text { Test } \\
\text { Groups }\end{array}$ & $\begin{array}{c}\text { Test } \\
\text { Grouping }\end{array}$ & $\begin{array}{c}\mathrm{UoD} \\
\left(\mathrm{ft}^{\wedge} \mathbf{2} / \mathrm{sec}\right)\end{array}$ & Test & Probe & $\begin{array}{c}\text { Blending } \\
\text { Time (min) }\end{array}$ \\
\hline Coils, water & Tests $41-44$ & 0.81 & 43 & pH Probe 1 & 7.74 \\
\hline Coils, water & Tests $41-44$ & 0.81 & 43 & pH Probe 2 & 6.03 \\
\hline Coils, water & Tests $41-44$ & 0.81 & 43 & pH Probe 3 & 5.47 \\
\hline Coils, water & Tests $41-44$ & 0.81 & 43 & pH Probe 4 & 4.41 \\
\hline Coils, water & Tests 41-44 & 0.81 & 43 & pH Probe 5 & 6.52 \\
\hline Coils, water & Tests $41-44$ & 0.81 & 43 & pH Probe 6 & 1.8 \\
\hline Coils, water & Tests $41-44$ & 0.81 & 44 & pH Probe 1 & 8.08 \\
\hline Coils, water & Tests $41-44$ & 0.81 & 44 & pH Probe 2 & 8.94 \\
\hline Coils, water & Tests $41-44$ & 0.81 & 44 & pH Probe 3 & 7.9 \\
\hline Coils, water & Tests $41-44$ & 0.81 & 44 & pH Probe 4 & 9.31 \\
\hline Coils, water & Tests $41-44$ & 0.81 & 44 & pH Probe 5 & 9.1 \\
\hline Coils, water & Tests $41-44$ & 0.81 & 44 & pH Probe 6 & 8.9 \\
\hline na & Tests $45-47$ & 0.81 & 45 & pH Probe 1 & 6.15 \\
\hline na & Tests $45-47$ & 0.81 & 45 & pH Probe 2 & 6.78 \\
\hline na & Tests $45-47$ & 0.81 & 45 & pH Probe 3 & 8.31 \\
\hline na & Tests $45-47$ & 0.81 & 45 & pH Probe 4 & 8.54 \\
\hline na & Tests $45-47$ & 0.81 & 45 & pH Probe 5 & 8.4 \\
\hline na & Tests $45-47$ & 0.81 & 45 & pH Probe 6 & 9.31 \\
\hline na & Tests $45-47$ & 0.81 & 46 & pH Probe 1 & 7.97 \\
\hline na & Tests $45-47$ & 0.81 & 46 & pH Probe 2 & 13.87 \\
\hline na & Tests $45-47$ & 0.81 & 46 & pH Probe 3 & 7.77 \\
\hline na & Tests $45-47$ & 0.81 & 46 & pH Probe 4 & 7.37 \\
\hline na & Tests $45-47$ & 0.81 & 46 & pH Probe 5 & 8.51 \\
\hline na & Tests $45-47$ & 0.81 & 46 & $\mathrm{pH}$ Probe 6 & 9.65 \\
\hline na & Tests $45-47$ & 0.81 & 47 & pH Probe 1 & 5.41 \\
\hline na & Tests $45-47$ & 0.81 & 47 & pH Probe 2 & 6.18 \\
\hline na & Tests $45-47$ & 0.81 & 47 & pH Probe 3 & 6.95 \\
\hline na & Tests $45-47$ & 0.81 & 47 & pH Probe 4 & 8.28 \\
\hline na & Tests $45-47$ & 0.81 & 47 & pH Probe 5 & 7.55 \\
\hline na & Tests $45-47$ & 0.81 & 47 & pH Probe 6 & 6.81 \\
\hline Coils, NaNO3 & Tests 48-51 & 0.81 & 48 & pH Probe 1 & 10.76 \\
\hline Coils, NaNO3 & Tests 48-51 & 0.81 & 48 & pH Probe 2 & 11.88 \\
\hline Coils, $\mathrm{NaNO}_{3}$ & Tests 48-51 & 0.81 & 48 & pH Probe 3 & 11.95 \\
\hline Coils, NaNO3 & Tests 48-51 & 0.81 & 48 & pH Probe 4 & 7.63 \\
\hline Coils, NaNO3 & Tests 48-51 & 0.81 & 48 & pH Probe 5 & 11.88 \\
\hline Coils, NaNO3 & Tests 48-51 & 0.81 & 48 & pH Probe 6 & 10.73 \\
\hline Coils, NaNO3 & Tests 48-51 & 0.81 & 49 & pH Probe 1 & 8.54 \\
\hline Coils, $\mathrm{NaNO}_{3}$ & Tests 48-51 & 0.81 & 49 & pH Probe 2 & 3.96 \\
\hline Coils, NaNO3 & Tests 48-51 & 0.81 & 49 & pH Probe 3 & 6.49 \\
\hline Coils, NaNO3 & Tests 48-51 & 0.81 & 49 & pH Probe 4 & 6.35 \\
\hline Coils, NaNO3 & Tests 48-51 & 0.81 & 49 & pH Probe 5 & 8.9 \\
\hline Coils, NaNO3 & Tests 48-51 & 0.81 & 49 & pH Probe 6 & 7.23 \\
\hline Coils, $\mathrm{NaNO}_{3}$ & Tests 48-51 & 0.81 & 50 & pH Probe 1 & 11.73 \\
\hline Coils, NaNO3 & Tests 48-51 & 0.81 & 50 & pH Probe 2 & 9.48 \\
\hline Coils, NaNO3 & Tests 48-51 & 0.81 & 50 & pH Probe 3 & 10.73 \\
\hline Coils, NaNO3 & Tests 48-51 & 0.81 & 50 & pH Probe 4 & 10.51 \\
\hline Coils, NaNO3 & Tests 48-51 & 0.81 & 50 & pH Probe 5 & 11.76 \\
\hline Coils, $\mathrm{NaNO}_{3}$ & Tests 48-51 & 0.81 & 50 & pH Probe 6 & 11.19 \\
\hline Coils, NaNO3 & Tests 48-51 & 0.81 & 51 & pH Probe 1 & 17.2 \\
\hline Coils, NaNO3 & Tests 48-51 & 0.81 & 51 & pH Probe 2 & . \\
\hline Coils, NaNO3 & Tests 48-51 & 0.81 & 51 & pH Probe 3 & \\
\hline Coils, NaNO3 & Tests 48-51 & 0.81 & 51 & pH Probe 4 & 8.14 \\
\hline Coils, NaNO3 & Tests 48-51 & 0.81 & 51 & pH Probe 5 & 8.4 \\
\hline Coils, NaNO3 & Tests 48-51 & 0.81 & 51 & pH Probe 6 & 9.77 \\
\hline Coils, NaNO3 & Tests $52-60$ & 0.7 & 52 & pH Probe 1 & 16.71 \\
\hline Coils, NaNO3 & Tests $52-60$ & 0.7 & 52 & pH Probe 2 & 5 \\
\hline Coils, NaNO3 & Tests $52-60$ & 0.7 & 52 & pH Probe 3 & \\
\hline Coils, NaNO3 & Tests $52-60$ & 0.7 & 52 & pH Probe 4 & 14.32 \\
\hline Coils, NaNO3 & Tests $52-60$ & 0.7 & 52 & pH Probe 5 & 8.43 \\
\hline Coils, $\mathrm{NaNO}_{3}$ & Tests $52-60$ & 0.7 & 52 & pH Probe 6 & 12.13 \\
\hline Coils, NaNO3 & Tests $52-60$ & 0.7 & 53 & pH Probe 1 & 16.29 \\
\hline Coils, NaNO3 & Tests $52-60$ & 0.7 & 53 & pH Probe 2 & 16.51 \\
\hline Coils, NaNO3 & Tests $52-60$ & 0.7 & 53 & pH Probe 3 & 13.24 \\
\hline
\end{tabular}


SRNL-STI-2011-00151

5/26/11 Revision 0

SRNL-L4221-2011-00005

March 17, 2011

Page 10 of 33

Table Al. Blending Times for EDL Tests

\begin{tabular}{|c|c|c|c|c|c|}
\hline $\begin{array}{c}\text { Test } \\
\text { Groups }\end{array}$ & $\begin{array}{c}\text { Test } \\
\text { Grouping }\end{array}$ & $\begin{array}{c}\mathrm{UoD} \\
\left(\mathrm{ft}^{\wedge} 2 / \mathrm{sec}\right) \\
\end{array}$ & Test & Probe & $\begin{array}{l}\text { Blending } \\
\text { Time (min) }\end{array}$ \\
\hline Coils, NaNO3 & Tests $52-60$ & 0.7 & 53 & pH Probe 4 & 14.58 \\
\hline Coils, NaNO3 & Tests $52-60$ & 0.7 & 53 & pH Probe 5 & 12.53 \\
\hline Coils, NaNO3 & Tests $52-60$ & 0.7 & 53 & pH Probe 6 & 15.97 \\
\hline Coils, NaNO3 & Tests $52-60$ & 0.7 & 54 & pH Probe 1 & 7.72 \\
\hline Coils, NaNO3 & Tests $52-60$ & 0.7 & 54 & pH Probe 2 & 4.36 \\
\hline Coils, NaNO3 & Tests $52-60$ & 0.7 & 54 & pH Probe 3 & 7.15 \\
\hline Coils, NaNO3 & Tests $52-60$ & 0.7 & 54 & pH Probe 4 & 6.55 \\
\hline Coils, NaNO3 & Tests $52-60$ & 0.7 & 54 & pH Probe 5 & 6.95 \\
\hline Coils, NaNO3 & Tests $52-60$ & 0.7 & 54 & pH Probe 6 & 738 \\
\hline Coils, NaNO3 & Tests $52-60$ & 0.7 & 55 & pH Probe 1 & 11.11 \\
\hline Coils, NaNO3 & Tests $52-60$ & 0.7 & 55 & $\mathrm{pH}$ Probe 2 & 5.24 \\
\hline Coils, NaNO3 & Tests $52-60$ & 0.7 & 55 & pH Probe 3 & 13.13 \\
\hline Coils, NaNO3 & Tests $52-60$ & 0.7 & 55 & pH Probe 4 & 7.69 \\
\hline Coils, NaNO3 & Tests $52-60$ & 0.7 & 55 & pH Probe 5 & 11.99 \\
\hline Coils, NaNO3 & Tests $52-60$ & 0.7 & 55 & pH Probe 6 & 13.41 \\
\hline Coils, NaNO3 & Tests $52-60$ & 0.7 & 56 & pH Probe 1 & 14.52 \\
\hline Coils, NaNO3 & Tests $52-60$ & 0.7 & 56 & pH Probe 2 & . \\
\hline Coils, NaNO3 & Tests $52-60$ & 0.7 & 56 & pH Probe 3 & \\
\hline Coils, NaNO3 & Tests $52-60$ & 0.7 & 56 & pH Probe 4 & 10.65 \\
\hline Coils, NaNO3 & Tests $52-60$ & 0.7 & 56 & pH Probe 5 & 10.73 \\
\hline Coils, NaNO3 & Tests $52-60$ & 0.7 & 56 & pH Probe 6 & 13.07 \\
\hline Coils, NaNO3 & Tests 52-60 & 0.7 & 57 & $\mathrm{pH}$ Probe 1 & 5.32 \\
\hline Coils, NaNO3 & Tests $52-60$ & 0.7 & 57 & pH Probe 2 & 4.53 \\
\hline Coils, NaNO3 & Tests $52-60$ & 0.7 & 57 & pH Probe 3 & 2.68 \\
\hline Coils, NaNO3 & Tests $52-60$ & 0.7 & 57 & pH Probe 4 & 2.51 \\
\hline Coils, NaNO3 & Tests $52-60$ & 0.7 & 57 & pH Probe 5 & 5.92 \\
\hline Coils, NaNO3 & Tests $52-60$ & 0.7 & 57 & pH Probe 6 & 2.28 \\
\hline Coils, NaNO3 & Tests $52-60$ & 0.7 & 58 & pH Probe 1 & 5.81 \\
\hline Coils, NaNO3 & Tests $52-60$ & 0.7 & 58 & pH Probe 2 & 8.34 \\
\hline Coils, NaNO3 & Tests $52-60$ & 0.7 & 58 & pH Probe 3 & 9.48 \\
\hline Coils, NaNO3 & Tests $52-60$ & 0.7 & 58 & pH Probe 4 & 8.71 \\
\hline Coils, NaNO3 & Tests $52-60$ & 0.7 & 58 & pH Probe 5 & 8.48 \\
\hline Coils, NaNO3 & Tests $52-60$ & 0.7 & 58 & pH Probe 6 & 9.79 \\
\hline Coils, NaNO3 & Tests $52-60$ & 0.7 & 59 & pH Probe 1 & 2.82 \\
\hline Coils, NaNO3 & Tests $52-60$ & 0.7 & 59 & pH Probe 2 & 2.48 \\
\hline Coils, NaNO3 & Tests $52-60$ & 0.7 & 59 & pH Probe 3 & 1.79 \\
\hline Coils, NaNO3 & Tests $52-60$ & 0.7 & 59 & pH Probe 4 & 1.45 \\
\hline Coils, NaNO3 & Tests $52-60$ & 0.7 & 59 & $\mathrm{pH}$ Probe 5 & 1.11 \\
\hline Coils, NaNO3 & Tests $52-60$ & 0.7 & 59 & pH Probe 6 & 2.08 \\
\hline Coils, $\mathrm{NaNO}_{3}$ & Tests $52-60$ & 0.7 & 60 & pH Probe 1 & 8.94 \\
\hline Coils, NaNO3 & Tests $52-60$ & 0.7 & 60 & pH Probe 2 & 7.69 \\
\hline Coils, NaNO3 & Tests $52-60$ & 0.7 & 60 & pH Probe 3 & 6.75 \\
\hline Coils, NaNO3 & Tests $52-60$ & 0.7 & 60 & pH Probe 4 & 5.44 \\
\hline Coils, NaNO3 & Tests $52-60$ & 0.7 & 60 & pH Probe 5 & 7.18 \\
\hline Coils, NaNO3 & Tests $52-60$ & 0.7 & 60 & pH Probe 6 & 5.81 \\
\hline na & Tests $61-63$ & 0.81 & 61 & $\mathrm{pH}$ Probe 1 & 3.19 \\
\hline na & Tests $61-63$ & 0.81 & 61 & pH Probe 2 & 3.19 \\
\hline na & Tests 61-63 & 0.81 & 61 & pH Probe 3 & 3.25 \\
\hline na & Tests 61-63 & 0.81 & 61 & $\mathrm{pH}$ Probe 4 & 2.99 \\
\hline na & Tests 61-63 & 0.81 & 61 & pH Probe 5 & 7.43 \\
\hline na & Tests 61-63 & 0.81 & 61 & pH Probe 6 & 3.02 \\
\hline na & Tests $61-63$ & 0.81 & 62 & pH Probe 1 & 6.81 \\
\hline na & Tests 61-63 & 0.81 & 62 & pH Probe 2 & 8.8 \\
\hline na & Tests 61-63 & 0.81 & 62 & pH Probe 3 & 2.16 \\
\hline na & Tests 61-63 & 0.81 & 62 & pH Probe 4 & 2.14 \\
\hline na & Tests $61-63$ & 0.81 & 62 & pH Probe 5 & 7.29 \\
\hline na & Tests 61-63 & 0.81 & 62 & pH Probe 6 & 5.67 \\
\hline na & Tests $61-63$ & 0.81 & 63 & pH Probe 1 & 2.79 \\
\hline na & Tests 61-63 & 0.81 & 63 & pH Probe 2 & 4.41 \\
\hline na & Tests $61-63$ & 0.81 & 63 & pH Probe 3 & 2.68 \\
\hline na & Tests 61-63 & 0.81 & 63 & pH Probe 4 & 3.22 \\
\hline na & Tests 61-63 & 0.81 & 63 & pH Probe 5 & 7.83 \\
\hline na & Tests $61-63$ & 0.81 & 63 & pH Probe 6 & 3.07 \\
\hline
\end{tabular}


SRNL-STI-2011-00151

5/26/11 Revision 0

SRNL-L4221-2011-00005

March 17, 2011

Page 11 of 33

Table Al. Blending Times for EDL Tests

\begin{tabular}{|c|c|c|c|c|c|}
\hline $\begin{array}{c}\text { Test } \\
\text { Groups }\end{array}$ & $\begin{array}{c}\text { Test } \\
\text { Grouping }\end{array}$ & $\begin{array}{c}\mathrm{UoD} \\
\left(\mathrm{ft}^{\wedge} 2 / \mathrm{sec}\right)\end{array}$ & Test & Probe & $\begin{array}{l}\text { Blending } \\
\text { Time (min) }\end{array}$ \\
\hline na & Tests $64-68$ & 0.81 & 64 & pH Probe 1 & 4.78 \\
\hline na & Tests $64-68$ & 0.81 & 64 & pH Probe 2 & 5.61 \\
\hline na & Tests $64-68$ & 0.81 & 64 & pH Probe 3 & 2.79 \\
\hline na & Tests $64-68$ & 0.81 & 64 & pH Probe 4 & 3.62 \\
\hline na & Tests $64-68$ & 0.81 & 64 & pH Probe 5 & 2.25 \\
\hline na & Tests $64-68$ & 0.81 & 64 & pH Probe 6 & 4.21 \\
\hline na & Tests $64-68$ & 0.81 & 65 & pH Probe 1 & 5.64 \\
\hline na & Tests $64-68$ & 0.81 & 65 & pH Probe 2 & 8.8 \\
\hline na & Tests $64-68$ & 0.81 & 65 & pH Probe 3 & 4.44 \\
\hline na & Tests $64-68$ & 0.81 & 65 & pH Probe 4 & 4.95 \\
\hline na & Tests $64-68$ & 0.81 & 65 & pH Probe 5 & 5.58 \\
\hline na & Tests $64-68$ & 0.81 & 65 & pH Probe 6 & 5.64 \\
\hline na & Tests $64-68$ & 0.81 & 66 & $\mathrm{pH}$ Probe 1 & 4.13 \\
\hline na & Tests $64-68$ & 0.81 & 66 & pH Probe 2 & 6.15 \\
\hline na & Tests $64-68$ & 0.81 & 66 & pH Probe 3 & 4.01 \\
\hline na & Tests $64-68$ & 0.81 & 66 & pH Probe 4 & 4.67 \\
\hline na & Tests $64-68$ & 0.81 & 66 & pH Probe 5 & 4.41 \\
\hline na & Tests $64-68$ & 0.81 & 66 & pH Probe 6 & 4.38 \\
\hline na & Tests $64-68$ & 0.81 & 67 & pH Probe 1 & 1.65 \\
\hline na & Tests $64-68$ & 0.81 & 67 & pH Probe 2 & 1.91 \\
\hline na & Tests $64-68$ & 0.81 & 67 & pH Probe 3 & 1.42 \\
\hline na & Tests $64-68$ & 0.81 & 67 & pH Probe 4 & 2.02 \\
\hline na & Tests $64-68$ & 0.81 & 67 & pH Probe 5 & 1.68 \\
\hline na & Tests $64-68$ & 0.81 & 67 & pH Probe 6 & 0.74 \\
\hline na & Tests $64-68$ & 0.81 & 68 & pH Probe 1 & 2.99 \\
\hline na & Tests $64-68$ & 0.81 & 68 & pH Probe 2 & 2.93 \\
\hline na & Tests $64-68$ & 0.81 & 68 & pH Probe 3 & 3.27 \\
\hline na & Tests $64-68$ & 0.81 & 68 & pH Probe 4 & 4.41 \\
\hline na & Tests $64-68$ & 0.81 & 68 & pH Probe 5 & 3.79 \\
\hline na & Tests $64-68$ & 0.81 & 68 & pH Probe 6 & 3.39 \\
\hline No Coils, $\mathrm{NaNO}_{3}$ & Tests 69-73 & 0.81 & 69 & pH Probe 1 & 6.12 \\
\hline No Coils, $\mathrm{NaNO}_{3}$ & Tests $69-73$ & 0.81 & 69 & pH Probe 2 & 7.83 \\
\hline No Coils, NaNO3 & Tests $69-73$ & 0.81 & 69 & pH Probe 3 & 6.63 \\
\hline No Coils, $\mathrm{NaNO}_{3}$ & Tests $69-73$ & 0.81 & 69 & pH Probe 4 & 6.81 \\
\hline No Coils, $\mathrm{NaNO} 3$ & Tests $69-73$ & 0.81 & 69 & pH Probe 5 & 5.44 \\
\hline No Coils, NaNO3 & Tests $69-73$ & 0.81 & 69 & pH Probe 6 & 5.01 \\
\hline No Coils, $\mathrm{NaNO}_{3}$ & Tests $69-73$ & 0.81 & 70 & pH Probe 1 & 4.9 \\
\hline No Coils, NaNO3 & Tests $69-73$ & 0.81 & 70 & pH Probe 2 & 6.15 \\
\hline No Coils, $\mathrm{NaNO}_{3}$ & Tests $69-73$ & 0.81 & 70 & pH Probe 3 & 3.56 \\
\hline No Coils, $\mathrm{NaNO}_{3}$ & Tests $69-73$ & 0.81 & 70 & pH Probe 4 & 3.05 \\
\hline No Coils, $\mathrm{NaNO}_{3}$ & Tests $69-73$ & 0.81 & 70 & pH Probe 5 & 3.87 \\
\hline No Coils, $\mathrm{NaNO}_{3}$ & Tests 69-73 & 0.81 & 70 & pH Probe 6 & 4.44 \\
\hline No Coils, $\mathrm{NaNO}_{3}$ & Tests $69-73$ & 0.81 & 71 & $\mathrm{pH}$ Probe 1 & 4.19 \\
\hline No Coils, $\mathrm{NaNO}_{3}$ & Tests $69-73$ & 0.81 & 71 & pH Probe 2 & 4.98 \\
\hline No Coils, $\mathrm{NaNO}_{3}$ & Tests $69-73$ & 0.81 & 71 & pH Probe 3 & 4.53 \\
\hline No Coils, $\mathrm{NaNO}_{3}$ & Tests $69-73$ & 0.81 & 71 & pH Probe 4 & 4.93 \\
\hline No Coils, $\mathrm{NaNO} 3$ & Tests $69-73$ & 0.81 & 71 & pH Probe 5 & 5.98 \\
\hline No Coils, $\mathrm{NaNO}_{3}$ & Tests $69-73$ & 0.81 & 71 & pH Probe 6 & 3.16 \\
\hline No Coils, NaNO3 & Tests $69-73$ & 0.81 & 72 & $\mathrm{pH}$ Probe 1 & 3.64 \\
\hline No Coils, $\mathrm{NaNO}_{3}$ & Tests $69-73$ & 0.81 & 72 & pH Probe 2 & 4.5 \\
\hline No Coils, $\mathrm{NaNO}_{3}$ & Tests $69-73$ & 0.81 & 72 & pH Probe 3 & 4.04 \\
\hline No Coils, $\mathrm{NaNO}_{3}$ & Tests $69-73$ & 0.81 & 72 & pH Probe 4 & 4.84 \\
\hline No Coils, $\mathrm{NaNO} 3$ & Tests 69-73 & 0.81 & 72 & pH Probe 5 & 4.41 \\
\hline No Coils, $\mathrm{NaNO}_{3}$ & Tests 69-73 & 0.81 & 72 & pH Probe 6 & 2.53 \\
\hline No Coils, $\mathrm{NaNO} 3$ & Tests $69-73$ & 0.81 & 73 & pH Probe 1 & 3.19 \\
\hline No Coils, $\mathrm{NaNO}_{3}$ & Tests $69-73$ & 0.81 & 73 & pH Probe 2 & 3.76 \\
\hline No Coils, $\mathrm{NaNO}_{3}$ & Tests $69-73$ & 0.81 & 73 & pH Probe 3 & 2.99 \\
\hline No Coils, NaNO3 & Tests 69-73 & 0.81 & 73 & pH Probe 4 & 2.93 \\
\hline No Coils, $\mathrm{NaNO}_{3}$ & Tests $69-73$ & 0.81 & 73 & pH Probe 5 & 2.79 \\
\hline No Coils, NaNO3 & Tests $69-73$ & 0.81 & 73 & pH Probe 6 & 2.96 \\
\hline No Coils, $\mathrm{NaNO}_{3}$ & Tests $74-77$ & 0.58 & 74 & pH Probe 1 & 4.07 \\
\hline No Coils, $\mathrm{NaNO}_{3}$ & Tests $74-77$ & 0.58 & 74 & pH Probe 2 & 5.38 \\
\hline No Coils, NaNO3 & Tests $74-77$ & 0.58 & 74 & pH Probe 3 & 3.36 \\
\hline
\end{tabular}


SRNL-STI-2011-00151

5/26/11 Revision 0

SRNL-L4221-2011-00005

March 17, 2011

Page 12 of 33

Table Al. Blending Times for EDL Tests

\begin{tabular}{|c|c|c|c|c|c|}
\hline $\begin{array}{c}\text { Test } \\
\text { Groups }\end{array}$ & $\begin{array}{c}\text { Test } \\
\text { Grouping }\end{array}$ & $\begin{array}{c}\mathrm{UoD} \\
\left(\mathrm{ft}^{\wedge} 2 / \sec \right)\end{array}$ & Test & Probe & $\begin{array}{c}\text { Blending } \\
\text { Time (min) }\end{array}$ \\
\hline No Coils, $\mathrm{NaNO} 3$ & Tests $74-77$ & 0.58 & 74 & pH Probe 4 & 1.04 \\
\hline No Coils, $\mathrm{NaNO} 3$ & Tests $74-77$ & 0.58 & 74 & pH Probe 5 & 3.99 \\
\hline No Coils, NaNO3 & Tests $74-77$ & 0.58 & 74 & pH Probe 6 & 4.47 \\
\hline No Coils, $\mathrm{NaNO} 3$ & Tests $74-77$ & 0.58 & 75 & pH Probe 1 & 7.52 \\
\hline No Coils, $\mathrm{NaNO} 3$ & Tests $74-77$ & 0.58 & 75 & pH Probe 2 & 8.6 \\
\hline No Coils, NaNO3 & Tests $74-77$ & 0.58 & 75 & pH Probe 3 & 4.87 \\
\hline No Coils, $\mathrm{NaNO} 3$ & Tests $74-77$ & 0.58 & 75 & pH Probe 4 & 5.69 \\
\hline No Coils, $\mathrm{NaNO} 3$ & Tests $74-77$ & 0.58 & 75 & pH Probe 5 & 6.01 \\
\hline No Coils, $\mathrm{NaNO} 3$ & Tests $74-77$ & 0.58 & 75 & pH Probe 6 & 6.15 \\
\hline No Coils, $\mathrm{NaNO}_{3}$ & Tests $74-77$ & 0.58 & 76 & pH Probe 1 & 3.45 \\
\hline No Coils, $\mathrm{NaNO}_{3}$ & Tests $74-77$ & 0.58 & 76 & $\mathrm{pH}$ Probe 2 & 4.36 \\
\hline No Coils, $\mathrm{NaNO} 3$ & Tests $74-77$ & 0.58 & 76 & $\mathrm{pH}$ Probe 3 & 3.1 \\
\hline No Coils, $\mathrm{NaNO} 3$ & Tests $74-77$ & 0.58 & 76 & pH Probe 4 & 3.42 \\
\hline No Coils, $\mathrm{NaNO} 3$ & Tests $74-77$ & 0.58 & 76 & pH Probe 5 & 4.53 \\
\hline No Coils, $\mathrm{NaNO} 3$ & Tests $74-77$ & 0.58 & 76 & pH Probe 6 & 3.56 \\
\hline No Coils, $\mathrm{NaNO} 3$ & Tests $74-77$ & 0.58 & 77 & pH Probe 1 & 4.95 \\
\hline No Coils, $\mathrm{NaNO} 3$ & Tests $74-77$ & 0.58 & 77 & pH Probe 2 & 6.92 \\
\hline No Coils, $\mathrm{NaNO} 3$ & Tests $74-77$ & 0.58 & 77 & pH Probe 3 & 4.44 \\
\hline No Coils, $\mathrm{NaNO} 3$ & Tests $74-77$ & 0.58 & 77 & pH Probe 4 & 5.01 \\
\hline No Coils, $\mathrm{NaNO} 3$ & Tests $74-77$ & 0.58 & 77 & pH Probe 5 & 4.24 \\
\hline No Coils, $\mathrm{NaNO}_{3}$ & Tests $74-77$ & 0.58 & 77 & pH Probe 6 & 4.7 \\
\hline na & Tests 78-81 & 0.81 & 78 & $\mathrm{pH}$ Probe 1 & 16.23 \\
\hline na & Tests 78-81 & 0.81 & 78 & pH Probe 2 & . \\
\hline na & Tests 78-81 & 0.81 & 78 & pH Probe 3 & \\
\hline na & Tests 78-81 & 0.81 & 78 & $\mathrm{pH}$ Probe 4 & 17.31 \\
\hline na & Tests $78-81$ & 0.81 & 78 & pH Probe 5 & 17.03 \\
\hline na & Tests $78-81$ & 0.81 & 78 & pH Probe 6 & 18.91 \\
\hline na & Tests 78-81 & 0.81 & 79 & pH Probe 1 & 8.57 \\
\hline na & Tests 78-81 & 0.81 & 79 & $\mathrm{pH}$ Probe 2 & \\
\hline na & Tests $78-81$ & 0.81 & 79 & pH Probe 3 & \\
\hline na & Tests $78-81$ & 0.81 & 79 & $\mathrm{pH}$ Probe 4 & 5.38 \\
\hline na & Tests $78-81$ & 0.81 & 79 & $\mathrm{pH}$ Probe 5 & 1.96 \\
\hline na & Tests $78-81$ & 0.81 & 79 & pH Probe 6 & 4.02 \\
\hline na & Tests 78-81 & 0.81 & 80 & pH Probe 1 & 14.64 \\
\hline na & Tests $78-81$ & 0.81 & 80 & pH Probe 2 & $\dot{.}$ \\
\hline na & Tests $78-81$ & 0.81 & 80 & pH Probe 3 & . \\
\hline na & Tests $78-81$ & 0.81 & 80 & pH Probe 4 & 8.63 \\
\hline na & Tests $78-81$ & 0.81 & 80 & $\mathrm{pH}$ Probe 5 & 8.37 \\
\hline na & Tests $78-81$ & 0.81 & 80 & pH Probe 6 & 9.74 \\
\hline na & Tests $78-81$ & 0.81 & 81 & $\mathrm{pH}$ Probe 1 & 10.62 \\
\hline na & Tests $78-81$ & 0.81 & 81 & $\mathrm{pH}$ Probe 2 & 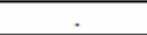 \\
\hline na & Tests $78-81$ & 0.81 & 81 & $\mathrm{pH}$ Probe 3 & \\
\hline na & Tests $78-81$ & 0.81 & 81 & $\mathrm{pH}$ Probe 4 & 7.32 \\
\hline na & Tests 78-81 & 0.81 & 81 & pH Probe 5 & 6.63 \\
\hline na & Tests $78-81$ & 0.81 & 81 & pH Probe 6 & 3.93 \\
\hline
\end{tabular}


SRNL-STI-2011-00151

5/26/11 Revision 0
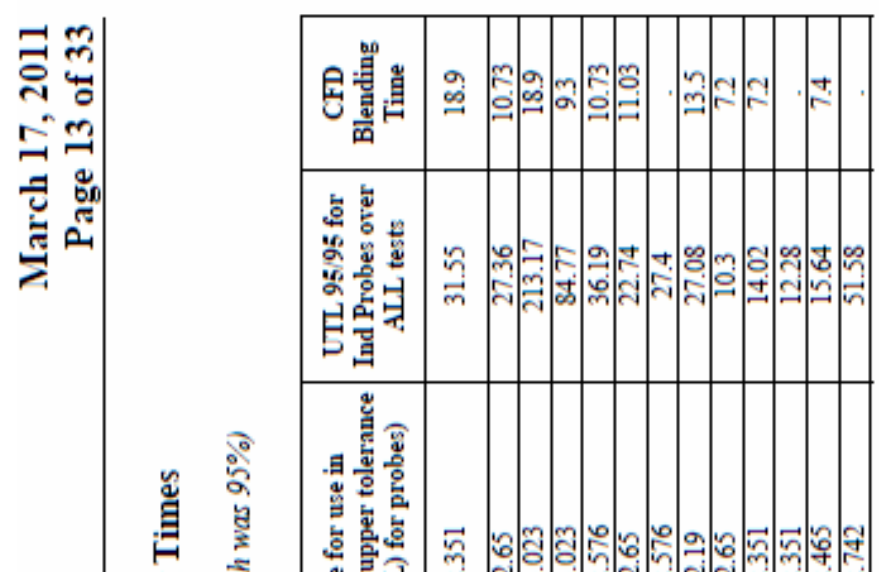

b 夏

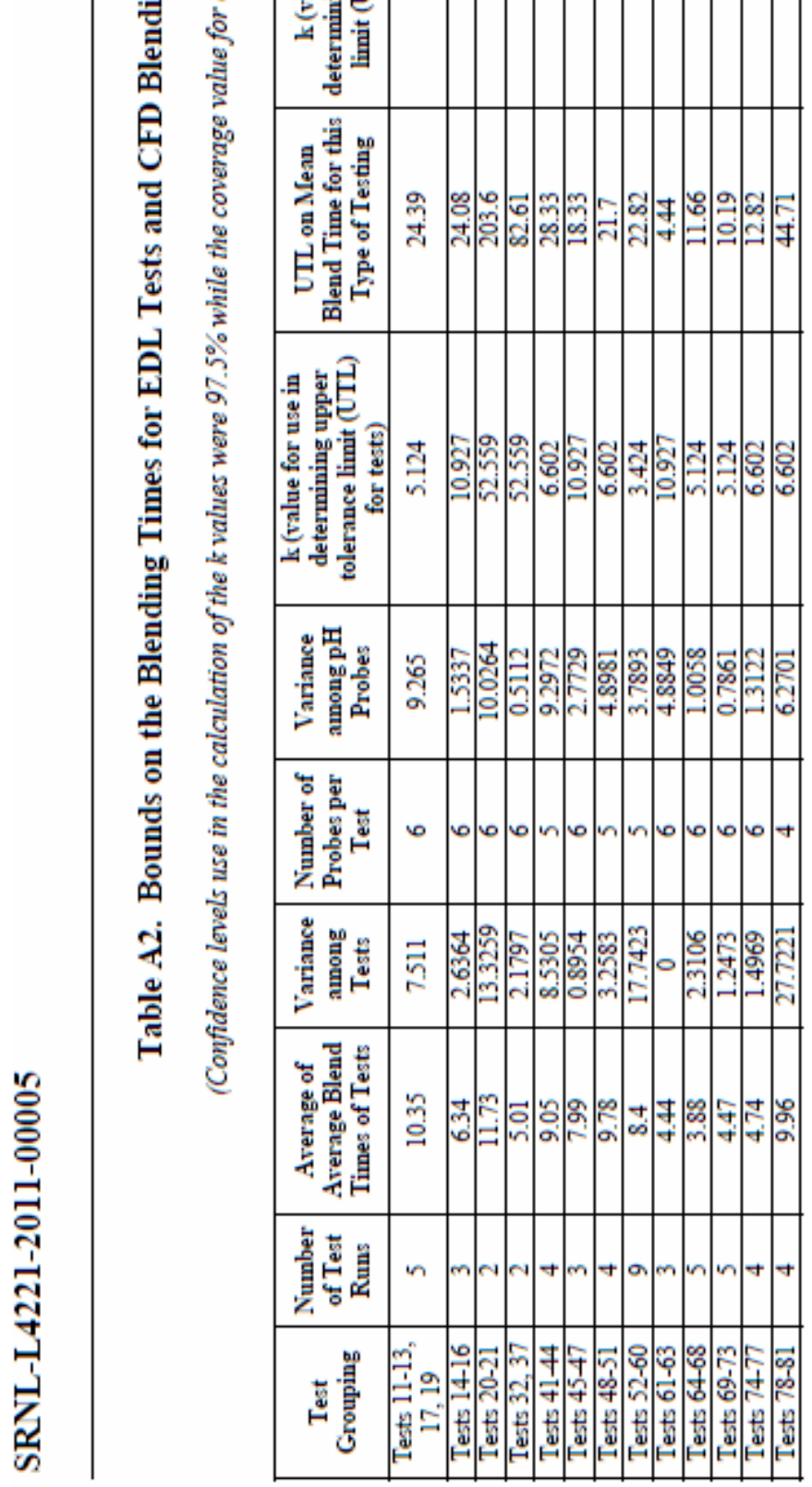


SRNL-STI-2011-00151

5/26/11 Revision 0

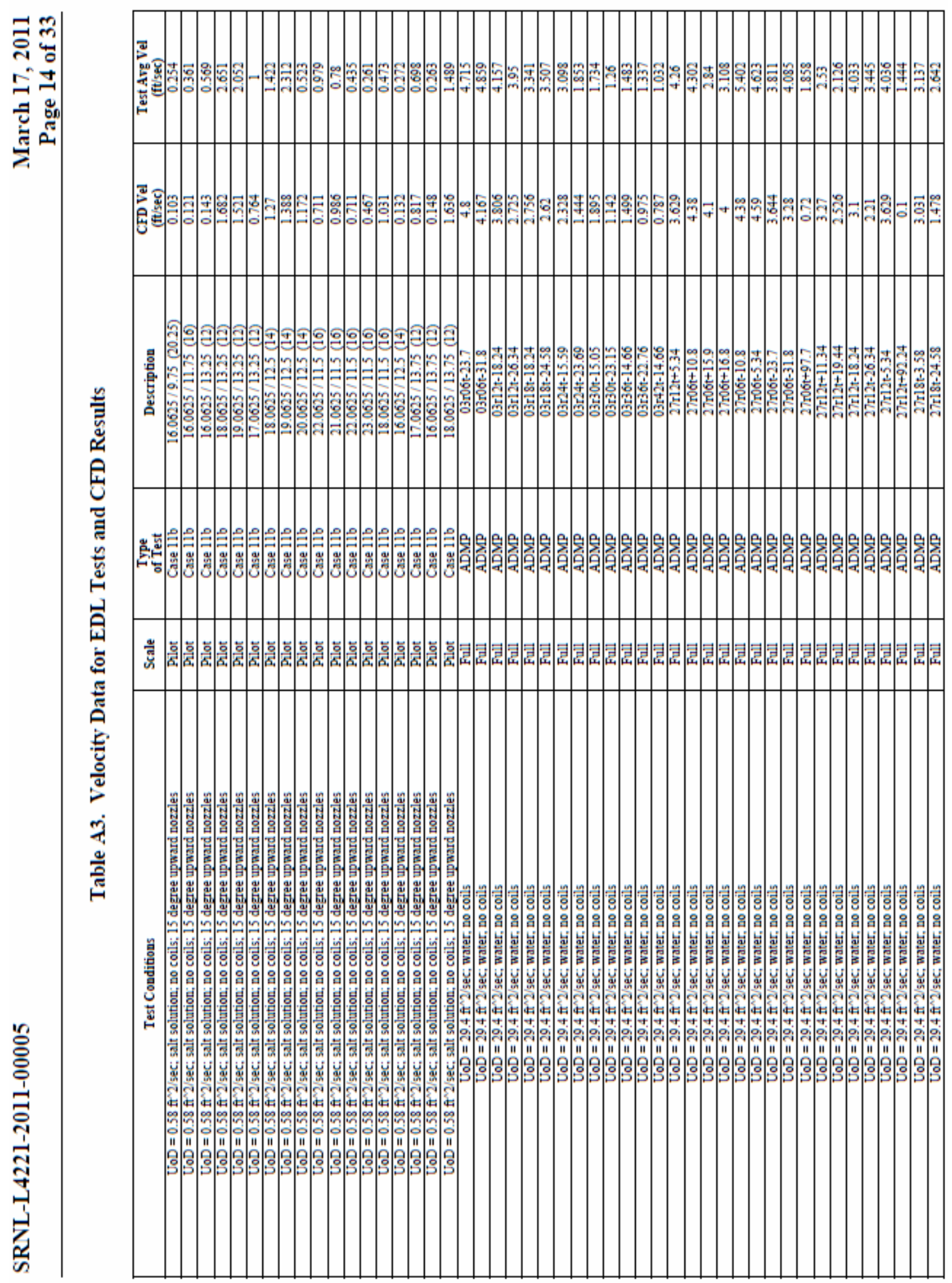


SRNL-STI-2011-00151

5/26/11 Revision 0

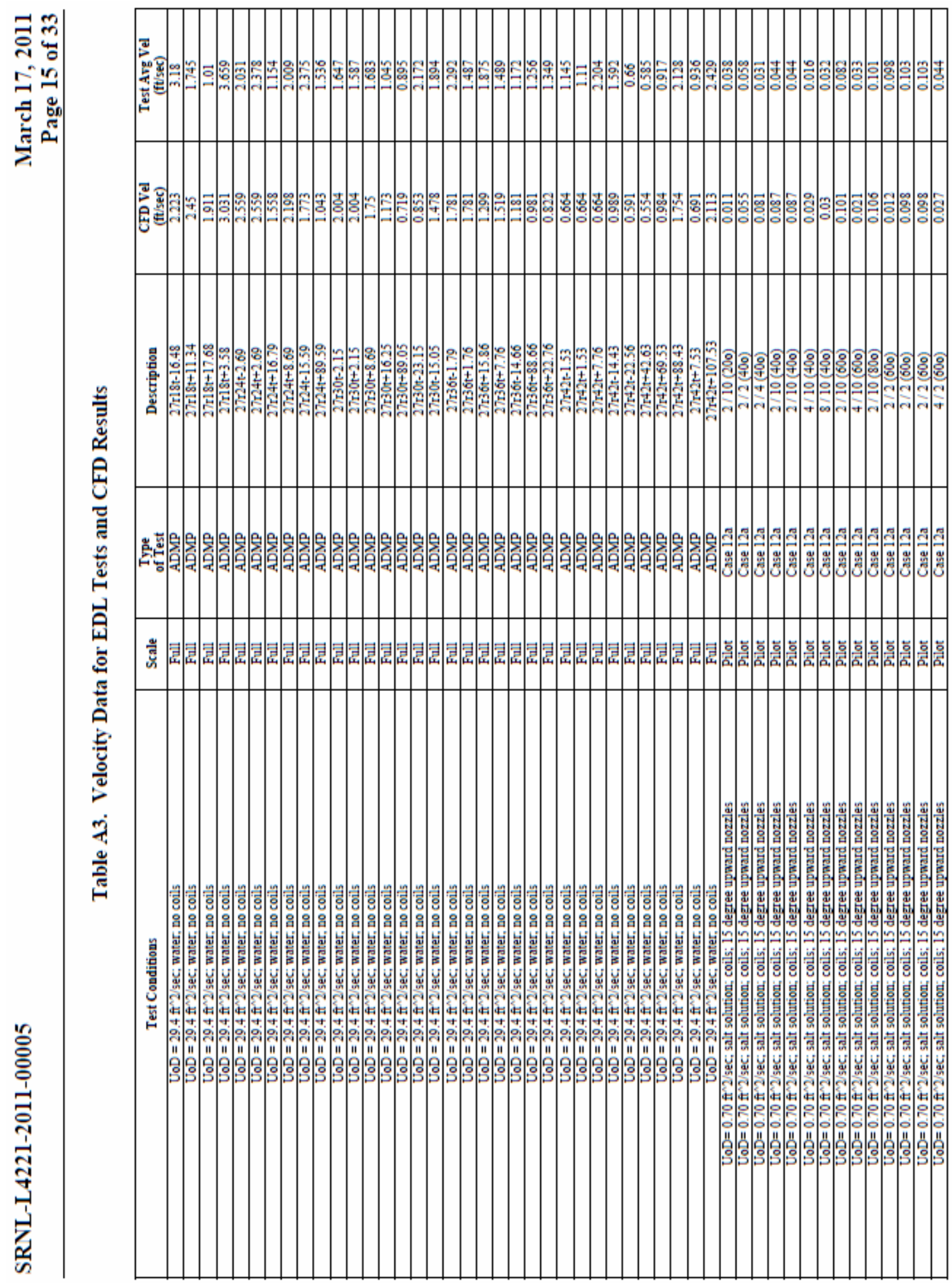


SRNL-STI-2011-00151

5/26/11 Revision 0

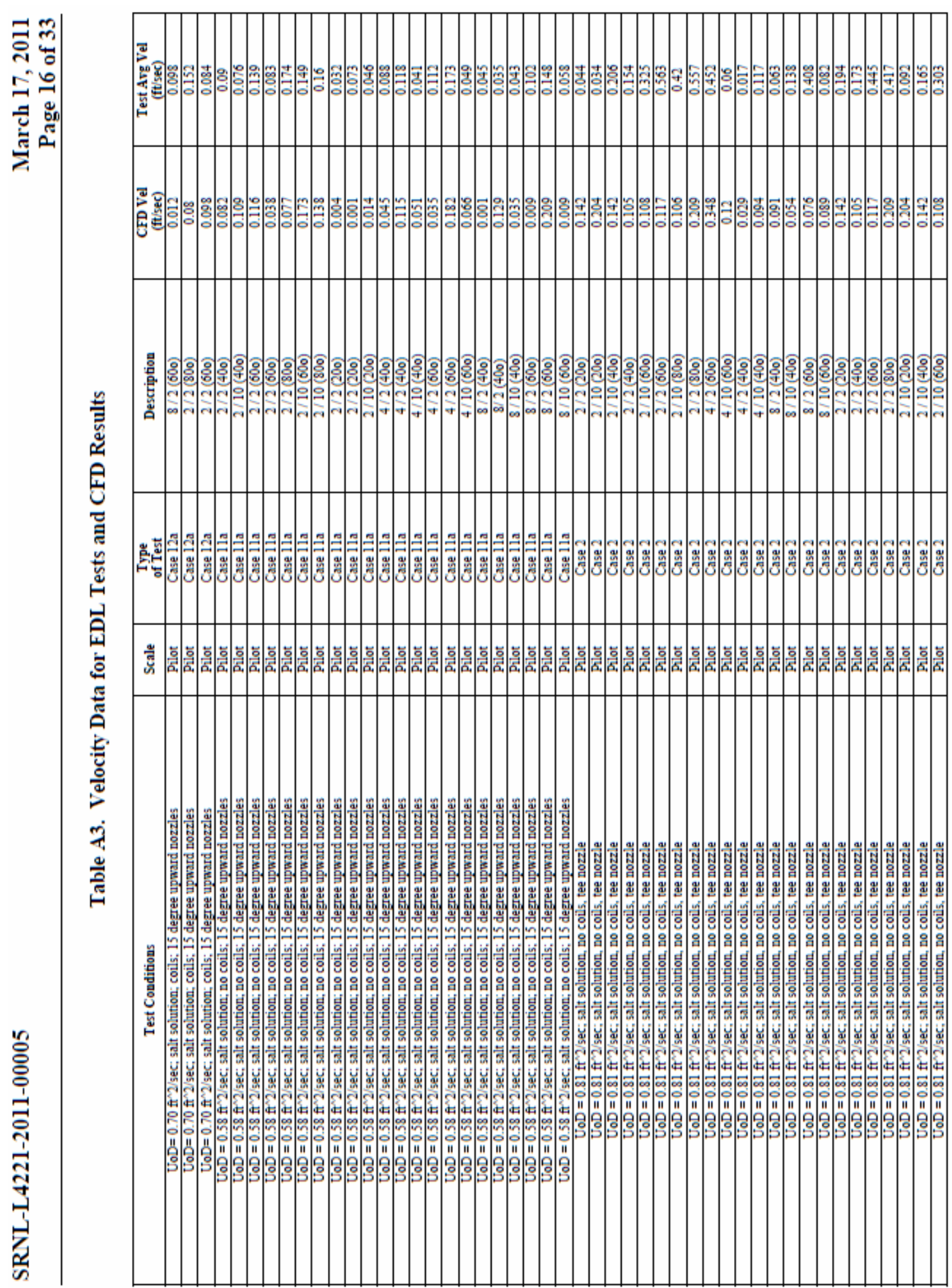


SRNL-STI-2011-00151

5/26/11 Revision 0

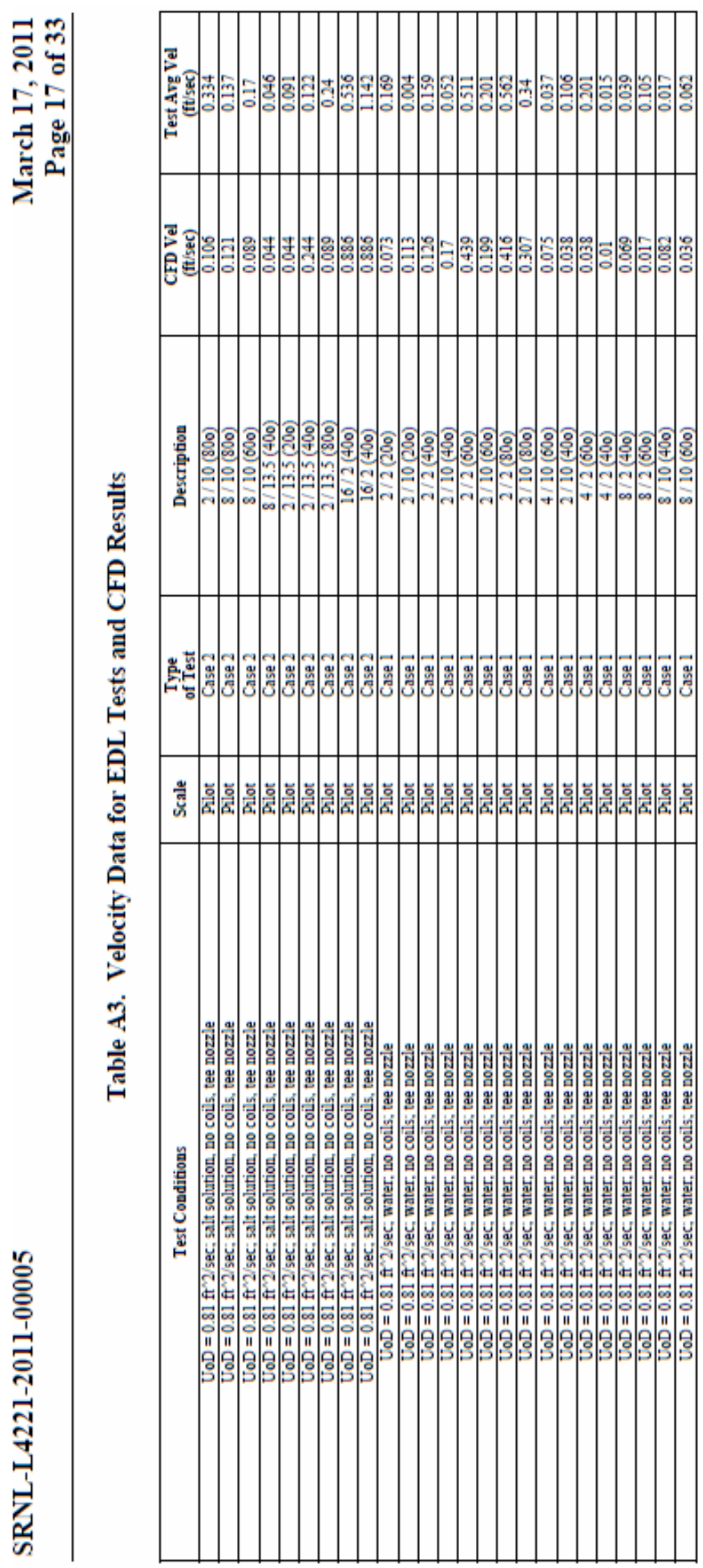


SRNL-STI-2011-00151

5/26/11 Revision 0

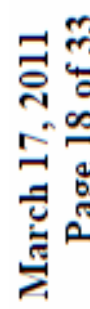

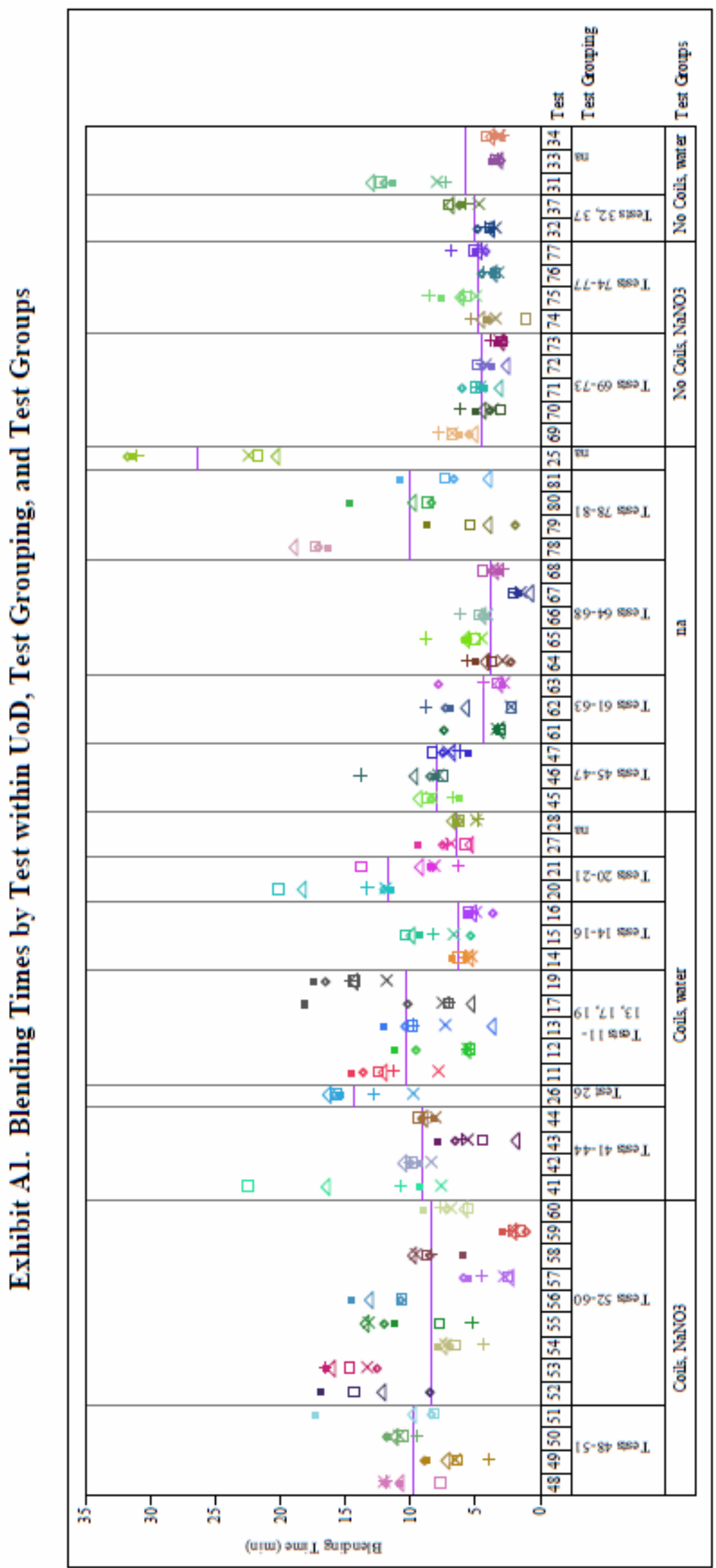


SRNL-STI-2011-00151

5/26/11 Revision 0

SRNL-L4221-2011-00005

March 17, 2011

Page 19 of 33

\section{Exhibit A2. Analysis of Variance of Blending Times by Test Groupings}

Response Blending Time (min) Test Grouping=Tests 11-13, 17, 19 Whole Model

Actual by Predicted Plot

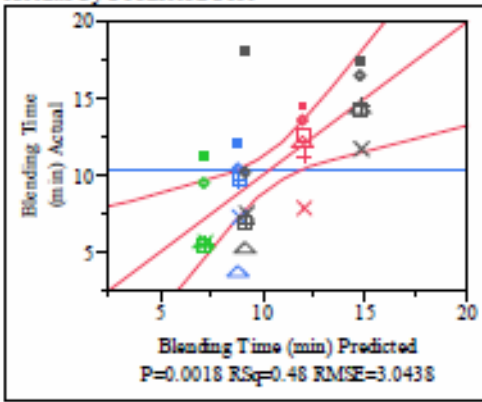

Summary of Fit

RSquare

RSquare Adj

Root Mean Square Error

Mean of Response

Observations (or Sum

Wgts)

Analysis of Variance

Source DF Sum of

Squares

217.32305

Enror $25 \quad 231.62553$

$\begin{array}{lll}\text { C. } & 29 & 448.94859\end{array}$

0.48407

0.40152

3.04385

10.3493

30
Residual by Predicted Plot

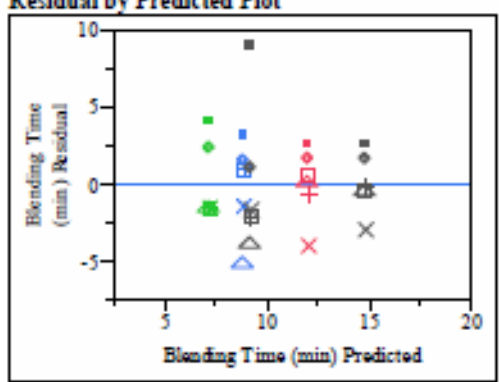

Erpected Mean Squares

The Mean Square per row by the Variance Component per column

EMS Intercep Test\&Rando

$\begin{array}{lrr} & \text { t } & \text { m } \\ \text { Intercept } & 0 & 0 \\ \text { Test\&Rando } & 0 & 6\end{array}$

$\mathrm{m}$

plus 1.0 times Residual Error Variance

$\begin{array}{lcr}\begin{array}{l}\text { Variance Component Estimates } \\ \text { Component }\end{array} & \begin{array}{r}\text { Var Comp Est } \\ \text { Percent of } \\ \text { Total }\end{array} \\ \begin{array}{lcr}\text { Test } \& \text { Rando } \\ \text { m }\end{array} & 7.510957 & 44.772 \\ \text { Residual } & 9.265021 & 55.228 \\ \text { Total } & 16.77598 & 100.000\end{array}$

These estimates based on equating Mean Squares to Expected Value.

Test Denominator Synthesis

Source MS Den DF Den Denom MS

Test\&Rando $9.26502 \quad 25 \begin{gathered}\text { Synthesis } \\ \text { Residual }\end{gathered}$

$\mathrm{m}$

Tests wrt Random Effects

Source SS MS Num DF Num F Prob $>$ F

Toat\& Ranin $21732 \quad 5433 n 8 \quad 4 \quad \begin{array}{r}\text { Ratio } \\ 5841\end{array} \quad n$ nols 
SRNL-STI-2011-00151

5/26/11 Revision 0

\section{Exhibit A2. Analysis of Variance of Blending Times by Test Groupings}

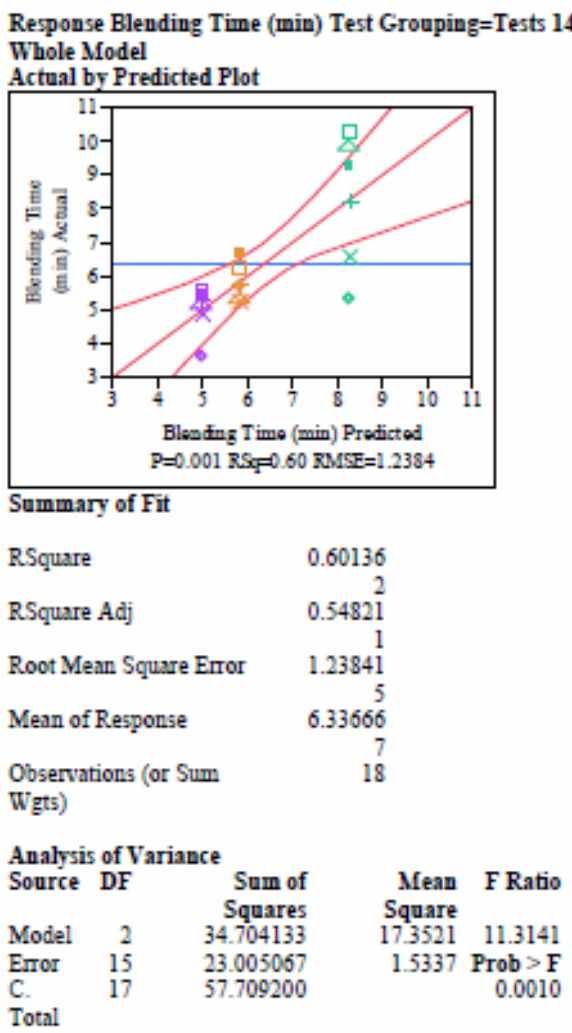

Erpected Mean Squares

The Mean Square per row by the Variance Component per column

EMS

$\begin{array}{lll} & \text { t } & \text { m } \\ \text { Intercept } & 0 & 0 \\ \text { Test\&Rando } & 0 & 6\end{array}$

plus 1.0 times Residual Error Variance

$\begin{array}{lrr}\begin{array}{l}\text { Variance Component Estimates } \\ \text { Component }\end{array} & \begin{array}{r}\text { Var Comp Est } \\ \text { Percent of } \\ \text { Total }\end{array} \\ \text { Test\&Rando } & 2.636399 & 63.222 \\ \text { m } & & \\ \text { Residual } & 1.533671 & 36.778 \\ \text { Total } & 4.17007 & 100.000\end{array}$

These estimates based on equating Mean Squares to Expected Value.

Test Denominator Synthesis

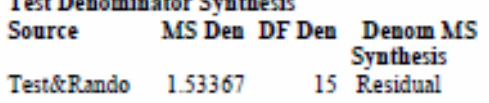

15 Residual

$\mathrm{m}$

Tests wrt Random Effects

Source SS MS Num DF Num F Ratio Prob > F

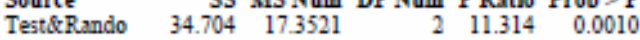

$\begin{array}{rrrrr}4.704 & 17.3521 & 2 & 11.314 & 0.0010 \\ 1 & & & 1 & \end{array}$

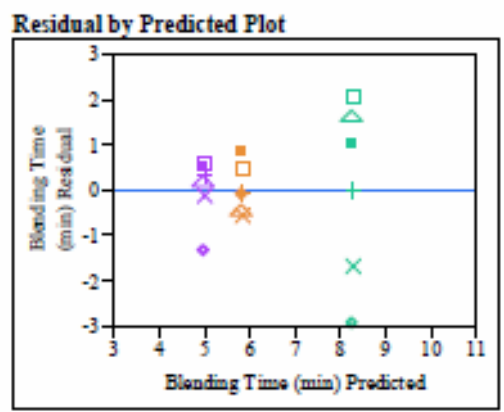

Response Blending Time (min) Test Grouping=Tests 20-21 Whole Model

Actual by Predicted Plot

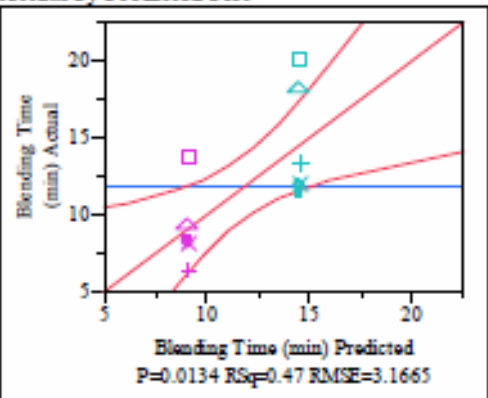

Summary of Fit

RSquare

0.47297

RSquare Adj

0.42027

Root Mean Square Error $\quad 3.16645$

Mean of Response

Observations (or Sum

Wgts)

Analysis of Variance

$\begin{array}{lrrrr}\text { Source } & \text { DF } & \begin{array}{r}\text { Sum of } \\ \text { Squares }\end{array} & \begin{array}{r}\text { Mean } \\ \text { Square }\end{array} & \text { F Ratio } \\ \text { Model } & 1 & 89.98163 & 89.9816 & 8.9744 \\ \text { Error } & 10 & 100.26437 & 10.0264 & \text { Prob }>\text { F } \\ \text { C. } & 11 & 190.24600 & & 0.0134 \\ \text { Total } & & & & \end{array}$

Erpected Mean Squares

The Mean Square per row by the Variance Component per column

EMS

Intercept

Test\& Rando

$\begin{array}{rr}\text { Intercep } & \text { Test\&Rando } \\ \mathbf{t} & \mathbf{m} \\ 0 & 0 \\ 0 & 6\end{array}$

plus 1.0 times Residual Error Variance

Variance Component Estimates

Component Var Comp Est Percent of

$\begin{array}{lrr}\text { Test\&Rando } & 13.32587 & \text { Total }\end{array}$

$\begin{array}{llr}\text { m } & & \\ \text { Residual } & 10.02644 & 42.936\end{array}$

$\begin{array}{lll}\text { Total } & 23.3523 & 100.000\end{array}$

These estimates based on equating Mean Squares to Expected Value 
SRNL-STI-2011-00151

5/26/11 Revision 0

\section{Exhibit A2. Analysis of Variance of Blending Times by Test Groupings}

\begin{tabular}{lll}
\multicolumn{2}{l}{ Test Denominator Synthesis } \\
Source & MS Den DF Den & $\begin{array}{c}\text { Denom MS } \\
\text { Synthesis }\end{array}$ \\
Test\&Rando & $10.0264 \quad 10$ & $\begin{array}{l}\text { Residual } \\
\text { Reside }\end{array}$
\end{tabular}

Test\&Rando $\quad 10.0264 \quad 10$ Residual

m

Tests wrt Random Effects

Source SS MS Num DF Num F Prob $>$ F

$\begin{array}{lrrrrrr}\text { Test\&Rando } & 89.981 & 89.9816 & 1 & 8.9744 & 0.0134 \\ \text { m } & 6 & & & & \end{array}$

Residual by Predicted Plot

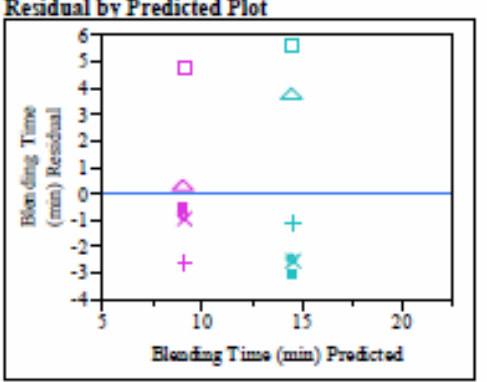

Response Blending Time (min) Test Grouping=Test 26 Whole Model Actual by Predicted Plot

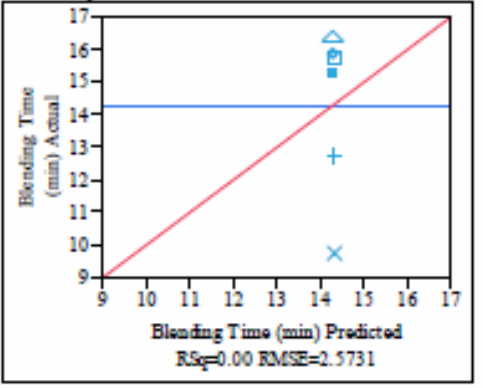

$$
\text { Summary of Fit }
$$

RSquare

RSoure Adj

Root Mean Square Error $\quad \begin{array}{r}0 \\ 2.57305 \\ 6\end{array}$

Mesn of Response $\quad 14.2716$

Observations (or Sum

Wgts)

Analysis of Variance

$\begin{array}{lcrrr}\text { Source } & \text { DF } & \begin{array}{r}\text { Sum of } \\ \text { Squares }\end{array} & \begin{array}{r}\text { Mean } \\ \text { Square }\end{array} & \text { F Ratio } \\ \text { Model } & 0 & 0.000000 & 0.00000 & \\ \text { Enror } & 5 & 33.103083 & 6.62062 & \text { Prob }>\text { F } \\ \text { C. } & 5 & 33.103083 & & \end{array}$

$\begin{array}{lll}\text { Error } & 5 & 33.103083 \\ \text { C. } & 5 & 33.103083\end{array}$

Total

Erpected Mean Squares

The Mean Square per row by the Variance Component per column

$\begin{array}{lrr}\text { EMS } & \text { Intercep } & \text { Test\&Rando } \\ & \mathrm{t} & \mathrm{m} \\ \text { Intercept } & 0 & 0 \\ \text { Test\&Rando } & 0 & 0\end{array}$

$\mathrm{m}$

plus 1.0 times Residual Enror Variance

\begin{tabular}{|c|c|c|}
\hline $\begin{array}{l}\text { Variance } \\
\text { Compone }\end{array}$ & $\begin{array}{l}\text { nt Estimates } \\
\text { omp Est }\end{array}$ & $\begin{array}{l}\text { Percent } \\
\text { Tot: }\end{array}$ \\
\hline $\begin{array}{l}\text { Residua } \\
\text { Total }\end{array}$ & $\begin{array}{l}6.620617 \\
6.620617\end{array}$ & $\begin{array}{l}100.000 \\
100.000\end{array}$ \\
\hline
\end{tabular}

These estimates based on equating Mean Squares to Expected Value.

Test Denominator Synthesis

Source MS Den DF Den $\begin{gathered}\text { Denom MS } \\ \text { Synthesis }\end{gathered}$

Test\&Rando $6.62062 \quad 5$ Residual

m

Tests wrt Random Effects

Source SS MSNum DF Num F Prob $>$ F

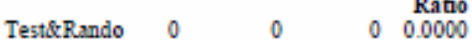

$\mathrm{m}$

Residual by Predicted Plot

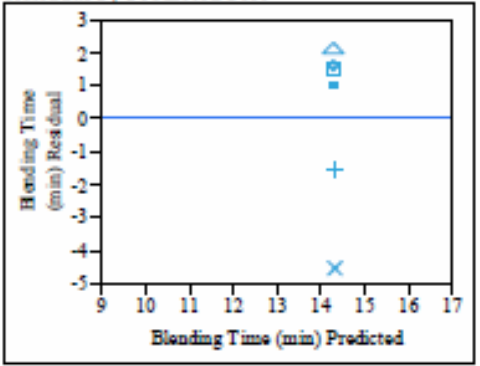

Response Blending Time (min) Test Grouping=Tests 32,37

Whole Model

Actual by Predicted Plot

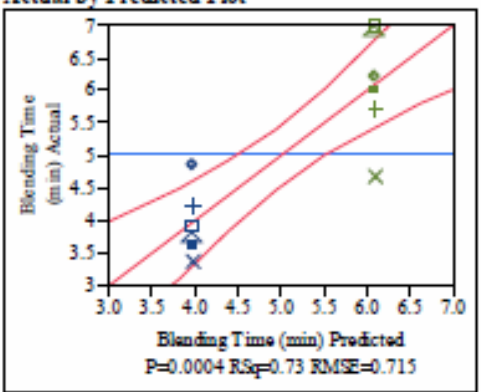

Summary of Fit

RSquare

RSquare Adj

Root Mean Square Error $\quad 0.71498$

Mean of Response $\quad 5.01416$

Observations (or Sum $\quad 12$

Wgts)

Analysis of Variance

Source DF Sum of Mean F Ratio

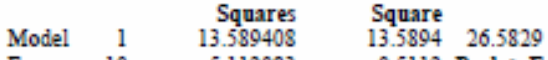

$\begin{array}{llll}\text { Error } & 10 & 5.112083 & 0.5112 \text { Prob }>\text { F }\end{array}$

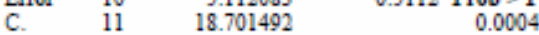

Total

Erpected Mean Squares

The Mean Square per row by the Variance Component per column 
SRNL-STI-2011-00151

5/26/11 Revision 0

\section{Exhibit A2. Analysis of Variance of Blending Times by Test Groupings}

\begin{tabular}{|c|c|c|}
\hline Test Denomi & ator Synthesis & \\
\hline Source & MS Den DF Den & $\begin{array}{l}\text { Denom MS } \\
\text { Synthesis }\end{array}$ \\
\hline Test\&\& Rando & 10.0264 & Residual \\
\hline
\end{tabular}

Test\&Rando $\quad 10.0264 \quad 10$ Residual

m

Tests wrt Random Effects

Source SS MS Num DF Num F Prob $>$ F

$\begin{array}{lrrrrrr}\text { Test\&Rando } & 89.981 & 89.9816 & 1 & 8.9744 & 0.0134 \\ \text { m } & 6 & & & & \end{array}$

Residual by Predicted Plot

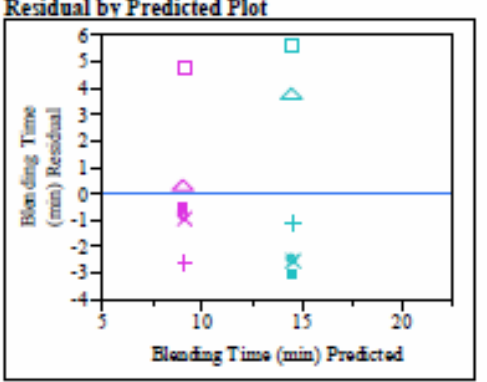

Response Blending Time (min) Test Grouping=Test 26 Whole Model Actual by Predicted Plot

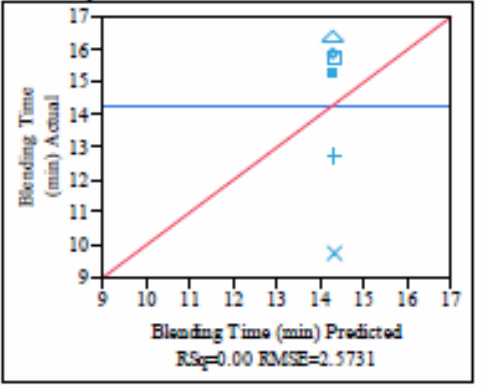

$$
\text { Summary of Fit }
$$

RSquare

RSoure Adj

Root Mean Square Error $\quad \begin{array}{r}0 \\ 2.57305 \\ 6\end{array}$

Mesn of Response $\quad 14.2716$

Observations (or Sum

Wgts)

Analysis of Variance

$\begin{array}{lcrrr}\text { Source } & \text { DF } & \begin{array}{r}\text { Sum of } \\ \text { Squares }\end{array} & \begin{array}{r}\text { Mean } \\ \text { Square }\end{array} & \text { F Ratio } \\ \text { Model } & 0 & 0.000000 & 0.00000 & \\ \text { Enror } & 5 & 33.103083 & 6.62062 & \text { Prob }>\text { F } \\ \text { C. } & 5 & 33.103083 & & \end{array}$

$\begin{array}{lll}\text { Error } & 5 & 33.103083 \\ \text { C. } & 5 & 33.103083\end{array}$

Total

Erpected Mean Squares

The Mean Square per row by the Variance Component per column

$\begin{array}{lrr}\text { EMS } & \text { Intercep } & \text { Test\&Rando } \\ & \mathrm{t} & \mathrm{m} \\ \text { Intercept } & 0 & 0 \\ \text { Test\&Rando } & 0 & 0\end{array}$

$\mathrm{m}$

plus 1.0 times Residual Enror Variance

\begin{tabular}{|c|c|c|}
\hline $\begin{array}{l}\text { Variance } \\
\text { Compone }\end{array}$ & $\begin{array}{l}\text { nt Estimates } \\
\text { omp Est }\end{array}$ & $\begin{array}{l}\text { Percent } \\
\text { Tot: }\end{array}$ \\
\hline $\begin{array}{l}\text { Residua } \\
\text { Total }\end{array}$ & $\begin{array}{l}6.620617 \\
6.620617\end{array}$ & $\begin{array}{l}100.000 \\
100.000\end{array}$ \\
\hline
\end{tabular}

These estimates based on equating Mean Squares to Expected Value.

Test Denominator Synthesis

Source MS Den DF Den $\begin{gathered}\text { Denom MS } \\ \text { Synthesis }\end{gathered}$

Test\&Rando $6.62062 \quad 5$ Residual

m

Tests wrt Random Effects

Source SS MSNum DF Num F Prob $>$ F

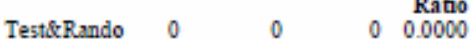

$\mathrm{m}$

Residual by Predicted Plot

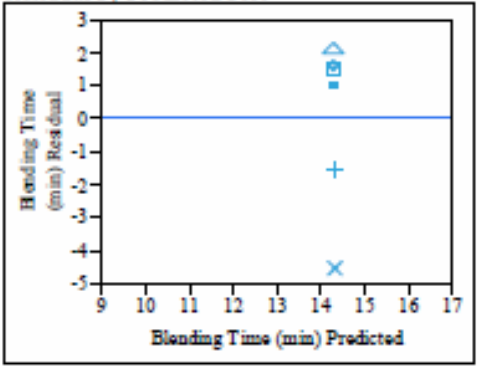

Response Blending Time (min) Test Grouping=Tests 32,37

Whole Model

Actual by Predicted Plot

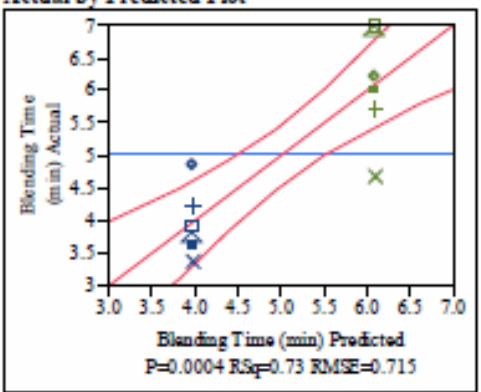

Summary of Fit

RSquare

RSquare Adj

Root Mean Square Error $\quad 0.71498$

Mean of Response $\quad 5.01416$

7.01416
7

Observations (or Sum

Wgt5)

Analysis of Variance

$\begin{array}{lrr}\text { Source DF } & \text { Sum of } & \text { Mean } \\ \text { Squares } & \text { Square } & \end{array}$

$\begin{array}{lrrrr} & & \text { Squares } & \text { Square } & \\ \text { Model } & 1 & 13.589408 & 13.5894 & 26.5829\end{array}$

$\begin{array}{lrrr}\text { Error } & 10 & 5.112083 & 0.5112 \text { Prob }>\text { F }\end{array}$

$\begin{array}{llll}\text { C. } & 11 & 18.701492 & 0.0004 \\ \text { Total } & & \end{array}$

Erpected Mean Squares

The Mean Square per row by the Variance Component per column 
SRNL-STI-2011-00151

5/26/11 Revision 0

SRNL-L4221-2011-00005

March 17, 2011

Page 22 of 33

Exhibit A2. Analysis of Variance of Blending Times by Test Groupings

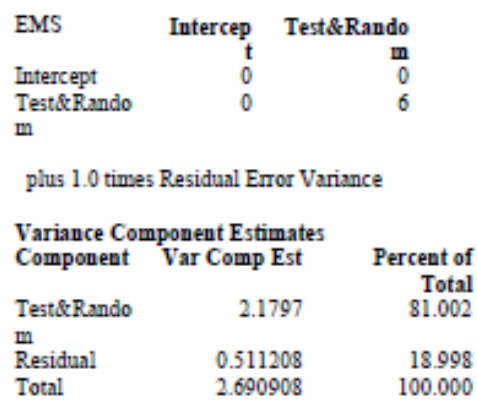

\begin{tabular}{|c|c|c|c|c|}
\hline \multicolumn{5}{|c|}{ Analysis of Variance } \\
\hline Source & DF & $\begin{array}{r}\text { Sum of } \\
\text { Squares }\end{array}$ & $\begin{array}{l}\text { Mean } \\
\text { Square }\end{array}$ & F Ratio \\
\hline $\begin{array}{l}\text { Model } \\
\text { Error }\end{array}$ & 3 & 174.76476 & 58.2549 & 6.2659 \\
\hline $\begin{array}{l}\text { Error } \\
\text { C. }\end{array}$ & 19 & 176.64677 & 9.2972 & Prob $>$ F \\
\hline $\begin{array}{l}\text { C. } \\
\text { Total }\end{array}$ & 22 & 351.41152 & & 0.0039 \\
\hline
\end{tabular}

Expected Mean Squares

The Mean Square per row by the Variance Component per column

EMS Intercep Test\&Rando

$\begin{array}{lrr}\text { Intercept } & \text { t } & \text { m } \\ \text { Test\&Rando } & 0 & 5.73913\end{array}$

$\mathrm{m}$

These estimates based on equating Mean Squares to Expected Value.

Test Denominator Synthesis

Source MS Den DF Den $\underset{\text { Synthesis }}{\text { Denom MS }}$

Test\&Rando $\quad 0.51121 \quad 10 \begin{gathered}\text { Synthesis } \\ \text { Residual }\end{gathered}$

$\mathrm{m}$

Tests wrt Random Effects

Source SS MS Num DF Num F Ratio Prob $>$ F $\begin{array}{lrrrrr}\text { Source } & \text { SS } & \text { MS Num } & \text { DF Num F Ratio } & \text { Prob > F } \\ \text { Test\&Rando } & 13.589 & 13.5894 & 1 & 26.582 & 0.0004\end{array}$ $\mathrm{m}$

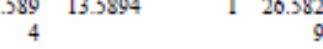

plus 1.0 times Residual Error Variance
$\begin{aligned} & \text { Variance Component Estimates } \\ & \text { Component }\end{aligned}$ Var Comp Est
$\begin{array}{lrr}\text { Test\&Rando } & \begin{array}{r}\text { Percent of } \\ \text { Total }\end{array} \\ \text { m } & 8.530512 & 47.850 \\ \text { Residual } & 9.297198 & 52.150 \\ \text { Total } & 17.82771 & 100.000\end{array}$

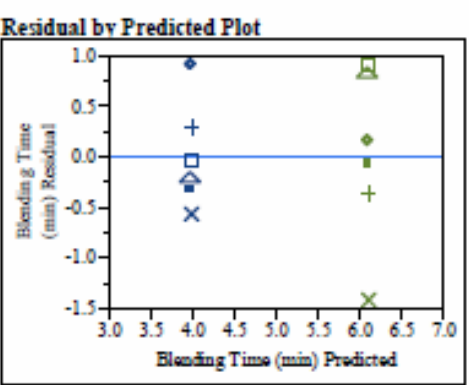

Response Blending Time (min) Test Grouping=Tests $41-44$ Whole Model

Actual by Predicted Plot

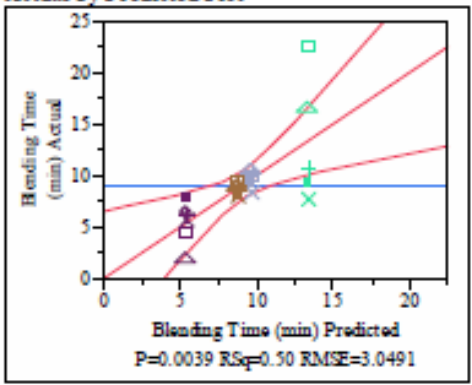

Summary of Fit

$\begin{array}{lr}\text { RSquare } & 0.49732 \\ \text { RSquare Adj } & 2 \\ \text { Root Mean Square Error } & 0.41795 \\ & 3.04913 \\ \text { Mean of Response } & 1 \\ \text { Observations (or Sum } & 9.05347 \\ \text { Wors) } & 83\end{array}$

Wgts)
These estimates based on equating Mean Squares to Expected Value.
Test Denominator Synthesis
Source MS Den DF Den Denom MS
Test\&Rando $\quad 9.2972 \quad 19 \begin{gathered}\text { Syuthesis } \\ \text { Residual }\end{gathered}$
$\mathrm{m}$
Tests wrt Random Effect
\begin{tabular}{lrrrrr} 
Source & \multicolumn{1}{c}{ SS MS Num DF Num } & \multicolumn{3}{c}{ F Prob $>$ F } \\
Test\&Rando & 174.76 & 58.2549 & 3 & 6.2659 & 0.0039 \\
m & 5 & & & &
\end{tabular}

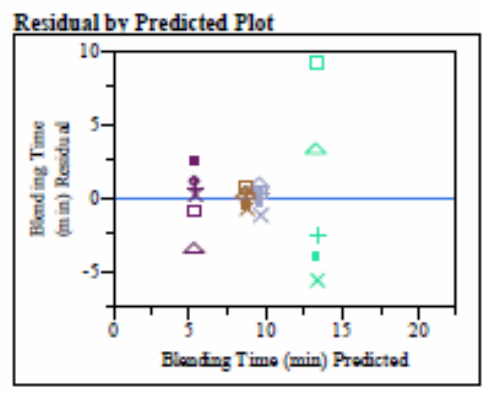

Response Blending Time (min) Test Grouping=Tests 45-47

Whole Model

Actual by Predicted Plot

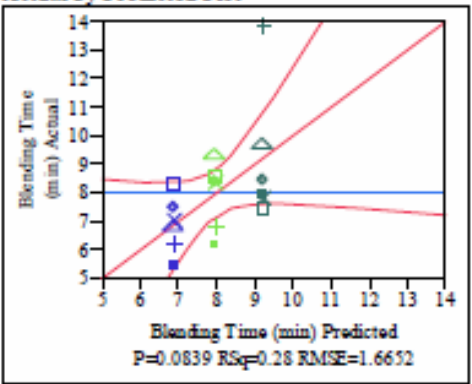

Summary of Fit

RSquare

0.28143 
SRNL-STI-2011-00151

5/26/11 Revision 0

Exhibit A2. Analysis of Variance of Blending Times by Test Groupings

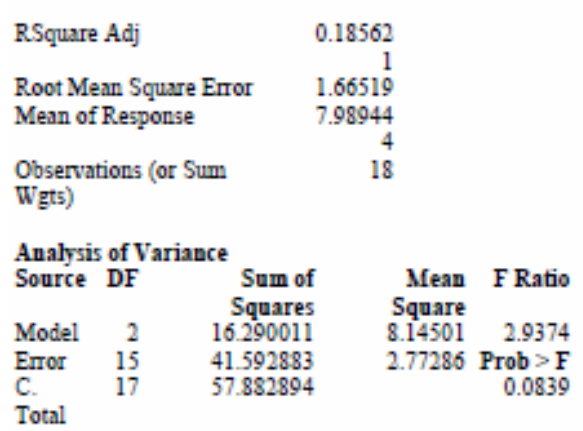

Erpected Mean Squares

The Mean Square per row by the Variance Component per column

EMS

Intercept

Test\&Rando

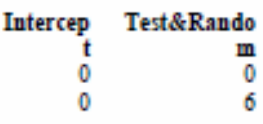

plus 1.0 times Residual Enor Variance

$\begin{array}{lrr}\text { Variance Component Estimates } & \\ \text { Component } & \text { Var Comp Est } & \begin{array}{r}\text { Percent of } \\ \text { Total }\end{array} \\ \text { Test\&Rando } & 0.895358 & 24.409 \\ \text { m } & & \\ \text { Residual } & 2.772859 & 75.591 \\ \text { Total } & 3.668217 & 100.000\end{array}$

These estimates based on equating Mean Squares to Expected Value.

Test Denominator Synthesis

Source MS Den DF Den Denom MS

Test\&Rando $2.77286 \quad 15$ Residual

m

Tests wrt Random Effects

Source SS MS Num DF Num $\underset{\text { Ratio }}{\text { F Prob }>\text { F }}$

$\begin{array}{lrrrrr}\text { Test\&Rando } & 16.2 & 8.14501 & 2 & 2.9374 & 0.0839\end{array}$

Residual by Predicted Plot

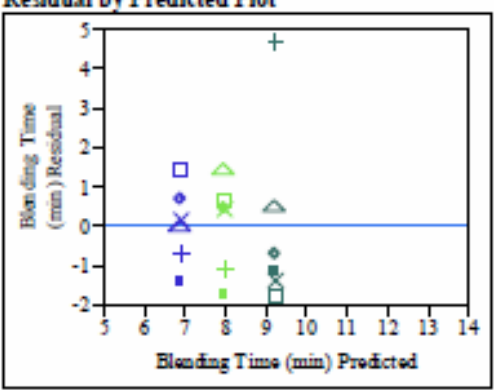

Response Blending Time (min) Test Grouping=Tests 48-51

Whole Model

Actual by Predicted Plot

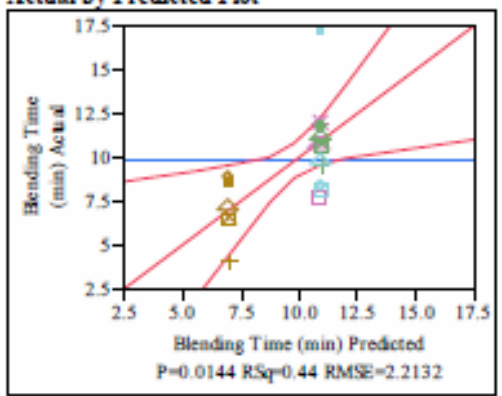

Summary of Fit

RSquare $\quad 0.43548$

RSquare Adj

Root Mean Square Error $\quad 2.21315$

Mean of Response $\quad 9.78227$

Observations (or Sum $\quad 22$

Wgts)

\begin{tabular}{|c|c|c|c|c|}
\hline \multicolumn{5}{|c|}{ Analysis of Variance } \\
\hline Source & DF & $\begin{array}{l}\text { Sum of } \\
\text { Squares }\end{array}$ & $\begin{array}{l}\text { Mean } \\
\text { Square }\end{array}$ & F Ratio \\
\hline Model & 3 & 68.01208 & 22.6707 & 4.6285 \\
\hline Error & 18 & 88.16491 & 4.8981 & Prob $>F$ \\
\hline $\begin{array}{l}\text { C. } \\
\text { Total }\end{array}$ & 21 & 156.17699 & & 0.0144 \\
\hline
\end{tabular}

Erpected Mean Squares

The Mean Square per row by the Variance Component per column

EMS

$\begin{array}{lrr} & \text { t } & \text { m } \\ \text { Intercept } & 0 & 0 \\ \text { Test\&Rando } & 0 & 5.45455\end{array}$

$\mathrm{m}$

plus 1.0 times Residual Error Variance

Variance Component Estimates

Component Var Comp Est Percent of

$\begin{array}{lrr} & \text { Total } \\ \text { Test\&Rando } & 3.258318 & 39.948\end{array}$

Residual $\quad 4.89805 \quad 60.052$

$\begin{array}{lrr}\text { Rotal } & \quad 8.896368 & 100.000\end{array}$

These estimates based on equating Mean Squares to Expected Value.

Test Denominator Synthesis

Source MS Den DF Den $\begin{gathered}\text { Denom MS } \\ \text { Syuthesis }\end{gathered}$

Test\& Rando $4.89805 \quad 18$ Residual

m

Tests wrt Random Effects

\begin{tabular}{lrrrrr} 
Source & \multicolumn{2}{c}{ SS MS Num DF Num } & $\begin{array}{r}\text { F Prob }>\text { F } \\
\text { Ratio }\end{array}$ \\
Test\&Rando & 68.012 & 22.6707 & 3 & 4.6285 & 0.0144 \\
m & 1 & & & &
\end{tabular}


SRNL-STI-2011-00151

5/26/11 Revision 0

\section{Exhibit A2. Analysis of Variance of Blending Times by Test Groupings}

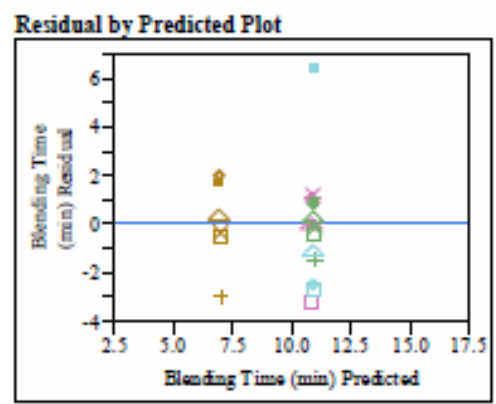

Response Blending Time (min) Test Grouping=Tests 52-60 Whole Model

Actual by Predicted Plot

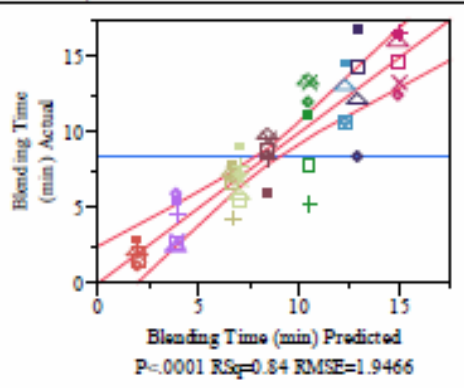

Summary of Fit

RSquare

RSquare Adj

Root Mean Square Error

Mean of Response

Observations (or Sum

Wgt5)

Analysis of Variance

$\begin{array}{lrrrrr}\text { Source } & \text { DF } & \begin{array}{r}\text { Sum of } \\ \text { Squares }\end{array} & \begin{array}{r}\text { Mean } \\ \text { Square }\end{array} & \text { F Ratio } \\ \text { Model } & 8 & 816.65102 & 102.081 & 26.9394 \\ \text { Error } & 41 & 155.36103 & 3.789 & \text { Prob }>\text { F } \\ \text { C. } & 49 & 972.01205 & & <.0001\end{array}$

Total

Erpected Mean Squares

The Mean Square per row by the Variance Component per column

EMS Intercep Test\&Rando

Intercept

Test\&Rando

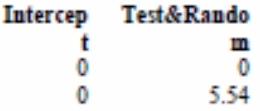

m

plus 1.0 times Residual Error Variance

Variance Component Estimates Component Var Comp Est

Percent of
Total
82.401
17.599
100.000

$\begin{array}{lrr}\text { Residual } & 3.789293 & 17.599 \\ \text { Total } & 21.53155 & 100.000\end{array}$

These estimates based on equating Mean Squares to Expected Value.

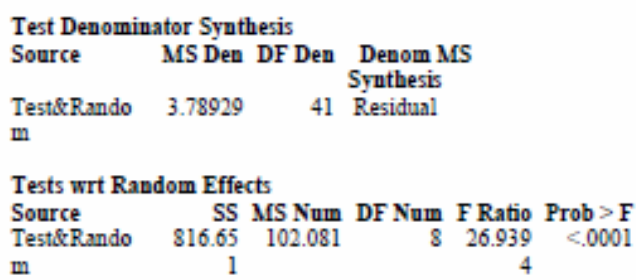

Residual by Predicted Plot

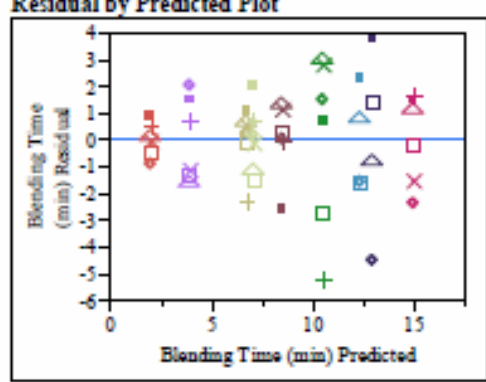

Response Blending Time (min) Test Grouping=Tests 61-63

Whole Model

Actual by Predicted Plot

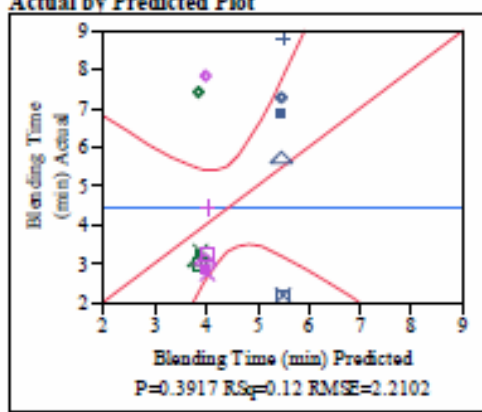

Summary of Fit

RSquare

0.11748
4

RSquare Adj

Root Mean Soure Error

Mean of Response

2
4.44111
1
18

Observations (or Sum

Wgts)

Analysis of Variance

$\begin{array}{lrrrrr}\text { Source } & \text { DF } & \begin{array}{r}\text { Sum of } \\ \text { Squares }\end{array} & \begin{array}{r}\text { Mean } \\ \text { Square }\end{array} & \text { F Ratio } \\ \text { Model } & 2 & 9.754544 & 4.87727 & 0.9984 \\ \text { Error } & 15 & 73.274233 & 4.88495 & \text { Prob }>\text { F } \\ \text { C. } & 17 & 83.028778 & & 0.3917 \\ \text { Total } & & & & \end{array}$

Erpected Mean Squares

The Mean Square per row by the Variance Component per column

EMS

Intercept

Intercep Test\&Rando

plus 1.0 times Residual Error Variance 
SRNL-STI-2011-00151

5/26/11 Revision 0

Exhibit A2. Analysis of Variance of Blending Times by Test Groupings

\begin{tabular}{lrr}
\multicolumn{2}{l}{$\begin{array}{l}\text { Variance Component Estimates } \\
\text { Component }\end{array}$} & $\begin{array}{r}\text { Var Comp Est } \\
\text { Percent of } \\
\text { Total }\end{array}$ \\
Test\&Rando & -0.00128 & -0.026 \\
m & & \\
Residual & 4.884949 & 100.026 \\
Total & 4.883669 & 100.000
\end{tabular}

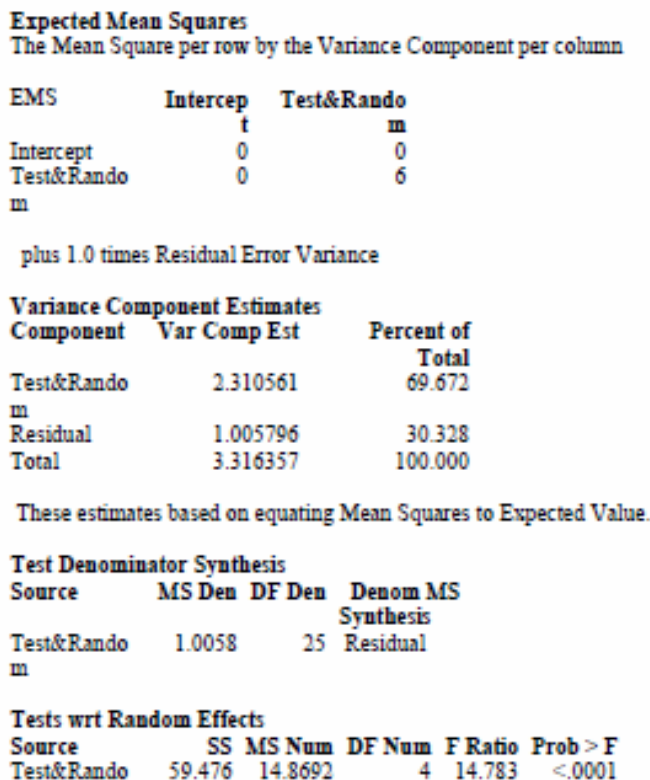

EMS

$\begin{array}{lll} & \text { t } & \text { m } \\ \text { Intercept } & 0 & 0 \\ \text { Test\&Rando } & 0 & 6\end{array}$

$\mathrm{m}$

plus 1.0 times Residual Error Variance

$\begin{array}{lcr}\begin{array}{l}\text { Variance Component Estimates } \\ \text { Component }\end{array} & \begin{array}{r}\text { Var Comp Est } \\ \text { Test\&Rando }\end{array} & \begin{array}{r}\text { Percent of } \\ \text { Total }\end{array} \\ \text { m } & 2.310561 & 69.672 \\ \text { Residual } & 1.005796 & 30.328 \\ \text { Total } & 3.316357 & 100.000\end{array}$

These estimates based on equating Mean Squares to Expected Value.

Test Denominator Synthesis

Source MSDen DF Den Denom MS

Test\&Rando $\quad 1.0058 \quad 25$ Residual

m

Tests wrt Random Effects

$\begin{array}{lrl}\text { Source } & \text { SS MS Num DF Num F Ratio Prob }>\text { F } \\ \text { Test \&Rando } & 59.476 & 148692 \\ 14.783 & <0001\end{array}$

These estimates based on equating Mean Squares to Expected Value.

Test Denominator Synthesis

\begin{tabular}{|c|c|}
\hline Source & MS Den DF Den \\
\hline Rando & 4.88495 \\
\hline
\end{tabular}

Test\& Rando $488495 \quad 15$ Residual

Tests wrt Random Effect:

Source SS MS Num DF Num F Prob $>$ F

$\begin{array}{lllllll}\text { Test\&Rando } & 9.7545 & 4.87727 & 2 & 0.9984 & 0.3917\end{array}$

$\mathrm{m}$

0.3917

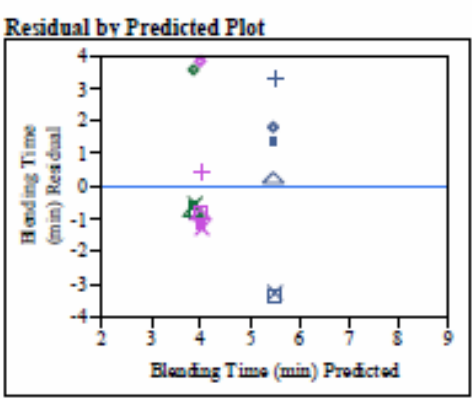

Response Blending Time (min) Test Grouping=Tests 64-68 Whole Model

Actual by Predicted Plot

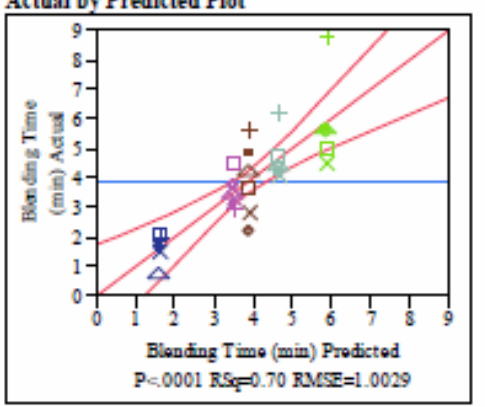

Summary of Fit

$\begin{array}{lr}\text { RSquare } & 0.70285 \\ \text { RSquare Adj } & 5 \\ & 0.65531 \\ \text { Root Mean Square Error } & 1 \\ & 1.00289 \\ \text { Mean of Response } & 4 \\ \text { Observations (or Sum } & 3.87533 \\ \text { Wgts) } & 3 \\ \end{array}$

Wet5)

Analysis of Variance

$\begin{array}{lrrrr}\text { Source } & \text { DF } & \begin{array}{r}\text { Sum of } \\ \text { Squares }\end{array} & \begin{array}{r}\text { Mean } \\ \text { Square }\end{array} & \text { F Ratio } \\ \text { Model } & 4 & 59.476647 & 14.8692 & 14.7835 \\ \text { Enror } & 25 & 25.144900 & 1.0058 & \begin{array}{r}\text { Prob }>\text { F } \\ \text { C. }\end{array} \\ \text { T. } & 29 & 84.621547 & & <.0001\end{array}$

Residual by Predicted Plot

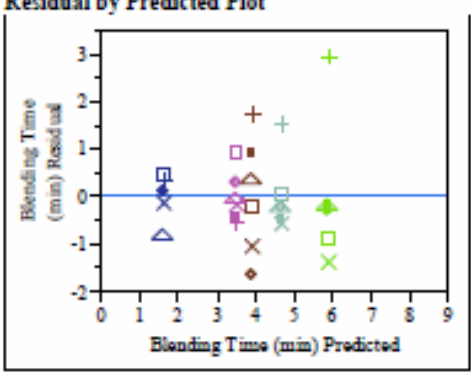

Response Blending Time (min) Test Grouping=Tests 69-73

Whole Model

Actual by Predicted Plot

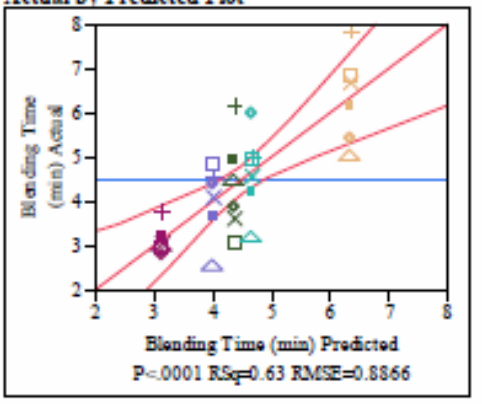

Summary of Fit

RSquare

RSquare Adj

Root Mean Square Error

Mean of Response

Observations (or Sum

Wgts) 
SRNL-STI-2011-00151

5/26/11 Revision 0

\section{Exhibit A2. Analysis of Variance of Blending Times by Test Groupings}

\begin{tabular}{|c|c|c|c|c|}
\hline \multicolumn{5}{|c|}{ Analysis of Variance } \\
\hline Source & DF & $\begin{array}{r}\text { Sum of } \\
\text { Squares }\end{array}$ & $\begin{array}{r}\text { Mean } \\
\text { Square }\end{array}$ & F Ratio \\
\hline Model & 4 & 33.080713 & 8.27018 & 10.5201 \\
\hline $\begin{array}{l}\text { Enror } \\
\text { C. }\end{array}$ & $\begin{array}{l}25 \\
29\end{array}$ & $\begin{array}{l}19.653367 \\
52.734080\end{array}$ & 0.78613 & $\begin{array}{r}\text { Prob }>\text { F } \\
<.0001\end{array}$ \\
\hline
\end{tabular}

Erpected Mean Squares

The Mean Square per row by the Variance Component per column

$\begin{array}{lrr}\text { EMS } & \text { Intercep } & \text { Test\&Rando } \\ \text { Intercept } & \text { t } & \text { m } \\ \text { Test\&Rando } & 0 & 0 \\ \text { m } & 0 & 6\end{array}$

plus 1.0 times Residual Enror Variance

$\begin{array}{lcr}\begin{array}{l}\text { Variance Component Estimates } \\ \text { Component }\end{array} & \begin{array}{r}\text { Var Comp Est } \\ \text { Percent of } \\ \text { Total }\end{array} \\ \text { Test\&Rando } & 1.247341 & 61.340 \\ \text { m } & & \\ \text { Residual } & 0.786135 & 38.660 \\ \text { Total } & 2.033475 & 100.000\end{array}$

These estimates based on equating Mean Squares to Expected Value.

Test Denominator Synthesis

\begin{tabular}{lll} 
Source & MS Den DF Den & $\begin{array}{c}\text { Denom MS } \\
\text { Synthesis }\end{array}$ \\
Test\&Rando & 0.78613 & 25 Residual \\
\hline$m$
\end{tabular}

m

Tests wrt Random Effects

Source SS MS Num DF Num F Ratio Prob $>$ F

$\begin{array}{lrrrrr}\text { Test\&Rando } & 33.080 & 8.27018 & 4 & 10.520 & <.0001 \\ \mathrm{~m} & 7 & 1 & \end{array}$

Residual by Predicted Plot

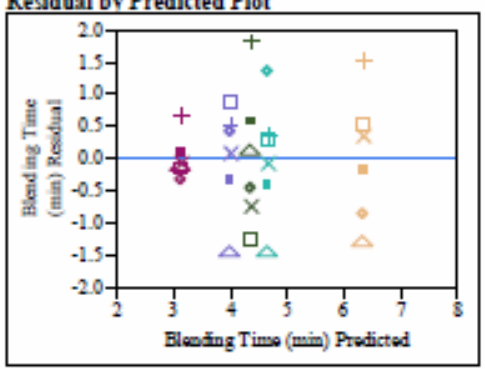

Response Blending Time (min) Test Grouping=Tests 74-77 Whole Model

Actual by Predicted Plot

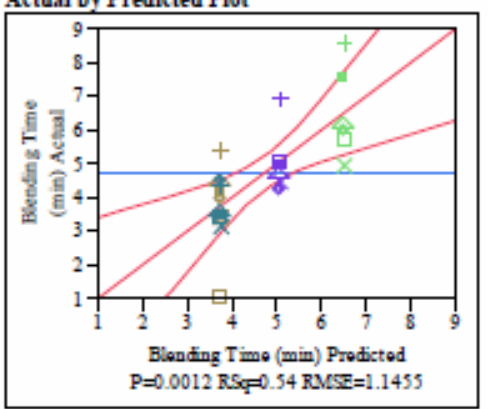

Summary of Fit

$\begin{array}{lr}\text { RSquare } & 0.54059 \\ \text { RSquare Adj } & 8 \\ & 0.47168 \\ \text { Root Mean Square Error } & 8 \\ & 1.14549 \\ \text { Mean of Response } & 3 \\ & 4.74291 \\ \text { Observations (or Sum } & 7 \\ \text { Tom } & 24\end{array}$

Wgts)

Analysis of Variance

Source DF Sum of Mean F Ratio

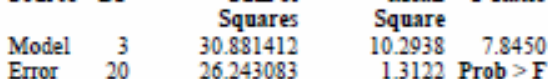

Error $20 \quad 26.243083 \quad 1.3122$ Prob $>$ F

$\begin{array}{llll}\text { C. } & 23 & 57.124496 & 0.0012\end{array}$

Erpected Mean Squares

The Mean Square per row by the Variance Component per column

EMS

Intercept

Test\&\&Rando

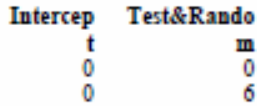

plus 1.0 times Residual Error Variance

Variance Component Estimates

Component Var Comp Est

Test\&Rando $\quad 1.496942$

Percent of

Total

Residual $\quad 1.312154 \quad 46.711$

$\begin{array}{llr}\text { Total } & 2.809096 & 400.711\end{array}$

These estimates based on equating Mean Squares to Expected Value.

Test Denominator Synthesis

Source MS Den DF Den $\begin{gathered}\text { Denom MS } \\ \text { Synthesis }\end{gathered}$

Test\&Rando $1.31215 \quad 20$ Residual

$\mathrm{m}$

Tests wrt Random Effect:

Source $\quad$ SS MS Num DF Num F Prob $>$ F

$\begin{array}{llllrl}\text { Test\&Rando } & 30.881 & 10.2938 & 3 & 7.8450 & 0.0012\end{array}$

$\mathrm{m}$

Residual by Predicted Plot

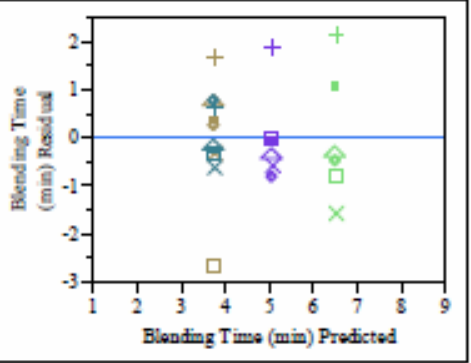


SRNL-STI-2011-00151

5/26/11 Revision 0

SRNL-L4221-2011-00005

March 17, 2011

Page 27 of 33

Exhibit A2. Analysis of Variance of Blending Times by Test Groupings

Response Blending Time (min) Test Grouping=Tests 78-81

Whole Model

Actual by Predicted Plot

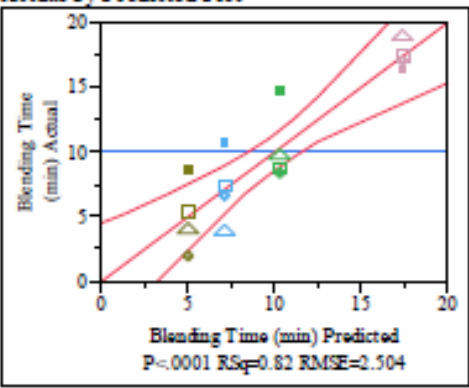

Summary of Fit

RSquare

RSquare Adj

0.82367
4
0.77959
2
2.50402
1
9.95562
5
16

Mean of Response

Observations (or Sum

Wgts)

Analysis of Variance

Source DF Sum of

Model $3 \quad 351.47592$

\begin{tabular}{lrr} 
Model & 3 & 351.47592 \\
Error & 12 & 75.24148 \\
\hline
\end{tabular}

$\begin{array}{llr}\text { Error } & 12 & 75.24148 \\ \text { C. } & 15 & 426.71739\end{array}$

Total

Erpected Mean Squares

The Mean Square per row by the Variance Component per column

EMS

Intercept

Test $\&$ Rando

$\begin{array}{rr}\text { Intercep } & \text { Test\&Rando } \\ \mathbf{t} & \mathrm{m} \\ 0 & 0 \\ 0 & 4\end{array}$

m

plus 1.0 times Residual Error Variance

Variance Component Estimates

Component Var Comp Est

Test\&Rando $\quad 27.7221$

mesidual $\quad 6.270123$

$\begin{array}{ll}\text { Residual } & 6.270123 \\ \text { Total } & 33.99225\end{array}$

These estimates based on equating Mean Squares to Expected Value.

Test Denominator Synthesis

Source MS Den DF Den $\begin{gathered}\text { Denom MS } \\ \text { Synthesis }\end{gathered}$

Test\&Rando $\quad 6.27012 \quad 12$ Residual

m

Tests wrt Random Effects

Source

SS MS Num DF Num F Ratio Prob > F

$\begin{array}{llllll}\text { Test\&Rando } & 351.47 & 117.159 & 3 & 18.685 & <.0001\end{array}$
F Ratio

18.6852

6.270 Prob $>F$

$<.0001$

Percent of
Total
81.554

18.446
100.000

13.685 m

Residual by Predicted Plot

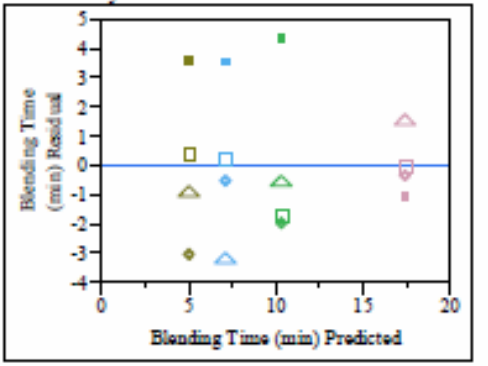

Response Blending Time (min) Test Grouping=na Whole Model

Actual by Predicted Plot

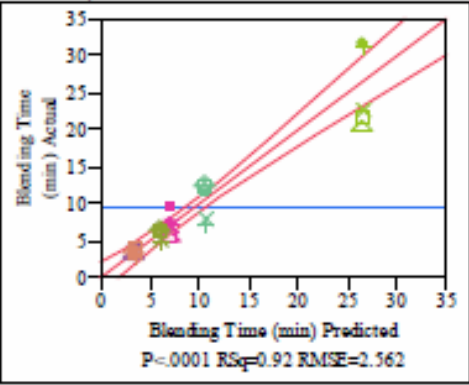

Summary of Fit

RSquare

RSquare Adj

0.92120

0.90807
7

Root Mean Square Error $\quad 2.56199$

Mean of Response

Observations (or Sum

Wgts)

9.40861

1
36

Analysis of Variance

Source DF Sum of

$\begin{array}{lllll}\text { Model } \quad 5 & 2302.2742 & 460.455 & 70.1507\end{array}$

Error $\quad 30 \quad 196.9140 \quad 6.564$ Prob $>$ F

$\begin{array}{llrr}\text { C. } & 35 & 2499.1882 & <.0001\end{array}$

Total

Erpected Mean Squares

The Mean Square per row by the Variance Component per column

EMS

Intercept

Test\&Rando

$\begin{array}{rr}\text { Intercep } & \text { Test\&Rando } \\ \mathbf{t} & \text { m } \\ 0 & 0 \\ 0 & 6\end{array}$

$\mathrm{m}$

plus 1.0 times Residual Error Variance

Variance Component Estimates

Component Var Comp Est Percent of

$\begin{array}{lll}\text { Test\&Rando } & 75.64851 & \text { Total }\end{array}$

$\begin{array}{lll}\text { mesidual } & 6.563799 & 7.984\end{array}$

$\begin{array}{llr}\text { Residual } & 6.563799 & 7.984 \\ \text { Total } & 82.21231 & 100.000\end{array}$

These estimates based on equating Mean Squares to Expected Value.

Test Denominator Synthesis

Source MS Den DF Den $\begin{gathered}\text { Denom MS } \\ \text { Synthesis }\end{gathered}$ 
SRNL-STI-2011-00151

5/26/11 Revision 0

SRNL-L4221-2011-00005

March 17, 2011

Page 28 of 33

\section{Exhibit A2. Analysis of Variance of Blending Times by Test Groupings}
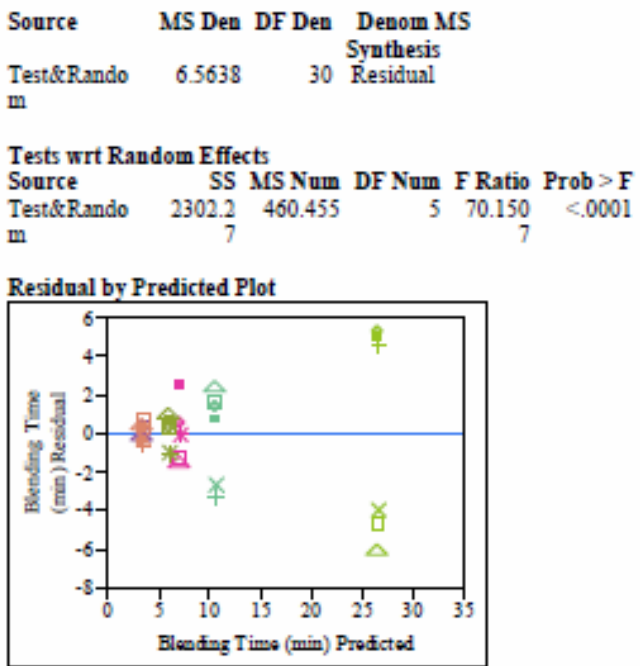
SRNL-STI-2011-00151

5/26/11 Revision 0

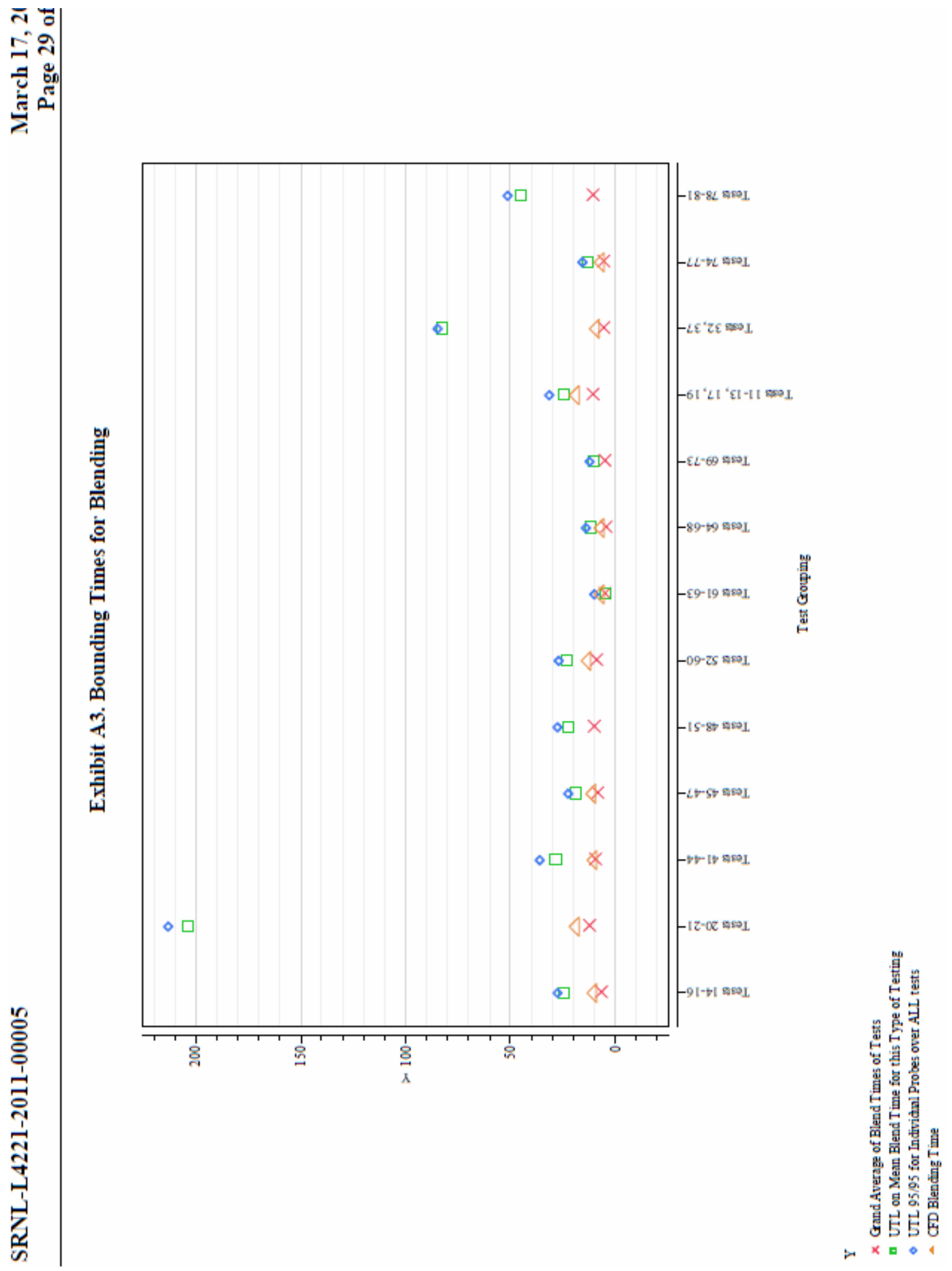


SRNL-STI-2011-00151

5/26/11 Revision 0

Exhibit A4. Plot of EDL Velocity Measurements versus CFD Values (in the top plot - in ft/sec and in common logarithms in the bottom plot)
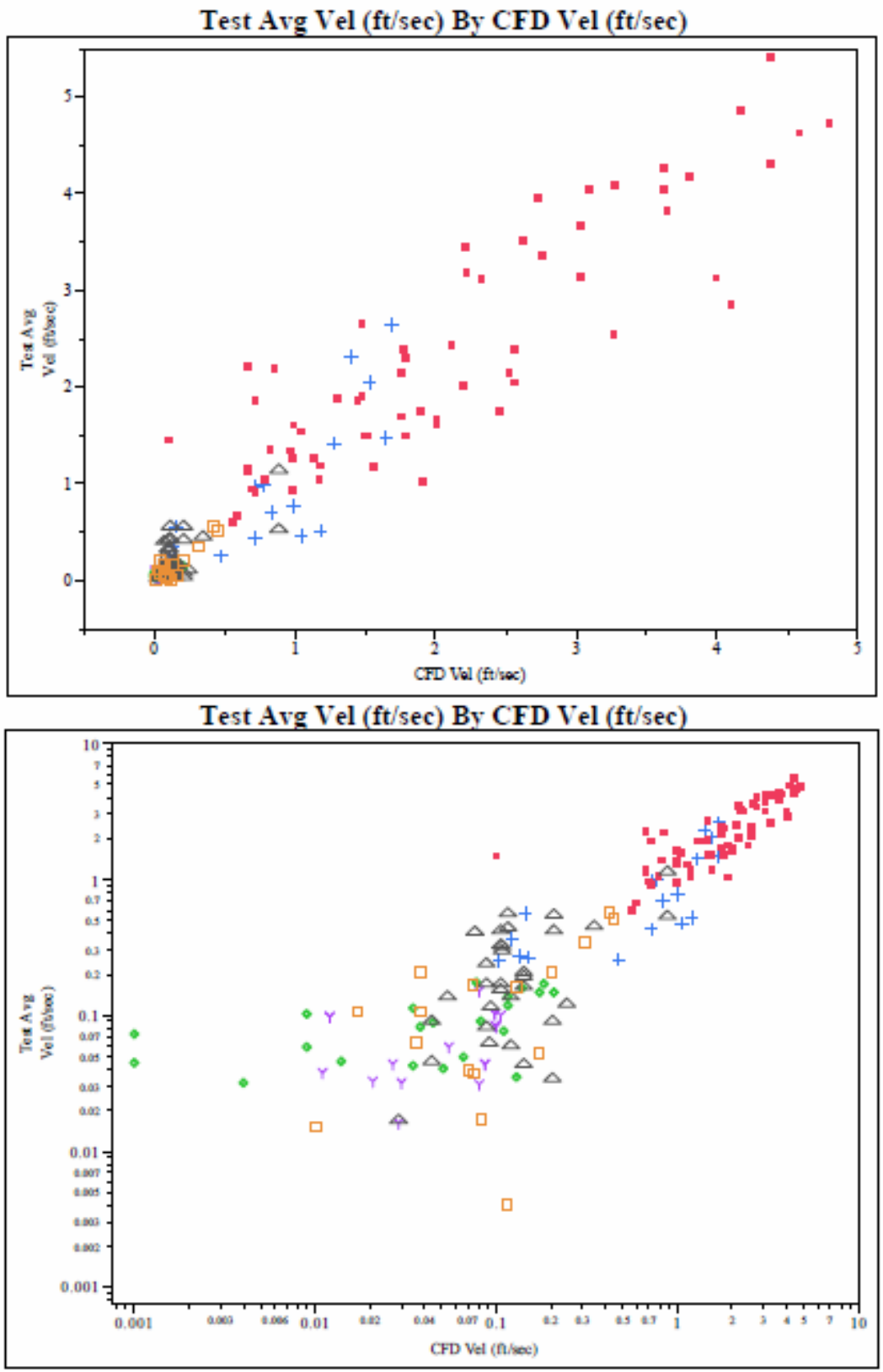

\begin{tabular}{|c|c|c|c|c|c|}
\hline $\begin{array}{l}4 \ldots \\
\Theta\end{array}$ & $(\mathbf{)}$ & Test Descriptinn & Text Connditinne & Seale & Type of Tast \\
\hline - & 1 & Full Scale, No Coils & $\mathrm{UoD}=29.4 \mathrm{ft} \cdot 2 / \mathrm{sec}$; water; no coils & Full & ADMP \\
\hline $\bar{Y}$ & 2 & Pilat Scale. Crits & 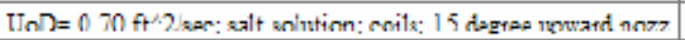 & Pilnt & $\operatorname{Cas} 12 x$ \\
\hline$\diamond$ & 3 & Pilot Scale, No Coils & $\mathrm{UoD}=0.58 \mathrm{ft} \cdot 2 / \mathrm{sac} ;$ salt solution; no coils; 15 degree upward & Pilot & Case $11 \mathrm{a}$ \\
\hline+ & 4 & Pilot Scale, No Coils & $\mathrm{UoD}=0.58 \mathrm{ft} \cdot 2 / \mathrm{sac} ;$ salt solution; no coils; 15 degree upward & Pilot & Case $11 b$ \\
\hline$\triangle$ & 5 & Pilot scale, No Coils & UoD $=0.81 \mathrm{ft} \cdot 2 / \mathrm{sec}$; salt solution, no coils, tee nozzle & Pilot & Case 2 \\
\hline$\square$ & 6 & Pilot Scale, No Coils & UoD $=0.81 \mathrm{ft} 2 / \mathrm{sac} ;$ water; no coils; tee nozzle & Pilot & Case 1 \\
\hline
\end{tabular}


SRNL-STI-2011-00151

5/26/11 Revision 0

Exhibit A5. Regression Analysis of $\ln$ (Test) versus $\ln ($ CFD) for the Velocity Data

Bivariate Fit of $\ln ($ Test) By $\ln$ (CFD) for CFD Results $>=0.026 \mathrm{ft} / \mathrm{sec}$

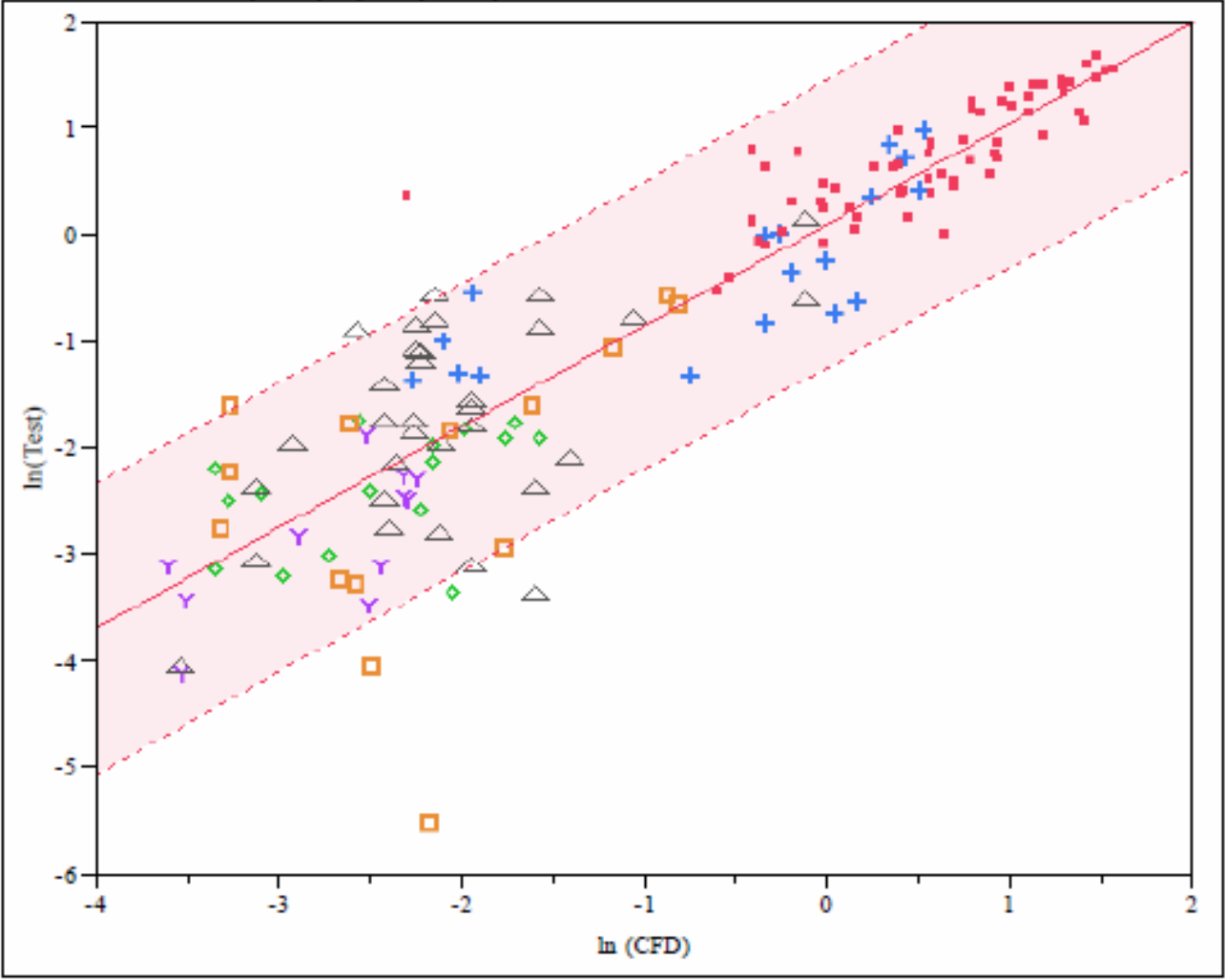

Linear Fit

Linear Fit

$\ln ($ Test $)=0.0948008+0.9489798^{*} \ln ($ CFD $)$

Summary of Fit

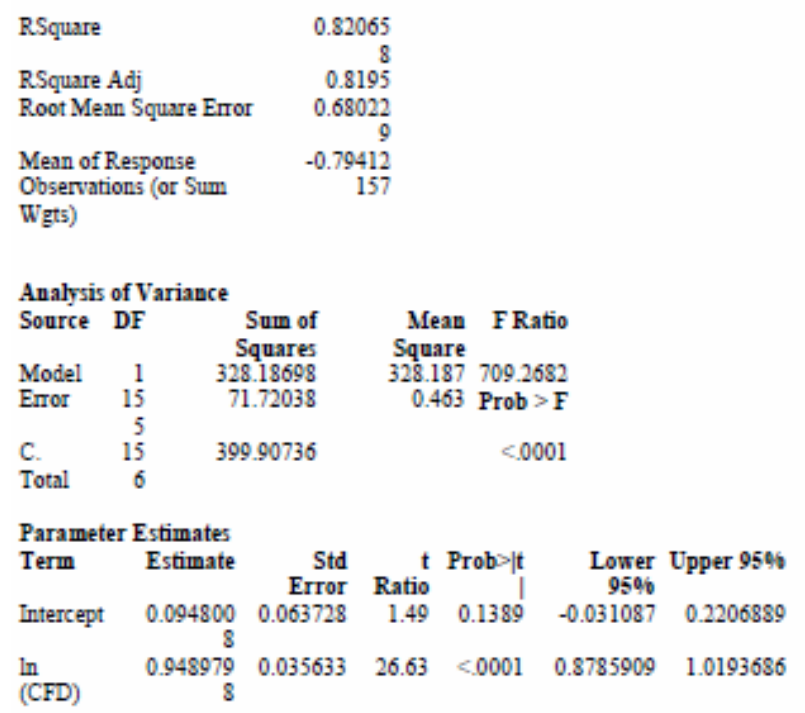


SRNL-STI-2011-00151

5/26/11 Revision 0

Exhibit A6. Estimation of Offset in Equation 6 (Left Panel) Upper Confidence Bound for Offset at 95\% Confidence (Right Panel)

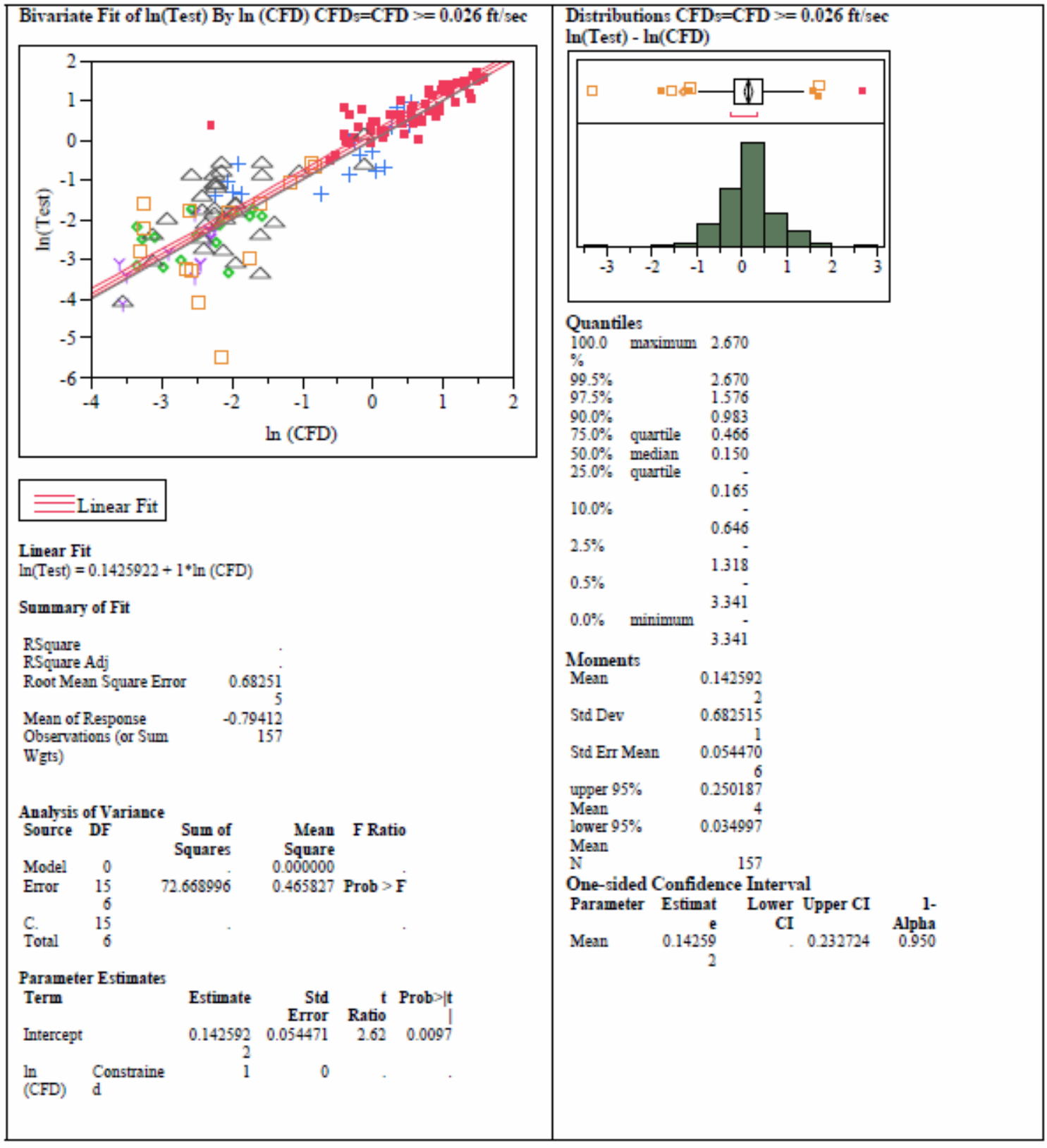


SRNL-STI-2011-00151

5/26/11 Revision 0

SRNL-L4221-2011-00005

March 17, 2011

Page 33 of 33

\section{Exhibit A7. Natural Logarithms of Velocities}

(UCL is upper confidence limit at $95 \%$ confidence)

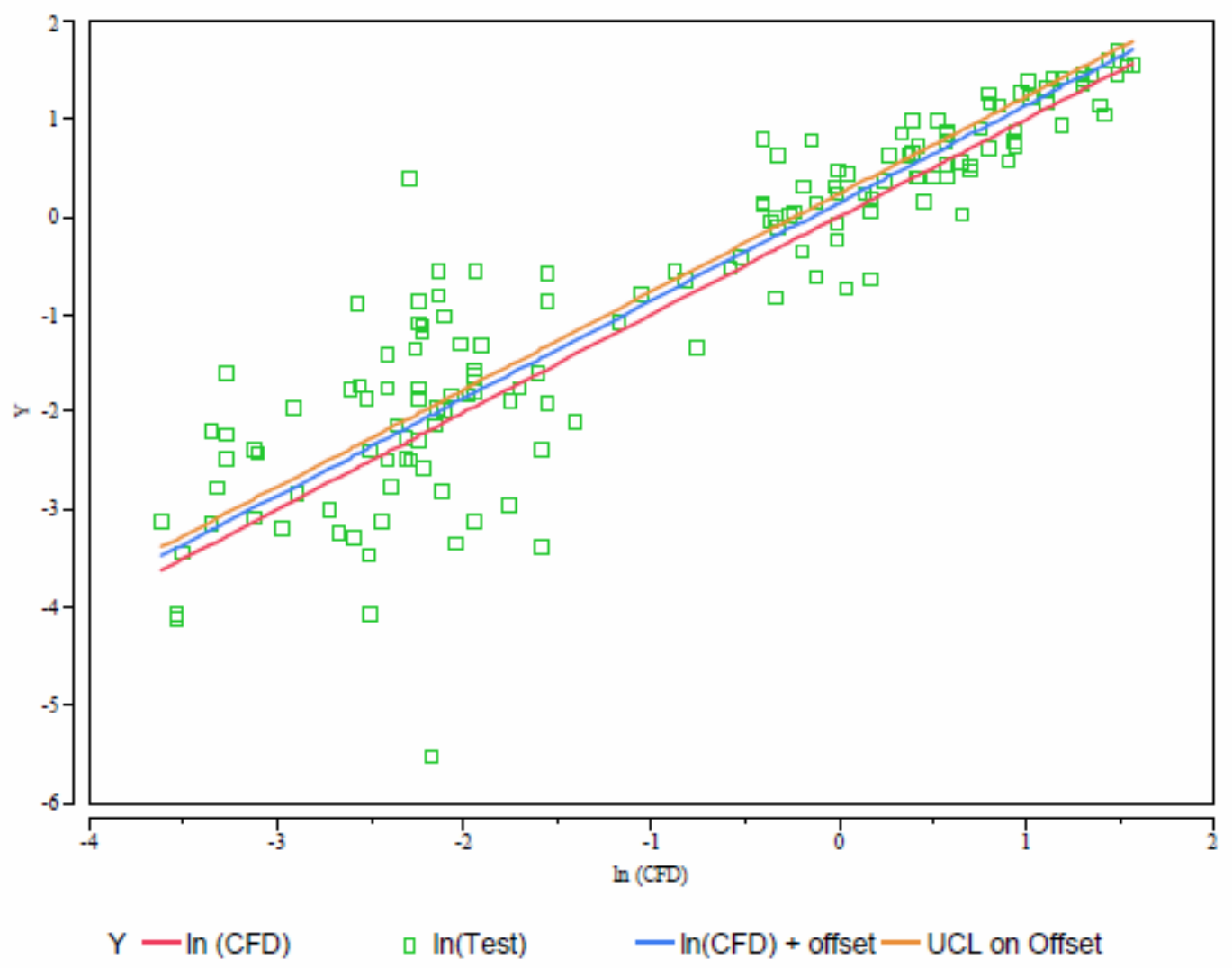


SRNL-STI-2011-00151

5/26/11 Revision 0

Appendix B: Velocity Test Data for Constant Pump Flow Rates 

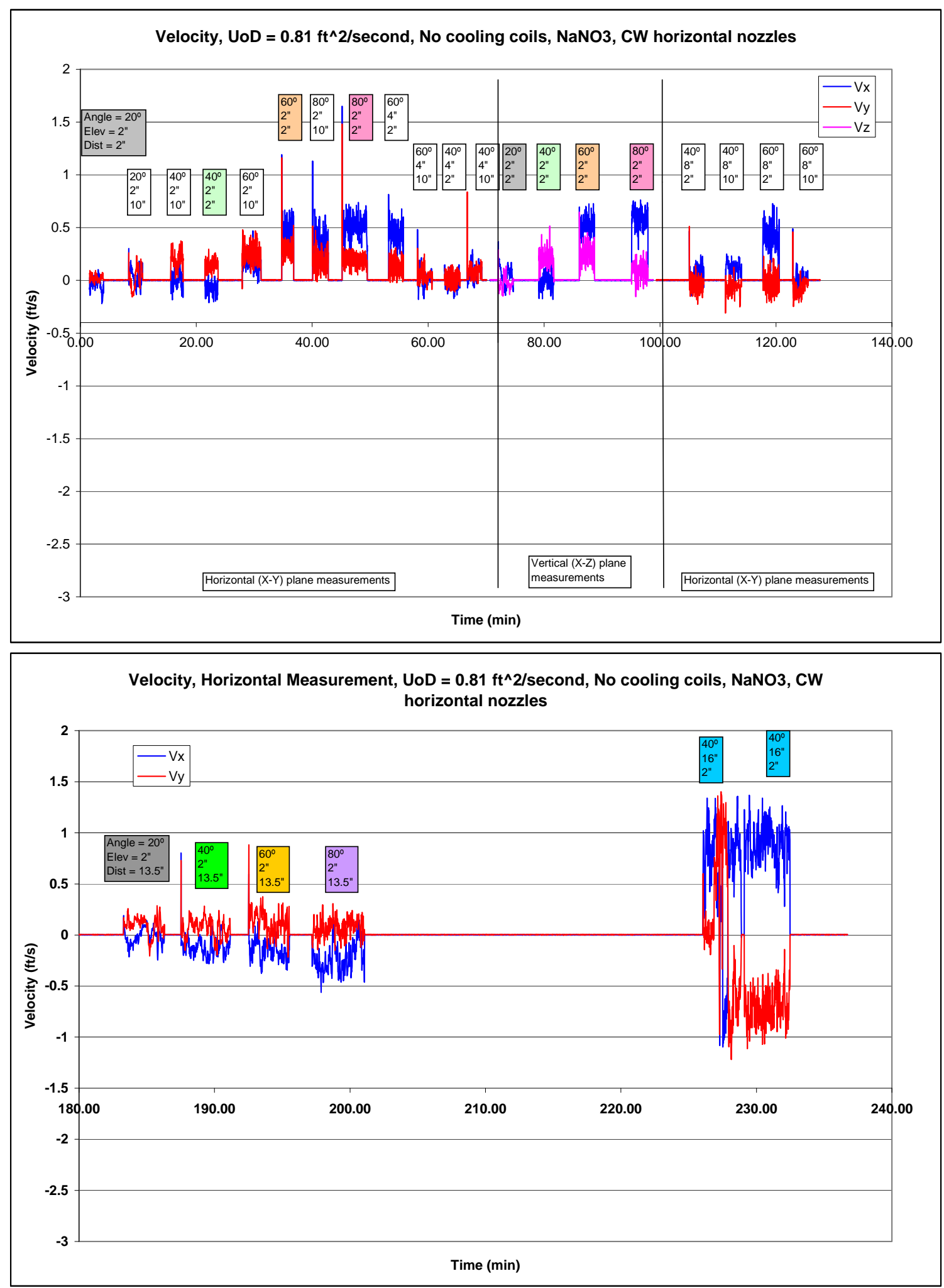

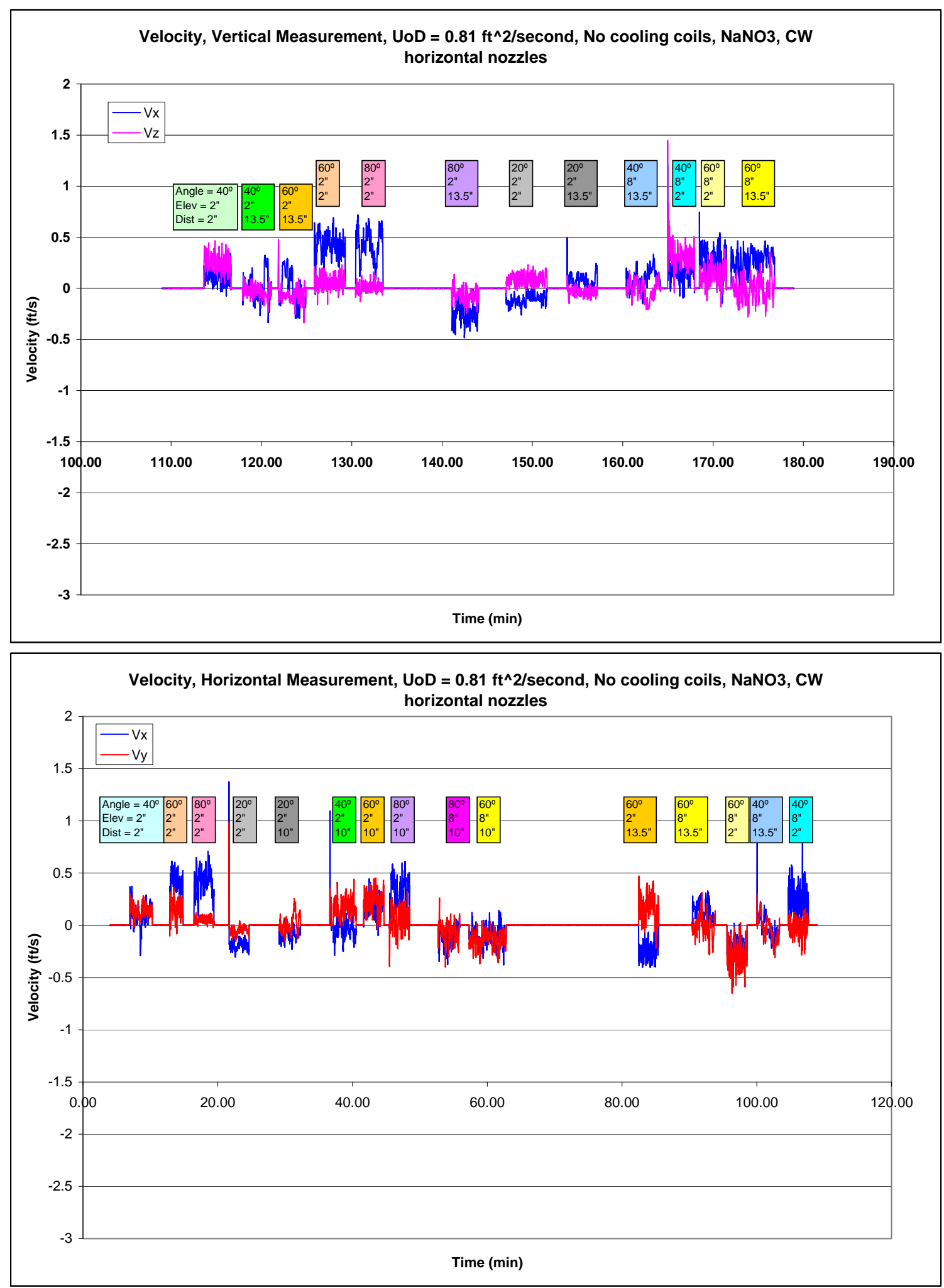
SRNL-STI-2011-00151

5/26/11 Revision 0
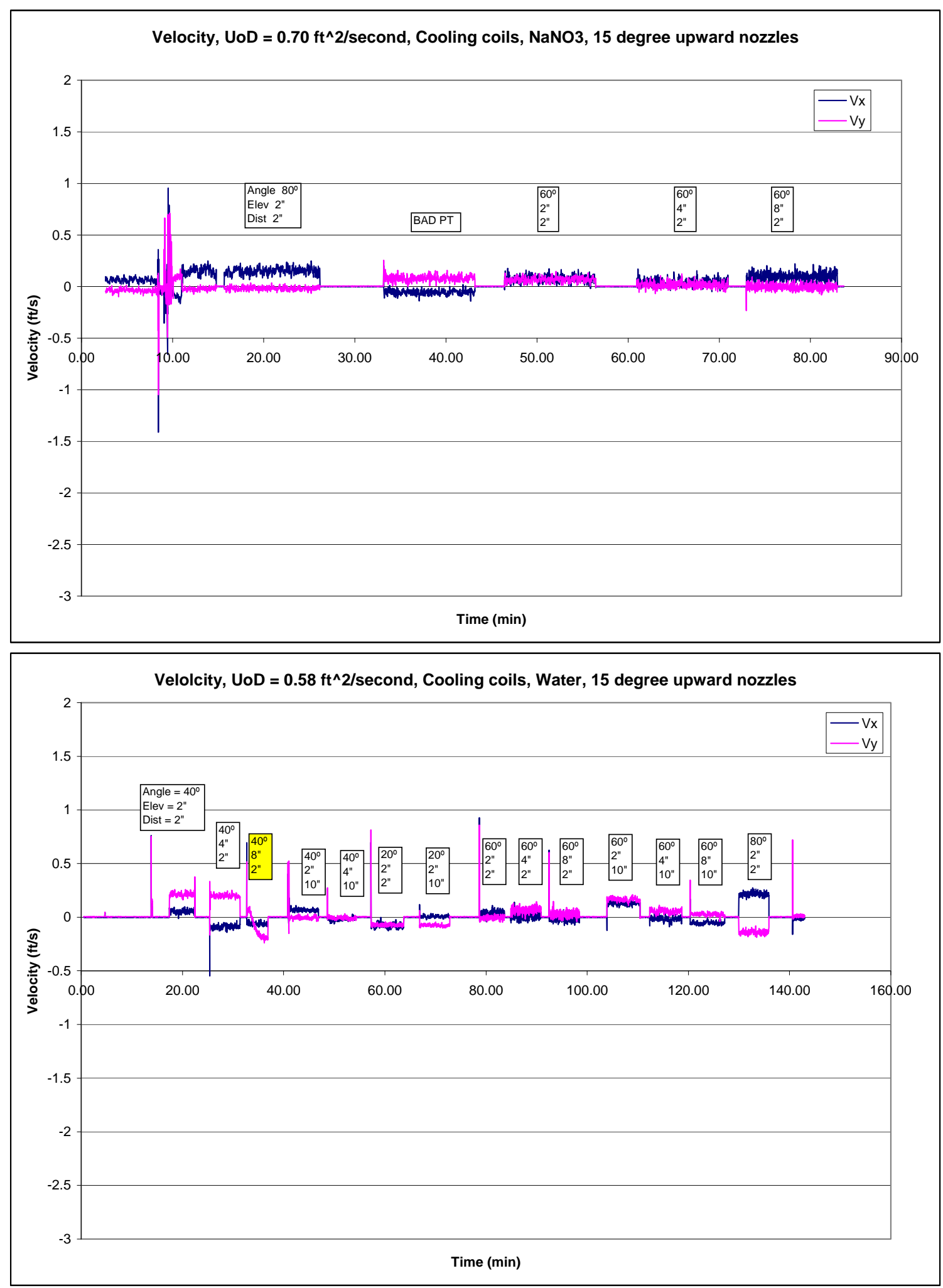
SRNL-STI-2011-00151

5/26/11 Revision 0
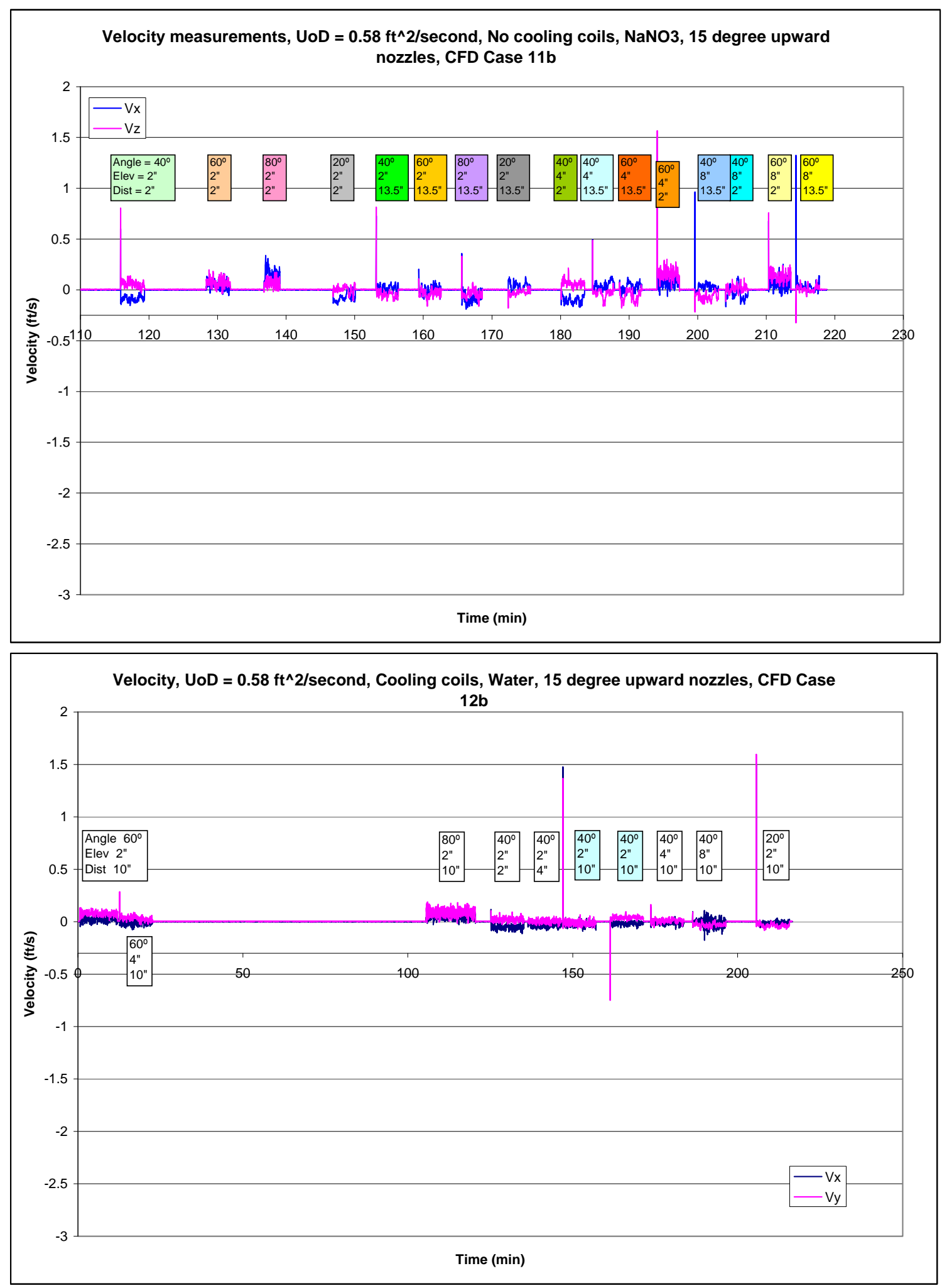
SRNL-STI-2011-00151

5/26/11 Revision 0

Appendix C: Sodium Concentration Measurements During Blending Tests 

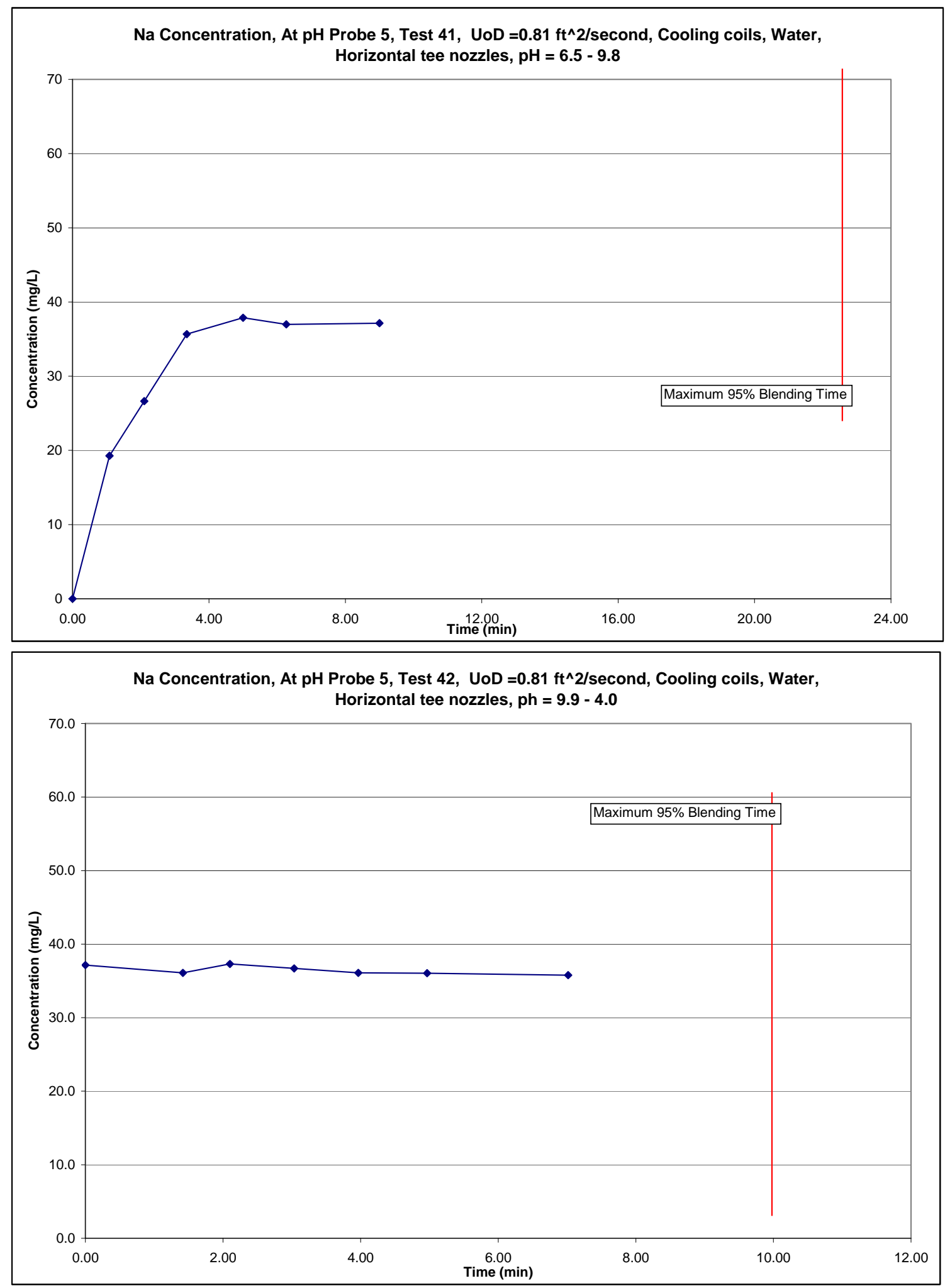
SRNL-STI-2011-00151

5/26/11 Revision 0
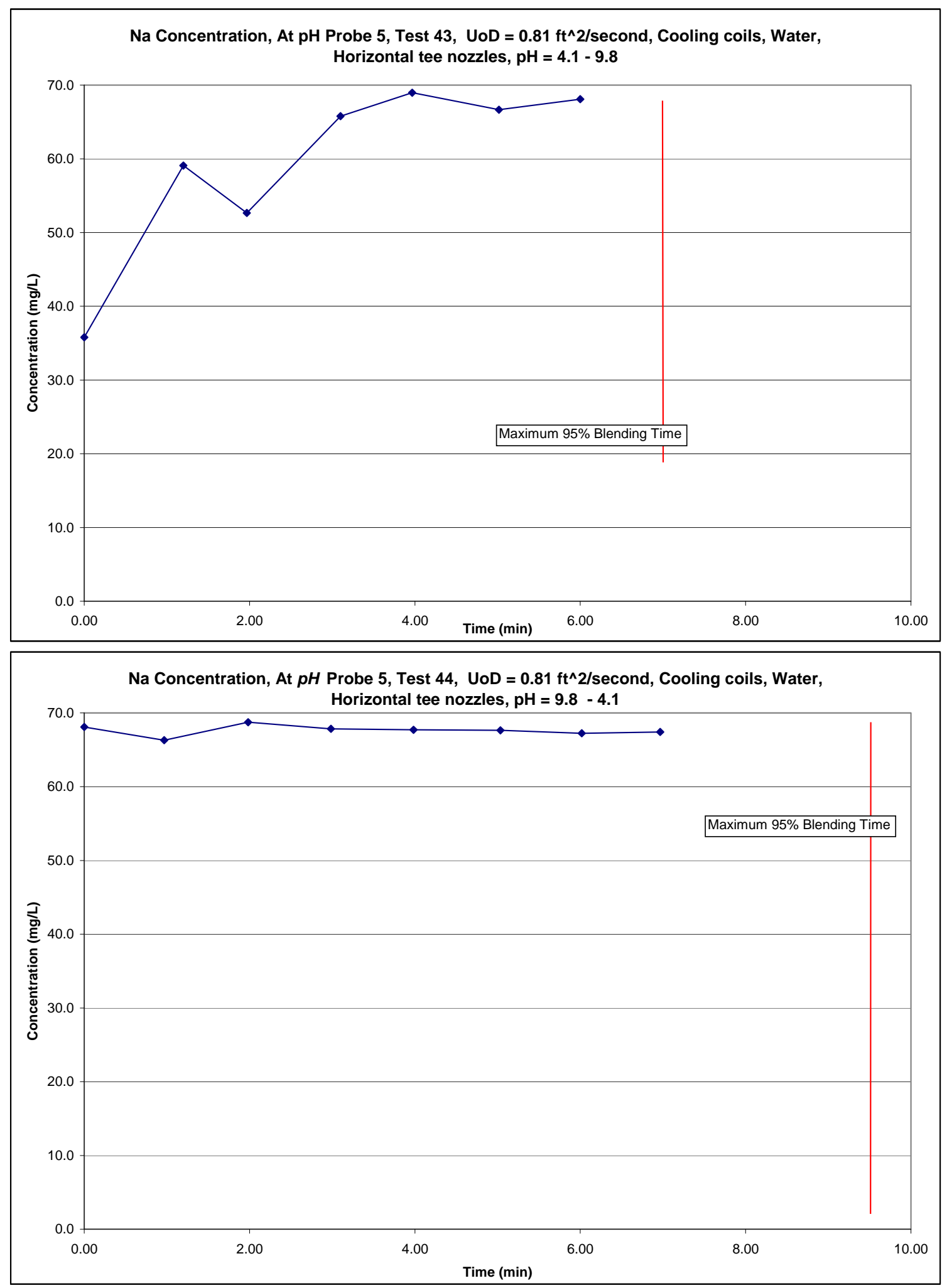
SRNL-STI-2011-00151

5/26/11 Revision 0

Appendix D: ADMP, Partial Velocity Data at the Elevation of the Jet Nozzles 
SRNL-STI-2011-00151

5/26/11 Revision 0
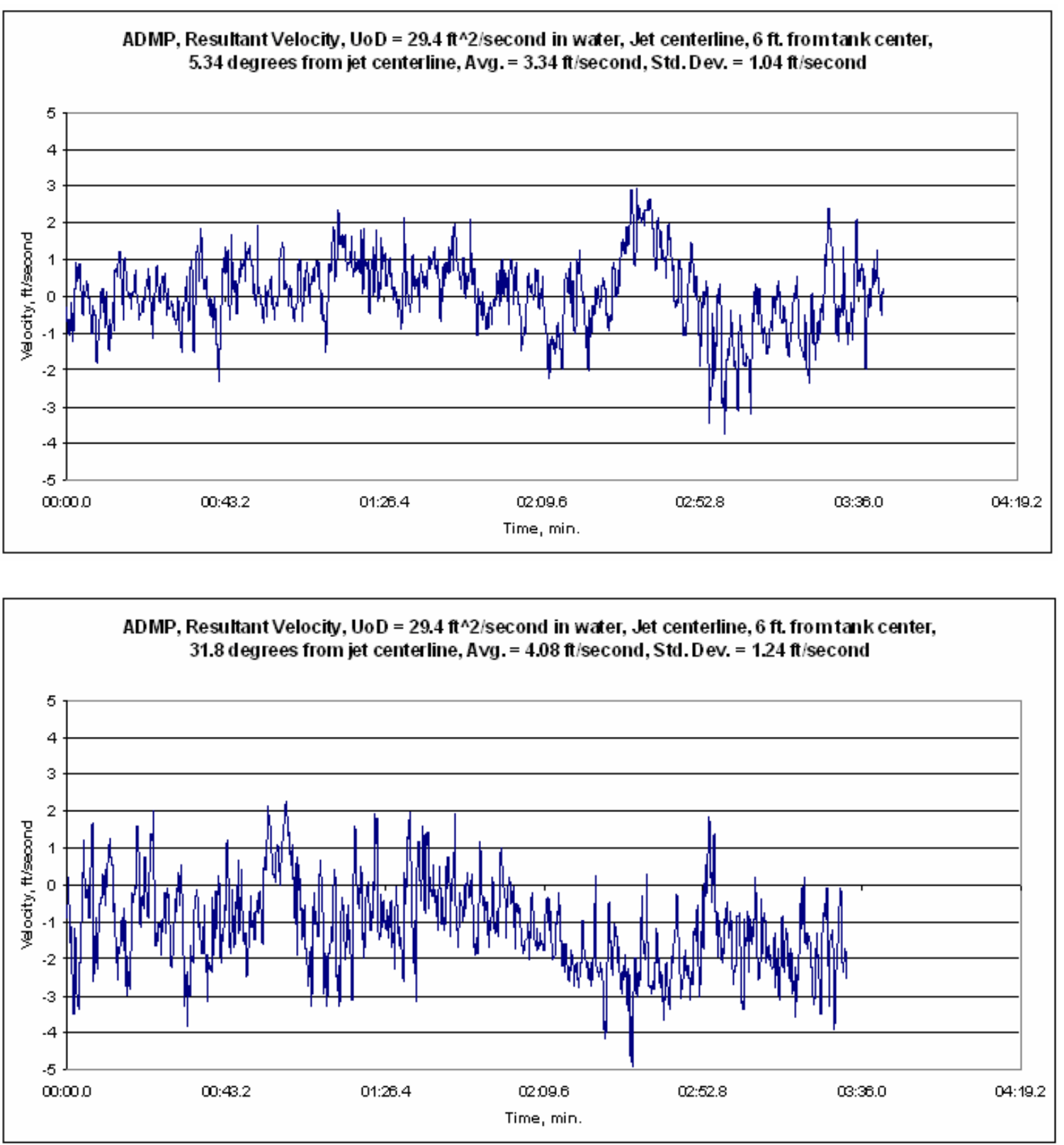
SRNL-STI-2011-00151

5/26/11 Revision 0
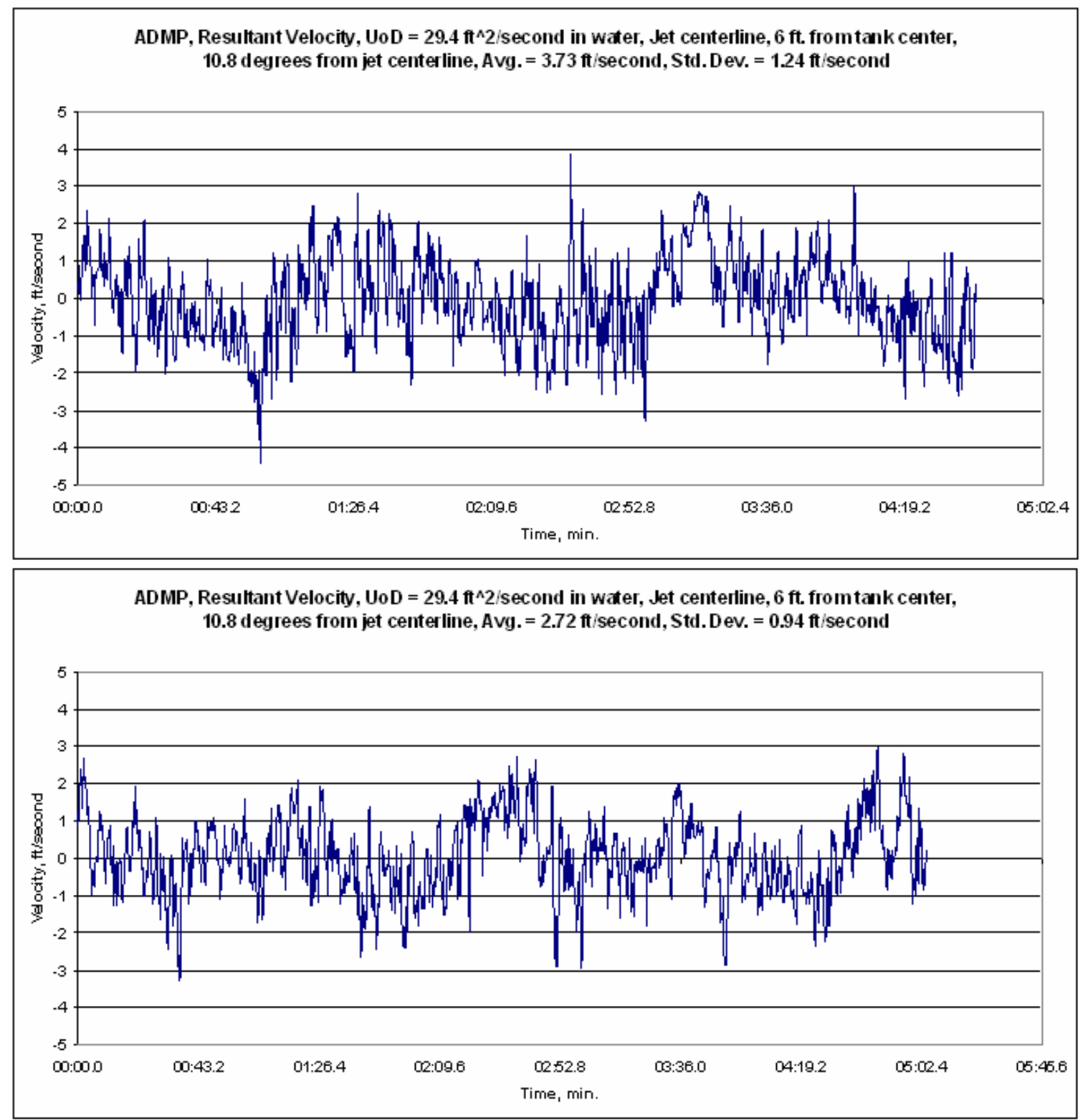
SRNL-STI-2011-00151

5/26/11 Revision 0
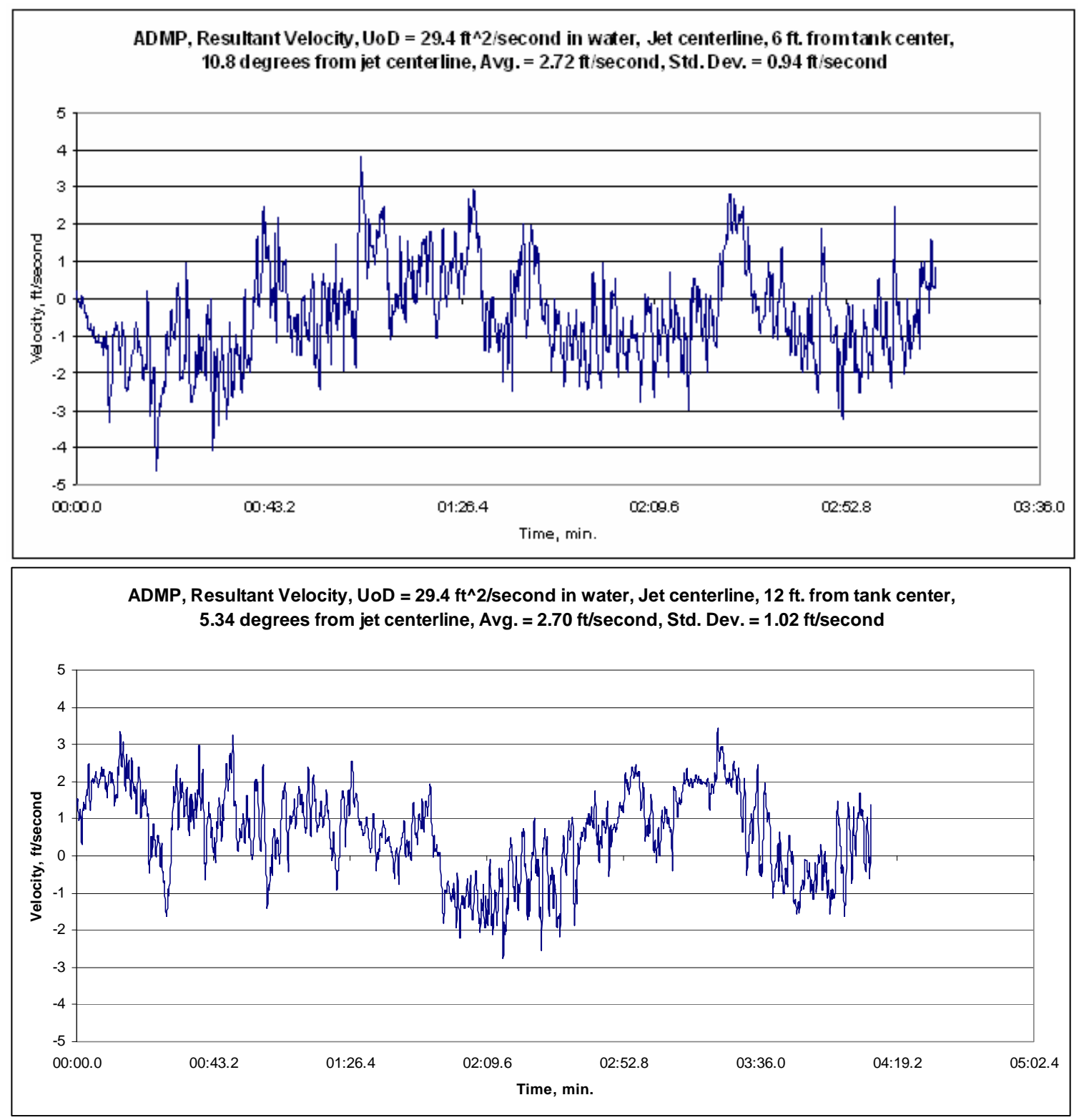
SRNL-STI-2011-00151

5/26/11 Revision 0
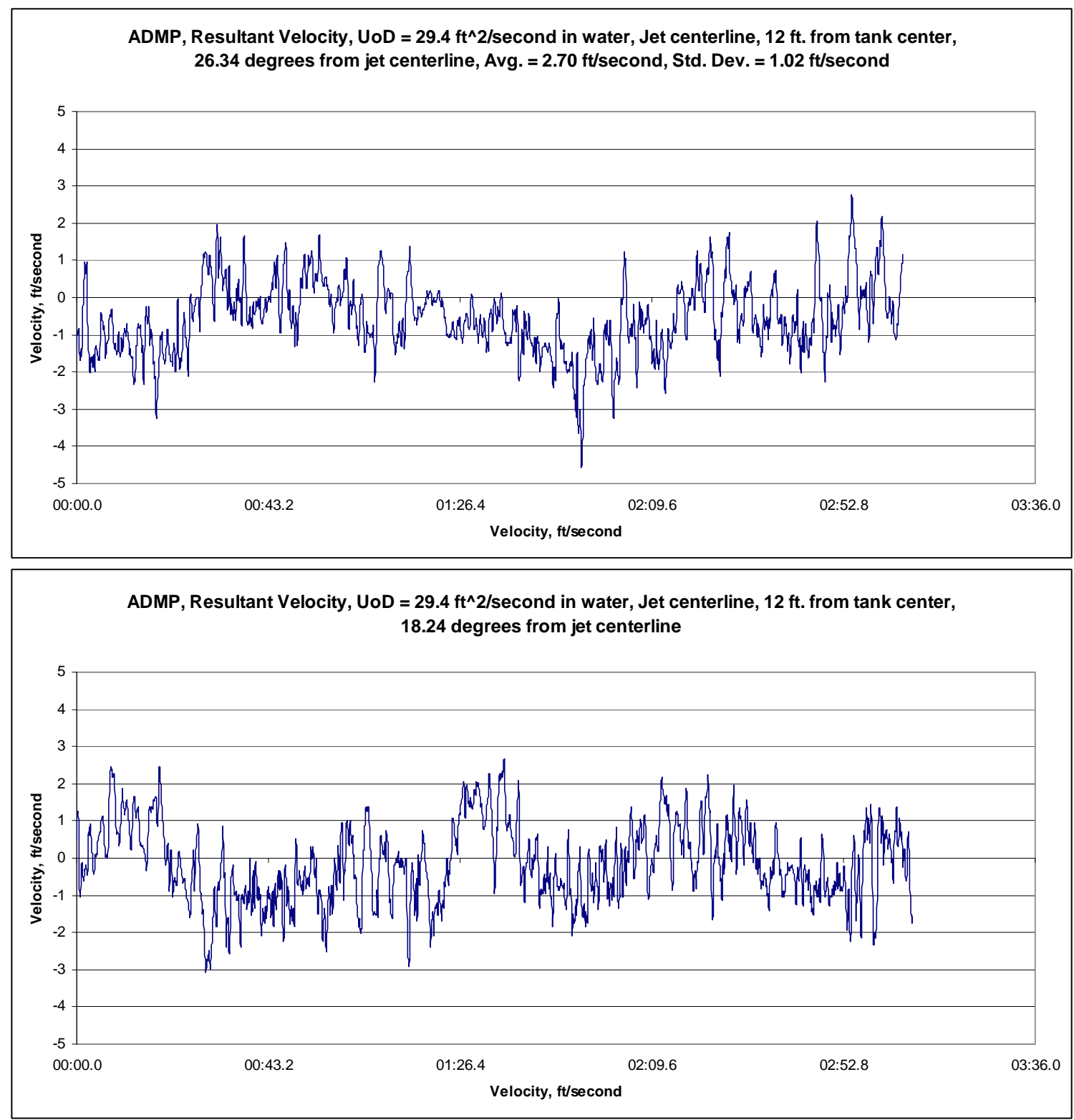
SRNL-STI-2011-00151

5/26/11 Revision 0
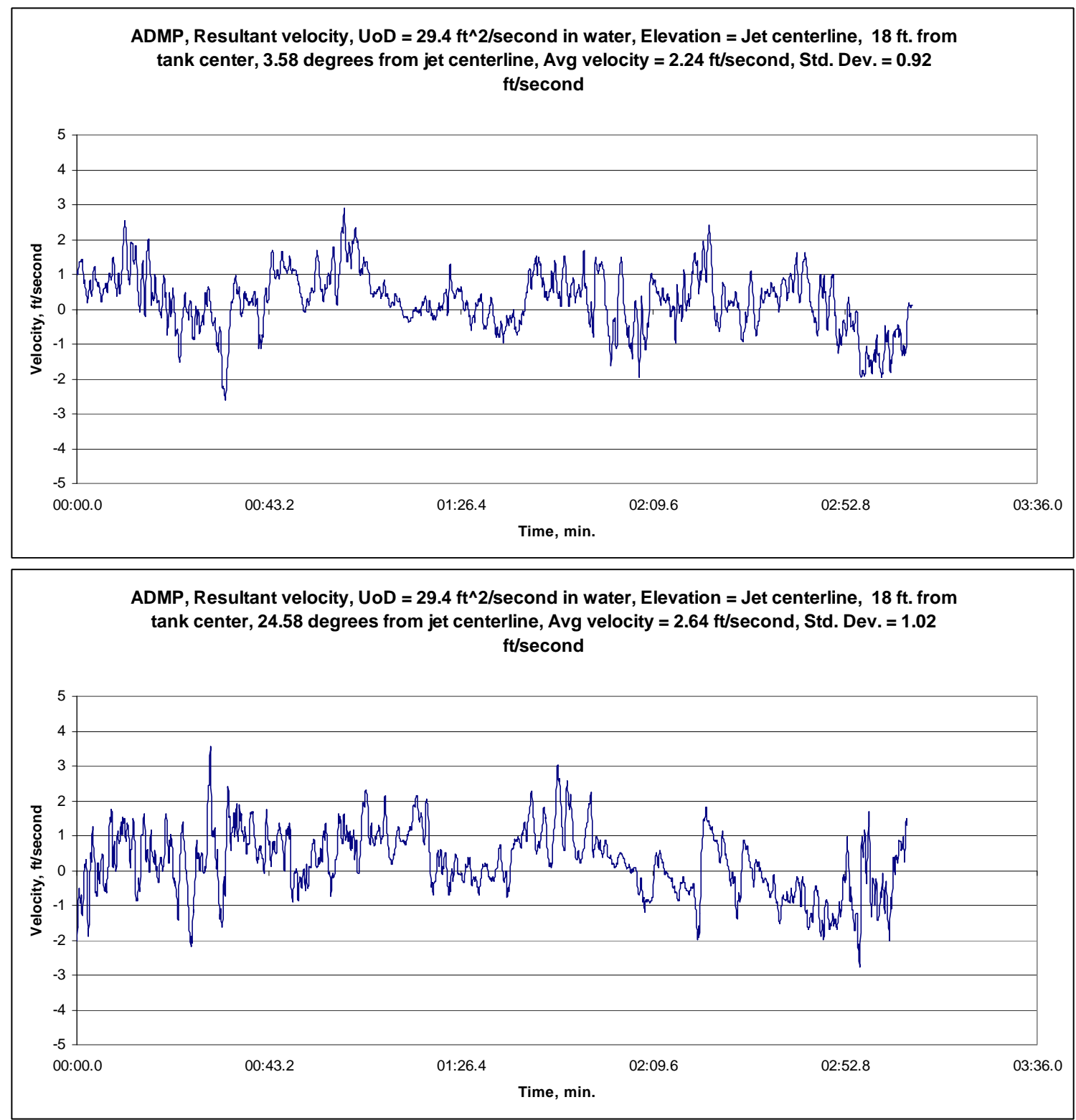
SRNL-STI-2011-00151

5/26/11 Revision 0
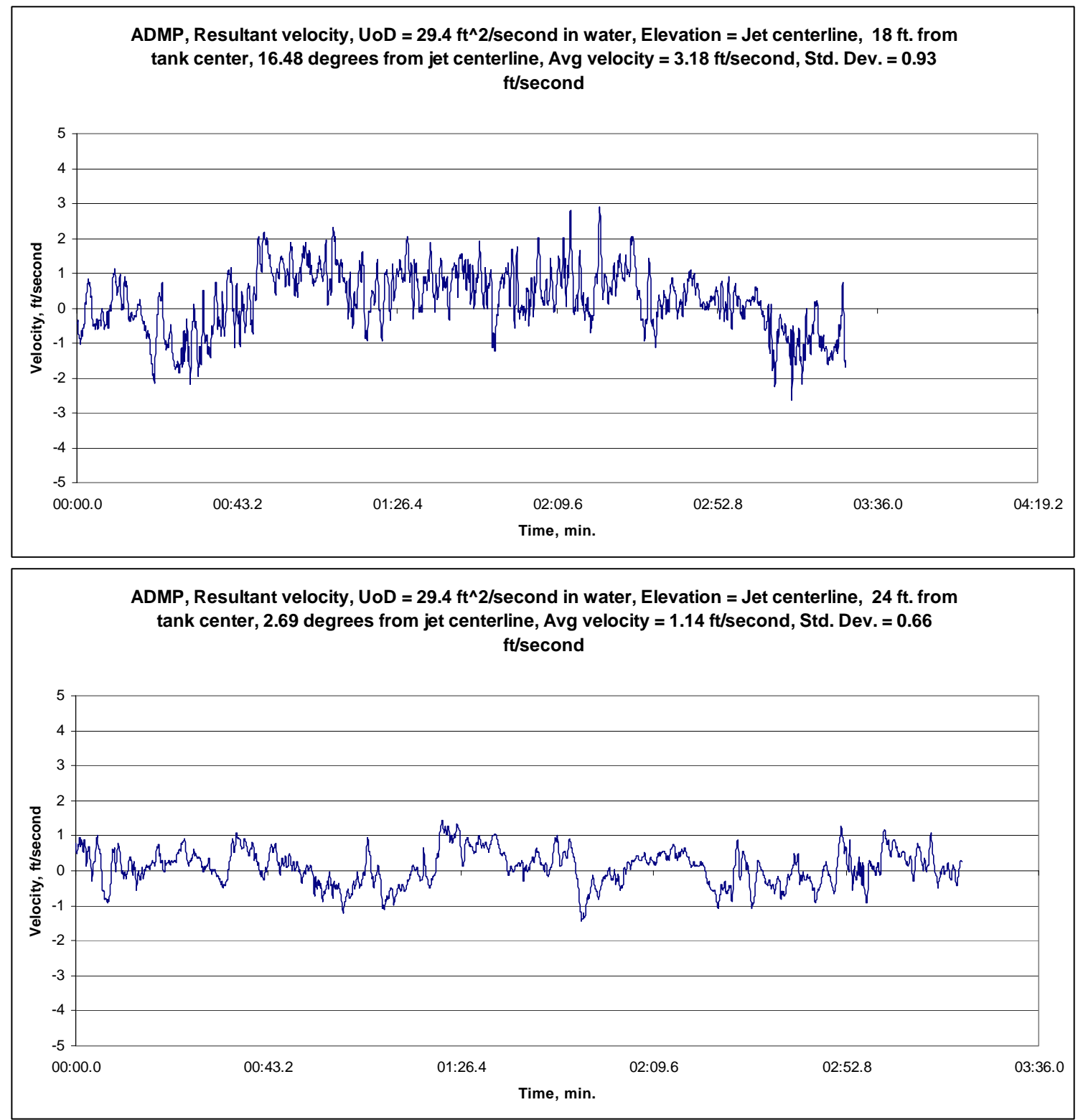
SRNL-STI-2011-00151

5/26/11 Revision 0
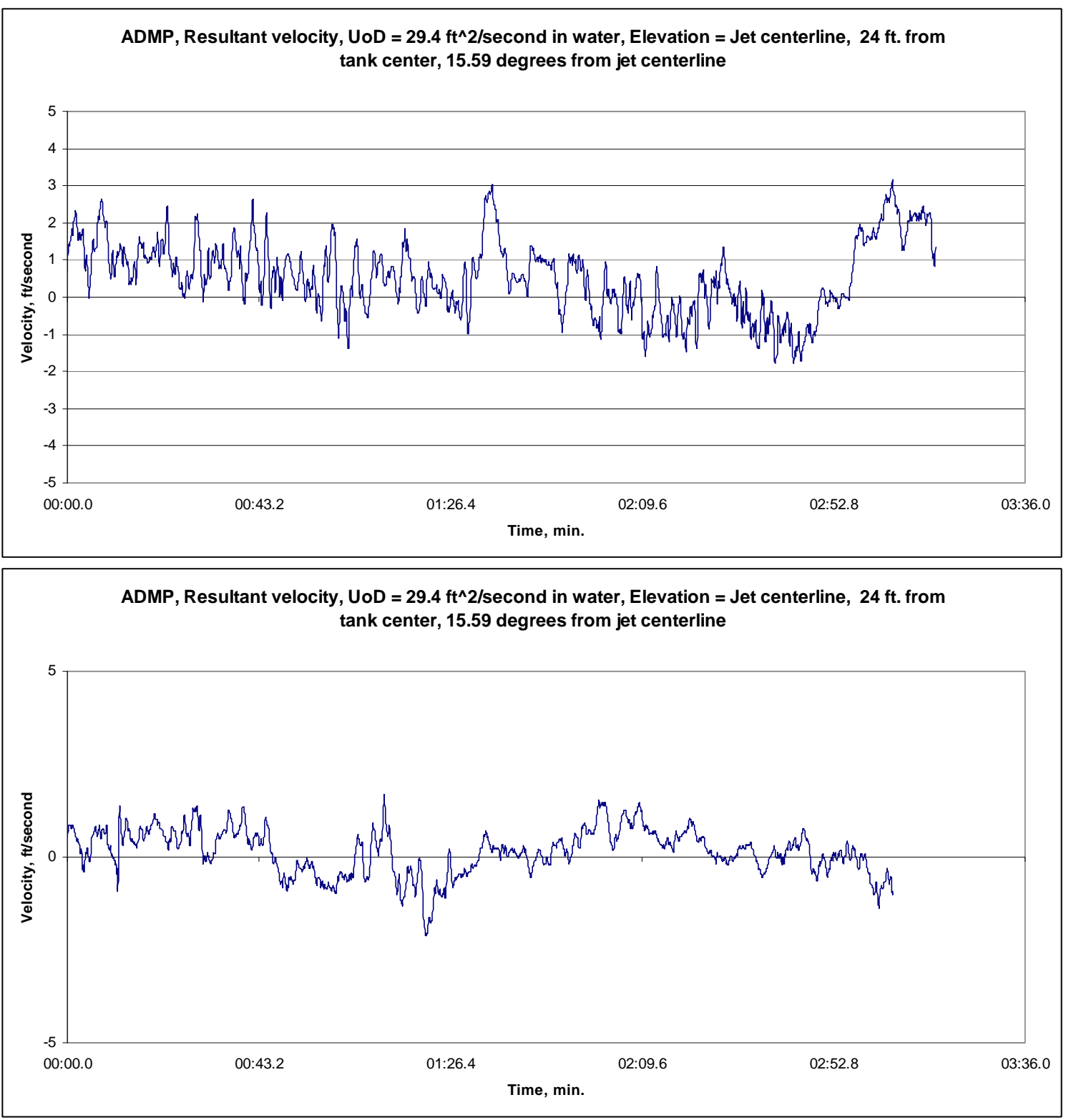


\section{Distribution:}
A. B. Barnes, 999-W
D. A. Crowley, 773-43A
S. D. Fink, 773-A
B. J. Giddings, 786-5A
C. C. Herman, 999-W
S. L. Marra, 773-A
A. M. Murray, 773-A
F. M. Pennebaker, 773-42A
W. R. Wilmarth, 773-A
M. E. Stone, 999-W
P. R. Jackson, 703-46A
J. M. Bricker, 704-27S
T. L. Fellinger, 704-26S
E. W. Holtzscheiter, 704-15S
M. T. Keefer, 766-H
C. E. Duffey, 704-61H
M. Hubbard, 241-162H
J. R. McCullough, 241-121H

K. D. Harp, 766H

W. B. Van Pelt, 766H

T. J. Steeper, 786-5A

R. A. Leishear, 786-5A

M. D. Fowley, 786-5A

M. R. Poirier, 773-42A

M. K. Lancaster, $766 \mathrm{H}$

R.C. Ervin, $766 \mathrm{H}$

R. M. Crouch, 241-120H

K. S. Parkinson, $766 \mathrm{H}$

R. J. Gray, 766H

D. B. Little, $766 \mathrm{H}$

W. C. Clark, $766 \mathrm{H}$

J. P. Schwenker, 766H

K. H. Subramanian, $766 \mathrm{H}$

S. D. Burke, $766 \mathrm{H}$

N. R. Davis, 704-26F

N. F. Chapman, $766 \mathrm{H}$ 